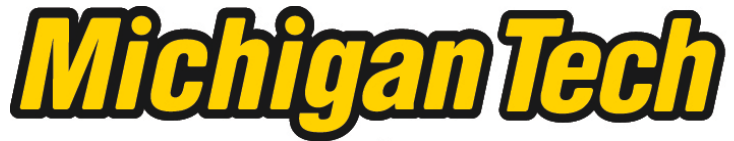 \\ Michigan Technological University Create the Future Digital Commons @ Michigan Tech
}

2013

\section{Oligodeoxynucleotide synthesis using protecting groups and a linker cleavable under non-nucleophilic conditions}

Xi Lin

Michigan Technological University

Follow this and additional works at: https://digitalcommons.mtu.edu/etds

Part of the Biochemistry Commons, Molecular Biology Commons, and the Organic Chemistry Commons

Copyright 2013 Xi Lin

\section{Recommended Citation}

Lin, Xi, "Oligodeoxynucleotide synthesis using protecting groups and a linker cleavable under nonnucleophilic conditions", Dissertation, Michigan Technological University, 2013.

https://doi.org/10.37099/mtu.dc.etds/676

Follow this and additional works at: https://digitalcommons.mtu.edu/etds

Part of the Biochemistry Commons, Molecular Biology Commons, and the Organic Chemistry Commons 


\title{
OLIGODEOXYNUCLEOTIDE SYNTHESIS USING PROTECTING GROUPS AND A LINKER CLEAVABLE UNDER NON- NUCLEOPHILIC CONDITIONS
}

\author{
By
}

$\mathrm{Xi}$ Lin

\section{A DISSERTATION}

Submitted in partial fulfillment of the requirements for the degree of

DOCTOR OF PHILOSOPHY

In Chemistry

MICHIGAN TECHNOLOGICAL UNIVERSITY

2013

(C)2013 Xi Lin 
This dissertation has been approved in partial fulfillment of the requirements for the Degree of DOCTOR OF PHILOSOPHY in Chemistry

Department of Chemistry

Dissertation Advisor: Dr. Shiyue Fang

Committee Member: $\quad$ Dr. Dallas K. Bates

Committee Member: $\quad$ Dr. Haiying Liu

Committee Member: $\quad$ Dr. Yun Hang Hu

Department Chair: Dr. Cary F. Chabalowski 


\section{Table of Contents}

List of Figures.......................................................................... vi

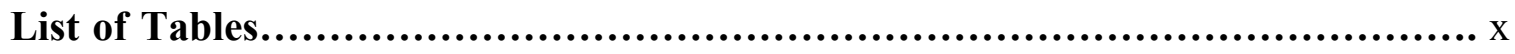

List of Schemes..................................................................... xi

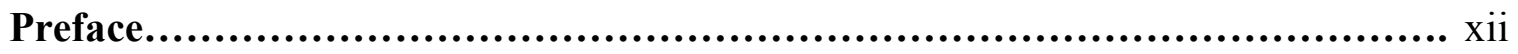

Acknowledgements.............................................................. xiii

Abstract...............................................................................

Chapter 1 Introduction............................................................ 1

1.1 General Introduction......................................................................... 1

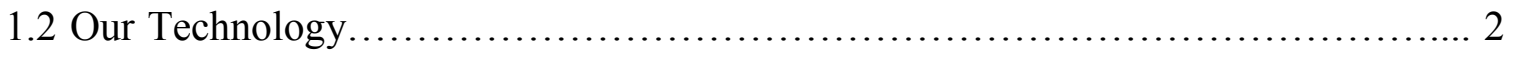

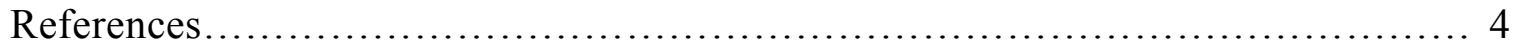

Chapter 2 History and Background............................................... 6

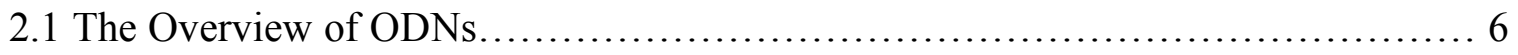

2.2 ODN Synthesis........................................................... 10

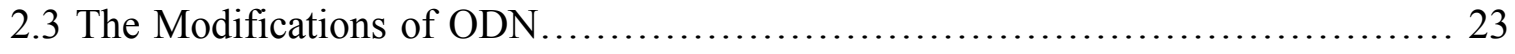

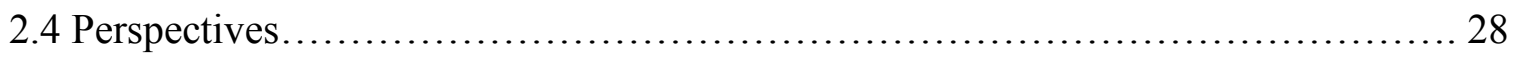

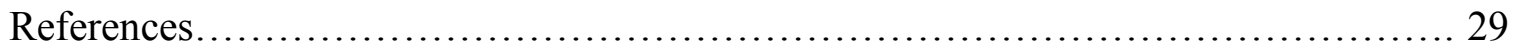

Chapter 3 Feasibility Studies......................................................... 36

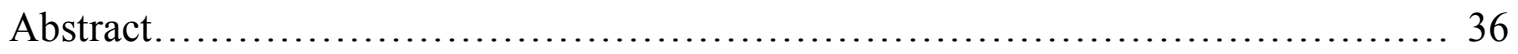

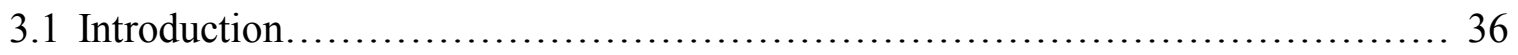

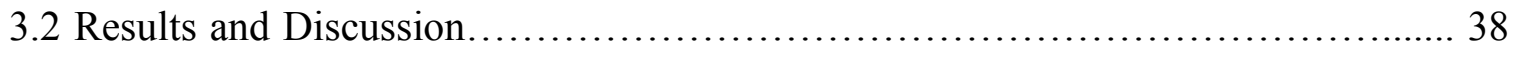

3.3 Conclusion........................................................................ 40

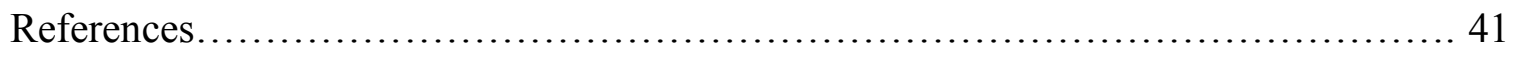


Chapter 4 Synthesis of dT-Dmoc Linker and Evaluation of Its Application in ODN

Synthesis........................................................................ 42

Abstract....................................................................... 42

4.1 Introduction.............................................................. 42

4.2 Results and Discussion.............................................. 47

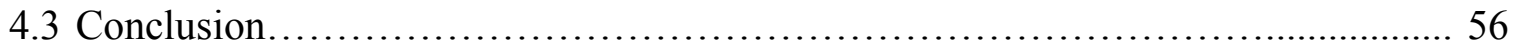

4.4 Experimental Section................................................. 56

References.............................................................. 66

Chapter 5 Synthesis of Dmoc-protected Phosphoramidite Monomers and Their Applications in ODN Synthesis.................................................. 69

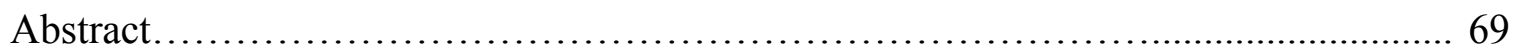

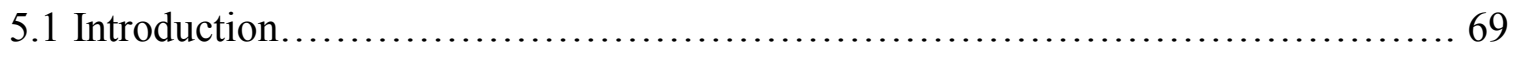

5.2 Results and Discussion................................................ 74

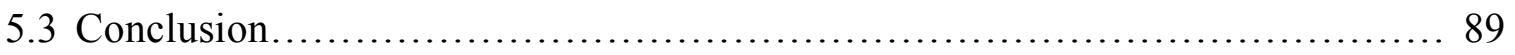

5.4 Experimental Section............................................ 89

References......................................................... 106

Chapter 6 Improved Synthesis of Dmoc-dG-amidite............................. 110

Abstract............................................................ 110

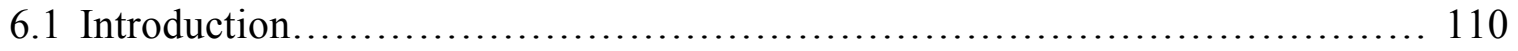

6.2 Results and Discussion................................................. 111

6.3 Conclusion........................................................... 114

6.4 Experimental Section............................................... 114

References........................................................ 120

Chapter 7 Future Research................................................... 121 
7.1 Dim Protecting Group for Phosphoramidites............................ 122

7.2 Deoc Protecting Groups for Nucleoside Bases............................. 123

7.3 Conclusion........................................................ 125

Appendix A. Supporting Information for Chapter 4............................ 126

Appendix B. Supporting Information for Chapter 5............................. 142

Appendix C. Supporting Information for Chapter 6............................. 167 


\section{List of Figures}

Figure 1.1. CPG with dT-Dmoc linker and Dmoc-protected phosphoramidites....... 2

Figure 2.1. Complementary base pairing ........................................ 6

Figure 2.2. Synthesis of first dinucleotide.................................. 10

Figure 2.3. Phosphodiester approach...................................... 11

Figure 2.4. Coupling of $\mathrm{dC}$ to polymer solid support......................... 12

Figure 2.5. Phosphotriester Approach...................................... 13

Figure 2.6. Phosphite-triester approach................................. 14

Figure 2.7. ODN synthesis cycle using phosphoramidite chemistry.............. 15

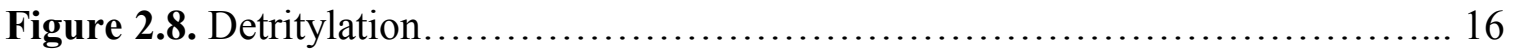

Figure 2.9. Coupling...................................................... 17

Figure 2.10. Capping failure sequence................................... 17

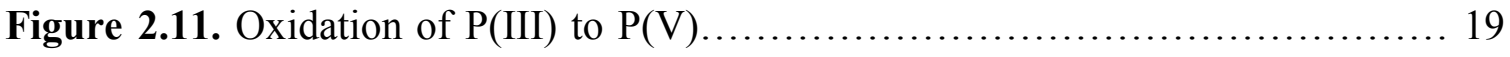

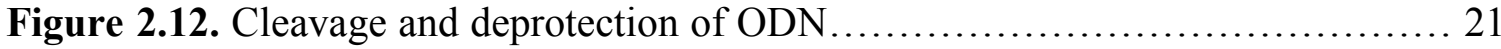

Figure 2.13. Michael addition to nucleoside base............................... 22

Figure 2.14. Synthesis of phosphothioates................................... 24

Figure 2.15. Modifications on sugar moiety................................ 24

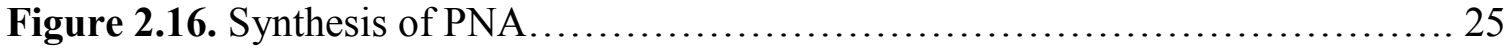

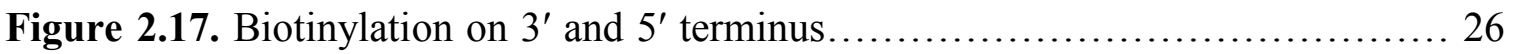

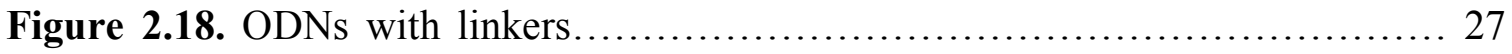

Figure 2.19. Modifications on nucleoside bases............................. 28

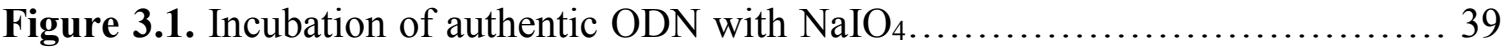

Figure 4.1. Solid supports for OGN synthesis............................. 43 
Figure 4.2. Linkers for electrophilic ODN synthesis.......................... 45

Figure 4.3. dT-Dmoc Linker............................................ 46

Figure 4.4. RP HPLC profiles of ODN 4.13 ............................... 49

Figure 4.5. Mechanism of the removal of $\beta$-cyanoethyl groups by DBU............. 50

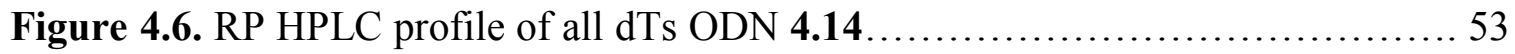

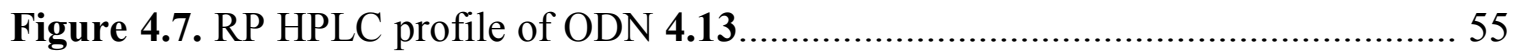

Figure 5.1. The trityl family............................................ 70

Figure 5.2. Standard protecting groups for nucleoside bases................... 71

Figure 5.3. Sekine's activated phosphite method........................... 72

Figure 5.4. Allylic protecting groups for ODN synthesis....................... 73

Figure 5.5. Dmoc-protected nucleoside phosphoramidite monomers............... 74

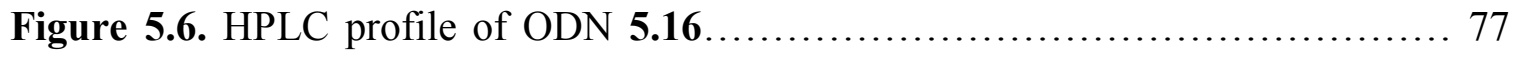

Figure 5.7. RP HPLC profile of ODN 5.19 from the unsuccessful deprotection....... 80

Figure 5.8. RP HPLC profiles of ODN 5.19 from the successful deprotection.......... 84

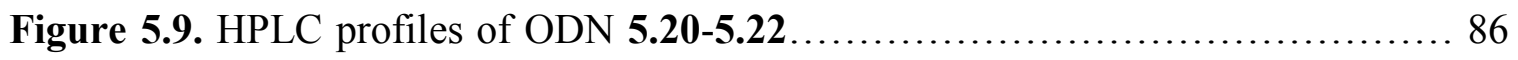

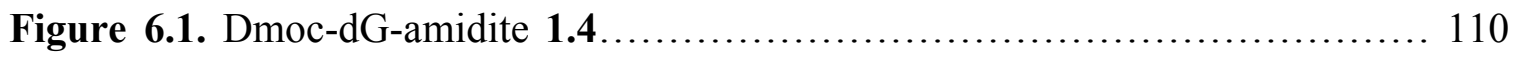

Figure 7.1. Dim-protected phosphoramidites............................. 122

Figure 7.2. Deoc-protected phosphoramidite monomers....................... 124

Figure A.1. ${ }^{1} \mathrm{H}$ NMR of compound 4.6................................. 127

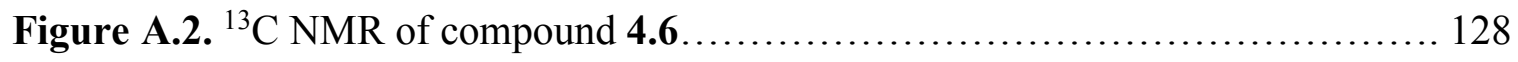

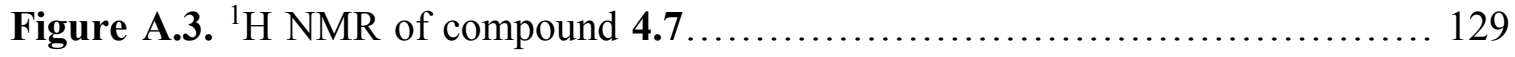

Figure A.4. ${ }^{13} \mathrm{C}$ NMR of compound 4.7................................ 130

Figure A.5. ${ }^{1} \mathrm{H}$ NMR of compound 4.8 ................................ 131

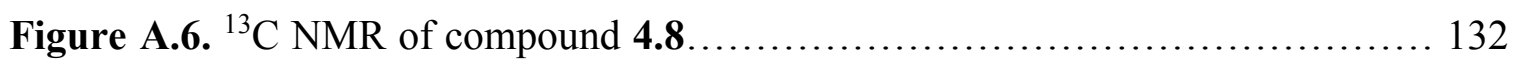




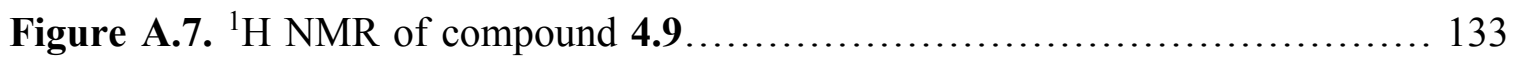

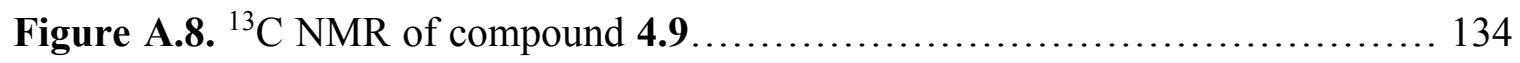

Figure A.9. ${ }^{1} \mathrm{H}$ NMR of compound 4.10................................. 135

Figure A.10. ${ }^{13} \mathrm{C}$ NMR of compound 4.10 ............................... 136

Figure A.11. ${ }^{1} \mathrm{H}$ NMR of compound 4.11 .................................. 137

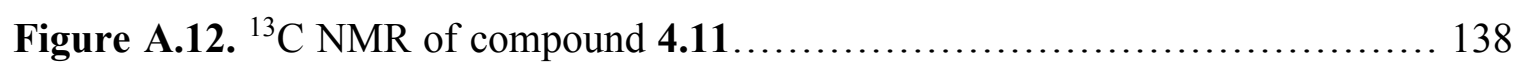

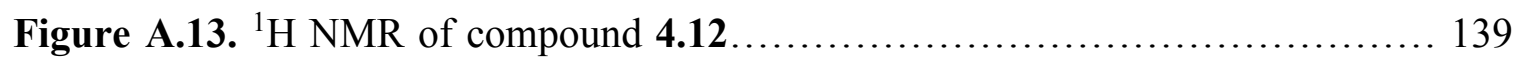

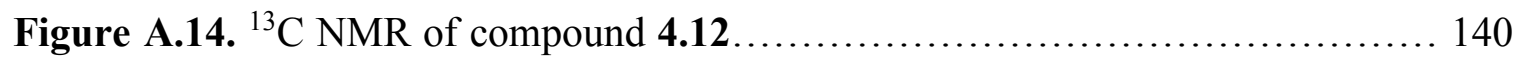

Figure A.15. MALDI-TOF spectrum of compound 4.13 ...................... 141

Figure B.1. ${ }^{1} \mathrm{H}$ NMR of compound 1.2 .............................. 143

Figure B.2. ${ }^{13} \mathrm{C}$ NMR of compound 1.2 ................................ 144

Figure B.3. ${ }^{31} \mathrm{P}$ NMR of compound 1.2 .............................. 145

Figure B.4. ${ }^{1} \mathrm{H}$ NMR of compound 1.3 ............................... 146

Figure B.5. ${ }^{13} \mathrm{C}$ NMR of compound 1.3.............................. 147

Figure B.6. ${ }^{31} \mathrm{P}$ NMR of compound 1.3 ................................ 148

Figure B.7. ${ }^{1} \mathrm{H}$ NMR of compound 1.4............................... 149

Figure B.8. ${ }^{13} \mathrm{C}$ NMR of compound 1.4................................ 150

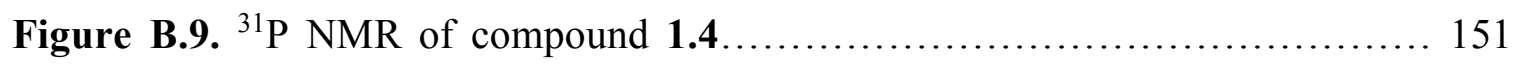

Figure B.10. ${ }^{1} \mathrm{H}$ NMR of compound 5.9............................... 152

Figure B.11. ${ }^{13} \mathrm{C}$ NMR of compound 5.9................................ 153

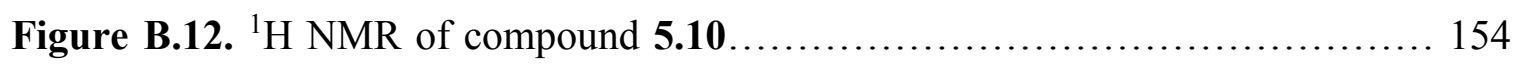

Figure B.13. ${ }^{13} \mathrm{C}$ NMR of compound 5.10 ................................ 155

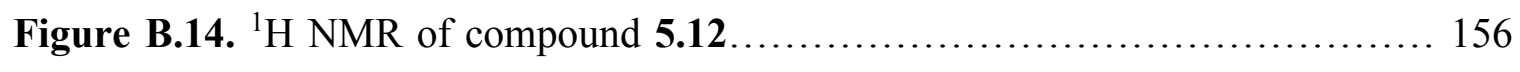

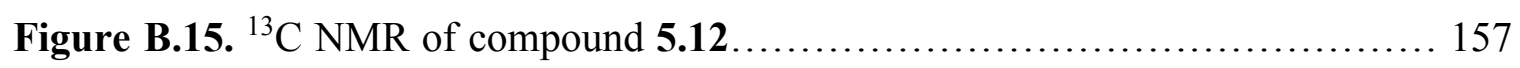

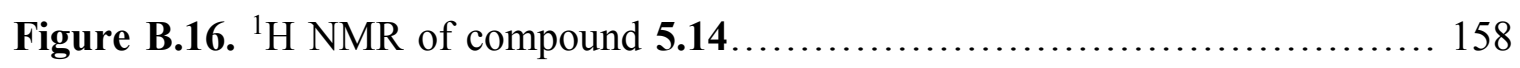

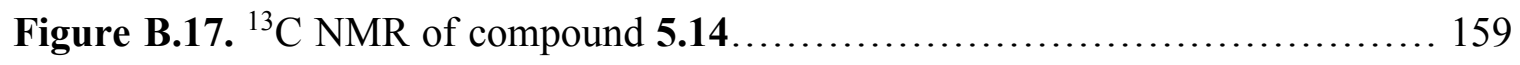

Figure B.18. ${ }^{1} \mathrm{H}$ NMR of compound 5.18 ............................... 160 


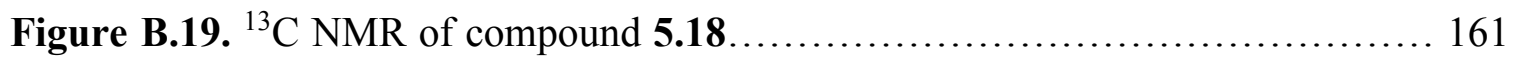

Figure B.20. MALDI-TOF spectrum of compound 5.16...................... 162

Figure B.21. MALDI-TOF spectrum of compound 5.19...................... 163

Figure B.22. MALDI-TOF spectrum of compound 5.20 ........................ 164

Figure B.23. MALDI-TOF spectrum of compound 5.21 ..................... 165

Figure B.24. MALDI-TOF spectrum of compound $5.22 \ldots \ldots \ldots \ldots \ldots \ldots \ldots \ldots \ldots \ldots$

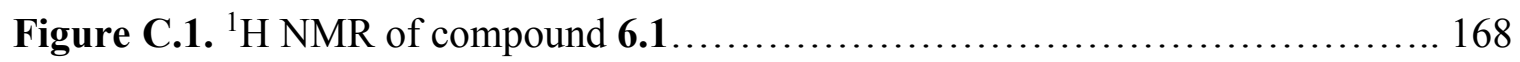

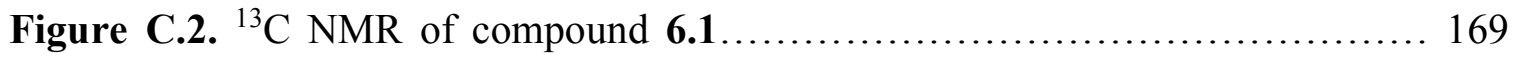

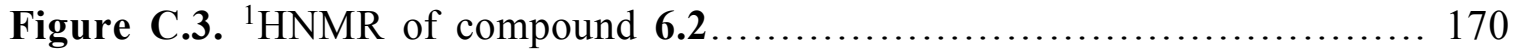

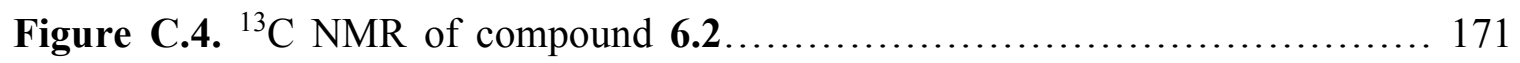




\section{List of Tables}

Table 2.1. Step durations in a typical cycle using phosphoramidite chemistry .......20 


\section{List of Schemes}

Scheme 1.1. Deprotection and cleavage of ODN protected and linked with Dmoc

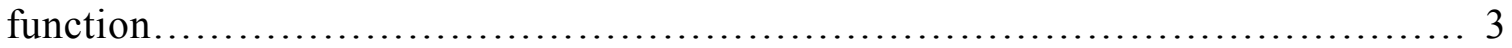

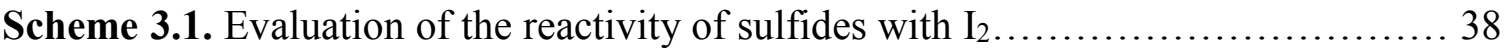

Scheme 3.2. Screening of conditions for the oxidation of 1,3 -dithiane.............. 38

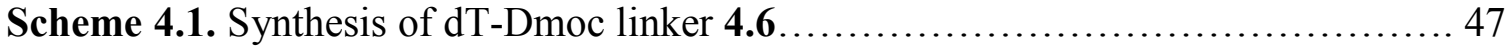

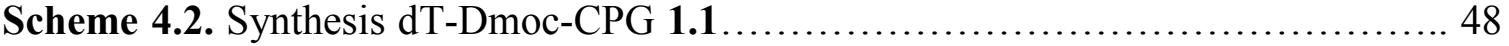

Scheme 4.3. Two-step cleavage strategy for the cleavage of all ODN 4.14 from CPG... 51

Scheme 4.4. Cleavage and deprotection of ODN 4.13 $\ldots \ldots \ldots \ldots \ldots \ldots \ldots \ldots \ldots \ldots \ldots \ldots$

Scheme 5.1. Synthesis of Dmoc protecting group precursor..................... 75

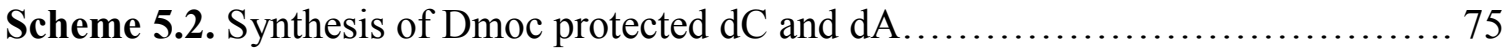

Scheme 5.3. Synthesis of Dmoc-dC-amidite and Dmoc dA-amidite ...................76

Scheme 5.4. The cleavage and deprotection of ODN 5.16 $\ldots \ldots \ldots \ldots \ldots \ldots \ldots \ldots \ldots . \ldots 7$

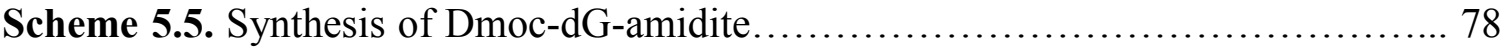

Scheme 5.6. Michael acceptor-an addcut from the removal of Dmoc protecting group. 81

Scheme 5.7. Cleavage and deprotection of ODN 5.19........................ 82

Scheme 6.1. Method A of introducing dG with Dmoc group.................... 112

Scheme 6.2 Method B of introducing dG with Dmoc group........................113

Scheme 6.3. Synthesis of Dmoc-dG-amidite 1.4 ................................ 114

Scheme 7.1. Proposed deprotection and cleavage utilizing Dim-protected

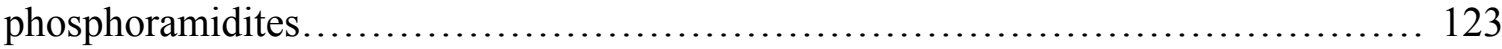

Scheme 7.2. Introduction of Deoc moieties to nucleoside bases.................. 125 


\section{Preface}

All of the experiments, data analysis and writing in this dissertation were conducted by Ms. Xi Lin. The investigations in this dissertation were under Dr. Shiyue Fang's supervision.

The contents in Chapter 4 and Chapter 5 were adapted into a journal paper “Oligonucleotide Synthesis Using Protecting Groups and a Linker Cleavable under Nonnucleophilic Conditions". This paper has been submitted to the Chemical Communications for peer review. The contents in Chapter 6 will be revised and be submitted to the Tetrahedron Letters. 


\section{Acknowledgements}

I am extremely grateful for everything I have experienced and learned from my $\mathrm{PhD}$ journey.

First, this dissertation would not have been possible without the guidance and support from my advisor Dr. Shiyue Fang. As I encountered a lot of problems in my project, he was always there guiding me through the dark forest. With great patience, he spent lots of time on nurturing me and training me to be a skillful researcher. Not to mention he is the first to spark my interest on nucleic acid chemistry. His guidance is greatly appreciated.

I am very grateful for the support and help from my former and present group members. They are Dr. Mingcui Zhang, Dr. Xiang Zhang, Dr. Zezhou Wang, Dr. Bin Cao, Suntara Fueangfung (Boat), Durga Pokeral, and Ashok Khanal. They have been very helpful and supportive through my study. I am also very grateful for the support and help from my colleagues, fellow graduate students, and staff from the Department of Chemistry. The encouragement and caring from them are greatly appreciated. I wish them all the best and success ahead.

I would like to express my deepest gratitude to the members of my dissertation committee - Dr. Dallas K. Bates, Dr. Haiying Liu and Dr. Yun Hang Hu. I thank them for their good natured support and constructive suggestions on my motivation of being a good scientist. 
Last but not least, I must acknowledge my family and my friends. Their supports always motivate me to become a better person. I would like to take this opportunity to thank my fiancé Ee Lim Tan and my best friend Nazmiye Yapici. Their encouragement has helped me gone through the hardest time in my graduate study. I will never forget the love and caring they gave to me, and cannot feel more blessed with them standing behind me. I am also grateful for the support from my father, Hui Lin, mother, Xiaodong Luo, my little brother, Shan Lin and the support from my fiancé's family. Their supports are greatly appreciated and this dissertation is partially dedicated to them. 


\begin{abstract}
Oligodeoxynucleotides (ODNs) containing latent electrophilic groups can be highly useful in antisense drug development and many other applications such as chemical biology and medicine, where covalent cross-linking of ODNs with mRNA, protein and ODN is required. However, such ODN analogues cannot be synthesized using traditional technologies due to the strongly nucleophilic conditions used in traditional deprotection/cleavage process.
\end{abstract}

To solve this long lasting and highly challenging problem in nucleic acid chemistry, I used the 1,3-dithian-2-yl-methoxycarbonyl (Dmoc) function to protect the exo-amino groups on the nucleobases $\mathrm{dA}, \mathrm{dC}$ and $\mathrm{dG}$, and to design the linker between the nascent ODN and solid support. These protecting groups and linker are completely stable under all ODN synthesis conditions, but can be readily cleaved under nonnucleophilic and nearly neutral conditions. As a result, the new ODN synthesis technology is universally useful for the synthesis of electrophilic ODNs.

The dissertation is mainly comprised of two portions. In the first portion, the development of the Dmoc-based linker for ODN synthesis will be described. The construction of the dT-Dmoc-linker required a total of seven steps to synthesize. The linker was then anchored to the solid support—controlled pore glass (CPG). In the second portion, the syntheses of Dmoc-protected phosphoramidites ODN synthesis monomers including Dmoc-dC-amidite, Dmoc-dA-amidite, Dmoc-dG-amidite are described. The protection of $\mathrm{dC}$ and $\mathrm{dA}$ with 1,3-dithian-2-yl-methyl 4-nitrophenyl carbonate proceeded smoothly giving Dmoc-dC and Dmoc-dA in good yields. However, when the same 
acylation procedure was applied for the synthesis of Dmoc-dG, very low yield was obtained. This problem was later solved using a highly innovative and environmentally benign procedure, which is expected to be widely useful for the acylation of the exoamino groups on nucleoside bases. The reactions to convert the Dmoc-protected nucleosides to phosphoramidite monomers proceeded smoothly with high yields. Using the Dmoc phosphoramidite monomers $\mathrm{dA}, \mathrm{dC}, \mathrm{dG}$ and the commercially available $\mathrm{dT}$, and the Dmoc linker, four ODN sequences were synthesized. In all cases, excellent coupling yields were obtained. ODN deprotection/cleavage was achieved by using nonnucleophilic oxidative conditions. The new technology is predicted to be universally useful for the synthesis of ODNs containing one or more electrophilic functionalities. 


\section{Chapter 1}

\section{Introduction}

\subsection{General Introduction}

Conventional solid phase oligodeoxynucleotide (ODN) synthesis technologies utilize the succinyl ester linker to link ODN to solid supports and acyl groups to protect the exo-amino groups on the nucleoside bases. At the end of synthesis, the cleavage and deprotection of ODN requires strongly nucleophilic reagents such as ammonium hydroxide, sodium hydroxide and potassium methoxide. These methods work well for un-modified ODN sequences and modified ones that are stable under strongly basic and nucleophilic conditions. However, they cannot be used to synthesize ODN analogues that contain one or more electrophilic functionalities.

ODN analogues that contain latent electrophilic groups are expected to find wide applications in research areas such as antisense drug development. ${ }^{1}$ Moreover, DNAs that are sensitive to bases and nucleophiles have been found in living cells and are believed to be important in biological processes. The synthesis of such model DNA will provide a basis for understanding the processes. ${ }^{2}$

For the synthesis of nucleophile-labile ODNs, two types approaches have been used in literature. One type attempts to use traditional methods to make a stable ODN precursor, which is later functionalized with electrophilic moieties after cleavage and deprotection. ${ }^{3}$ These methods are inconvenient, have to be developed case by case and are not always feasible. The other approach uses protecting groups and linkers that can be 
cleaved under nearly neutral conditions. However, functionalities in organic chemistry suitable for the need are limited. The ones used in the literatures were the palladiumremovable allyl groups ${ }^{4}$ and the photo-labile $o$-nitrobenzyl linker ${ }^{5}$. ODN synthesis methods relying on them suffer from drawbacks such as high cost of palladium, difficulty to remove transition metal, and DNA photo damages. Besides the above two strategies, enzymatic reactions have also been used to access electrophilic ODNs. ${ }^{6}$ Drawbacks include high cost and narrow applications.

\subsection{Our Technology}

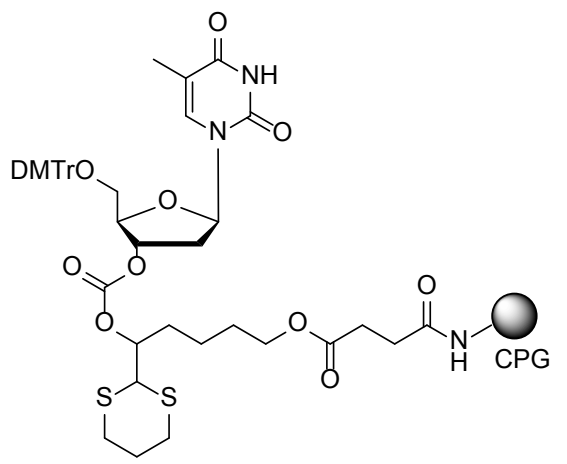

dT-Dmoc-CPG 1.1

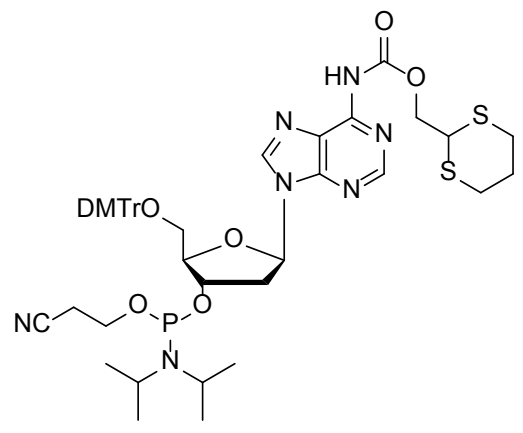

Dmoc-dA-amidite 1.3

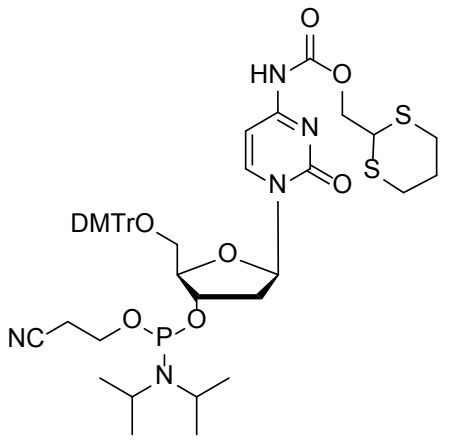

Dmoc-dC-amidite 1.2

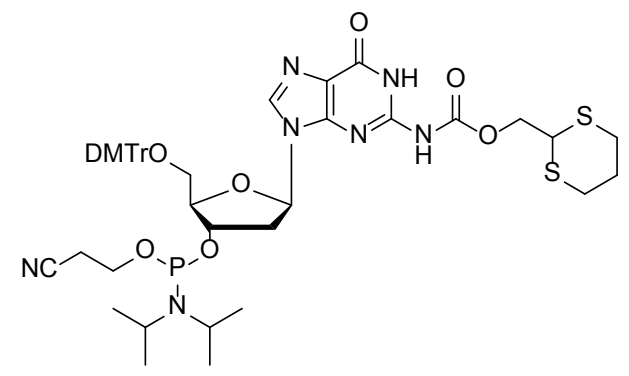

Dmoc-dG-amidite 1.4

Figure 1.1. CPG with dT-Dmoc linker and Dmoc-protected phosphoramidites 
To overcome the above problems in the synthesis of ODNs that contain sensitive functionalities, we designed the 1,3-dithian-2-yl-methoxycarbonyl (Dmoc) based protecting groups and linkers for ODN synthesis (1.1-1.4, Figure 1.1). The Dmoc-based groups and linkers are stable under all ODN synthesis conditions. During the postsynthetic steps, oxidation of the sulfides in Dmoc groups drastically increase the acidity of $\mathrm{H}-2$ in the 1,3-dithiane functions as shown in Scheme 1.1. The protecting groups and linkers can be cleaved under nearly neutral and non-nucleophilic conditions.
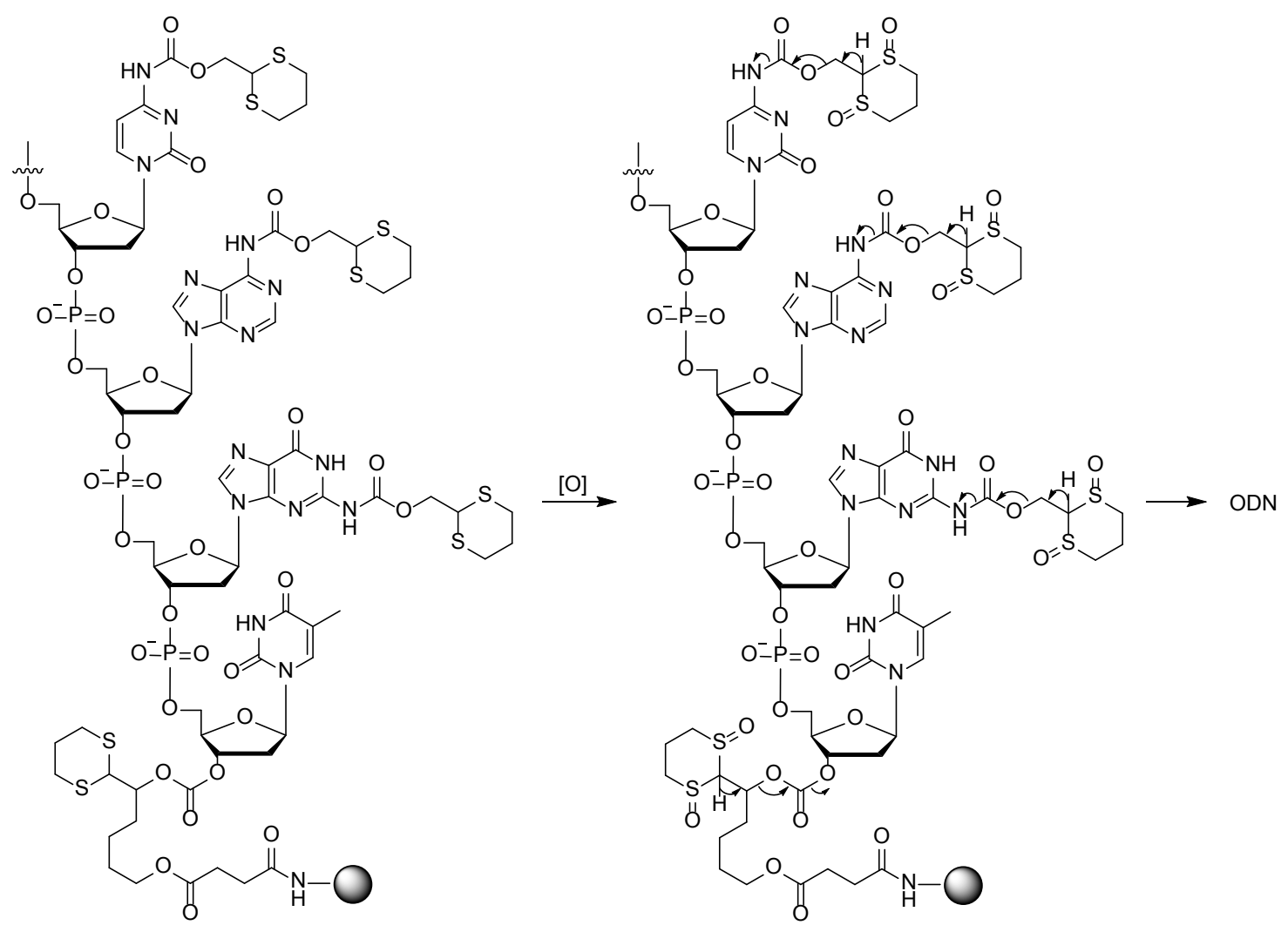

Scheme 1.1. Deprotection and cleavage of ODN protected and linked with Dmoc function 
The novelty of the design includes (i) an oxidatively-cleavable linker for ODN synthesis; (ii) protecting groups removable under non-nucleophilic oxidative condtions for ODN synthesis; and (iii) non-nucleophilic cleavage and deprotection conditions for ODN synthesis.

The specific tasks for realizing the design has been described in the following chapters (Chapter 3-7). In Chapter 3, the feasibility of adapting Dmoc moieties for ODN synthesis is explored. In Chapter 4, the synthesis of dT-Dmoc-CPG $\mathbf{1 . 1}$ and its application in ODN synthesis is described. In Chapter 5, the syntheses of three Dmocprotected nucleoside phosphoramidite monomers (1.2-1.4) are reported and the nonnucleophilic cleavage/deprtection conditions for ODN synthesis are disclosed in details. In Chapter 6, an improved synthesis of Dmoc-dG-amidite (1.4) is presented. In Chapter 7, continuous efforts on enabling the synthesis of electrophilic ODNs are outlined.

\section{References}

1. Patil, S. D.; Rhodes, D. G.; Burgess, D. J., DNA-based therapeutics and DNA delivery systems: a comprehensive review. The AAPS journal 2005, 7 (1), 61-77.

2. Kamiya, H., Mutagenic potentials of damaged nucleic acids produced by reactive oxygen/nitrogen species: approaches using synthetic oligonucleotides and nucleotides. Nucleic Acids Research 2003, 31 (2), 517-531.

3. (a) Pande, P.; Shearer, J.; Yang, J. H.; Greenberg, W. A.; Rokita, S. E., Alkylation of nucleic acids by a model quinone methide. Journal of the American Chemical Society 1999, 121 (29), 6773-6779; (b) Ali, M. M.; Oishi, M.; Nagatsugi, F.; Mori, K.; Nagasaki, 
Y.; Kataoka, K.; Sasaki, S., Intracellular inducible alkylation system that exhibits antisense effects with greater potency and selectivity than the natural oligonucleotide. Angewandte Chemie 2006, 45 (19), 3136-40; (c) Lukhtanov, E. A.; Mills, A. G.; Kutyavin, I. V.; Gorn, V. V.; Reed, M. W.; Meyer, R. B., Minor groove DNA alkylation directed by major groove triplex forming oligodeoxyribonucleotides. Nucleic Acids Research 1997, 25 (24), 5077-5084; (d) Grant, K. B.; Dervan, P. B., Sequence-specific alkylation and cleavage of DNA mediated by purine motif triple helix formation. Biochemistry 1996, 35 (38), 12313-12319.

4. (a) Hayakawa, Y.; Wakabayashi, S.; Kato, H.; Noyori, R., The allylic protection method in solid-phase oligonucleotide synthesis - an efficient preparation of solidanchored DNA oligomers. Journal of the American Chemical Society 1990, 112 (5), 1691-1696; (b) Spinelli, N.; Meyer, A.; Hayakawa, Y.; Imbach, J. L.; Vasseur, J. J., Use of allylic protecting groups for the synthesis of base-sensitive prooligonucleotides. European Journal of Organic Chemistry 2002, (1), 49-56.

5. (a) Greenberg, M. M.; Gilmore, J. L., Cleavage of oligonucleotides from solidphase supports using $O$-nitrobenzyl photochemistry. Journal of Organic Chemistry 1994, 59 (4), 746-753; (b) Matray, T. J.; Greenberg, M. M., Site-specific incorporation of the alkaline labile, oxidative stress product (5r)-5,6-dihydro-5-hydroxythymidine in an oligonucleotide. Journal of the American Chemical Society 1994, 116 (15), 6931-6932.

6. Goodchild, J., Conjugates of oligonucleotides and modified oligonucleotides: a review of their synthesis and properties. Bioconjugate Chemistry 1990, 1 (3), 165-187. 


\section{Chapter 2}

\section{History and Background}

\subsection{The Overview of ODNs}

\subsubsection{The origin of ODN research}

DNA research can be dated back to the mid of 19th century. At that time, ODNs were not considered as important substances. When Friedrich Miescher discovered DNA in 1869 , he named it nuclein. ${ }^{1}$ DNA was considered as a high molecular weight polymer for over five decades. It didn't attract significant attention from the scientific community. In early 1940s, Avery reported an altered transformation of bacteria in which DNAs were removed. ${ }^{2}$ Scientists realized that DNAs might be of genetic importance. Investigations on the structures and chemistry of DNA started since then.
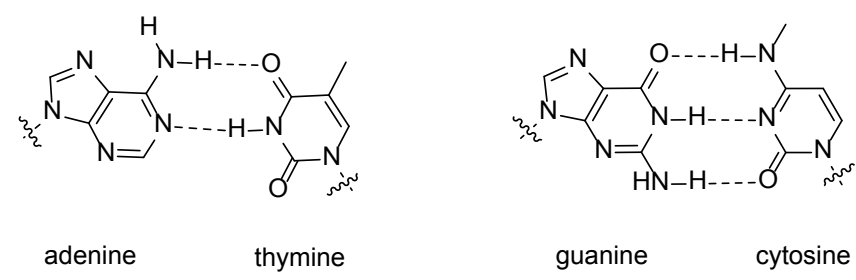

Figure 2.1. Complementary base pairing

Due to the advantage of X-ray crystallography technology, the structure of mononucleotides and double stranded nucleotides were elucidated. In 1953, Watson and Crick revealed one of the most important scientific discoveries. They built a double helix DNA model, which featured complementary base pairing (Figure 2.1). The model revealed how genetic information was coded in DNA. ${ }^{3}$ Later, Nirenberg and his 
coworkers reported their work on the translation of a poly-uracil polynucleotide into polypeptide in a cell-free system. ${ }^{4}$ The successful translation from nucleotide to protein uncovered the role of RNA and the process of gene expression. These discoveries ushered scientists entering into the era of molecular biology.

At that time, Gobind Khorana believed that chemical synthesis of polynucleotides could be important for understanding the fundamental process in biology, which is from DNA to RNA to protein. During 1970 s, Khorana and his group chemically synthesized a series of RNAs and DNAs. ${ }^{5}$ However few scientists shared Khorana's vision. Many biologists thought his gene syntheses have little practical application. A striking turnover came in 1977. The groups of Itakura and Boyer demonstrated that the homone somatostatin could be expressed from a chemically synthesized gene in bacterium. ${ }^{6}$ This work set a milestone for the routine application of synthetic genes in the production of proteins. ODNs became invaluable assets in understanding the fundamental basis of genetic studies, and found wide applications in biological and biomedical research areas.

\subsubsection{The importance of ODNs}

\subsubsection{ODNs in understanding fundamental biology}

The availability of synthetic ODN increased the momentum to nucleotide structure studies. While using the synthetic dinucleoside phosphate ApU, Rich's group and Klug's group discovered a series of alternative base pairs and base triples other than traditional Watson-Crick complimentary paring (Figure 2.1$){ }^{7}$ Later, Wang discovered a left-handed Z-conformation in synthetic $\mathrm{d}(\mathrm{CGCGCG}) .{ }^{8}$ Followed a sequence of 
demonstration of synthetic ODNs in a B-DNA helix by Dickerson ${ }^{9}$ and a A-DNA helix by Kennard, ${ }^{10}$ the idea that DNA has a stubborn, rod-like structure was concluded.

Synthetic ODNs also provide opportunities to study the interactions between DNAs and other molecules, such as mutagens, carcinogens and proteins. One example is the research on the mutagenic 2-amino-1-methyl-6-phenylimidazo[4,5-b]pyridine (PhIP), a heterocyclic amines found abundant in cooked meat. Because this heterocyclic amine is believed to be mutagen and carcinogen after their metabolic activation and subsequent binding with DNAs, ${ }^{11}$ a synthetic dG-C8-PhIP ODN was synthesized by Fukuda to uncover the molecular mechanism of the PhIP induced mutation. ${ }^{12}$ Another example is the investigations on the interactions of DNAs with proteins. In a report published by Bazzi and his coworker, a synthetic mini-cTAR ODN was applied to bind with a HIV-1 nucleocapsid protein. With the structure insights obtained from nuclear magnetic resonance and gel retardation assays, they concluded that the binding activity between ODN and protein is based on the conformation differences, such as major and minor grooves. $^{13,14}$

\subsubsection{ODNs in biotechnology}

In the last 30 years, biotechnology has reshaped the life science. Synthetic ODNs are one of the fundamentals for such advances. For example, ODNs are required in DNA sequencing, cloning and gene detection. ${ }^{15}$

In classical Sanger DNA sequencing, a short ODN primer was hybridized with a single stranded DNA template. ${ }^{16}$ Through enzymatic reaction, the elongation from the primer was achieved by incorporating normal deoxynucleosidetriphosphates (dNTPs). 
During the elongation process, dideoxynucleosidetriphosphates (ddNTPs) were introduced to terminate the elongation. Gel electrophoresis analysis of the DNA sequences with different length reveals the sequence of template DNA. Since the DNA polymerase can only start from a primer hybridized to the template, chemically synthesized ODN is required for the production of the desired double stranded DNA.

PCR is a technology that amplifies a piece of DNA by generating millions of copies of template DNA. ${ }^{17}$ Similar to DNA sequencing, the concept of PCR is elongating DNA sequences on ODN primers through enzymatic reaction. The difference is that the template is a double stranded DNA instead of single strand one. Thus, two ODN primers are used. One primer is complementary to the $3^{\prime}$ end of one DNA strand, while the other primer is hybridized to the $3^{\prime}$ end of the other DNA strand. The elongation will be terminated when reaching the restriction sites at $5^{\prime}$ ends of each DNA strand. Nowadays, many DNA sequences are known for organisms. Thus, utilizing various chemically synthesized ODN primers, PCR can easily provide DNAs or genes with interests.

DNA fingerprinting is another important technology that require synthetic ODNs. ${ }^{18}$ In DNA fingerprinting, photo or radio labeled ODNs, called ODN probes are used to hybridize with hypervariables in sample solution. The resulting double-stranded DNA fragments are separated by gel electrophoresis and detected by the fluorescence or radio activity. Based on the hybridization assay, specific gene sequence in sample can be readily deleted. This technology is widely used in forensic studies.

ODN microarrays, also called DNA chips, are miniature parallel analytical devices containing libraries of oligonucleotides robotically spotted or synthesized on 
solid surfaces (glass, coated glass, silicon or plastic). ${ }^{19}$ Treated with a solution of fluorescently labeled ODNs (also called mobile probes), the target oligonucleotides can be identified by detecting fluorescence of the hybridized ODNs. This technology provides a classified gene inventory for living organisms.

Recently, researchers have also found other important application of ODNs and ODN analogues, such as in antisense therapeutic study, modulating gene expression and constructing DNA chips. ${ }^{20}$ These important research projects are not possible without advances on ODN synthesis methodology.

\subsection{ODN Synthesis}

\subsubsection{The history of ODN synthesis}

\subsubsection{First dinucleotide}
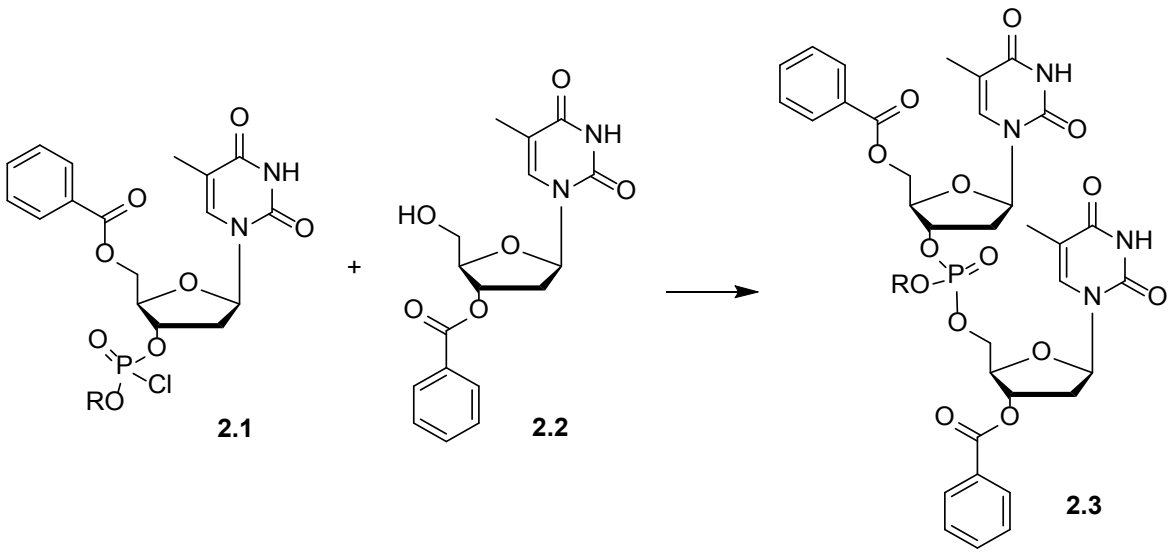

Figure 2.2. Synthesis of first dinucleotide

The first chemical synthesis of an ODN was reported by Michelson and Todd in 1955. ${ }^{21}$ In their report, two thymidine nucleosides were linked together by the formation of a phosphate internucleotide linkage (Figure 2.2). They first prepared two starting 
materials. One of them is the thymidine phosphoryl chloride 2.1. The other is $3^{\prime}$-benzoyl deoxythymidine (dT) 2.2. The two were then reacted with each other to give the dinucleotide product $\mathbf{2 . 3}$.

\subsubsection{Phosphodiester method}

Inspired by Todd's work, Khorana's group continued the studies on ODN synthesis. In the protocol he and his coworkers published in 1956, the phosphodiester method was developed for ODN synthesis (Figure 2.3). ${ }^{22}$ Instead of using the easily hydrolyzable phosphoryl chloride as starting materials, they prepared nucleoside phosphates. These nucleoside phosphates were subsequently activated using a condensation reagent. For example, the DMTr-protected thymidine phosphate 2.4 was activated with dicyclohexyl carbodiimide (DCC) and reacted with 2.5 to give the dithymidine nucleotide $\mathbf{2 . 6}$.
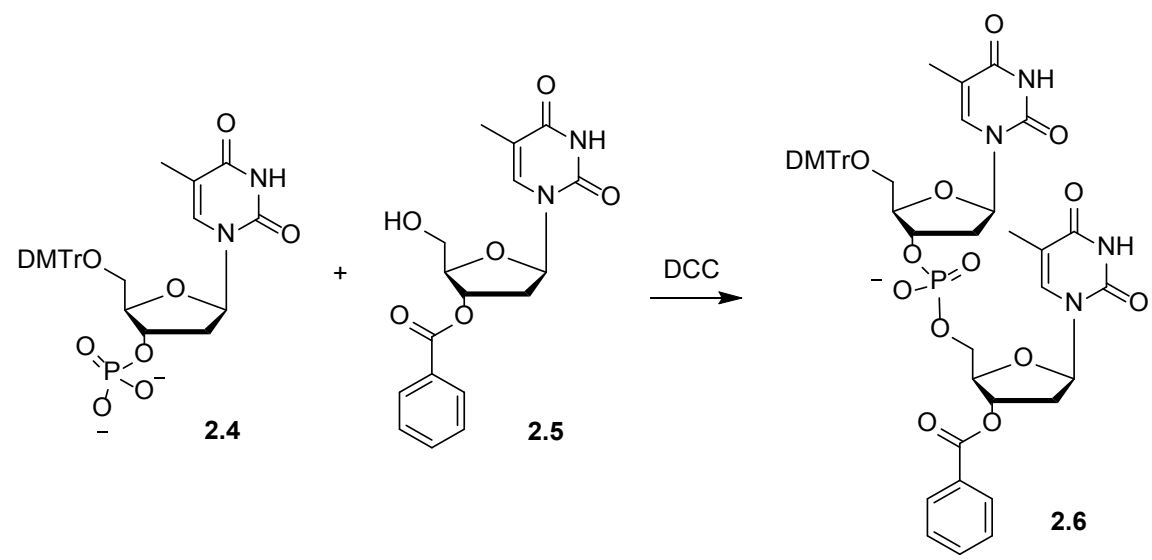

Figure 2.3. Phosphodiester approach

Since the phosphate itself was not protected, branching at the internucleotide phosphate linkages from the previous couplings became a problem. As the 
oligonucleotide length increased, the percentage of branching also increases and makes the purification of ODN a challenging task.

2.2.1.3 The introduction of solid phase chemistry to ODN synthesis

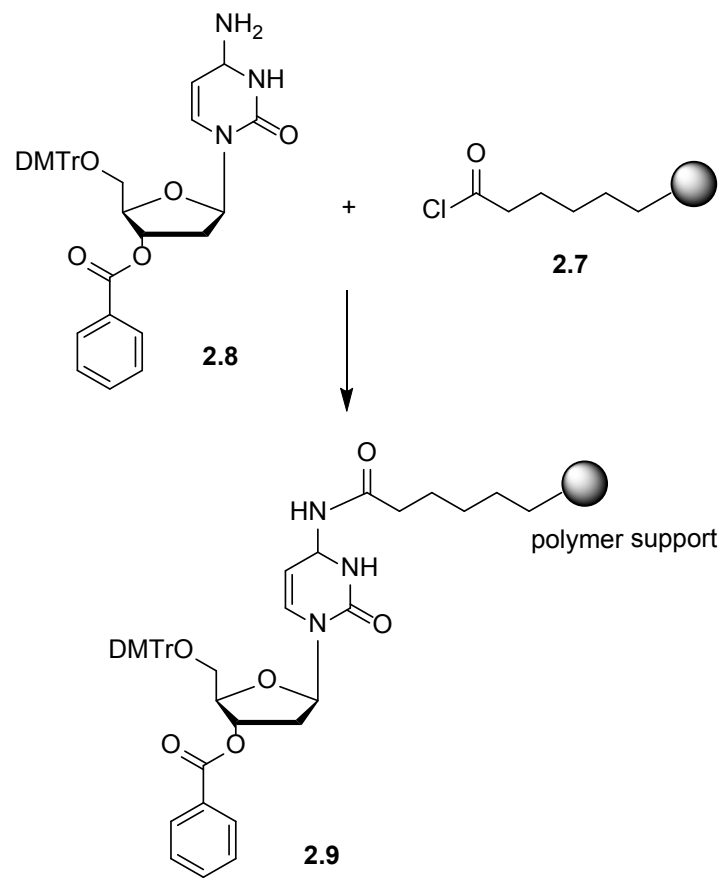

Figure 2.4. Coupling of dC to polymer solid support

In the early 1960s, solid phase chemistry has been successfully applied to organic synthesis and peptide synthesis. Robert Letsinger was the first to adapt the technology to ODN synthesis. In his paper published in 1965, he described the synthesis of dimer and trimer ODNs using the styrene-divinylbenzene polymer as solid support. ${ }^{23}$ As shown in Figure 2.4, the polymer support was first modified with acetic chloride and gave the modified polymer support 2.7. With both $3^{\prime}$ - and 5'- hydroxyl groups protected by dimethoxytrityl (DMTr) and benzoyl groups, the 4-amino groups of protected deoxycytidine (dC) 2.8 reacted with the solid support 2.7. The DMTr group was then 
removed with mild acid to prepare for the coupling of next nucleoside. The attachment to solid support 2.9 was cleaved with strong bases and released the ODN.

\subsubsection{Phosphotriester method}

In 1969, Letstinger's group published a series of papers describing the phosphotriester method for ODN synthesis. For example, as shown in Figure 2.5, 2cyanoethyl protected dT phosphate $\mathbf{2 . 1 0}$ reacted with $\mathrm{dC}$-linked polymer support $\mathbf{2 . 1 1}$ and gave phosphotriester 2.12. ${ }^{24}$ The major advance of this method was the protection of the phosphate group that prevents the branching on internucleotide linkage. The protecting group used was the $\beta$-cyanoethyl group which could be easily removed with ammonium hydroxide through $\beta$-elimination.
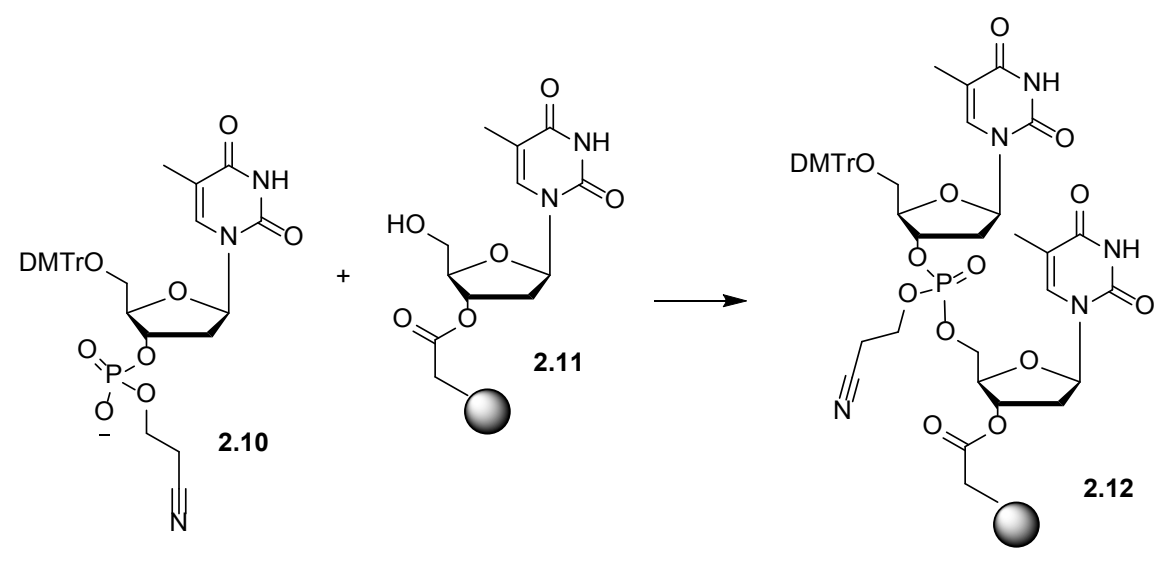

Figure 2.5. Phosphotriester Approach

The major drawback for phosphotriester chemistry is the low average step-wise yield, which often fell below 95\%. The inefficient coupling limited the routine synthesis of ODN to the length of less than 20 bases. 


\subsubsection{Phosphite-triester method}

In the mid-1970s, Letsinger's continuous efforts in ODN synthesis led to the development of a new ODN synthesis method-the phosphite-triester method (Figure 2.6) ${ }^{25}$ This chemistry is based on the highly reactive nucleoside phosphorus(III) chlorides such as 2.13. Phosphorus(III) chlorides are much more reactive than the previous used phosphorus $(\mathrm{V})$ chlorides. The synthesis process required an additional step-oxidation to prepare the natural $\mathrm{P}(\mathrm{V})$ backbone. This chemistry significantly reduced the coupling time due to the highly reactive nature of the nucleoside phosphorochloridite.

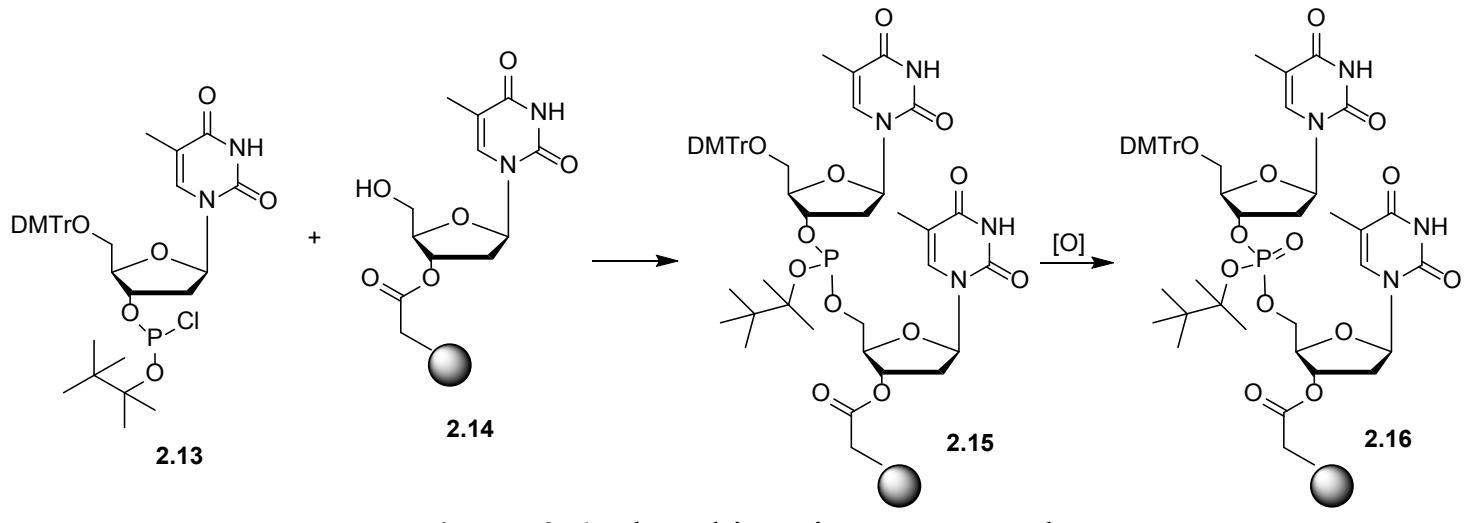

Figure 2.6. Phosphite-triester approach

The research community quickly accepted the new chemistry. However, the phosphite-triester method still has one serious drawback. The nucleoside phosphorochloridite intermediate is highly sensitive to moisture and air. Each nucleoside phosphorochloridite must be freshly synthesized prior to coupling.

\subsubsection{The most widely used phosphoramidite chemistry}

Due to the drawbacks of phosphite-triester method, research on inventing new coupling reactions for ODN synthesis continues. In 1980s, Marvin Caruthers' research 
group developed the phosphoramidite approach. He and his coworkers solved two major problems. One is the swelling problem of solid supports, which was overcome by using controlled pore glass $(\mathrm{CPG})$. The other problem they solved was the instability of nucleoside intermediates. They utilized the nucleoside phosphoramidites as the intermediates, which are much more stable than phosphites. The phosphoramidite chemistry became the most widely used technology of ODN synthesis, and the core barely changed over the years. ${ }^{26}$ The general synthesis cycle of phosphoramidite chemistry (Figure 2.7) includes 4 steps, which are described in the following sections.

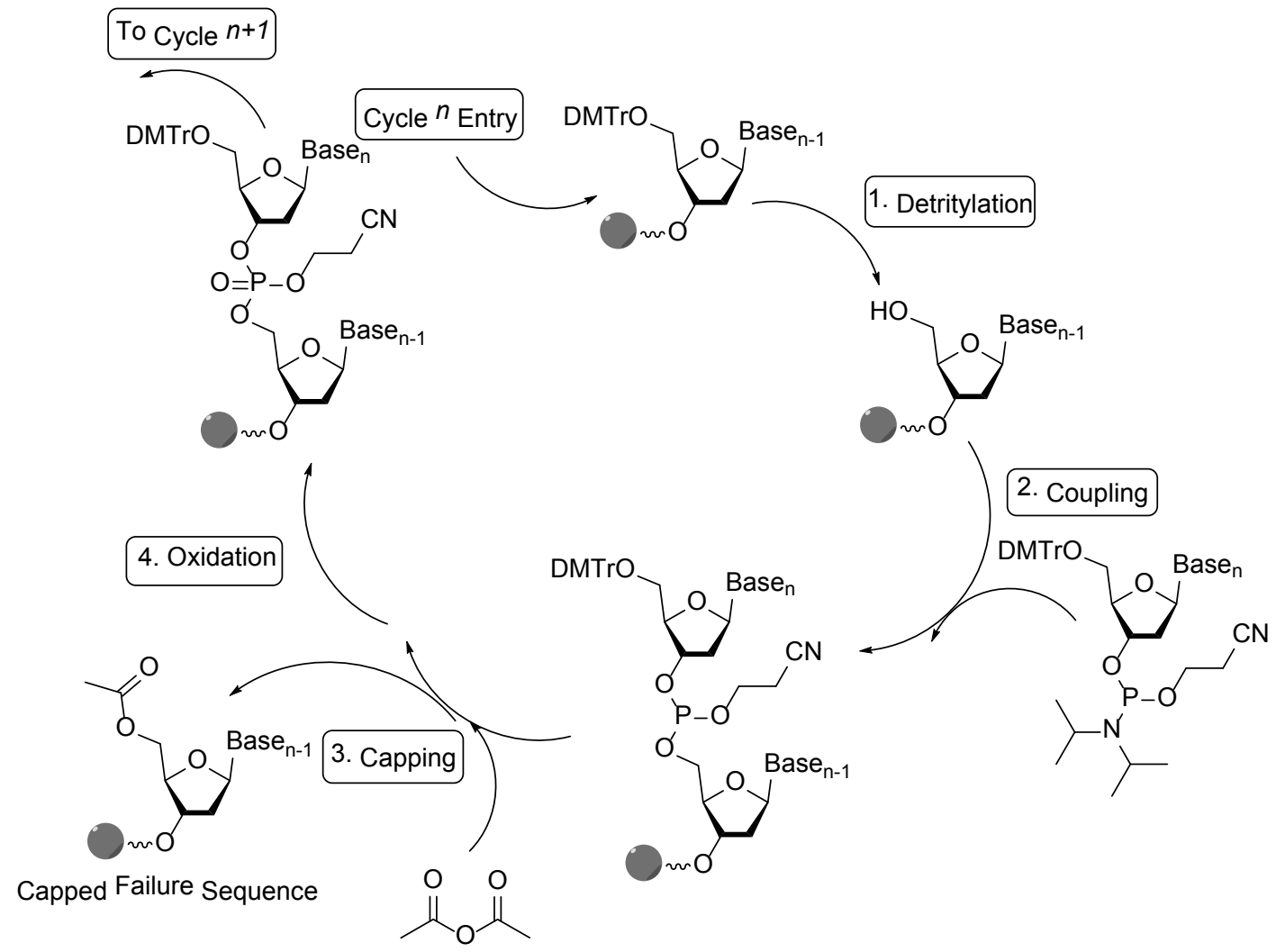

Figure 2.7. ODN synthesis cycle using phosphoramidite chemistry 


\subsubsection{Detritylation}

The 5'-OH group of nucleoside phosphoramidite are protected with a 4.4'dimethoxytrityl (DMTr) group. As a result, the 5'-end of growing ODN on solid support has a DMTr group. The first step in a synthesis cycle is to remove this protecting group, which is called detritylation. Detritylation is achieved by the treatment with trichloroacetic acid. The mechanism of the removal of DMTr group is shown in Figure 2.8 .

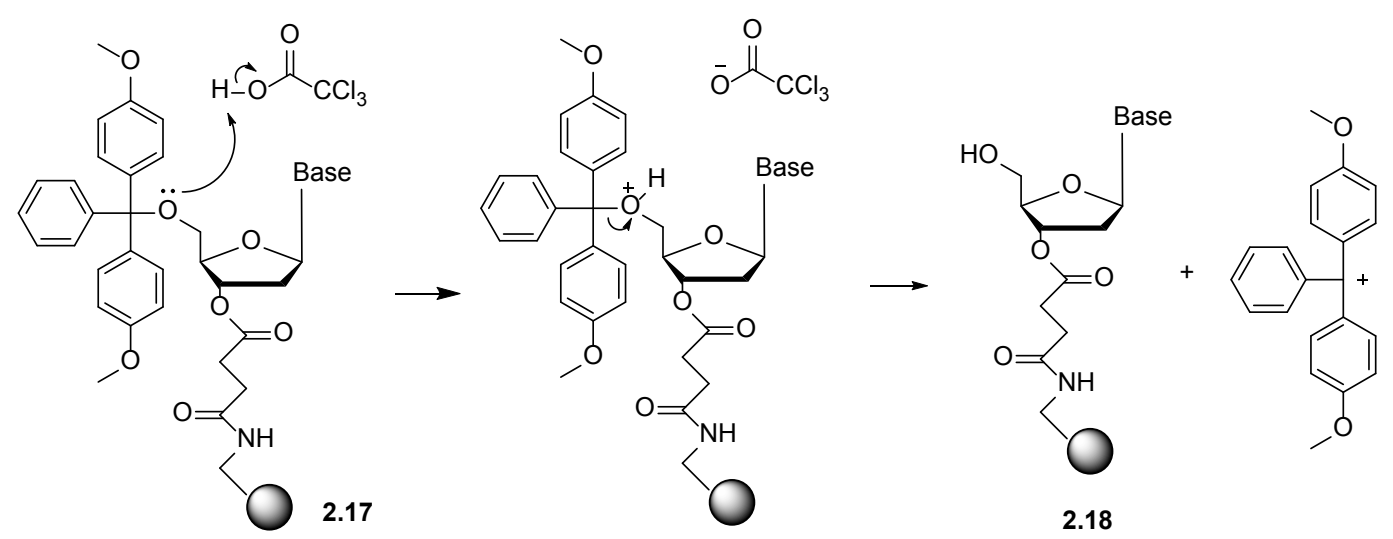

Figure 2.8. Detritylation

\subsubsection{Coupling}

Following detritylation, a large excess of nucleoside phosphoramidite solution in acetonitrile was added to the solid support. Activated by tetrazole or other weakly acidic activators, the diisopropylamino group of nucleoside phosphoramidite $\mathbf{2 . 1 9}$ is protonated and converts to a good leaving group. The coupling of two nucleosides is achieved by the nucleophilic attack from support-bound nucleoside 2.20 to nucleoside phosphoramidite 2.19 (Figure 2.9). 


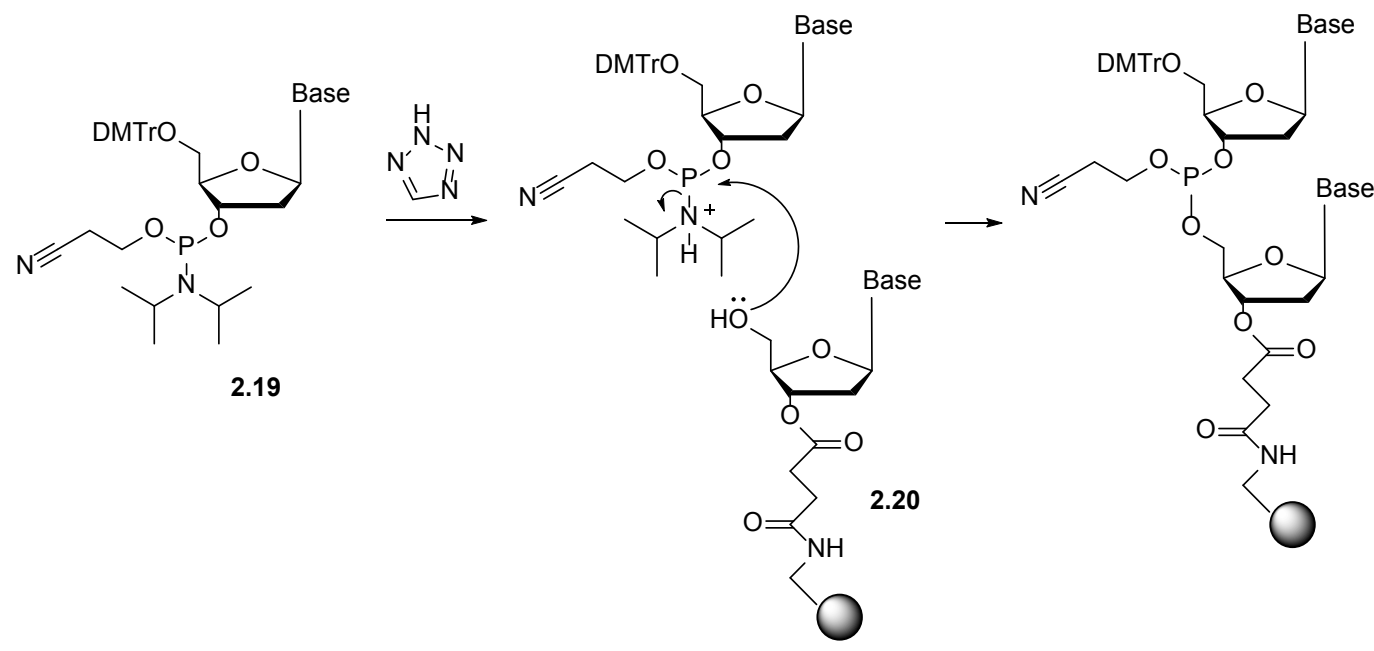

Figure 2.9. Coupling

\subsubsection{Capping}

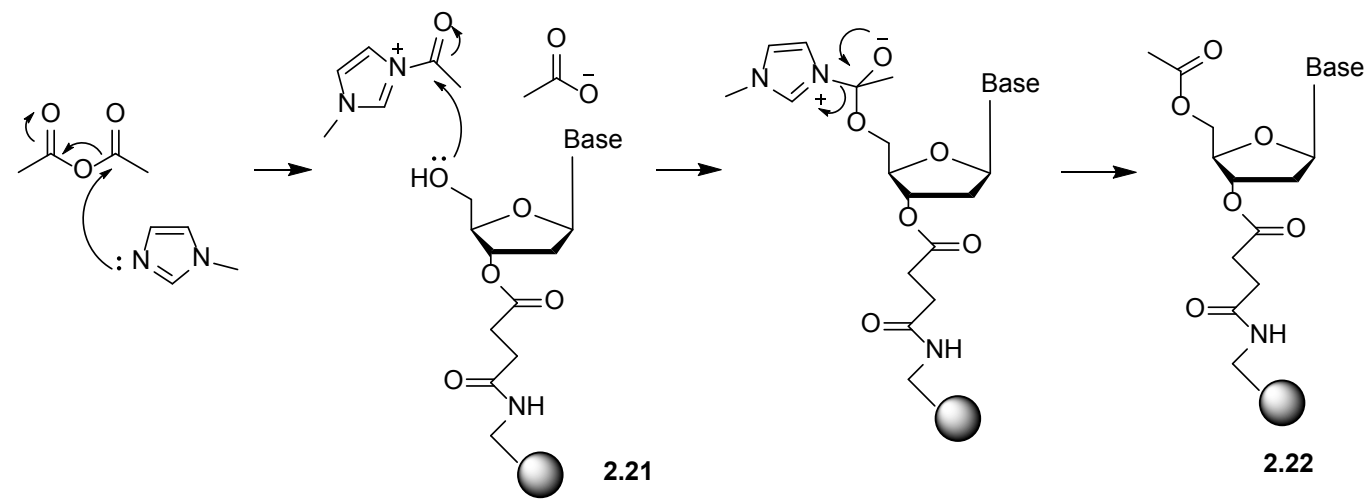

Figure 2.10. Capping failure sequence

Since a yield of $100 \%$ is not achievable even for the most efficient reaction, there will always be a few support-bound nucleosides which haven't reacted with the nucleoside phosphoramidite during the coupling step. The unreacted 5'-OH groups of the failed coupling will react with next nucleoside base in the following coupling. The resulted ODN sequence will be missing one base. Without appropriate check, these ODN failure sequences with missing bases would accumulate from each successive cycle, and 
the final product would be a complex mixture of ODNs. These ODN failure sequences will carry incorrect genetic information, and be difficult to remove.

By introducing a capping step right after coupling, the unreacted 5'-hydroxyl groups will be blocked with acetyl groups and be voided reacting with the nucleoside phosphoramidite in the next synthesis cycles.

Capping reagents acetic anhydride and $N$-methylimidazole (NMI) are dissolved in tetrahydrofuran with the addition of a small quantity of pyridine. The mixture is then delivered to the solid support. As shown in Figure 2.10, the electrophilic mixture rapidly acetylates alcohols and caps the reactive 5'-hydroxy groups on the failure sequence $\mathbf{2 . 2 1}$. The presence of pyridine ensures that the $\mathrm{pH}$ remains basic so that the nucleoside phosphoramidite won't be detritylated.

\subsubsection{Oxidation}

The phosphite-triester formed in the coupling step is unstable to acid and must be converted to a stable $\mathrm{P}(\mathrm{V})$ species prior to the next detritylation step. This is achieved by iodine oxidation in the presence of water and pyridine (Figure 2.11). 


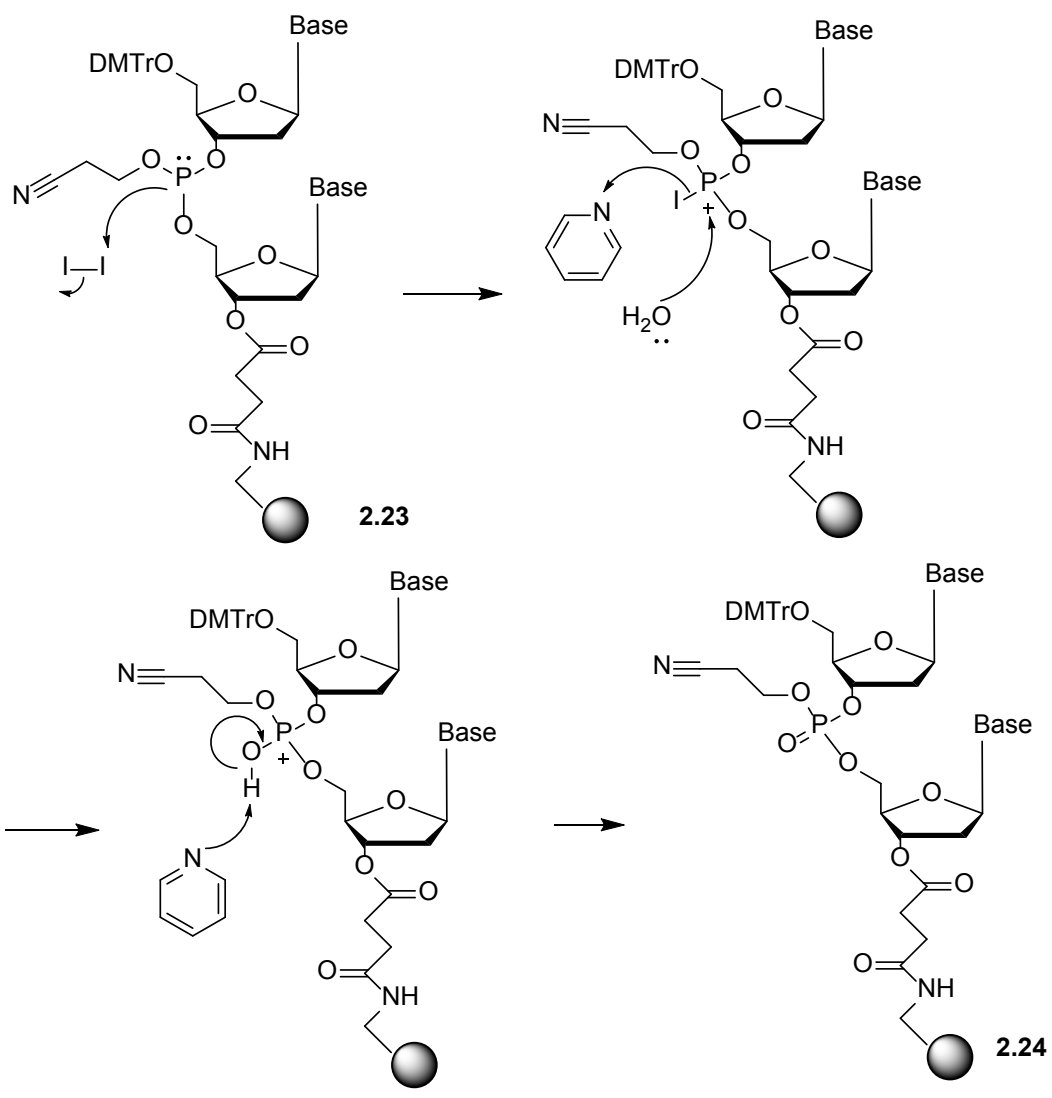

Figure 2.11. Oxidation of $\mathrm{P}(\mathrm{III})$ to $\mathrm{P}(\mathrm{V})$

\subsubsection{Automation}

The combination of the highly efficient phophoramidite chemistry for the formation of internucleotide phosphate linkage with solid phase methodology led to the automation of ODN synthesis. Caruthers designed a DNA synthesizer based on phosphoramidite chemistry and set up a company called ABI. The typical process used in phosphoramidite chemistry synthesizer is shown below in Table 2.1. 
Table 2.1. Step durations in a typical cycle using phosphoramidite chemistry

\begin{tabular}{|l|l|l|}
\hline Operation & Reagent/solvent & Time \\
\hline Detritylate & $3 \%$ trichloroacetic acid in dichloromethane & $50 \mathrm{~s}$ \\
\hline Couple & $0.1 \mathrm{M}$ phosphoramidite monomer and $0.5 \mathrm{M}$ tetrazole in acetonitrile & $30 \mathrm{~s}$ \\
\hline Cap & $\begin{array}{l}\text { acetic anhydride/pyridine/THF } 1 / 1 / 8 \text { and } 17.6 \% \mathrm{w} / \mathrm{V} \text { N-methyl } \\
\text { imidazole in acetonitrile }\end{array}$ & $30 \mathrm{~s}$ \\
\hline Oxidize & $0.015 \mathrm{M}$ iodine in water/pyridine/THF $2 / 20 / 78$ & $45 \mathrm{~s}$ \\
\hline
\end{tabular}

\subsubsection{Cleavage and deprotection}

\subsubsection{Cleavage from solid support}

Mostly, the ODNs are synthesized on solid support through the succinyl linker. This linker is readily cleaved by treatment with concentrated ammonium hydroxide at room temperature for one hour (Figure 2.12). The cleavage reaction is carried out automatically on some synthesizers. The ammonium solution containing the ODNs is delivered to a glass vial. Alternatively, the cleavage can be carried out manually by taking the column off the synthesizer and washing the solid support with ammonium hydroxide solution.

\subsubsection{Deprotection of phosphodiester backbone}

The phosphate groups are protected with $\beta$-cyanoethyl groups throughout ODN synthesis, and must be deprotected to obtain the desired ODNs. As shown in Figure 2.12, the cyanoethyl groups can also be removed by ammonium hydroxide through $\beta$ elimination. 


\subsubsection{Deprotection of nucleic bases}

The exocyclic amino groups on the heterocyclic bases (A, C, and $\mathrm{G})$ are protected during oligonucleotide synthesis. As mentioned earlier, different protecting groups are applied on different nucleoside bases. The benzoyl groups on A and C are cleaved readily in ammonium hydroxide, but the isobutyryl protecting group on guanine is much more resistant to ester hydrolysis. With treatment of concentrated ammonium hydroxide at 55 ${ }^{\circ} \mathrm{C}$ for 5 hours, isobutyryl groups can be removed quantitatively (Figure 2.12).
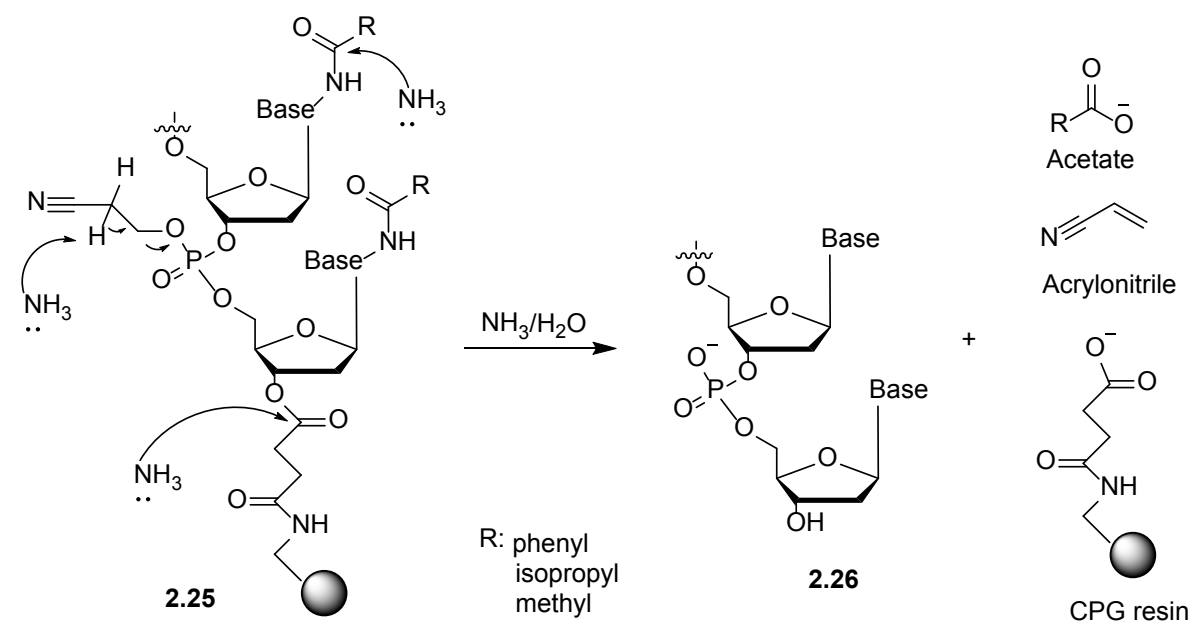

Figure 2.12. Cleavage and deprotection of ODN

\subsubsection{Scavenging of by-products}

Acrylonitrile, a by-product of phosphotriester deprotection, is a Michael acceptor. Under the strong basic conditions used for ODN deprotection, 2-cyanoethyl adducts can react with the hetereocyclic bases through Michael addition (Figure 2.13). Thereby, the product will be Michael conjugates of ODNs and the desired ODN won't be obtained. By treating with a solution of a weak base in an organic solvent (e.g. 10\% diethylamine in 
acetontrile, or 1:1 triethylamine/acetonitrile), the acrylonitrile can be scavenged and its reaction with nucleoside bases can be avoided.

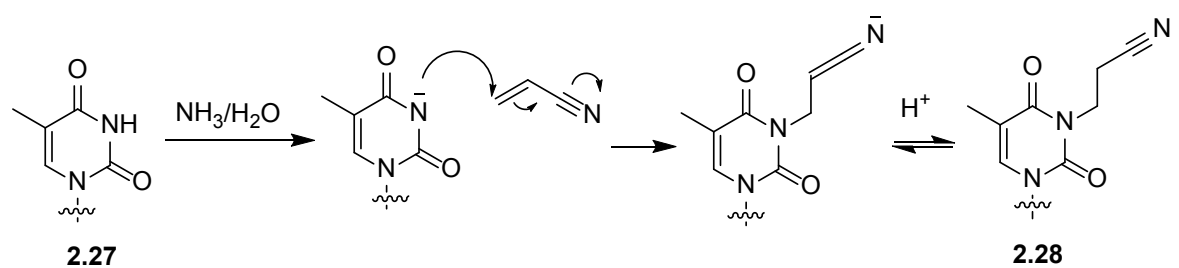

Figure 2.13. Michael addition to nucleoside base

\subsubsection{Purification of ODNs}

The most commonly used purification methods are polyacrylamide gel electrophoresis (PAGE) and high performance liquid chromatography (HPLC). The choice of ODN purification method depends on the ODN applications.

Electrophoresis using high percentage acrylamide gels is the most efficient method to separate the full-length product from all shorter species. Although it is impossible to recover all full-length ODN products from a gel, the loss from PAGE is typically acceptable considering the high purity. PAGE is strongly recommended for the purification of ODNs with over 60 bases in length.

HPLC is a chromatographic technique that utilizes a column to hold a stationary phase while the sample is eluted within a mobile phase. Due to specific chemical and physical properties, each analyte interacts with the stationary phase or mobile phase differently. Therefore, each analyte has an unique retention time. HPLC is usually reserved for ODNs that have been modified, such as ODNs with the addition of a linker or spacer, a non-standard base or bases, or hydrophobic molecules. Based on the 
differences on solvent affinity or net charge, ODNs can be separated by reverse-phase HPLC or ion-exchange HPLC with high resolution.

\subsubsection{Characterization of ODNs}

The widely used ODN characterization methods are electrospray ionization (ESI) mass spectrometry and matrix-assisted laser desorption/ionization-time of flight (MALDI-TOF) mass spectrometry.

ESI mass spectrometry can give mass of long ODNs (up to $\sim 150$ bases in length). The ODNs are dissolved with a solvent and are injected into electrospray chamber. Once the solvent is evaporated, the ions will separate from each other and reach the detector at different times. The detector will measure the mass to charge ratio of each ion, from which the molecular weight of ODN can be deduced.

MALDI-TOF mass spectrometry is a useful tool for the mass determination of ODNs up to 50 bases in length ( 15,000 Daltons). The concept of MALDI-TOF is based on that the speed of an ion is proportional to its mass. ODN samples are ionized and moved by a certain potential energy. By detecting the arrival time of each ion, the molecular weight of ODNs can be calculated.

\subsection{The Modifications of ODN}

Due to the advances on ODN chemical synthesis, various modifications can be made on ODNs. The derived ODN analogues have been found or are predicted to have wide applications as therapeutic agents and biosensors. 


\subsubsection{Backbone modification}

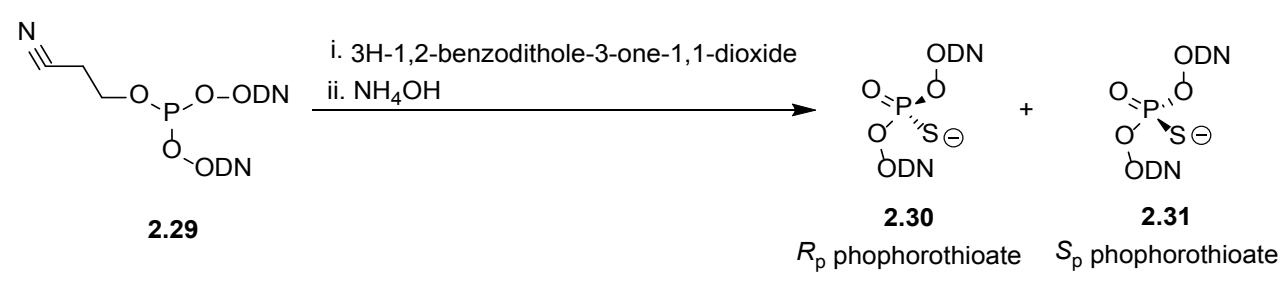

Figure 2.14. Synthesis of phosphothioates

The phosphate backbones of natural ODNs are degraded by nucleases easily and have limited the ODN application toward in vivo antisense therapeutic study. Eckstein's group replaced the $\mathrm{P}-\mathrm{O}$ bond of phosphate with a $\mathrm{P}-\mathrm{S}$ bond on the internucleotide linkage. ${ }^{27}$ The resulted phosphothioates greatly enhance the nuclease stability of ODNs. ${ }^{28}$ When phosphothioates hybridize with RNA, the lifetime of the helix is prolonged. Thus, phosphothioates are expected to be potential antisense therapeutics. $^{29}$

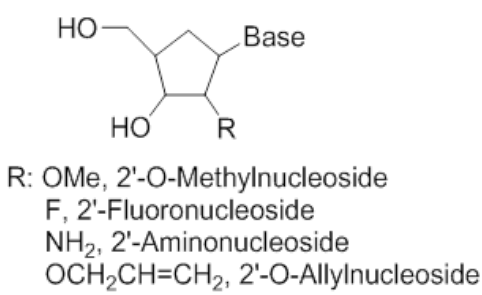

Figure 2.15. Modifications on sugar moiety

With the chiral center on phosphorus, phosphothiate can also be applied in studying the stereo activity of enzymatic reactions. Due to the ability of binding with "soft" metals, phosphothiate is very useful in investigating the interference activity with small molecules. ${ }^{30}$ The synthesis of phosphothioates can be easily achieved by utilizing 
sulfurizing reagents (such as $3 H$-1,2-benzodithole-3-one-1,1-dioxide) in the oxidation step (Figure 2.14). ${ }^{31}$

Modifications of sugar moiety are usually conducted on $2^{\prime}$ position. The modifications on $2^{\prime}$ position with methoxy, fluoro, amino and allyloxy groups were employed to probe hammerhead ribozyme catalysis. ${ }^{32}$

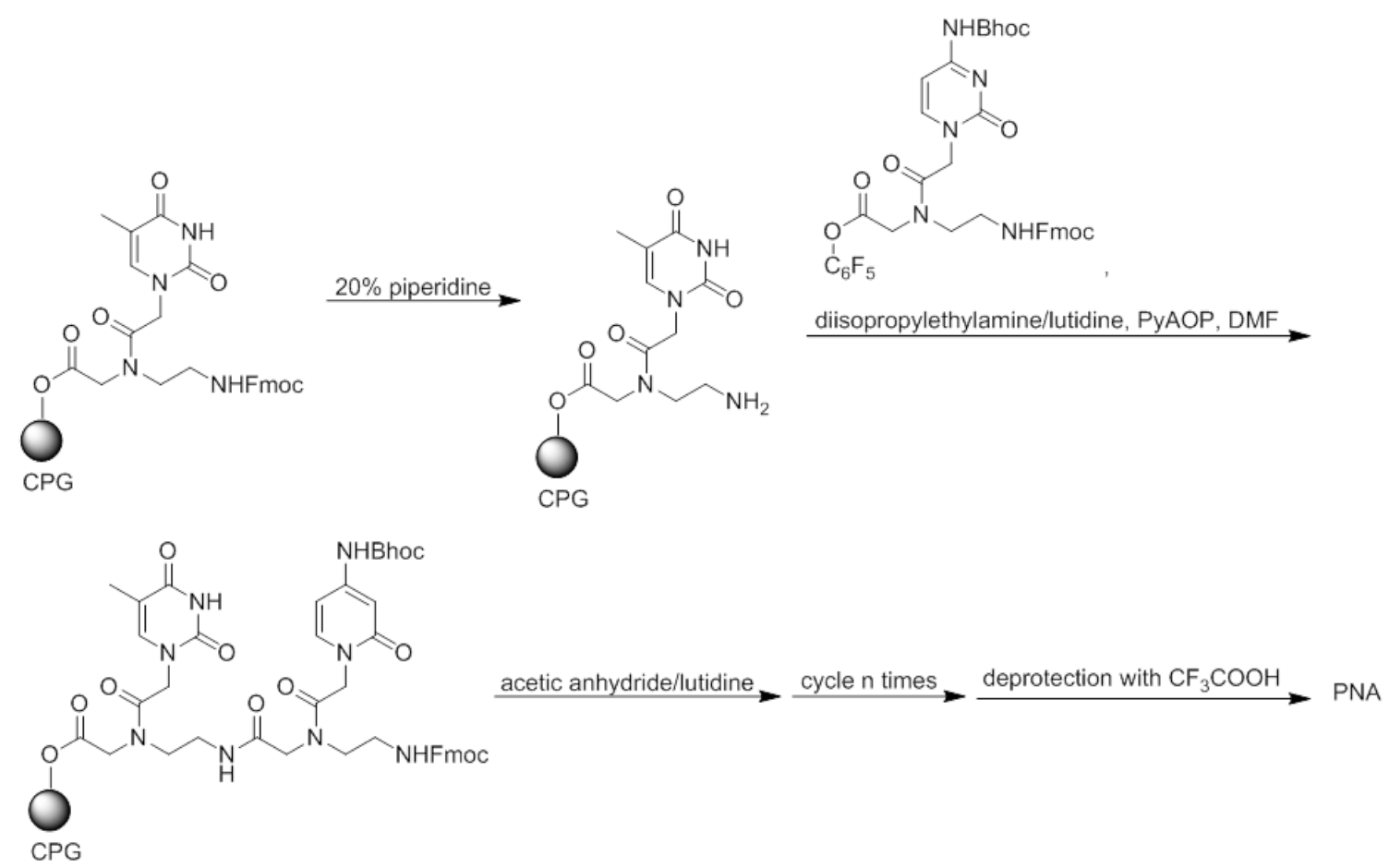

Figure 2.16. Synthesis of PNA

Peptide nucleic acids (PNAs) are a type of modified nucleic acid analogues without traditional phosphate backbone. PNA was first introduced by Buchardt and Nielsen in 1980s. ${ }^{33}$ The general synthesis of PNA is shown in Figure 2.16. With a 2aminoethyl-glycine linkage, the simple synthetic molecule is non-ionic, achiral, and stable towards nuclease. At the same time, the nucleoside bases are anchored to PNA 
backbone via a carbonyl linker. Thus PNAs are able to complementarily pairing with bases on DNAs or RNAs. PNAs are considered as potential drug candidates for antisense therapy. In Norden's review paper, the roles of PNAs as antigene drugs and molecular tools were discussed in details. ${ }^{34}$

\subsubsection{Terminus modification}

An important group of modified ODNs are ODN analogues with labeling groups at the terminus. For examples, ODNs are functionalized with fluorophores, radioactive moieties, and biotins on the $5^{\prime}$ - and $3^{\prime}$-terminals. ${ }^{35}$ These ODNs analogues are very useful in areas, such as quantifying, identifying and isolating oligonucleotides. For example, based on the strong interaction of biotin with streptavidin, ODN biotinylated with the reagent shown in Figure 2.17 can be easily separated from other molecules.

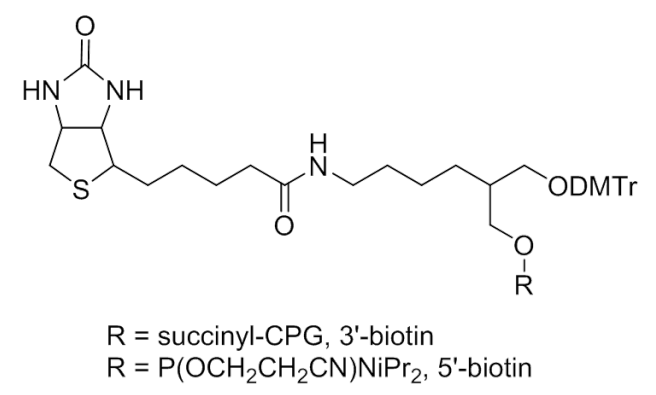

Figure 2.17. Biotinylation on $3^{\prime}$ and $5^{\prime}$ terminus

ODNs with linkers have also become important substrates in biology study. Like the linkers shown in Figure 2.18, which can generate terminal reactive groups (amino or thio groups), they can conjugate ODNs to other biomolecules and increase the interference ability. ${ }^{36}$ 


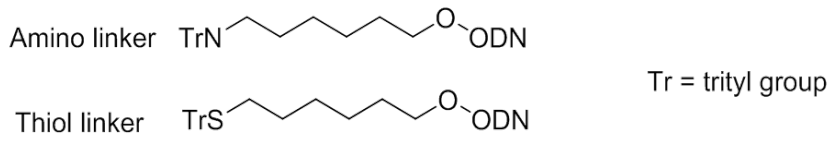

Figure 2.18. ODNs with linkers

The synthesis of these terminus modifications can be achieved using specific modified phosphoramidites. Reaction of ODNs with appropriate reagents after ODN synthesis cycle can also give ODNs on $5^{\prime}$ or $3^{\prime}$ terminus. Another convenient synthesis method for terminus modified ODNs is enzymatic ligation. ${ }^{37}$

\subsubsection{Base modification}

More ODN modifications were done on the nucleoside bases. The heterocyclic rings of purine and pyrimidine bases provide hydrogen-bonding moieties that are the most important contributors to DNA stability and reactivity. Modifications on the heterocyclic rings would drastically change the DNA stability and affect the interaction between DNA and other molecules.

Numbers of base-modified nucleoside phosphoramadites are commercially available for the synthesis of ODN analogues. Using different synthesis methods with/without protecting groups, base modifications can be achieved through phosphoramidite chemistry.

Carefully designed base analogues are extremely useful in improving the interaction in DNA, RNA, or nucleic acid-protein complexes. ${ }^{38}$ For example, 5-propynyl$\mathrm{dU}$ (Figure 2.19) allows improved stacking ability with neighbouring bases in DNA duplexes. 8-Hydroxy-dG (Figure 2.19), a DNA lesion caused by reactive oxygen species 
(ROS) is believed to play an important role in mutagenesis. The synthesis of 8-hydroxydG will provide basic research substrate for understanding the process that how damaged DNAs disturb the genetic information heredity. ${ }^{39}$ 2-Amino-6-vinylpurine deoxynucleotide (Figure 2.19) is designed by Sasaki as a cross-linking reagent. It could form a covalent bond with cytosine on RNA. The cross-linking activity is expected to be employed for the inhibition of gene expression. ${ }^{40}$ The modified ODNs analogues can form a nucleotide pool for antisense or antigene therapeutic studies.
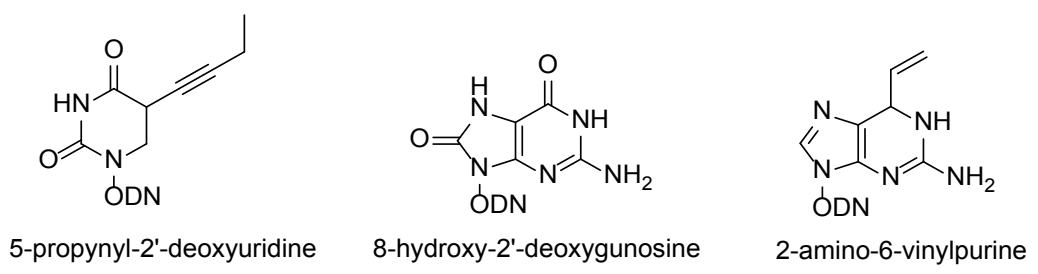

Figure 2.19. Modifications on nucleoside bases

\subsection{Perspectives}

With the development in ODN synthesis, chemically synthesized ODNs have been successfully employed in biology and biotechnology. Particularly, the tailor-made ODN analogues have been and are expected to play important roles in understanding biochemical processes and act as invaluable tools in biomedical area. However, a great challenge remains. To date, only the modifications that are relatively stable have been evaluated. Due to the harsh conditions of current ODN synthesis technology, many ODN analogues, such as ODNs with electrophilic functionalities, are not accessible. Novel synthesis strategies, such as new protecting strategy that can perform deprotection under 
very mild conditions, are in urgent needs to fully unlock the potential of ODNs and ODN analogues.

\section{References}

1. Dahm, R., Friedrich Miescher and the discovery of DNA. Developmental Biology 2005, $278(2), 274-288$.

2. Avery, O. T.; Macleod, C. M.; McCarty, M., Studies on the chemical nature of the substance inducing transfromation of pneumococcal types-induction of transformation by a deoxyribonucleic-acid fraction isolated from pneumococcus type-III (Reprinted from Journal of Experimental Medicine, Vol 79, Pg 137-158, 1944). Molecular Medicine 1995, 1 (4), 344-365.

3. Watson, J. D.; Crick, F. H. C., Molecular-structure of nucleic-ccids - a structure for deoxyribose nucleic-acid (Reprinted from Nature, Vol 171, Pg 737, 1953). Annals of New York Academy of Science 1995, 758, 737-738.

4. Nirenberg, M. W.; Matthaei, J. H.; Jones, O. W.; Martin, R. G.; Barondes, S. H., Approximation of genetic code via cell-free protein synthesis directed by template RNA. Federation Proceedings 1963, 22, 55-61.

5. (a) Khorana, H. G., Polynucleotide synthesis and the genetic code. Federation Proceedings 1965, 24 (6), 1473-87; (b) Khorana, H. G., Studies on nucleic-acids - total synthesis of a biologically functional gene. Bioorganic Chemistry 1978, 7 (3), 351-393;

(c) Fritz, H. J.; Khorana, H. G., Synthesis of polynucleotides in study of structurefunction-relationships in promoter-region of transfer-RNA gene1. Nucleic Acids 
Research 1975, S177-S181; (d) Khorana, H. G., Total synthesis of a gene. Science 1979, 203 (4381), 614-625.

6. $\quad$ Itakura, K.; Hirose, T.; Crea, R.; Riggs, A. D.; Heyneker, H. L.; Bolivar, F.; Boyer, H. W., Expression in escherichia-coli of a chemically synthesized gene for homone somatostatin. Science 1977, 198 (4321), 1056-1063.

7. (a) Ladner, J. E.; Jack, A.; Robertus, J. D.; Brown, R. S.; Rhodes, D.; Clark, B. F.; Klug, A., Structure of yeast phenylalanine transfer RNA at 2.5 A resolution. Proceedings of the National Academy of Sciences of the United States of America 1975, 72 (11), 44148; (b) Kim, S. H.; Suddath, F. L.; Quigley, G. J.; McPherson, A.; Sussman, J. L.; Wang, A. H.; Seeman, N. C.; Rich, A., Three-dimensional tertiary structure of yeast phenylalanine transfer RNA. Science 1974, 185 (4149), 435-40.

8. Wang, A. H. J.; Quigley, G. J.; Kolpak, F. J.; Vandermarel, G.; Vanboom, J. H.; Rich, A., Left-handed double helical DNA-variations in the backbone conformation. Science 1981, 211 (4478), 171-176.

9. Wing, R.; Drew, H.; Takano, T.; Broka, C.; Tanaka, S.; Itakura, K.; Dickerson, R. E., Crystal-structure analysis of a complete turn of B-DNA. Nature 1980, 287 (5784), $755-758$.

10. Shakked, Z.; Rabinovich, D.; Cruse, W. B. T.; Egert, E.; Kennard, O.; Sala, G.; Salisbury, S. A.; Viswamitra, M. A., Crystalline A-DNA- the X-ray analysis of the fragment d(G-G-T-A-T-A-C-C). Proceedings of the Royal Society Series B-Biological Sciences 1981, 213 (1193), 479-487. 
11. Ohgaki, H.; Takayama, S.; Sugimura, T., Carcinogenicities of heterocyclic amines in cooked food. Mutation Research 1991, 259 (3-4), 399-410.

12. Fukuda, H.; Takamura-Enya, T.; Masuda, Y.; Nohmi, T.; Seki, C.; Kamiya, K.; Sugimura, T.; Masutani, C.; Hanaoka, F.; Nakagama, H., Translesional DNA synthesis through a C8-guanyl adduct of 2-amino-1-methyl-6-phenylimidazo 4,5-b pyridine (PhIP) in vitro. Journal of Biological Chemistry 2009, 284 (38), 25585-25592.

13. Tolstorukov, M. Y.; Jernigan, R. L.; Zhurkin, V. B., Protein-DNA hydrophobic recognition in the minor groove is facilitated by sugar switching. Journal of Molecular Biology 2004, 337 (1), 65-76.

14. Bazzi, A.; Zargarian, L.; Chaminade, F.; Boudier, C.; De Rocquigny, H.; Rene, B.; Mely, Y.; Fosse, P.; Mauffret, O., Structural insights into the cTAR DNA recognition by the HIV-1 nucleocapsid protein: role of sugar deoxyriboses in the binding polarity of NC. Nucleic Acids Research 2011, 39 (9), 3903-3916.

15. Blackburn, G. M., Nucleic Acids in Chemistry and Biology. 3rd ed.; RSC Pub.: Cambridge, UK, 2006; 470 p.

16. Shendure, J.; Ji, H. L., Next-generation DNA sequencing. Nature Biotechnology 2008, 26 (10), 1135-1145.

17. VanGuilder, H. D.; Vrana, K. E.; Freeman, W. M., Twenty-five years of quantitative PCR for gene expression analysis. Biotechniques 2008, 44 (5), 619-626.

18. Lindstedt, B. A., Multiple-locus variable number tandem repeats analysis for genetic fingerprinting of pathogenic bacteria. Electrophoresis 2005, 26 (13), 2567-2582. 
19. Sassolas, A.; Leca-Bouvier, B. D.; Blum, L. J., DNA biosensors and microarrays. Chemical Reviews 2008, 108 (1), 109-139.

20. (a) Follmann, H., Deoxyribonucleotides: the unusual chemistry and biochemistry of DNA precursors. Chemical Society Reviews 2004, 33 (4), 225-233; (b) Rossi, J. J.; June, C. H.; Kohn, D. B., Genetic therapies against HIV. Nature Biotechnology 2007, 25 (12), 1444-1454; (c) Pirrung, M. C., How to make a DNA chip. Angewandte ChemieInternational Edition 2002, 41 (8), 1277; (d) Heise, C.; Bier, F. F., Immobilization of DNA on microarrays. Top Current Chemistry 2005, 261, 1-25; (e) Herweijer, H.; Wolff, J. A., Progress and prospects: naked DNA gene transfer and therapy. Gene Therapy 2003, $10(6), 453-458$.

21. Buchanan, J. G., Lord Todd - 1907-1997. Advances in Carbohydrate Chemistry and Biochemistry 2000, 55, 13.

22. Tener, G. M.; Gilham, P. T.; Razzell, W. E.; Turner, A. F.; Khorana, H. G., Studies on the chemical synthesis and enzymatic degradation of desoxyribooligonucleotides. Annals of the New York Academy of Sciences 1959, 81, 757.

23. Letsinger, R. L.; Mahadevan, V., Oligonucleotide synthesis on a polymer support. Journal of the American Chemical Society 1965, 87, 3526-3527.

24. Brown, D. M., A brief history of oligonucleotide synthesis. Methods in Molecular Biology 1993, 20, 1-17.

25. (a) Letsinger, R. L.; Finnan, J. L.; Heavner, G. A.; Lunsford, W. B., Nucleotide chemistry 20: phosphite coupling procedure for generating internucleotide links. Journal 
of the American Chemical Society 1975, 97 (11), 3278-3279; (b) Letsinger, R. L.; Lunsford, W. B., Synthesis of thymidine oligonucleotides by phosphite triester intermediates. Journal of the American Chemical Society 1976, 98 (12), 3655-3661.

26. (a) Beaucage, S. L.; Caruthers, M. H., Deoxynucleoside phosphormidites- a new class of key intermediates for deoxypolynucleotide synthesis. Tetrahedron Letter 1981, 22 (20), 1859-1862; (b) Matteucci, M. D.; Caruthers, M. H., Nucleotide chemistry 4: synthesis of deoxyoligonucleotides on a polymer support. Journal of the American Chemical Society 1981, 103 (11), 3185-3191; (c) McBride, L. J.; Caruthers, M. H., Nuceotide chemistry 10: an investigation of several deoxynucleoside phosphramidites useful for synthesizing deoxyoligonucleotides. Tetrahedron Letter 1983, 24 (3), 245-248.

27. Eckstein, F., Phosphorothioate analogs of nucleotides-tools for the investigation of biochemical processes. Angewandte Chemie-International Edition in English 1983, 22 (6), 423-439.

28. Eckstein, F., Stabilization of DNA by incorporation of phosphothioate groups. Nucleosides \& Nucleotides 1985, 4 (1-2), 77-79.

29. Dias, N.; Stein, C. A., Antisense oligonucleotides: basic concepts and mechanisms. Molecular Cancer Therapeutics 2002, 1 (5), 347-55.

30. Yamanaka, G.; Eckstein, F.; Stryer, L., Stereochemistry of the guanyl nucleotide binding-site of transducin probed by phosphorothioate analogs of GTP and GDP. Biochemistry 1985, 24 (27), 8094-8101. 
31. Agrawal, S., Protocols for Oligonucleotides and Analogs : Synthesis and Properties. Humana Press: Totowa, N.J., 1993; 502 p.

32. (a) Pieken, W. A.; Olsen, D. B.; Benseler, F.; Aurup, H.; Eckstein, F., Kinetic characterization of ribonuclease-resistant 2'-modified hammerhead ribozymes. Science 1991, 253 (5017), 314-317; (b) Jarvis, T. C.; Wincott, F. E.; Alby, L. J.; McSwiggen, J. A.; Beigelman, L.; Gustofson, J.; DiRenzo, A.; Levy, K.; Arthur, M.; MatulicAdamic, J.; Karpeisky, A.; Gonzalez, C.; Woolf, T. M.; Usman, N.; Stinchcomb, D. T., Optimizing the cell efficacy of synthetic ribozymes - site selection and chemical modifications of ribozymes targeting the proto-oncogene c-myb. Journal of Biological Chemistry 1996, 271 (46), 29107-29112.

33. (a) Egholm, M.; Buchardt, O.; Nielsen, P. E.; Berg, R. H., Peptide nucleic-acid (PNA)-oligonucleotide analogs with an achiral peptide backbone. Journal of the American Chemical Society 1992, 114 (5), 1895-1897; (b) Egholm, M.; Buchardt, O.; Christensen, L.; Behrens, C.; Freier, S. M.; Driver, D. A.; Berg, R. H.; Kim, S. K.; Norden, B.; Nielsen, P. E., PNA hybridizes to complementary oligonucleotides obeying the Watson-Crick hydrogen bonding rules. Nature 1993, 365 (6446), 566-568.

34. Ray, A.; Norden, B., Peptide nucleic acid (PNA): its medical and biotechnical applications and promise for the future. Faseb Journal 2000, 14 (9), 1041-1060.

35. Zane, L.; Bargelloni, L.; Patarnello, T., Strategies for microsatellite isolation: a review. Molecular Ecology 2002, 11 (1), 1-16. 
36. Goodchild, J., Conjugates of oligonucleotides and modified oligonucleotides: a review of their synthesis and properties. Bioconjugate chemistry 1990, 1 (3), 165-187.

37. Murasugi, A.; Wallace, R. B., Biotin-labeled oligonucleotides - enzymatic synthesis and use as hybridization Probes. DNA-A Journal of Molecular and Cellular Biology 1984, 3 (3), 269-277.

38. (a) Hensley, P., Defining the structure and stability of macromolecular assemblies in solution: the re-emergence of analytical ultracentrifugation as a practical tool. Structure 1996, 4 (4), 367-373; (b) Herdewijn, P., Heterocyclic modifications of oligonucleotides and antisense technology. Antisense \& Nucleic Acid Drug Development 2000, 10 (4), 297-310.

39. Kamiya, H., Mutagenic potentials of damaged nucleic acids produced by reactive oxygen/nitrogen species: approaches using synthetic oligonucleotides and nucleotides. Nucleic Acids Research 2003, 31 (2), 517-531.

40. Sasaki, S.; Onizuka, K.; Taniguchi, Y., The oligodeoxynucleotide probes for the site-specific modification of RNA. Chemical Society Reviews 2011, 40 (12), 5698-5706. 


\title{
Chapter 3
}

\section{Feasibility Studies}

\begin{abstract}
The feasibility of using the Dmoc function for ODN synthesis was evaluated in two respects: (1) the stability of Dmoc function under conditions of ODN synthesis using phosphoramidite chemistry; (2) the appropriate oxidation conditions for removing Dmoc moieties. With these investigations, we demonstrated the feasibility of designed Dmoc-based cleavage and protection strategy for ODN synthesis.
\end{abstract}

\subsection{Introduction}

Dmoc moiety was first introduced by Kunz's group and have been successfully applied applied to glycopeptide synthesis. ${ }^{1}$ In Kunz and his coworkers' work, Dmoc groups are inert to acids and bases, but after oxidation of the sulfur to sulfone, they can be cleaved by $\beta$-elimination. Thus, Dmoc groups are expected to be good protecting groups for organic synthesis. Surprisingly, we found little research of Dmoc for other applications.

In our strategy for ODN cleavage and deprotection, we will synthesize dTDmoc-CPG (1.1), Dmoc-dC-amidite (1.2), Dmoc-dA-amidite (1.3) and Dmoc-dGamidite (1.4), and apply these compounds in ODN synthesis using phosphoramidite chemistry. With appropriate oxidizing conditions, the sulfide of Dmoc moieties will be converted to sulfoxide or sulfone, which intrigues $\beta$-elimination for simultaneous 
deprotection and cleavage. Prior to synthesizing these compounds, the feasibility of the Dmoc-based ODN synthetic strategy need to be demonstrated in two respects: (1) the stability of Dmoc moieties through phosphoramidite chemistry; (2) the appropriate oxidation conditions for removing Dmoc moieties.

Since the sulfides in the Dmoc group are accessible to oxidation, the potential reaction of sulfide with iodine that is used for the convertion of $\mathrm{P}(\mathrm{III})$ to $\mathrm{P}(\mathrm{IV})$ in ODN synthesis is a great concern. To use the Dmoc moiety for ODN synthesis by phosphoramidite chemistry, experiments have to been carried out to demonstrate that sulfide wouldn't react with iodine under the ODN synthesis conditions.

It is known that ODNs can potentially be damaged under oxidative conditions. As Dmoc groups are desgined to be removed under oxidative conditions, an oxidative condition that can oxidize Dmoc but won't cause ODN damages is needed for using Dmoc for ODN synthesis. From literature search, we found certain oxidizing reagents, such as $(1 S)-(+)-\left(10\right.$-camphorsulfonyl)oxaziridine (CSO), $\mathrm{H}_{2} \mathrm{O}_{2}$ and $\mathrm{NaIO}_{4}$, have been applied in ODN research without damaging ODNs. ${ }^{2}$ However these oxidants have never been used for removing Dmoc moieties. Screening for oxidants that can rapidly oxidize the sulfides in Dmoc function while do not oxidize DNA is needed.

In this chapter, we will explore the stability of Dmoc moieties in the presence of iodine and screen several oxidizing reagents for oxidizing the Dmoc moiety. With these investigations, we will be able to predict the feasibility of using the Dmoc function for ODN synthesis. 


\subsection{Results and Discussion}

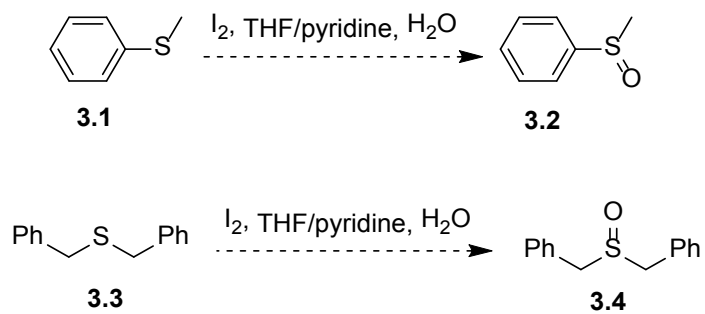

Scheme 3.1. Evaluation of the reactivity of sulfides with $\mathrm{I}_{2}$

To evaluate the reactivity of sulfides with iodine, phenyl methyl sulfide (3.1) and dibenzyl sulfide (3.3) were chosen as substrates. The evaluation was carried out with $0.02 \mathrm{M}$ iodine in $\mathrm{THF} /$ pyridine $/ \mathrm{H}_{2} \mathrm{O}$, which is the oxidizing conditions used in ODN synthesis using the phoshporamidite chemistry (Scheme 3.1). Excess iodine (10 equivalent) was used. The resulting reaction mixture were analyzed by gas chromatography-mass spectrometry after periods of 1 hour, 3 hours and 6 hours, respectively. From the results of GC/MS analysis, starting materials 3.1 and 3.3 were the major peaks and no oxidized products (3.2 and 3.4) were found.

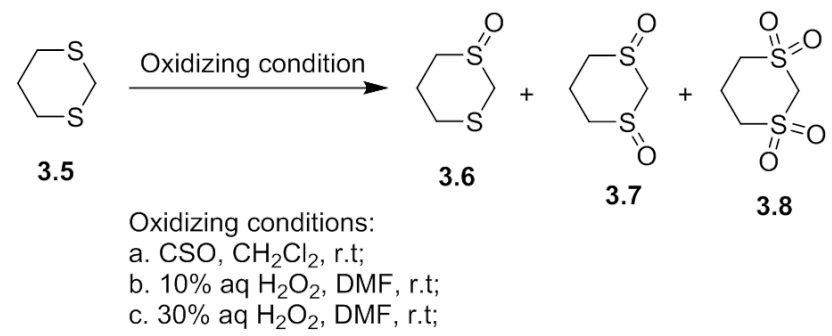

Scheme 3.2. Screening of conditions for the oxidation of 1,3-dithiane 

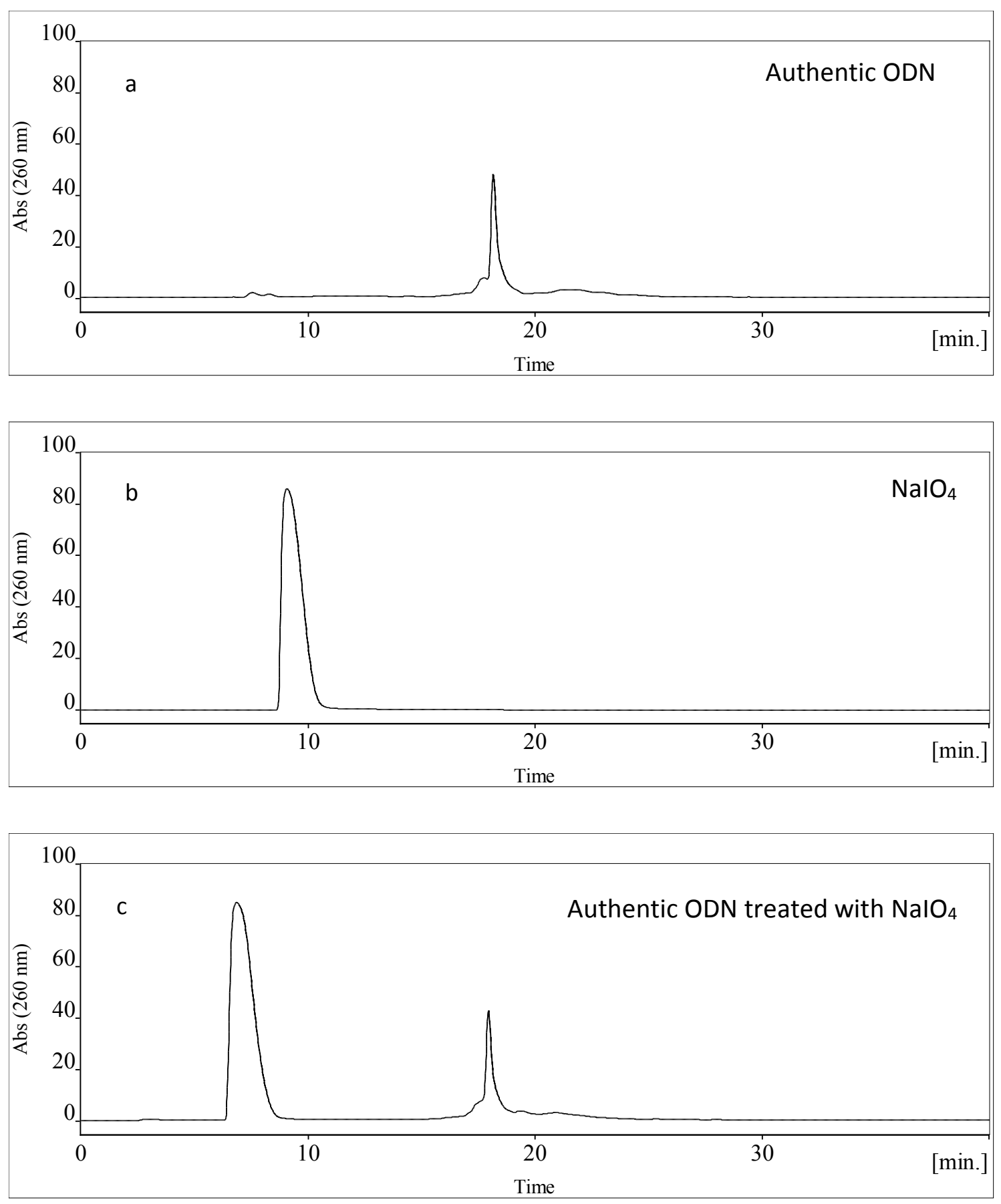

Figure 3.1. Incubation of authentic ODN with $\mathrm{NaIO}_{4}$

In ODN synthesis, the reaction time for oxidation in each cycle is only 45 seconds. The total oxidation time for a 20 -mer ODN synthesis is about 15 minutes. As 
no oxidation occurred on these two sulfides during six hours period, the sulfides of Dmoc moiety should be inert to oxidizing conditions used for ODN synthesis. Thus we shall not expect premature oxidative cleavage of Dmoc by $\mathrm{I}_{2}$ during ODN synthesis.

As mentioned earlier, $\mathrm{CSO}, \mathrm{H}_{2} \mathrm{O}_{2}, \mathrm{NaIO}_{4}$ and $m$-CPBA have been used as oxidants in ODN studies without damaging ODN. A proof is shown in Figure 3.2. Authentic ODN sample was incubated with $\mathrm{NaIO}_{4}$ solution for 12 hours. The resulted mixture was analyzed by HPLC. The profile is shown in trace c. The same retention times shown in trace a and c suggested that ODN was not damged. The mass obtained from MALDI-TOF further proved that ODN was stable through the incubation of $\mathrm{NaIO}_{4}$

Next, the screening of reagents to oxidize Dmoc was carried out by reacting 1,3dithiane with each oxidizing reagent. Oxidizing conditions were shown in Scheme 3.2. The resulting reaction mixtures were partitioned between $\mathrm{CH}_{2} \mathrm{Cl}_{2}$ and water. The organic layers were then analyzed by GC/MS. From the analysis of GC/MS results, we found that: (1) CSO gave very little oxidized products; (2) $10 \% \mathrm{H}_{2} \mathrm{O}_{2}$ aqueous solution converted 1,3-dithiane (3.5) completely to oxidized derivatives (3.6-3.8) in 1 hour and 3.8 was the major product; (3) $30 \% \mathrm{H}_{2} \mathrm{O}_{2}$ aqueous only gave $\mathbf{3 . 8}$ as product after 2 hours reaction.

\subsection{Conclusion}

The reaction of sulfide with iodines didn't give oxidized derivatives. 1,3Dithiane were converted to sulfoxides or sulfone under the oxidizing conditions which 
were intert to ODNs. With these investigations, we proved the feasibility of using Dmoc function for ODN synthesis.

\section{References}

1. (a) Kunz, H.; Waldmann, H., 1,3-Dithian-2-yl methyl ester as 2-step protecting group fro the carboxy function in peptide synthesis. Angewandte Chemie-International Edition in English 1983, 22 (1), 62-62; (b) Kunz, H., Synthesis of glycopeptides, partial structures of biological recognition components. Angewandte Chemie-International Edition in English 1987, 26 (4), 294-308.

2. (a) Kataoka, M.; Hattori, A.; Okino, S.; Hyodo, M.; Asano, M.; Kawai, R.; Hayakawa, Y., Ethyl(methyl)dioxirane as an efficient reagent for the oxidation of nucleoside phosphites into phosphates under nonbasic anhydrous conditions. Organic letters 2001, 3 (6), 815-818; (b) Skrzypczynski, Z.; Wayland, S., New reagents for the introduction of reactive functional groups into chemically synthesized DNA probes. Bioconjugate Chemistry 2003, 14 (3), 642-652; (c) Trevisiol, E.; Renard, A.; Defrancq, E.; Lhomme, J., The oxyamino-aldehyde coupling reaction: an efficient method for the derivatization of oligonucleotides. Tetrahedron Letter 1997, 38 (50), 8687-8690. 


\title{
Chapter 4
}

\section{Synthesis of Dmoc-dT Linker and Evaluation of Its Application in ODN Synthesis ${ }^{1}$}

\begin{abstract}
A novel linker for oligodeoxynucleotide (ODN) synthesis utilizing 1,3-dithiane-2yl-methoxycarbonyl (Dmoc) moiety was synthesized. The resulting dT-Dmoc CPG was successfully applied for the automated ODN synthesis. Efficient cleavage from solid support was achieved under non-nucleophilic oxidative conditions.
\end{abstract}

\subsection{Introduction}

ODN chemical synthesis has been extensively studied in the past six decades. Since Letsinger introduced solid phase chemistry to ODN synthesis, ${ }^{1}$ solid phase ODN synthesis became the most widely used method for ODN synthesis in both research labs and manufacturer millers. Compared to other ODN synthesis methods (such as solution phase, enzyme ligation), the advantages of solid phase ODN synthesis are vivid. There are three main reasons contributing to the widely acceptance of the solid phase technique. ${ }^{2}$ (i) Simple chemical process. Usually the completion of reactions only require three simple steps: reagents addition, filtration and resin washing. Due to the convenience

\footnotetext{
${ }^{1}$ The contents of Chapter 4 were adapted into a journal paper "Oligonucleotide Synthesis Using Protecting Groups and a Linker Cleavable under Non-nucleophilic Conditions”. This paper has been submitted to the Chemical Communication for peer review.
} 
of conducting reactions, reactions with repeated cycles can be automated with equipped instruments. (ii) Easy purification. In a multiple-step solid phase synthesis, the only purification needed is washing resin with massive solvents until the final product is attained on the solid support. (iii) High reaction efficiency. Because excess reagents can be used, the reaction efficiency could be driven to quantitative level.

To successfully accomplish a solid phase ODN synthesis, two problems need to be addressed. They are: (i) what solid support to choose; and (ii) what linkage method to use for attaching materials to solid support and what cleavage method to use for cleaving materials from solid support.

Unlike the swellable solid support used in organic solid-phase synthesis and peptide synthesis, the best solid supports that work for ODN synthesis are non-swellable or low swellable materials. Controlled pore glass (CPG) and macroporous polystyrene (MPPS) are the most commonly used solid supports in ODN synthesis. ${ }^{3}$ In order to recover the ODN from solid support after completion of synthesis, a cleavable linker has to be introduced to between the ODN and solid support.

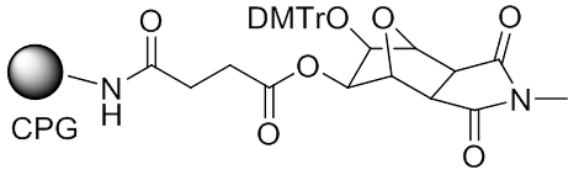

4.1

Universal solid support

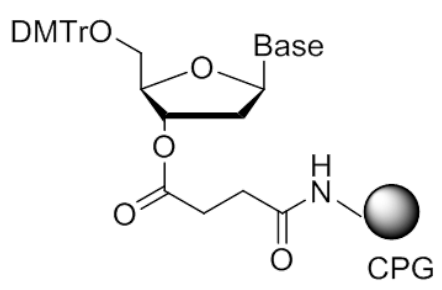

4.2

Nucleosidic solid support

Figure 4.1. Solid supports for OGN synthesis 
Conventionally, two types of linkers are used (Figure 4.1). (i) Non-nucleosidic linkers (universal linkers). ${ }^{3 a}$ Prior to assembling nucleoside blocks, a non-nucleosidic linker is attached to the amino group of the solid support and forms a non-nucleosidic solid support. For example, in the ODN synthesis using solid support 4.1, DMTr group of 4.1 was removed in the first synthetic cycle. The uncovered hydroxyl group was covalently bonded to the phosphorus atom of nucleoside phosphoramidite. Once the chain reaction was completed, the expected ODN could be obtained using treatment with strong bases by cleaving the P-O bond at 3 '-terminus of nucleotide. This type of linker can be universally used to synthesize any oligonucleotide sequence, thus, non-nucleosidic linker is known as universal linker. (ii) Nucleosidic Linkers. ${ }^{4}$ With this approach, a nucleoside is first attached to the solid support via, most often, succinyl arm. The produced nucleosidic solid support is then used for the oligonucleotide chain assembly. For example, when applying solid support 4.2 in ODN synthesis, detritylated 4.2 would react with nucleoside phosphoramitidite. At the end of the synthesis, the nucleoside of $\mathbf{4 . 2}$ became the 3'-terminus of the synthesized ODN. The ODN product is obtained through ester hydrolysis under strongly basic and nucleophilic conditions. Both non-nucleosidic and nucleosidic solid supports require strong nucleophilic reagents for ODN cleavage, such as gaseous ammonia, aqueous ammonium hydroxide, $\mathrm{NaOH}, \mathrm{KOH}$, or potassium methoxide $\left(\mathrm{K}_{2} \mathrm{CO}_{3}\right.$ in anhydrous methanol). ${ }^{3-5}$ 


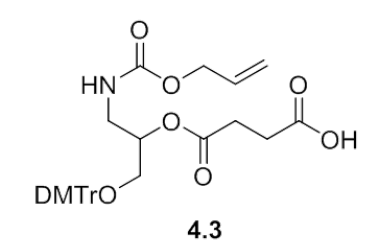

4.3

3-N-allyloxycarbonyl protected linker
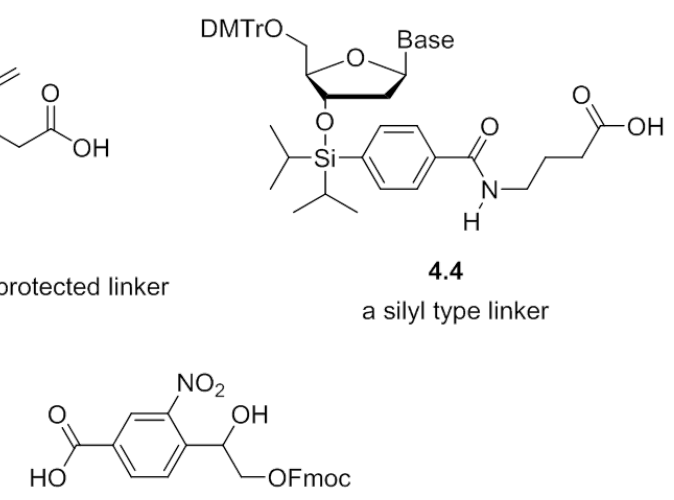

4.5

a o-nitrophenyl-1,3-propanediol linker

Figure 4.2. Linkers for electrophilic ODN synthesis

However, many modified ODN syntheses, particularly the syntheses of ODNs that contain one or more latent electrophilic groups, are not compatible with the strongly nucleophilic conditions. With increasing interests of using these ODN analogues as diagnostic probes and therapeutics, new linking approaches to solid support are needed. ${ }^{6}$

A variety of linkers have been developed for ODN synthesis to solve the problem. Lyttle reported a universal CPG solid support by immobilizing 1-O-(4,4' dimehtoxytriyl)2-O-succinoyl-3- $\mathrm{N}$-allyloxycarbonylpropane (4.3, in Figure 4.2$){ }^{7}$ Under very mild alkaline conditions (aqueous TEAA/ $\mathrm{NH}_{3}$ buffer, $\mathrm{pH}=10$, room temperature), the 3-Nallyloxycarbonyl group was removed from the linker. Further, the derived amino group attacked the 3'-terminal phosphate group and released the desired ODN from CPG. However in this protocol, the key to a successful cleavage relied on the removal of the allyoxycarbonyl group, which can only be allowed with the mediation of Palladium $(0)$. Due to the difficulty to remove palladium from product, this type of linker is not favored for ODN synthesis, and is not applicable for the synthesis of ODNs with therapeutic 
applications. Another linker 4.4 utilizing a silyl moiety was reported by Ohkubo's groups to synthesize modified ODN under almost neutral condition. ${ }^{8}$ In their report, the silyl-type linker could be cleaved by treating with $0.2 \mathrm{M} \mathrm{Et}_{3} \mathrm{~N} / 3 \mathrm{HF}$ at room temperature. Albeit of the mild alkaline condition, HF is a highly toxic reagent and is not very compatible with CPG. Photocleavable linkers are another genre of linkers which are widely explored. ${ }^{9}$ For example, the linker 4.5 was used for ODN synthesis. Based on the photochemistry of $O$-nitrobenzyl group, the desired ODN can be cleaved from the solid support using either a transilluminator $\left(\lambda_{\max } 365 \mathrm{~nm}\right)$ or the $400 \mathrm{~nm}$ band from a highpressure $\mathrm{Hg} / \mathrm{Xe}$ lamp. However the unpredictible photo damages on ODNs has discouraged the application of photo labile linkers.

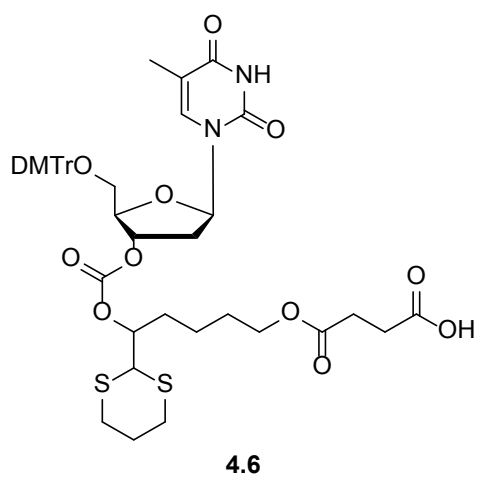

Figure 4.3. dT-Dmoc Linker

To solve the problem, we designed a novel oxidatively-cleavable dT-Dmoc linker 4.6 for ODN synthesis. This dT-Dmoc linker is stable under all ODN synthesis conditions. Upon oxidation of the dithianyl moiety, the linker can be cleaved under nonnucleophilic conditions. This new linker is universally useful for the synthesis of un- 
modified ODNs and modified ODN analogues including those that contain base-labile and electrophilic groups.

\subsection{Results and Discussion}

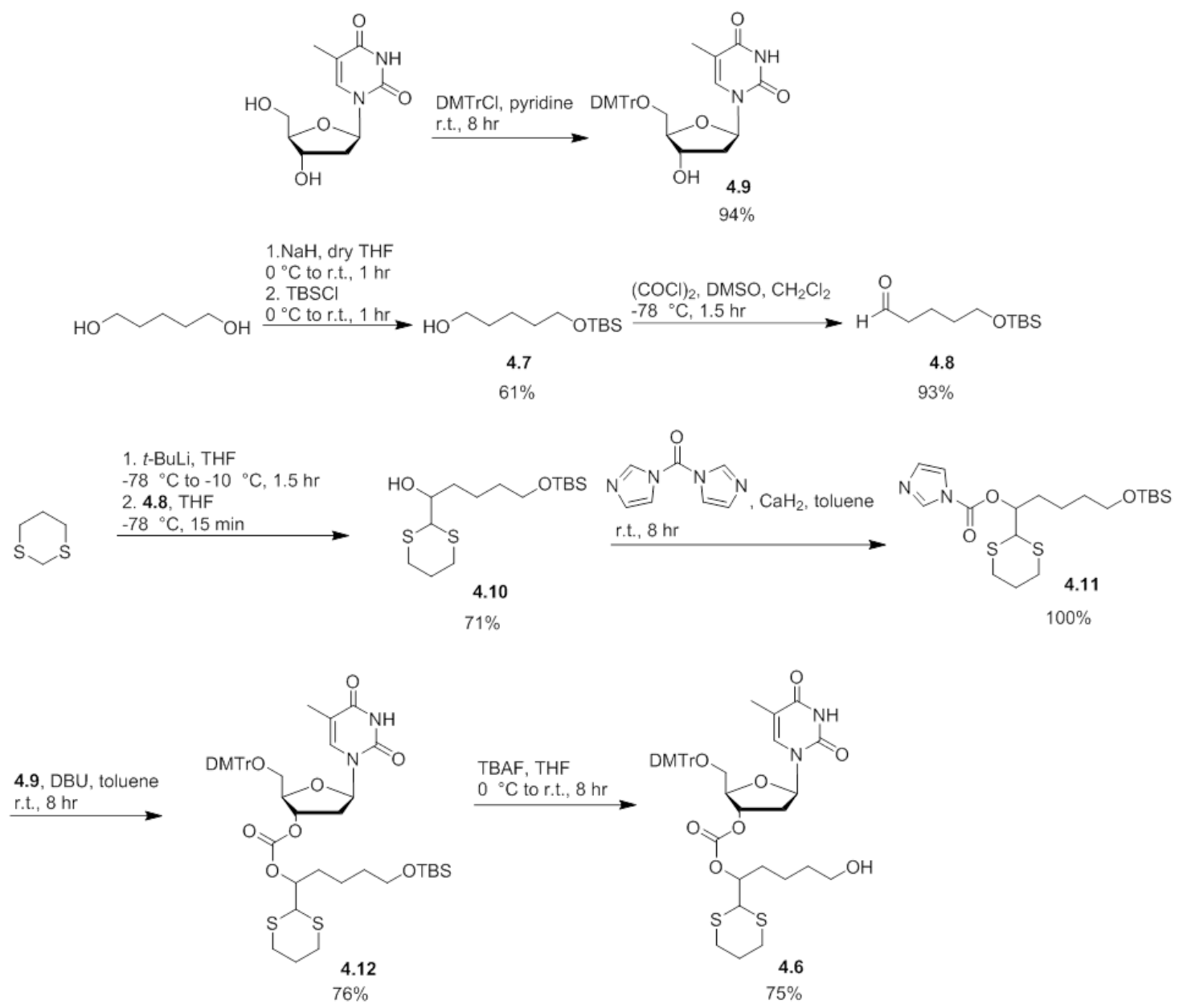

Scheme 4.1. Synthesis of dT-Dmoc linker 4.6

To carry out an ODN synthesis under non-nucleophilic cleavage condition utilizing the Dmoc functionality, the oxidatively cleavable dT-Dmoc linker 4.6 needs to be synthesized. The preparation of dT-Dmoc linker 4.6 is shown in Scheme 4.1. The DMTr protected deoxythymidine 4.9 was obtained from the tritylation of deoxythymidine. 
tert-Butyldimehtyl siloxyl pentanal $\mathbf{4 . 8}$ was produced from swern oxidation of $\mathbf{4 . 7}$, which was derived from pentandiol. The anion generated by treating 1,3-dithiane with $t$-BuLi was then reacted with 5-((tert-butyldimethylsilyl) oxy)pentanal (4.8) to give 4.10, which was converted to 4.11 by reacting with $1,1^{\prime}$-carbonyldiimidazole in the presence of calcium hydride. Reaction of $\mathbf{4 . 1 1}$ with DMTr-protected thymidine using DBU as the base gave 4.12. Removal of the TBS group afforded 4.6.
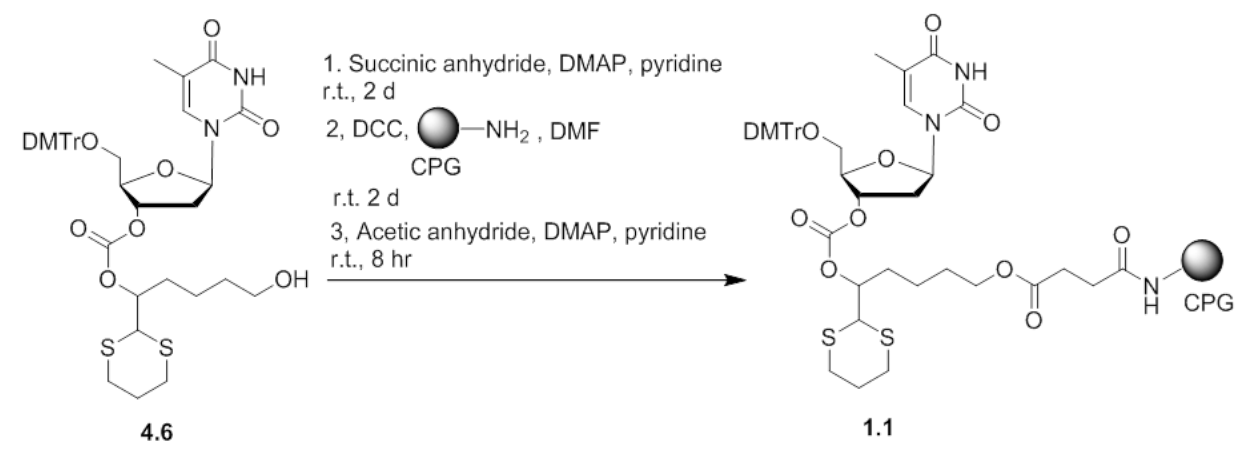

Scheme 4.2. Synthesis dT-Dmoc-CPG 1.1

The dT-Dmoc linked CPG $\mathbf{1 . 1}$ for ODN synthesis was obtained from attaching the dT-Dmoc linker 4.6 to long chain alkyl amino CPG (Scheme 4.2). dT-Dmoc-linker 4.6 was reacted with succinic anhydride. Without purification, the resulting product was added to CPG to react in the presence of DCC. After 2-day incubation, the CPG resin was capped with acetic anhydride. After washing with pyridine, methanol and acetone, the dT-Dmoc linker 4.6 was anchored to CPG and gave the dT-Dmoc linked CPG 1.1. The successful linkage could be detected by detritylation test. Because we installed the 1,3dithiane moiety at the side of the linkage instead of in the linkage, the construction of $\mathbf{1 . 1}$ was quite simple. All the reagents used in the synthesis were inexpensive, and the yields 
in all the steps were high. The reactions were widely used ones in organic chemistry and can potentially be easy to scale up.
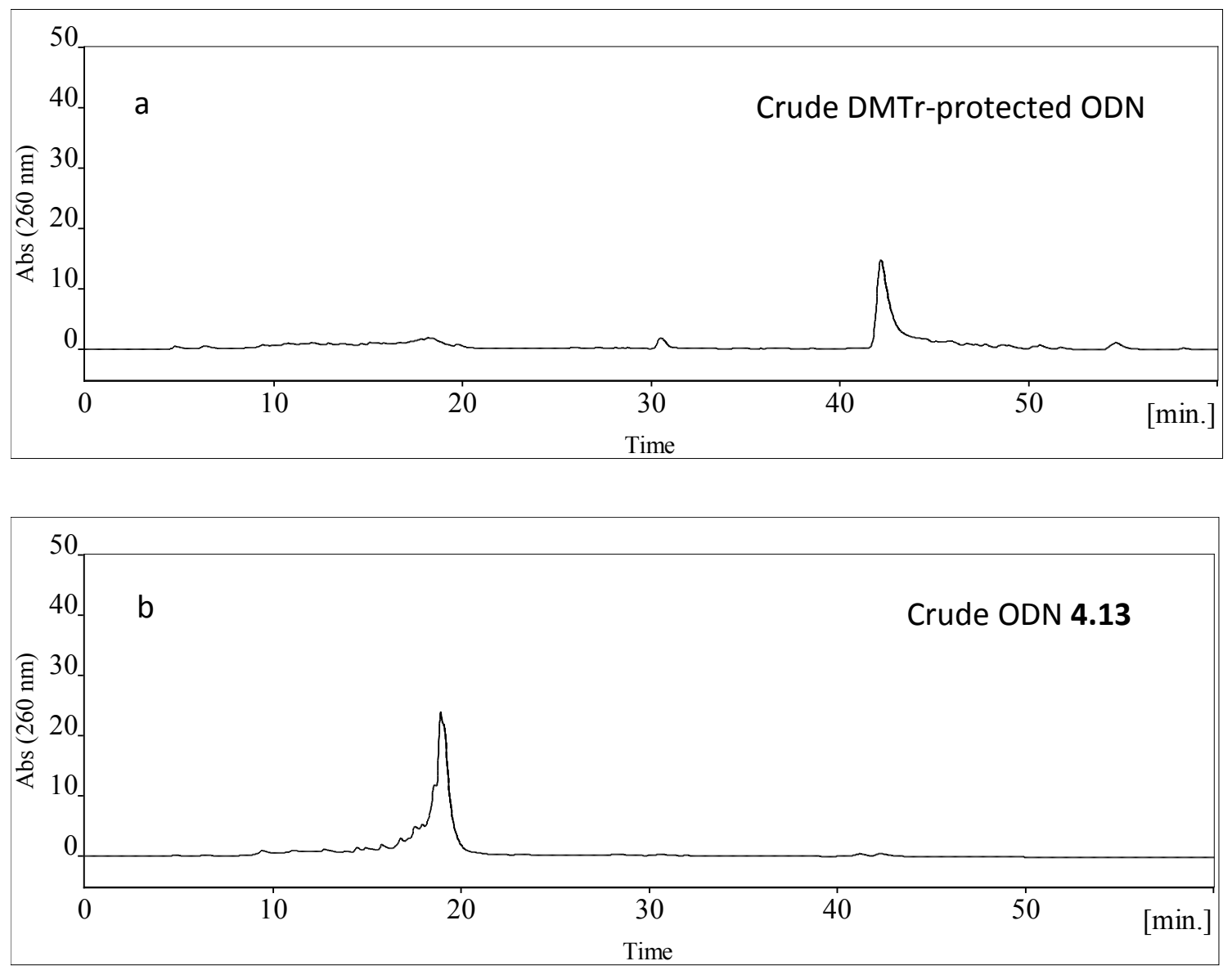

Figure 4.4. RP HPLC profiles of ODN 4.13

Utilizing the dT-Dmoc-CPG 1.1, an ODN sequence 4.13 (5'-TCA TTG CTG CTT AGA CCG CT-3') was synthesized on ABI DNA synthesizer utilizing commercially available nucleoside phosphoramadite reagents: Pac-dA, 4-isopropyl-Pac-dG, Ac-dC, and dT. The synthesis procedure and conditions were the same as those in traditional synthesis. The phosphoramidite concentration was $0.1 \mathrm{M}$. At the end of synthesis, DMTr group was kept. The trityl assay indicated a successful ODN synthesis with the new 
linker. The overall yield was $74 \%$. One portion of CPG was treated with ammonium hydroxide. The DMTr protected ODN was cleaved from CPG, which was analyzed by HPLC (trace a in Figure 4.4). When the ODN was detritylated, the crude ODN 4.13 was obtained and was shown in trace b.
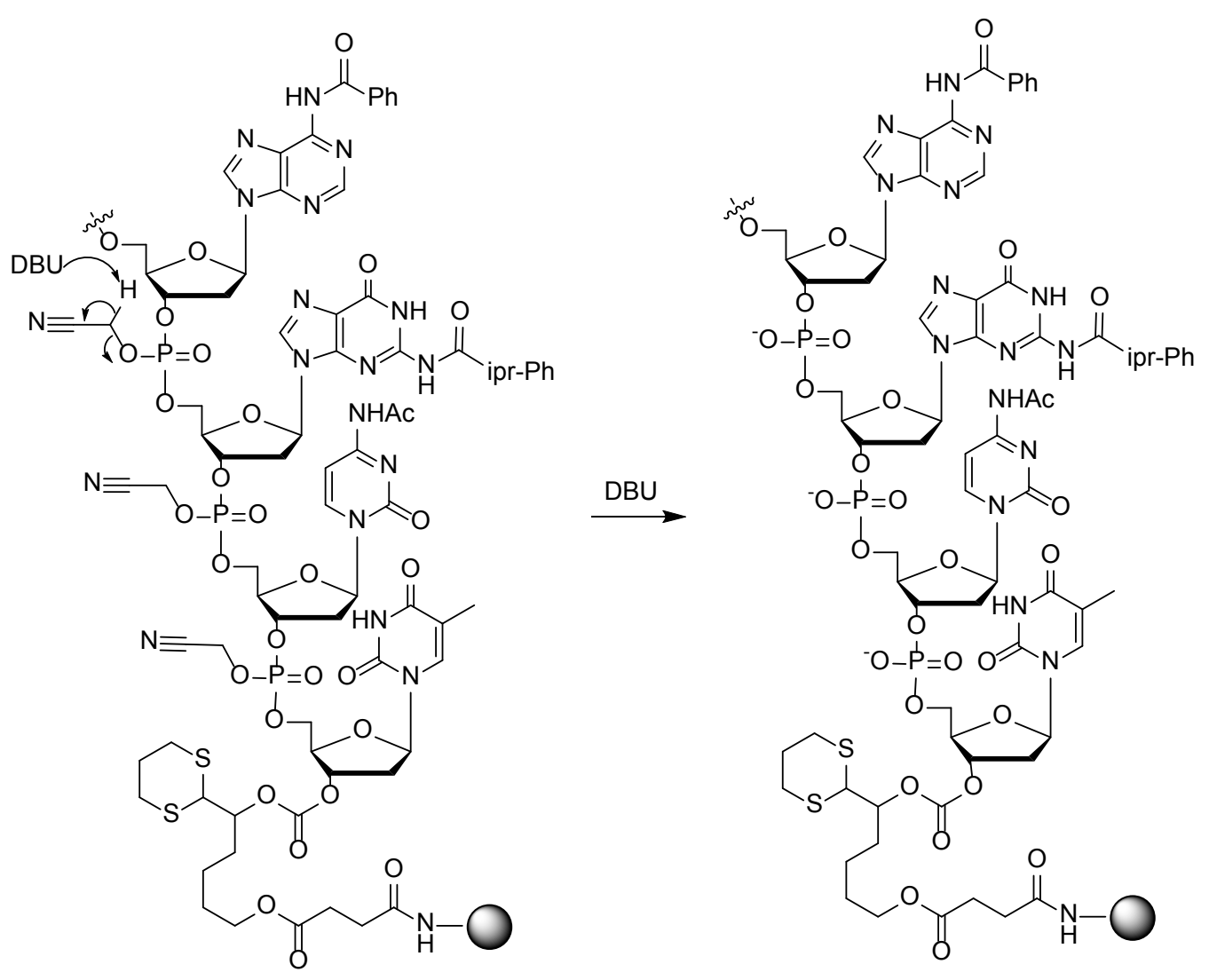

Figure 4.5. Mechanism of the removal of $\beta$-cyanoethyl groups by DBU

In order to cleave ODN from CPG under non-nucleophilic conditions, a group of oxidizing reagents such as (1S)-(+)-(10-camphorsulfonyl)oxaziridine (CSO), $\mathrm{H}_{2} \mathrm{O}_{2}$, metachloroperoxybenzoic acid (m-CPBA) and $\mathrm{NaIO}_{4}$ were screened to oxidize Dmoc moiety and trigger linker cleavage. Surprisingly, we found little success with these oxidizing reagents. First we thought the unsuccessful cleavage was the result from failing $\beta$ - 
elimination due to the absence of base. Carbonate buffer ( $\mathrm{pH} 10)$ was mixed with $\mathrm{NaIO}_{4}$ solution during the oxidization process. The addition of base didn't bring any success.

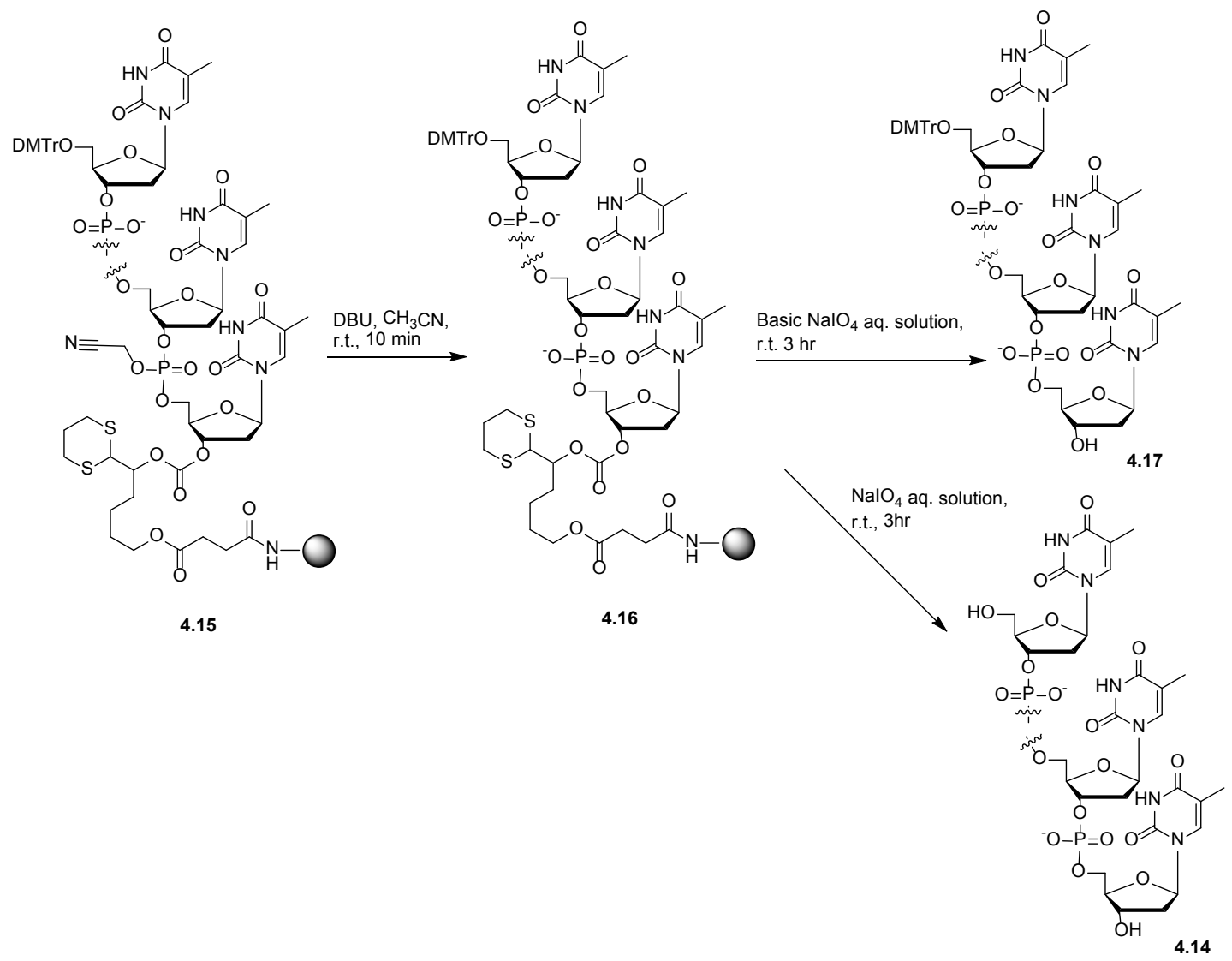

Scheme 4.3. Two-step cleavage strategy for the cleavage of all ODN 4.14 from CPG

The failure led us to hypothesize that the fully protected ODN was too hydrophobic to react with oxidants in aqueous solution such as the $\mathrm{NaIO}_{4}$ aqueous solution. Before deprotection, the phosphate and amino groups are protected with cyanoethyl groups and acetyl groups, respectively. These organic groups are hydrophobic and limit the solubility of ODNs in aqueous solution. To assist the oxidants such as $\mathrm{IO}_{4}^{-}$to reach the linker, which is buried in the hydrophobe protected ODN layer, a phase transfer agent-tetrabutylammonium acetate $\left(\mathrm{Bu}_{4} \mathrm{NOAc}\right)$ was added. However, the results were 
still very disappointing. Most oxidants failed to cleave ODN from CPG. Only the treatment of $\mathrm{NaIO}_{4}$ and $\mathrm{Bu} 4 \mathrm{NOAc}$ gave small amount of ODN. To solve the solubility problem, another approach was designed. In hypothesis, if the cyanoethyl groups of the phosphate are removed, the derived ionized phosphate groups are hydrophilic and will greatly increase the solubility of ODN in water. The mechanism of the removale of cyanoethyl groups by DBU treatment was shown in Figure 4.5.

To support our hypothesis, a 30-base-long ODN sequence $\left(\mathbf{4 . 1 4}, 5^{\prime}\right.$-TTT TTT TTT TTT TTT TTT TTT TTT TTT TTT TTT-3') with only deoxythymidines was synthesized on dT-Dmoc linked CPG 1.1. The synthesis conditions are the same as the synthesis of 4.13. The ODN attached to CPG only had protecting groups on phosphates. The cleavage was processed in two steps (Scheme 4.3).

To remove the cyanoethyl protecting groups, CPG 4.15 was incubated with DBU, a strong but non-nucleophilic base, for 10 minutes. After rinsing CPG with acetonitrile and water sequentially, $\mathrm{CPG} 4.16$ was treated with basic $\mathrm{NaIO}_{4}$ aqueous solution (mixed with carbonate buffer, $\mathrm{pH}$ 10). The resulted solution was concentrated and injected to HPLC. The results are shown in Figure 4.6. The 5'-DMTr-protected ODN 4.17 was observed in HPLC (trace a) with high yield. When treating 4.16 with $\mathrm{NaIO}_{4}$ solution without carbonate buffer, detritylation was observed (trace b). The desired fully deprotected ODN 4.14 was purified by HPLC (trace c). 

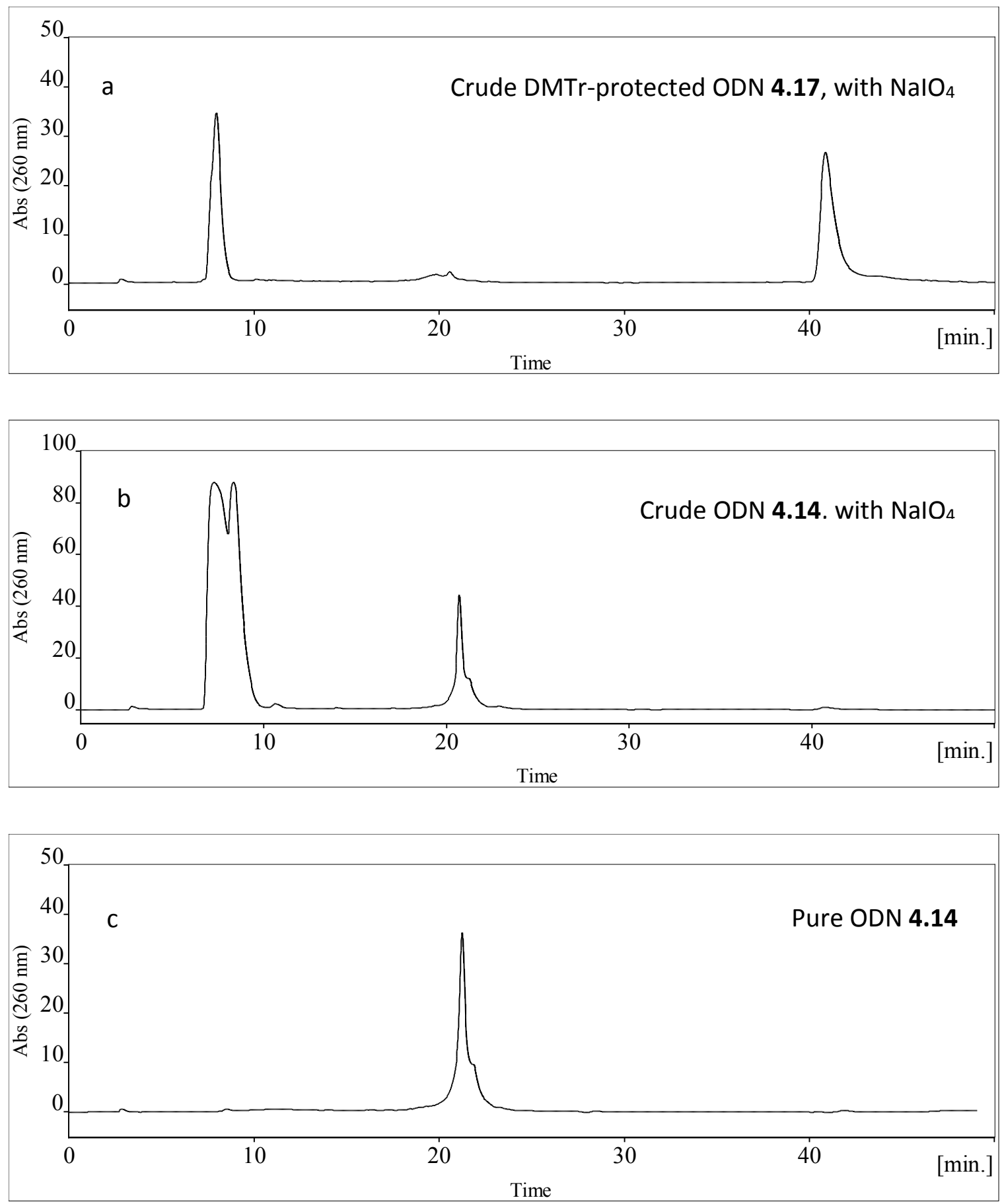

Figure 4.6. RP HPLC profile of all dTs ODN 4.14 

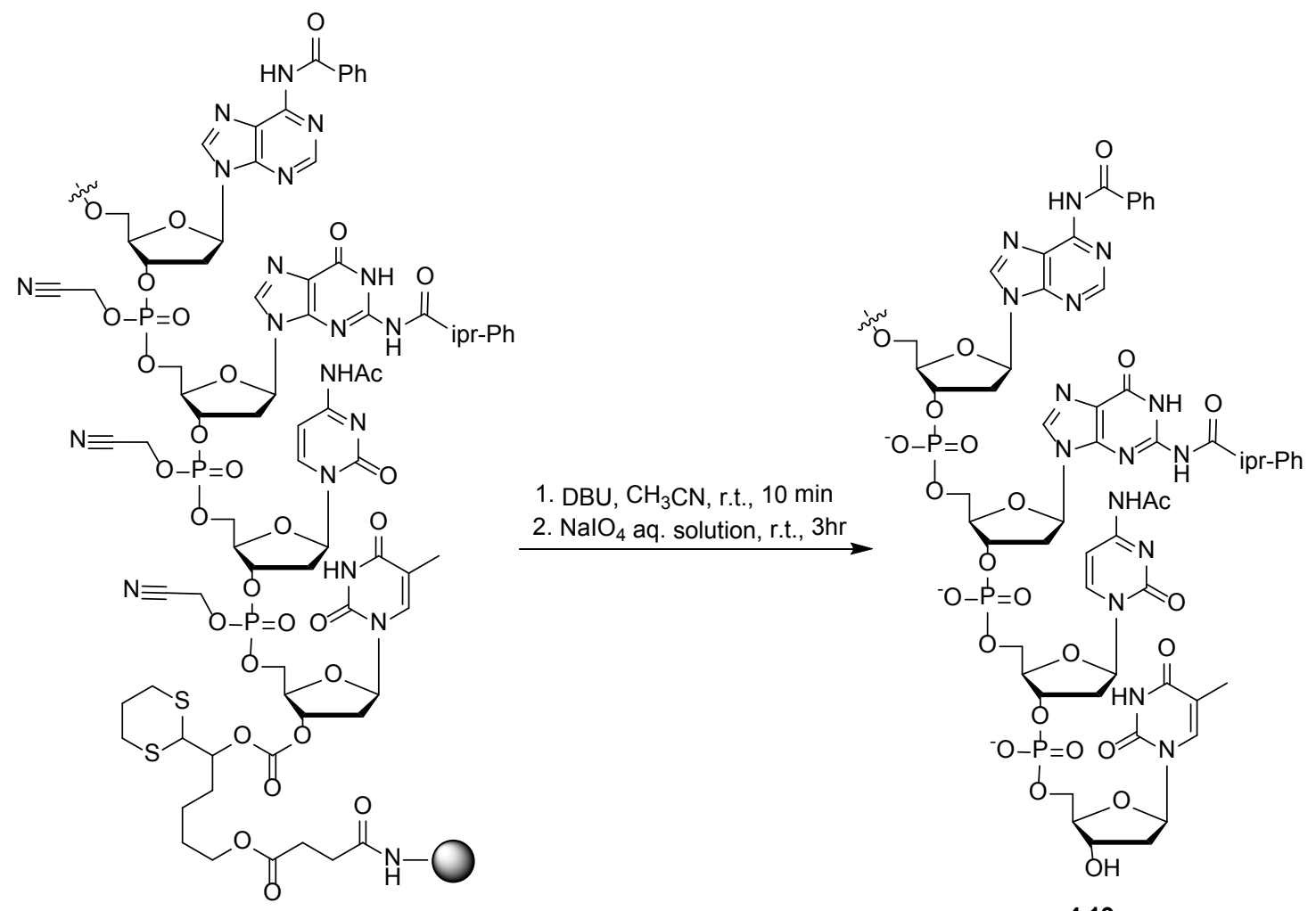

4.18

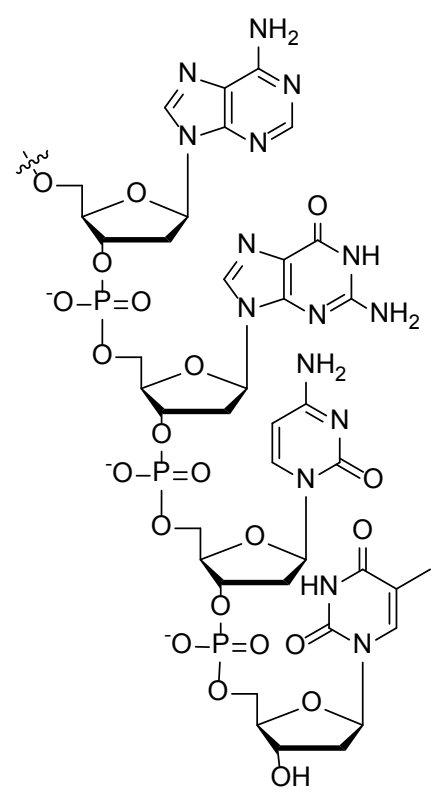

4.19

con'd $\mathrm{NH}_{4} \mathrm{OH}$

4.13

Scheme 4.4. Cleavage and deprotection of ODN 4.13 
The two-step cleavage method was applied to the cleavage of ODN 4.13 (Scheme 4.4). The ODN linked CPG 4.18 was incubated with DBU solution and sequentially with $\mathrm{NaIO}_{4}$ solution. The resulting ODN 4.19 aqueous solution was further treated with ammonium hydroxide to deprotect the exocyclic amino groups. The ODN 4.13 was shown at 18 minute in Figure 4.7. The ODN peak was collected, concentrated and analyzed by MALDI-TOF, which gave the correct molecular weight value of 4.13.

The ability of being cleaved under both ammonium hydroxide condition and mild non-nucleophilic oxidative conditions made the novel dT -Dmoc linker an alternative to the current linking strategies for ODN synthesis. Moreover, although DBU is an organic base, it is non-nucleophilic. Thus, this novel Dmoc-base linker 4.6 will be useful to the synthesis of electrophilic functionalized ODNs.

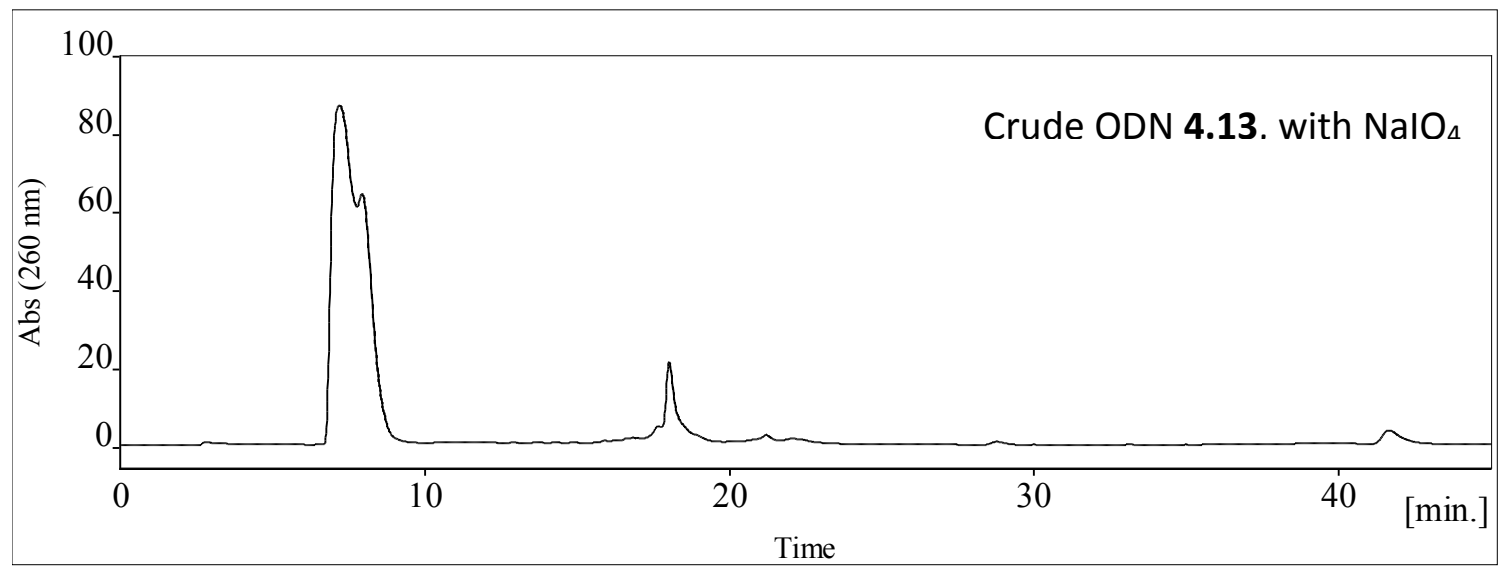

Figure 4.7. RP HPLC profile of ODN 4.13 


\subsection{Conclusion}

We have developed a novel dT-Dmoc linker for ODN synthesis. Using this linker, cleavage can be carried out under non-nucleophilic conditions. Therefore, the dT-Dmoc linker is expected to be useful for the synthesis of electrophilic ODNs.

\subsection{Experimental Section}

\section{General Experimental}

All reactions were performed in over-dried glassware under a nitrogen atmosphere using standard Schlenk techniques. Reagents and solvents available from commercial sources were used as received unless otherwise noted. $\mathrm{CH}_{2} \mathrm{Cl}_{2}$, pyridine, and toluene were distilled over $\mathrm{CaH}_{2}$. THF was distilled over $\mathrm{Na} /$ benzophenone. Thin layer chromatography (TLC) was performed using Sigma-Aldrich TLC plates, silica gel 60F254 over glass support, $0.25 \mu \mathrm{m}$ thickness. Flash column chromatography was performed using Selecto Scientific silica gel, particle size $32-63 \mu \mathrm{m} .{ }^{1} \mathrm{H}$ and ${ }^{13} \mathrm{C}$ NMR spectra were measured on Varian UNITY INOVA spectrometer at 400 and $100 \mathrm{MHz}$, respectively; chemical shifts $(\delta)$ were reported in reference to solvent peaks (residue $\mathrm{CHCl}_{3}$ at $\delta 7.24$ ppm for ${ }^{1} \mathrm{H}$ and $\mathrm{CDCl}_{3}$ at $\delta 77.00 \mathrm{ppm}$ for ${ }^{13} \mathrm{C}$ ), unless otherwise noted. High resolution

mass spectra were obtained at Mass Spectrometry Technical Services at University of Michigan.

ODNs were synthesized on a standard ABI 394 solid phase synthesizer. HPLC was performed on a JASCO LC-2000Plus System: pump, PU-2089Plus Quaternary Gradient; detector UV-2075Plus. A C-18 reverse phase analytical column (5 $\mu \mathrm{m}$ diameter, 
$100 \AA, 250 \times 3.20 \mathrm{~mm}$ ) was used. Solvent A: $0.1 \mathrm{M}$ triethylammonium acetate, $5 \%$ acetonitrile. Solvent B: $90 \%$ acetonitrile. All profiles were generated by detection of absorbance of ODN at $260 \mathrm{~nm}$ using the linear gradient solvent system: solvent B ( $0 \%$ $45 \%$ ) in solvent A over 60min followed by solvent B (45\%-100\%) in solvent A over 20 min at a flow rate of $0.5 \mathrm{~mL} / \mathrm{min}$. Lcaa-CPG (pore size $497 \AA$ ) was provided by Prime Synthesis, Inc., and 5'-DMTr, 2-cyanoethyl phosphoramidites acetyl-dC, Pac-dA, 4isopropyl-Pac-dG and dT were purchased from Glen Research, Inc. D-Salt ${ }^{\mathrm{TM}}$ dextran desalting column (5K MWCO, $10 \mathrm{~mL}$ ) was purchased from Pierce Biotechnology, Inc.

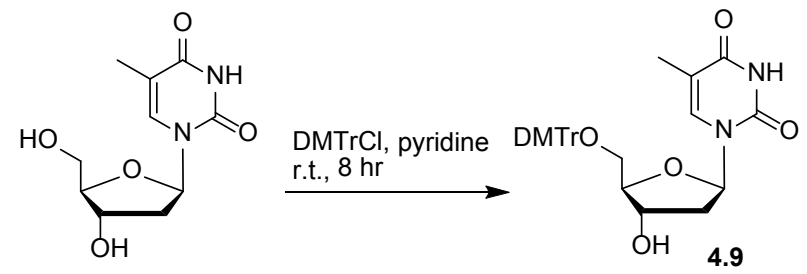

Compound 4.9. A round-bottom flask containing thymidine $(5.000 \mathrm{~g}, 20.642$ mmol) and a magnetic stirring bar was evacuated and then refilled with nitrogen. The evacuation and nitrogen-filling cycle was repeated for two more times. Pyridine $(75 \mathrm{~mL})$ was added via syringe. The suspension was cooled on an ice bath. Under positive $\mathrm{N}_{2}$ pressure, dimethoxytrityl chloride $(7.344 \mathrm{~g}, 21.674 \mathrm{mmol})$ was added to the suspension and the reaction mixture was warmed up to room temperature and stirred overnight. $\mathrm{CH}_{2} \mathrm{Cl}_{2}(75 \mathrm{~mL})$ and aqueous $5 \% \mathrm{NaHCO}_{3}$ solution $(100 \mathrm{~mL})$ were added sequentially. The mixture was partitioned. The aqueous portion was extracted with $\mathrm{CH}_{2} \mathrm{Cl}_{2}$ twice. The organic extracts were combined and dried over anhydrous $\mathrm{NaSO}_{4}$ and filtered. After concentration, the crude product was purified by flash column chromatography (1:3 hexanes/EtOAc) and compound 4.9 was obtained as a white solid $(10.563 \mathrm{~g}, 94 \%): \mathrm{R}_{\mathrm{f}}=$ 
$0.33($ hexanes/EtOAc $=1: 3) ;{ }^{1} \mathrm{H}$ NMR $(400 \mathrm{MHz}$, DMSO-d 6$) \delta 1.35(\mathrm{~s}, 3 \mathrm{H}), 1.43-1.64$ (m, 4H), 1.70-1.82 (m, 3H), 1.88-2.08 (m, 3H), 2.37-2.44 (m, 1H), 2.56-2.76 (m, 3H), 2.84-2.93 (m, 2H), 3.42-3.51 (m, 2H), 3.61-3.65 (m, 2H), $3.77(\mathrm{~s}, 6 \mathrm{H}), 3.97-3.99(\mathrm{~d}, J=$ $8.0 \mathrm{~Hz}, 1 \mathrm{H}), 4.24(\mathrm{~s}, 1 \mathrm{H}), 4.97-5.02(\mathrm{~m}, 1 \mathrm{H}), 5.34-5.35(\mathrm{~d}, J=4 \mathrm{~Hz}, 1 \mathrm{H}), 6.41-6.44$ (dd, $J=4.0 \mathrm{~Hz}, 4.0 \mathrm{~Hz}, 1 \mathrm{H}), 6.81-6.83(\mathrm{~d}, J=8.0 \mathrm{~Hz}, 4 \mathrm{H}), 7.20-7.37(\mathrm{~m}, 9 \mathrm{H}), 7.58(\mathrm{~s}, 1 \mathrm{H})$, 8.78 (br s, $1 \mathrm{H}) ;{ }^{13} \mathrm{C}$ NMR (100 MHz, DMSO-d 6 ) $\delta 11.4,14.2,21.0,21.6,25.4,28.4,28.6$, 31.6, 32.1, 38.0, 48.9, 55.2, 60.4, 62.4, 63.7, 78.7, 79.1, 83.7, 84.4, 87.2, 111.6, 113.3, $127.2,128.0,128.1,130.1,130.1,135.1,135.2,135.3,144.2,150.3,154.2,158.8,158.8$, 163.5 .

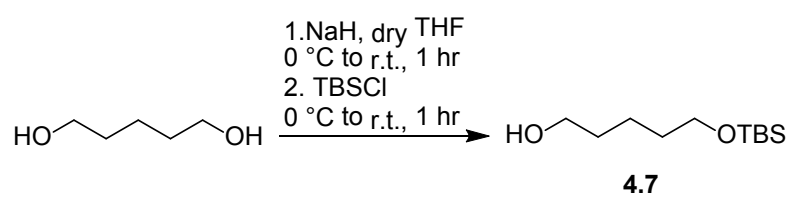

Compound 4.7. ${ }^{10}$ To a $250 \mathrm{~mL}$ 2-neck round-bottom flask, sodium hydride (60\% dispersion in oil, $4.609 \mathrm{~g}, 115.218 \mathrm{mmol})$ and anhydrous THF $(150 \mathrm{~mL})$ were added. The suspension was cooled to $0{ }^{\circ} \mathrm{C}$, and 1,5-pentanediol was added slowly via syringe $(10 \mathrm{~g}$, $10.06 \mathrm{~mL}, 96.015 \mathrm{mmol})$. After stirring for 1 hour at room temperature, the reaction mixture was cooled to $0{ }^{\circ} \mathrm{C}$, and tert-butyldimethylchlorosilane (14.472 g, $\left.96.015 \mathrm{mmol}\right)$ was added slowly. The mixture was allowed to acclimate to room temperature and stirred for an additional hour. The reaction was quenched with $10 \%$ aqueous $\mathrm{K}_{2} \mathrm{CO}_{3}$. The product was extracted with ether. The combined extracts were dried over anhydrous $\mathrm{Na}_{2} \mathrm{SO}_{4}$, filtered and concentrated. Flash column chromatography (3:1 hexanes/EtOAc) gave compound 4.7 as colorless oil $(12.806 \mathrm{~g}, 61 \%)$ : $\mathrm{R}_{\mathrm{f}}=0.34$ (hexanes/EtOAc $=3: 1$, 
dark purple spot with 5\% $\mathrm{H}_{2} \mathrm{SO}_{4}$ stain solution); ${ }^{1} \mathrm{H}$ NMR (400 $\left.\mathrm{MHz}, \mathrm{CDCl}_{3}\right) \delta 0.06(\mathrm{~s}$, $6 \mathrm{H}), 0.90(\mathrm{~s}, 9 \mathrm{H}), 1.37-1.45(\mathrm{~m}, 2 \mathrm{H}), 1.52-1.63(\mathrm{~m}, 4 \mathrm{H}), 1.71$ (br s, 1H), 3.61-3.67 (m, $4 \mathrm{H}) ;{ }^{13} \mathrm{C} \mathrm{NMR}\left(100 \mathrm{MHz}, \mathrm{CDCl}_{3}\right) \delta-5.6,18.0,21.7,25.6,32.1,62.5,62.8 ;$ HRMS (ESI) $m / z$ calcd for $\mathrm{C}_{11} \mathrm{H}_{27} \mathrm{O}_{2} \mathrm{Si}[\mathrm{M}+\mathrm{H}]^{+} 219.1775$, found 219.1777 .

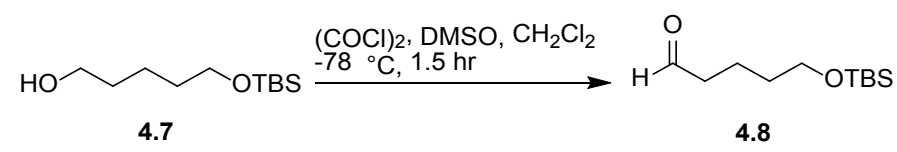

Compound 4.8. ${ }^{10}$ A solution of oxalyl chloride (3.252 g, $2.20 \mathrm{~mL}, 25.617 \mathrm{mmol}$ ) in dry $\mathrm{CH}_{2} \mathrm{Cl}_{2}(15 \mathrm{~mL})$ was cooled to $-78{ }^{\circ} \mathrm{C}$ under $\mathrm{N}_{2}$. A solution of DMSO (4.003 g, $3.64 \mathrm{~mL}, 51.234 \mathrm{mmol})$ in $\mathrm{CH}_{2} \mathrm{Cl}_{2}(15 \mathrm{~mL})$ was added dropwise. After stirring for $5 \mathrm{~min}$, a solution of tert-butyldimethylsiloxyl pentanol 4.7 (5.595 g, $25.617 \mathrm{mmol})$ in $\mathrm{CH}_{2} \mathrm{Cl}_{2}$ $(20 \mathrm{~mL})$ was added dropwise, and the resulting mixture was stirred for $15 \mathrm{~min}$. Then $\mathrm{Et}_{3} \mathrm{~N}$ (12.961 g, $\left.14 \mathrm{~mL}, 128.961 \mathrm{mmol}\right)$ was added slowly. After stirring for another 10 minutes at $-78^{\circ} \mathrm{C}$, the cooling bath was removed and the reaction was allowed to warm to ambient temperature for 1 hour. The reaction was quenched with water $(15 \mathrm{~mL})$. After stirring for 15 minutes, the reaction mixture was separated by separatory funnel and the organic layer was successively washed with aqueous $5 \% \mathrm{HCl}$, saturated $\mathrm{NaHCO}_{3}$ solution, and brine. The organic layer was dried over anhydrous $\mathrm{Na}_{2} \mathrm{SO}_{4}$, filtered and concentrated. Flash column chromatography (19:1 hexanes/EtOAc) gave compound $\mathbf{4 . 8}$ as colorless oil $(5.148 \mathrm{~g}, 93 \%): \mathrm{R}_{\mathrm{f}}=0.28$ (hexanes/EtOAc $=19: 1$, dark blue spot with vanillin stain solution) ; ${ }^{1} \mathrm{H} \mathrm{NMR}\left(400 \mathrm{MHz}^{\mathrm{CDCl}} \mathrm{CD}_{3}\right) \delta 0.00(\mathrm{~s} 6 \mathrm{H}), 0.85(\mathrm{~s}, 9 \mathrm{H}), 1.47-$ $1.54(\mathrm{~m}, 2 \mathrm{H}), 1.62-1.70(\mathrm{~m}, 2 \mathrm{H}), 2.39-2.43(\mathrm{dt}, J=8 \mathrm{~Hz}, 1.6 \mathrm{~Hz}, 2 \mathrm{H}), 3.57-3.60(\mathrm{t}, J=6$ 
$\mathrm{Hz}, 2 \mathrm{H}), 9.72(\mathrm{~s}, 1 \mathrm{H}) ;{ }^{13} \mathrm{C} \mathrm{NMR}\left(100 \mathrm{MHz}, \mathrm{CDCl}_{3}\right) \delta-5.4,18.2,18.6,25.9,32.1,43.5$, 62.5, 202.5; HRMS (ESI) $m / z$ calcd for $\mathrm{C}_{11} \mathrm{H}_{25} \mathrm{O}_{2} \mathrm{Si}[\mathrm{M}+\mathrm{H}]^{+}$217.1624, found 217.1609.

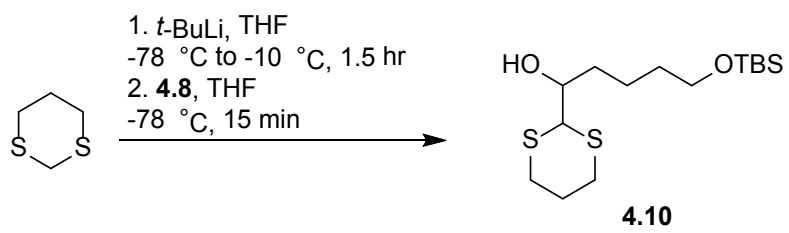

Compound 4.10. A solution of 1,3-dithiane (3.254 g, $27.060 \mathrm{mmol})$ in dry THF $(50 \mathrm{~mL})$ was cooled to $-78{ }^{\circ} \mathrm{C}$ under $\mathrm{N}_{2}$. A solution of tert-butyllithium (1.7 $\mathrm{M}$ in pentane, 16.0 $\mathrm{mL}, 27.060 \mathrm{mmol}$ ) was added dropwise. After addition, the reaction mixture was allowed to warm to $-40{ }^{\circ} \mathrm{C}$ and stayed at the temperature for 1 hour. The reaction mixture was cooled back to $-78{ }^{\circ} \mathrm{C}$, and a solution of tert-butyldimethylsiloxyl pentanal $\mathbf{4 . 8}$ $(4.880 \mathrm{~g}, 22.550 \mathrm{mmol})$ in dry THF $(30 \mathrm{~mL})$ was added slowly via canula. The reaction mixture was allowed to react for 15 minutes, and then quenched with saturated $\mathrm{NH}_{4} \mathrm{Cl}$ solution $(50 \mathrm{~mL})$. The mixture was allowed to warm up to ambient temperature. The organic layer was separated and the aqueous layer was extracted by EtOAc. The combined organic layer was washed with water and brine. The organic layer was dried over anhydrous $\mathrm{Na}_{2} \mathrm{SO}_{4}$, filtered and concentrated. Flash column chromatography (9:1 hexanes/EtOAc) gave compound 4.10 as colorless oil $(5.402 \mathrm{~g}, 71 \%): \mathrm{R}_{\mathrm{f}}=0.2$ (hexanes/EtOAc=9:1) ; ${ }^{1} \mathrm{H}$ NMR (400 MHz, $\left.\mathrm{CDCl}_{3}\right) \delta 0.02$ (s, 6H), 0.86 (s, 9H), 1.38$1.48(\mathrm{~m}, 1 \mathrm{H}), 1.49-1.59(\mathrm{~m}, 4 \mathrm{H}), 1.77-1.84(\mathrm{~s}, 1 \mathrm{H}), 1.89-1.98(\mathrm{~s}, 1 \mathrm{H}), 2.01-2.10(\mathrm{~s}, 1 \mathrm{H})$ $2.43(\mathrm{~d}, J=3,6 \mathrm{~Hz}, 1 \mathrm{H}), 2.68-2.78(\mathrm{~m}, 2 \mathrm{H}), 2.86-2.94(\mathrm{~m}, 2 \mathrm{H}), 3.59(\mathrm{t}, J=10.4 \mathrm{~Hz}, 2 \mathrm{H})$, 3.80-3.85 (m, $1 \mathrm{H}), 3.87-3.89(\mathrm{~d}, J=6 \mathrm{~Hz}, 1 \mathrm{H}) ;{ }^{13} \mathrm{C} \mathrm{NMR}\left(100 \mathrm{MHz}, \mathrm{CDCl}_{3}\right) \delta-5.3,18.3$, 
$22.1,25.7,26.0,28.0,28.5,32.6,33.8,52.5,63.0,72.2$; HRMS (ESI) $m / z$ calcd for $\mathrm{C}_{15} \mathrm{H}_{33} \mathrm{O}_{2} \mathrm{~S}_{2} \mathrm{Si}[\mathrm{M}+\mathrm{H}]^{+}$337.1686, found 337.1695.

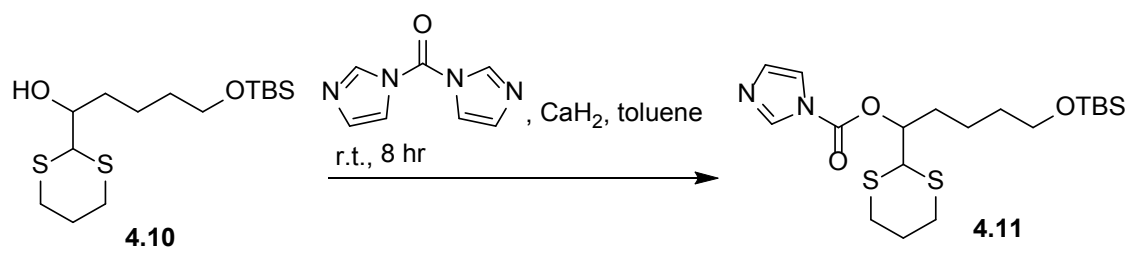

Compound 4.11. A mixture of carbonyldiimidazole (2.606 g, $16.071 \mathrm{mmol})$, compound 4.10 (2.164 g, $6.428 \mathrm{mmol}), \mathrm{CaH}_{2}(90 \%$ grade, $0.752 \mathrm{~g}, 16.071 \mathrm{mmol})$ and dry toluene $(100 \mathrm{~mL})$ was stirred at room temperature overnight. The reaction mixture was filtered and concentrated. After flash column chromatography (3:1 hexanes/EtOAc), compound 4.11 was obtained as colorless sticky oil $(2.833 \mathrm{~g}, 100 \%): \mathrm{R}_{\mathrm{f}}=0.2$ (hexanes/EtOAc =3:1); ${ }^{1} \mathrm{H}$ NMR (400 MHz, $\left.\mathrm{CDCl}_{3}\right) \delta 0.01$ (s, 6H), 0.82 (s, 9H), 1.39$1.56(\mathrm{~m}, 5 \mathrm{H}), 1.80-2.08(\mathrm{~m}, 5 \mathrm{H}), 2.67-2.78(\mathrm{~m}, 2 \mathrm{H}), 2.84-2.95(\mathrm{~m}, 2 \mathrm{H}), 3.56-3.58(\mathrm{t}, J=$ $4 \mathrm{~Hz}, 2 \mathrm{H}), 4.10-4.11(\mathrm{~d}, J=4 \mathrm{~Hz}, 1 \mathrm{H}), 5.28-5.33(\mathrm{~m}, 1 \mathrm{H}), 7.04(\mathrm{~s}, 1 \mathrm{H}), 7.40(\mathrm{~s}, 1 \mathrm{H}), 8.12$ (s, $1 \mathrm{H}) ;{ }^{13} \mathrm{C}$ NMR $\left(100 \mathrm{MHz}, \mathrm{CDCl}_{3}\right) \delta$-5.4, 18.2 21.7, 25.4, 25.8, 28.4, 28.6, 31.4, 32.2, 48.9, 62.4, 78.4, 117.2, 130.6, 137.2, 148.3; HRMS (ESI) $m / z$ calcd for $\mathrm{C}_{19} \mathrm{H}_{35} \mathrm{~N}_{2} \mathrm{O}_{3} \mathrm{~S}_{2} \mathrm{Si}$ $[\mathrm{M}+\mathrm{H}]^{+}$431.1853, found 431.1858.

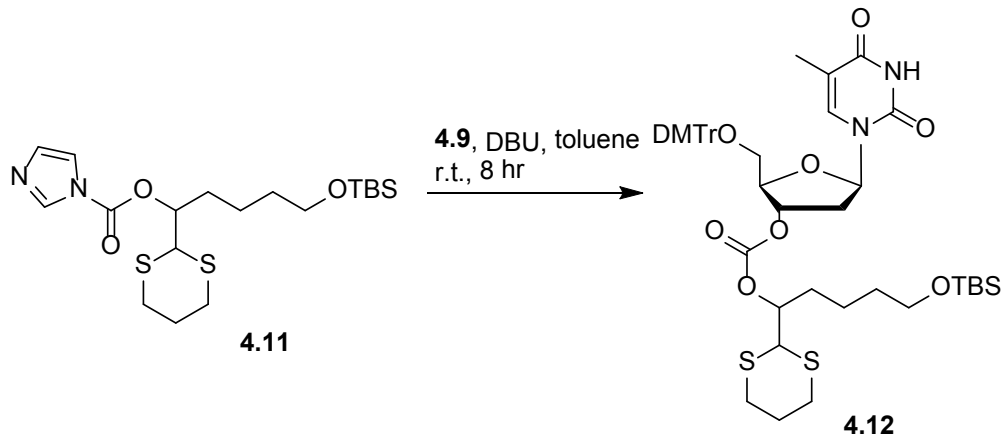


Compound 4.12. A mixture of compound 4.9 (3.721 g, $6.833 \mathrm{mmol}$ ), compound 4.11 (1.962 g, $4.555 \mathrm{mmol})$ and $\mathrm{DBU}(0.208 \mathrm{~g}, 0.20 \mathrm{~mL}, 1.367 \mathrm{mmol})$ in dry toluene (50 $\mathrm{mL}$ ) was stirred at room temperature for 8 hours. The reaction mixture was concentrated on a rotary evaporator and purified with flash column chromatography (hexanes/EtOAc $=$ 3:1, 0.5\% $\left.\mathrm{Et}_{3} \mathrm{~N}\right)$. Compound 4.12 was obtained as a white foam $(3.140 \mathrm{~g}, 76 \%)$ : M. P. = 81.2-82.6 ${ }^{\circ} \mathrm{C} ; \mathrm{R}_{\mathrm{f}}=0.45($ hexanes/EtOAc $=1: 1) ;{ }^{1} \mathrm{H}$ NMR $\left(400 \mathrm{MHz}, \mathrm{CDCl}_{3}\right) \delta(\mathrm{TMS}$ as the reference) $0.00(\mathrm{~s}, 6 \mathrm{H}), 0.84(\mathrm{~s}, 9 \mathrm{H}), 1.31(\mathrm{~s}, 3 \mathrm{H}), 1.36-2.00(\mathrm{~m}, 11 \mathrm{H}), 2.34-2.74(\mathrm{~m}$, 5H), 2.80-2.89 (m, 2H), 3.41-3.47 (m, 2H), 3.55-3.59 (t, $J=8 \mathrm{~Hz}, 2 \mathrm{H}), 3.75(\mathrm{~s}, 6 \mathrm{H})$, 3.93-3.95 (d, $J=8 \mathrm{~Hz}, 1 \mathrm{H}), 4.20(\mathrm{~s}, 1 \mathrm{H}), 4.91-4.96(\mathrm{~m}, 1 \mathrm{H}), 5.34-5.36(\mathrm{~d}, J=8 \mathrm{~Hz}, 1 \mathrm{H})$, 6.40-6.44 (dd, $J=4 \mathrm{~Hz}, 8 \mathrm{~Hz}, 1 \mathrm{H}), 6.78-6.80(\mathrm{~d}, J=8 \mathrm{~Hz}, 4 \mathrm{H}), 7.18-7.34(\mathrm{~m}, 9 \mathrm{H}), 7.54$ (s, 1H), 8.08 (br s, $1 \mathrm{H}) ;{ }^{13} \mathrm{C}$ NMR $\left(100 \mathrm{MHz}, \mathrm{CDCl}_{3}\right) \delta$-5.3, 11.6, 18.3, 21.7, 25.4, 26.0, $28.4,28.6,31.6,32.3,37.9,48.9,55.3,62.7,63.7,78.8,78.9,84.0,84.3,87.2,111.5$, $113.3,127.2,128.0,128.1,130.1,135.2,135.3,135.4,144.2,150.0,154.3,158.8,163.3$; HRMS (ESI) $m / z$ calcd for $\mathrm{C}_{47} \mathrm{H}_{62} \mathrm{~N}_{2} \mathrm{O}_{10} \mathrm{~S}_{2} \mathrm{SiNa}[\mathrm{M}+\mathrm{Na}]^{+}$929.3507, found 929.3497.
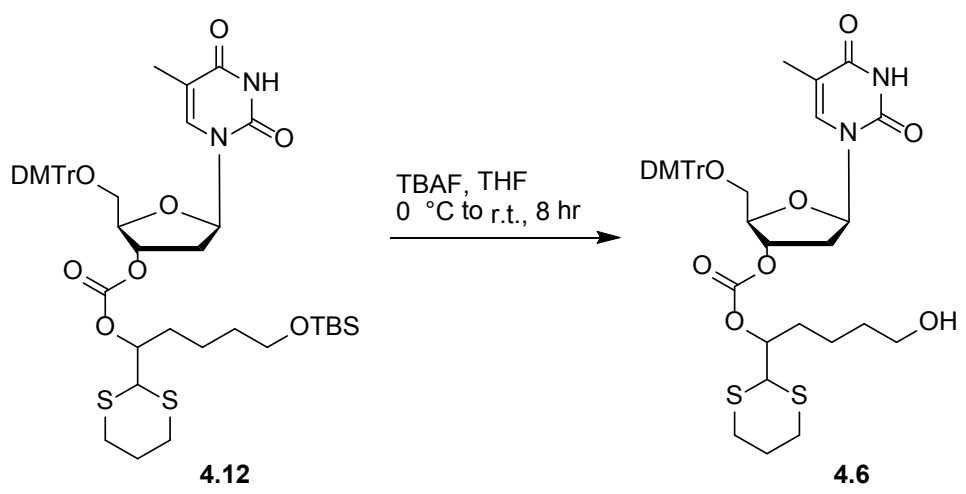

dT-Dmoc-Linker 4.6. To a THF (40 mL) solution of compound 4.12 (1.470 g, $1.620 \mathrm{mmol})$ at $0{ }^{\circ} \mathrm{C}$, TBAF $(1.95 \mathrm{~mL}, 1.0 \mathrm{M}$ in THF) was added dropwise. The reaction 
mixture was warmed to room temperature and stirred overnight. The mixture was partitioned between EtOAc $(40 \mathrm{~mL})$ and $\mathrm{H}_{2} \mathrm{O}(40 \mathrm{~mL})$. The aqueous layer was extracted with EtOAc twice. The combined organic layers were dried over anhydrous $\mathrm{Na}_{2} \mathrm{SO}_{4}$, filtered and concentrated. Flash column chromatography (hexanes/EtOAc=1:1) gave compound 4.6 as a white foam $(0.958 \mathrm{~g}, 75 \%): \mathrm{T}_{\mathrm{M}}=90.6-92.3{ }^{\circ} \mathrm{C} ; \quad \mathrm{R}_{\mathrm{f}}=0.3$ (hexanes/EtOAc $=1: 3) ;{ }^{1} \mathrm{H}$ NMR $\left(400 \mathrm{MHz}, \mathrm{CDCl}_{3}\right) \delta 1.35(\mathrm{~s}, 3 \mathrm{H}), 1.41-1.63(\mathrm{~m}, 4 \mathrm{H})$, 1.69-1.81 (m, 3H), 1.89-2.08 (m, 4H), 2.37-2.44 (m, 1H), 2.56-2.75 (m, 3H), 2.84-2.93 (m, 2H), 3.42-3.51 (m, 2H), 3.61-3.65 (m, 2H), 3.77 (s, 6H), 3.97-3.99 (d, $J=8 \mathrm{~Hz}, 1 \mathrm{H})$, $4.24(\mathrm{~s}, 1 \mathrm{H}), 4.97-5.01(\mathrm{~m}, 1 \mathrm{H}), 5.34-5.35(\mathrm{~d}, J=4 \mathrm{~Hz}, 1 \mathrm{H}), 6.41-6.44(\mathrm{dd}, J=4 \mathrm{~Hz}, 8$ $\mathrm{Hz}), 6.81-6.83(\mathrm{~d}, J=8 \mathrm{~Hz}, 4 \mathrm{H}), 7.20-7.37(\mathrm{~m}, 9 \mathrm{H}), 7.58(\mathrm{~s}, 1 \mathrm{H}), 8.78(\mathrm{~s}, 1 \mathrm{H}) ;{ }^{13} \mathrm{C}$ NMR $\left(100 \mathrm{MHz}, \mathrm{CDCl}_{3}\right) \delta 11.6,14.2,21.0,21.6,25.4,28.4,28.6,31.6,32.1,38.0,48.9,55.2$, $60.4,62.4,63.7,78.7,79.1,83.7,84.4,87.2,111.6,113.3,127.2,128.0,128.1,130.1$, $130.1,135.1,135.2,135.3,144.2,150.3,154.2,158.8,158.8,163.5$; HRMS (ESI) $\mathrm{m} / \mathrm{z}$ calcd for $\mathrm{C}_{41} \mathrm{H}_{48} \mathrm{~N}_{2} \mathrm{O}_{10} \mathrm{~S}_{2} \mathrm{Na}[\mathrm{M}+\mathrm{Na}]^{+}$815.2643, found 815.2636.
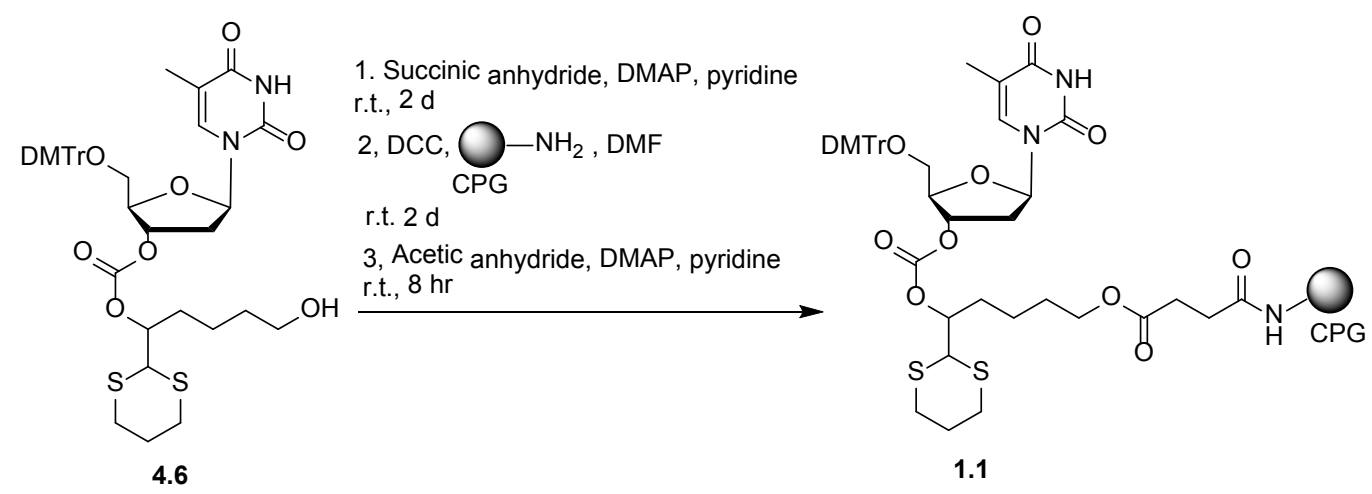

dT-Dmoc-CPG 1.1. ${ }^{11}$ A mixture of Dmoc-dT linker 4.6 (0.100 g, 0.126 mmol), succinic anhydride $(0.050 \mathrm{~g}, 0.504 \mathrm{mmol})$, and DMAP (0.031 g, $0.252 \mathrm{mmol})$ in 
anhydrous pyridine $(3 \mathrm{~mL})$ was stirred at room temperature. After 2 days, the mixture was partitioned between EtOAc $(5 \mathrm{~mL})$ and $\mathrm{H}_{2} \mathrm{O}(5 \mathrm{~mL})$. The organic layer was washed with saturated aqueous $\mathrm{NaHCO}_{3}$ and brine, dried over anhydrous $\mathrm{Na}_{2} \mathrm{SO}_{4}$ and concentrated. The residue was dissolved in dry DMF (3 mL). To the solution, amino-

lcaa-controlled pore glass $(0.251 \mathrm{~g}, 0.027 \mathrm{mmol}, 107 \mu \mathrm{M} / \mathrm{g}, 497 \AA$, Prime Synthesis, Inc.) and DCC $\left(0.027 \mathrm{~mL}, 1.0 \mathrm{M}\right.$ in $\left.\mathrm{CH}_{2} \mathrm{Cl}_{2}\right)$ was added. The mixture was kept at room temperature for 2 days. After the resin was washed with pyridine, $5 \mathrm{~mL}$ of a capping solution (0.1 M DMAP in pyridine: $\left.\mathrm{Ac}_{2} \mathrm{O}, 9: 1, \mathrm{v} / \mathrm{v}\right)$ was added, and the whole mixture was kept at room temperature for 2 days. The resin was subsequently washed with pyridine, $\mathrm{MeOH}, \mathrm{DMF}$ and acetone, and was dried under vacuum.

\section{ODN synthesis, cleavage, deprotection and analysis}

\section{5'-TTT TTT TTT TTT TTT TTT TTT TTT TTT TTT-3' (4.14)}

Synthesis. The CPG with Dmoc-dT linker $1.1(50 \mathrm{mg}, 5.35 \mu \mathrm{mol})$ with a pore size of $497 \AA$ was packed in a standard DNA synthesis column. The 30-mer ODN was synthesized on an ABI DNA/RNA synthesizer at $1 \mu$ mol scale. 5'-DMTr-protected 2cyanoethyl dT phosphoramidite monomer was used for the synthesis. $\mathrm{THF} /$ pyridine/ $\mathrm{Pac}_{2} \mathrm{O}$ was used as the capping reagent. The manufacturer recommended synthetic cycle was followed. Manual cleavage and DMTr on functions were chosen. After synthesis, the CPG was dried, weighed and equally distributed into 10 vials. 
Cleavage. One portion of CPG (7.3 mg) was suspended with a solution of DBU in dry $\mathrm{CH}_{3} \mathrm{CN}(10 \%, \mathrm{v} / \mathrm{v}, 500 \mu \mathrm{L})$, and was hand shaken for 10 minutes. The supernatant was pipetted out and the CPG was washed with dry $\mathrm{CH}_{3} \mathrm{CN}$ three times $(200 \mu \mathrm{L}$ each time) and also washed with $\mathrm{DI}-\mathrm{H}_{2} \mathrm{O}$ three times $(200 \mu \mathrm{L}$ each time). To the $\mathrm{CPG}$, a $\mathrm{NaIO}_{4}$ aqueous solution $(0.05 \mathrm{M}, 1000 \mu \mathrm{L})$ was added. After the incubation at room temperature with rotating for 3 hours, the supernatant was transferred to an Eppendorf tube. The CPG was washed with deionized water three times $(200 \mu \mathrm{L}$ each time). The combined aqueous solution was desalted over a dextran desalting column $(5 \mathrm{~K}$ MWCO, $10 \mathrm{~mL}$ ) with the DI- $\mathrm{H}_{2} \mathrm{O}$ as eluent. Fractions were collected every milliliter. Fractions 3, 4, 5, 6 were combined and concentrated. The ODN was dissolved in $200 \mu \mathrm{L} \mathrm{H}_{2} \mathrm{O}$, and 20 $\mu \mathrm{L}$ solution was injected into RP HPLC. ODN 4.14 was shown in Figure 4.6.

\section{5'-TCA TTG CTG CTT AGA CCG CT-3' (4.13)}

Synthesis. The CPG with Dmoc-dT linker $1.1(50 \mathrm{mg}, 5.35 \mu \mathrm{mol})$ with a pore size of $497 \AA$ was packed in a standard DNA synthesis column. The 20-mer was synthesized on an ABI DNA/RNA synthesizer at $1 \mu$ mol. The following 5'-DMTrprotected 2-cyanoethyl phosphoramidite monomers were used for the synthesis: Pac-dA, 4-isopropyl-Pac-dG, Ac-dC, and dT. THF/pyridine/ $\mathrm{Pac}_{2} \mathrm{O}$ was used as the capping reagent. The manufacturer recommended synthetic cycle was followed. Manual cleavage and DMTr on functions were chosen. After synthesis, the CPG was dried, weighed and evenly distributed into 10 vials. 
Cleavage and deprotection. One portion of CPG (4.2 mg) was suspended with a solution of DBU in dry $\mathrm{CH}_{3} \mathrm{CN}(10 \%$, v/v, $500 \mu \mathrm{L})$, and was hand shaken for 10 minutes. The supernatant was pipetted out and the $\mathrm{CPG}$ was washed with $\mathrm{CH}_{3} \mathrm{CN}$ three times (200 $\mu \mathrm{L}$ each time). To the $\mathrm{CPG}$, a $\mathrm{NaIO}_{4}$ aqueous solution $(0.05 \mathrm{M}, 1000 \mu \mathrm{L})$ was added. After the incubation at room temperature with rotating for 3 hours, the supernatant was transferred to an Eppendorf tube. The CPG was washed with deionized water three times (200 $\mu \mathrm{L}$ each time). The combined aqueous solution was concentrated. To the residue, $28 \%$ $\mathrm{NH}_{3}$ aqueous solution $(1000 \mu \mathrm{L})$ was added. The resulting solution was votexed and kept at room temperature for 8 hours. After concentration, the resulted mixture was dissolved in $200 \mu \mathrm{L} \mathrm{H} \mathrm{H}_{2} \mathrm{O}$, and $20 \mu \mathrm{L}$ solution was injected into RP HPLC. ODN 4.13 was shown in Figure 4.7. MALDI-TOF cald mass 6059, found 6058.594.

\section{References}

1. Letsinger, R. L.; Mahadevan, V., Oligonucleotide synthesis on a polymer support. Journal of the American Chemical Society 1965, 87, 3526-3527.

2. Guillier, F.; Orain, D.; Bradley, M., Linkers and cleavage strategies in solid-phase organic synthesis and combinatorial chemistry. Chemical Reviews 2000, 100 (10), 3859.

3. (a) Guzaev, A. P., Solid-phase supports for oligonucleotide synthesis. Current Protocols in Nucleic Acid Chemistry 2013, Chapter 3, Unit 3.1; (b) Pon, R. T., Solidphase supports for oligonucleotide synthesis. Methods in Molecular Biology 1993, 20, 465-96. 
4. Guzaev, A. P.; Pon, R. T., Attachment of nucleosides and other linkers to solidphase supports for oligonucleotide synthesis. Current Protocols in Nucleic Acid Chemistry 2013, Chapter 3, Unit 32.

5. Jensen, M. A.; Anderson, K. M.; Davis, R. W., Gas-phase cleavage and dephosphorylation of universal linker-bound oligodeoxynucleotides. Nucleosides, Nucleotides \& Nucleic acids 2010, 29 (11), 867-78.

6. (a) Dias, N.; Stein, C. A., Antisense oligonucleotides: basic concepts and mechanisms. Molecular Cancer Therapeutics 2002, 1 (5), 347-55; (b) Heller, M. J., DNA microarray technology: devices, systems, and applications. Annual Review of Biomedical Engineering 2002, 4, 129-53; (c) Patil, S. D.; Rhodes, D. G.; Burgess, D. J., DNA-based therapeutics and DNA delivery systems: a comprehensive review. The AAPS journal 2005, 7 (1), 61-77.

7. Lyttle, M. H.; Hudson, D.; Cook, R. M., A new universal linker for solid phase DNA synthesis. Nucleic Acids Research 1996, 24 (14), 2793-2798.

8. Ohkubo, A.; Kasuya, R.; Aoki, K.; Kobori, A.; Taguchi, H.; Seio, K.; Sekine, M., Efficient synthesis of functionalized oligodeoxyribonucleotides with base-labile groups using a new silyl linker. Bioorganic \& Medicinal Chemistry 2008, 16 (9), 5345-5351.

9. (a) Greenberg, M. M., Photochemical cleavage of oligonucleotides from solid phase supports. Tetrahedron Letter 1993, 34 (2), 251-254; (b) Dell'Aquila, C., Iambach, J. L., Rayner, B., Photolabile linker for the solid-phase synthesis of base-sensitive oligonucleotides. Tetrahedron Letter 1997, 38 (30), 5289. 
10. Frankowski, K., Golder. J. E., Zeng. Y., Lei. Y, Aubé J., Syntheses of the stemona alkaloids (+/-)-stenine, (+/-)-neostenine, and (+/-)-13-epineostenine using a stereodivergent Diels-Alder/Azido-Schmidt Reaction. Journal of American Chemical Society 2008, 130 (18), 6018-6024.

11. Ueno, Y.; Shibata, A.; Matsuda, A.; Kitade, Y., Synthesis of 3'-3'-linked oligonucleotides branched by a pentaerythritol linker and the thermal stabilities of the triplexes with single-stranded DNA or RNA. Bioconjugate Chemistry 2003, 14 (3), 684689. 


\title{
Chapter 5
}

\section{Synthesis of Dmoc-protected Phophoramidite Monomers and Their Applications in ODN Synthesis ${ }^{1}$}

\begin{abstract}
Dmoc protected phosphoramidites were synthesized and used to synthesize ODNs along with the dT-Dmoc linker. The deprotection and cleaveage of ODNs from CPG was achieved under non-nucleophilic conditions.
\end{abstract}

\subsection{Introduction}

The chemical synthesis of ODN has made a great contribution to the biological study and biomedical application of nucleic acids. The most commonly used synthetic strategy is phophoramadite chemistry. One key element to have an efficient ODN synthesis is to have a good protecting group scheme. The protecting scheme should allow the selective removal of a specific protecting group at a desired time. To make matters more challenging, the protecting groups must be removable almost quantitatively. Otherwise, the yield of desired product will be low and the product itself may be irresolvable from contaminants. Furthermore, purines are susceptible to depurination under mildly to acidic conditions. Hence strong acids should be avoided.

\footnotetext{
${ }^{1}$ The contents of Chapter 5 were adapted into a journal paper "Oligonucleotide Synthesis Using Protecting Groups and a Linker Cleavable under Non-nucleophilic Conditions”. This paper has been submitted to the Chemical Communication for peer review.
} 
Three functional groups need to be protected: 1) the 5' hydroxyl groups; 2) the exocyclic amino groups; 3) the phosphates.

The most common protecting groups for $5^{\prime}$ hydroxyl group is the trityl group (Figure 5.1), which was reported by Khorana et al.. ${ }^{1}$ The combination of good stability and easiness for removal with mild acid has made it superior over others. The reason that the trityl family cleaves so readily under acidic conditions lies in the formation of carbocations. The trityls have distinctive colors when ionized, which have made them extremely useful as diagnostic tools. The dimethoxytrityl (DMTr) carbocation has a very strong orange color in mild acid. It has a high extinction coefficient that can still be accurately measured using optical approach even at very low concentrations. The monomethoxytrityl (MMTr) carbocation has a yellow color, while the parent trityl ( $\mathrm{Tr}$ ) itself is deep red. The efficiency of each cycle of nucleoside addition can be followed by measuring the absorbance of the released DMTr groups.
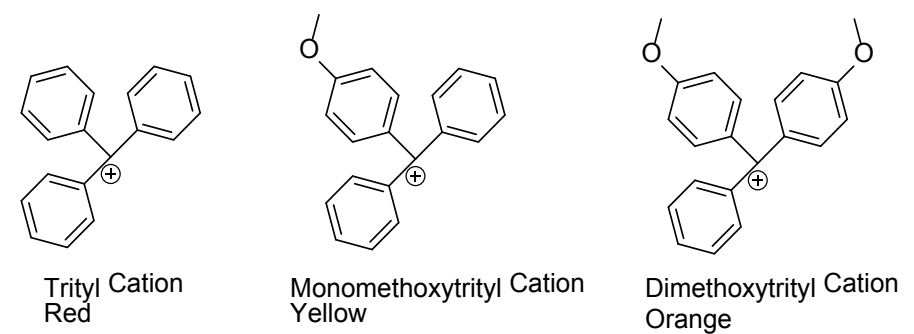

Figure 5.1. The trityl family

Khorana also introduced the protecting groups for the exocyclic amino groups of nucleosidic bases. They are isobutyryl for guanosine and benzoyl for adenosine and cytidine (Figure 5.2). To date, they are known as standard protecting groups. ${ }^{2}$ Acetylprotected cytidine is also widely used in ODN synthesis. The removal of these acyl 
groups is carried out with strong nucleophiles, such as concentrated ammonium hydroxide.

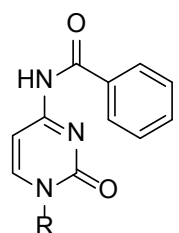

N-Benzoyl Cytidine

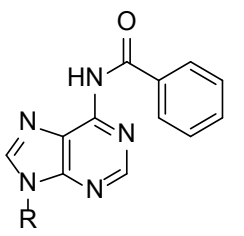

N-Benzoyl Adenosine

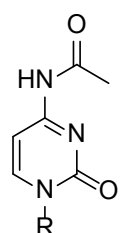

N-Acety Cytidine

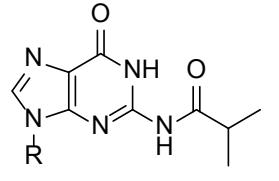

N-Isobutyryl Guanosine

Figure 5.2. Standard protecting groups for nucleoside bases

Phosphate moieties are usually protected by $\beta$-cyanoethyl groups. These groups were introduced by Letsinger on phosphite chemistry and later adapted by Caruthers on phosphoramidites. ${ }^{3}$ With base-induced $\beta$-elimination, the deprotection of $\beta$-cyanoethyl groups can be simply achieved with strong bases which are also required for deprotecting exocyclic amino acyl protecting groups.

However, the ODN synthesis methods utilizing conventional protecting groups is not compatible with some modified ODN syntheses, especially those ODNs with electrophilic functionalities. $\beta$-Cyanoethyl group can be removed by non-nucleophilic bases, such as DBU. ${ }^{4}$ However the deprotection of exocyclic amino groups needs strong nucleophiles. So far, there are two strategies to synthesize such electrophilic ODN analogues. One methodology is to use nucleosidic phosphoramidites without base protection. $^{4-5}$ Sekine and his coworkers have proposed a method using activated 
phosphite (Figure 5.3); where they activated phosphoramidite $\mathbf{5 . 1}$ with 1hydroxybenzotriazole (HOBt) ${ }^{5 b}$ The derived triester $\mathbf{5 . 3}$ can be highly selective with the $5^{\prime}$ hydroxyl group of 5.2. However these methods have to be customized to each specific modification and cannot be universally applied on all electrophilic ODN syntheses. Moreover, the method has low coupling yields, and therefore cannot be used to synthesize long ODNs.
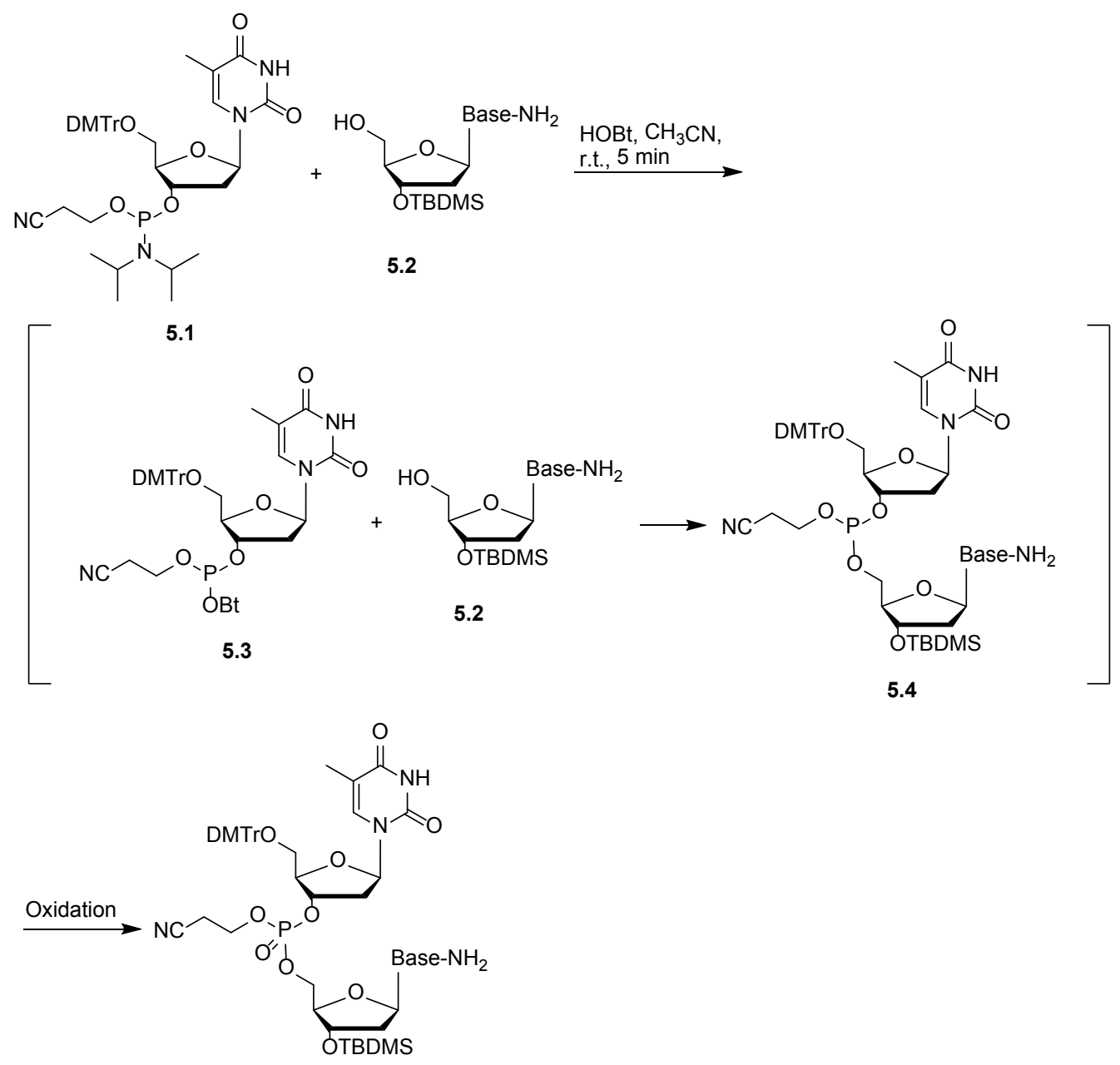

5.5

Figure 5.3. Sekine's activated phosphite method 
Another strategy is to investigate on protecting groups which can be removed under mild conditions. However the functionalities in organic chemistry suitable for this need are limited. Hazawa and his coworkers have reported an allylic protection method for modified ODN synthesis. ${ }^{6}$ In the protocol, they protected the internucleotide linkages with allylic groups and nucleoside bases with allyloxycarbonyl groups. The modified ODNs can be obtained after deprotection by treating with a mixture of $\operatorname{Pd}(0)$ complexes, triphenylphosphine, butylamine and fomic acid. However the application of $\operatorname{Pd}(0)$ complexes has resulted in the difficulties of complete removal of $\operatorname{Pd}(0)$ and high reagent cost.

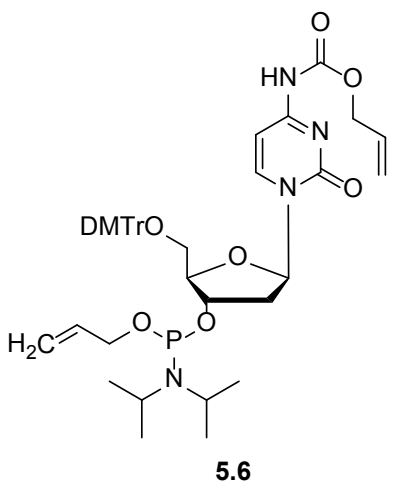

Allylic protected $\mathrm{dC}$-amidite

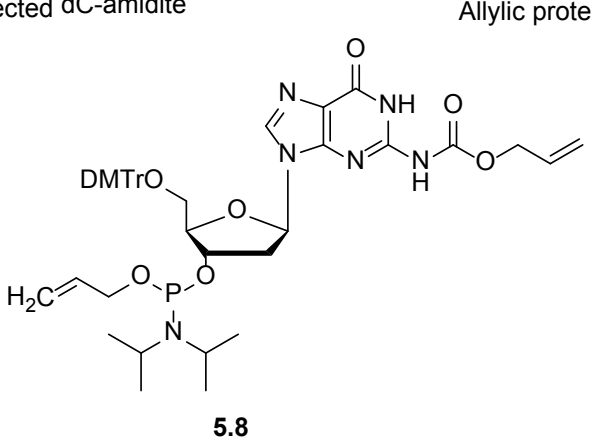

Allylic protected dG-amidite 西

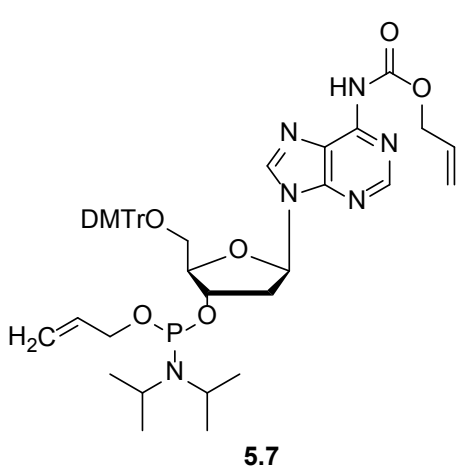

Allylic protected $\mathrm{dA}$-amidite 
In this chapter, we report Dmoc-based protecting groups for nucleoside phosphoramidites (1.2-1.4, Figure 5.5) which can be removed under non-nucleophilic conditions with cost effective oxidizing reagents. The combination of these Dmocprotected phosphoramidites and dT-Dmoc linker shall provide a universal method for electrophilic ODN synthesis.

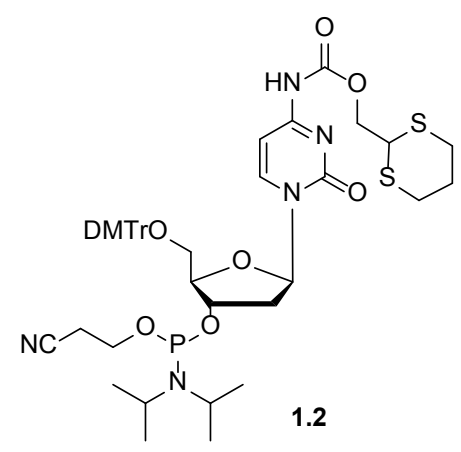

Dmoc-dC-amidite

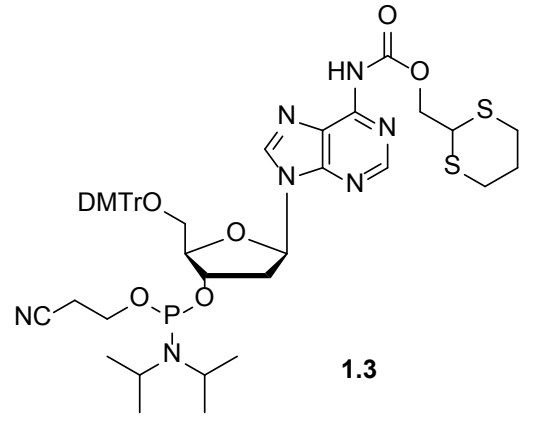

Dmoc-dA-amidite

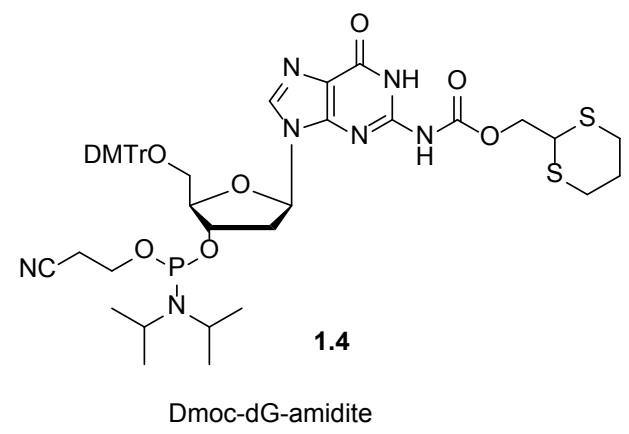

Figure 5.5. Dmoc-protected nucleoside phosphoramidite monomers

\subsection{Results and Discussion}

As shown in Scheme 5.2, the Dmoc moieties were introduced to nucleosidic bases using Dmoc precursor 5.10, which was produced from the convertion of dithianyl ethanol 5.9 with $p$-nitrochloroformate (Scheme 5.1). 


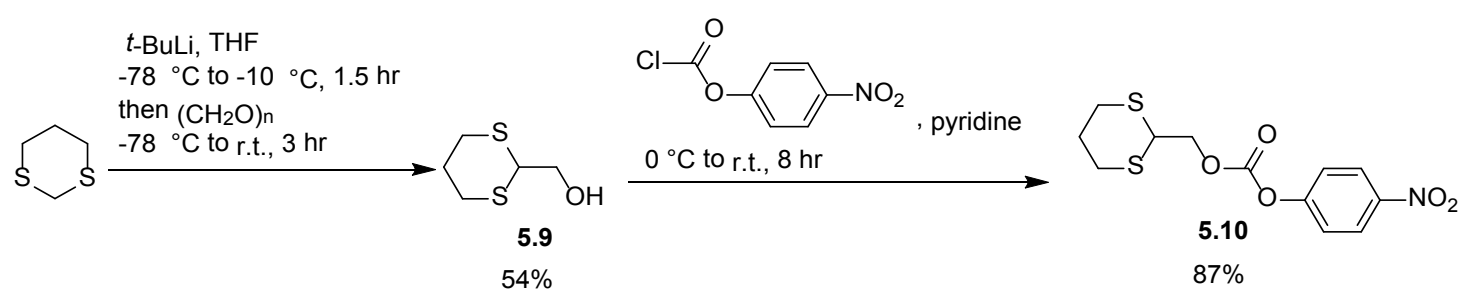

Scheme 5.1. Synthesis of Dmoc protecting group precursor

The exo-amino groups of DMTr protected $\mathrm{dC}$ (5.11) and $\mathrm{dA}$ (5.13) were conveniently protected using (1,3-dithian-2-yl)methyl 4-nitrophenyl carbonate (5.10) by first protecting the 3 -hydroxyl group with trimethylsilyl chloride (TMSCl) temporarily followed by stirring the reactants at room temperature with DMAP as the catalyst. The products $\mathbf{5 . 1 2}$ and $\mathbf{5 . 1 4}$ were obtained in $100 \%$ and $57 \%$ yields, respectively. When the same acylation method was applied to synthesize the Dmoc protected dG 5.18, no desired product could be isolated.
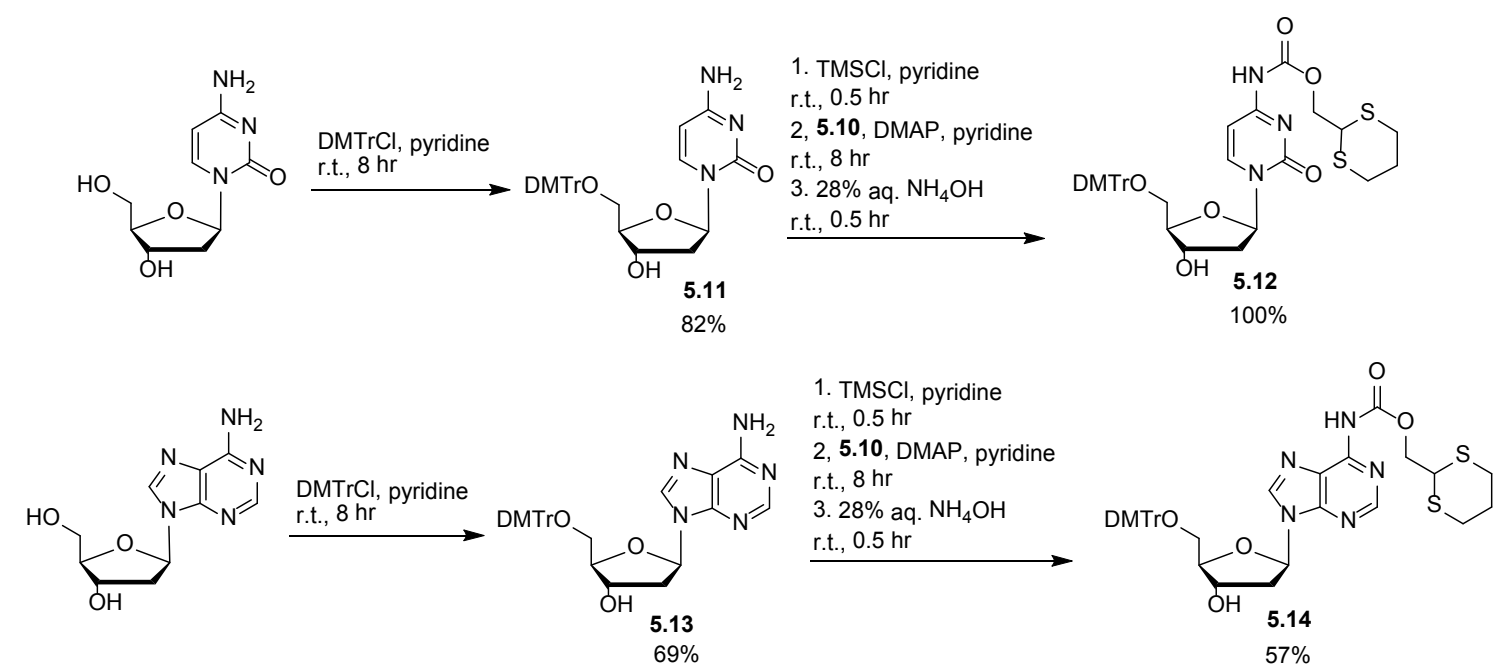

Scheme 5.2. Synthesis of Dmoc protected dC and dA

After testing several conditions for the synthesis of 5.18, we realized this was a difficult task. However we knew that we could solve the problem. It only took time. The 
more challenging problem to be solved is the application of the Dmoc protected phosphoramidites and Dmoc-linker for ODN synthesis under non-nucleophilic conditions. As a result we decided to put the synthesis of $\mathbf{5 . 1 8}$ aside and forwarded to synthesize Dmoc-dC-amidite 1.2 and Dmoc-dA-amidite 1.3 (Scheme 5.3).

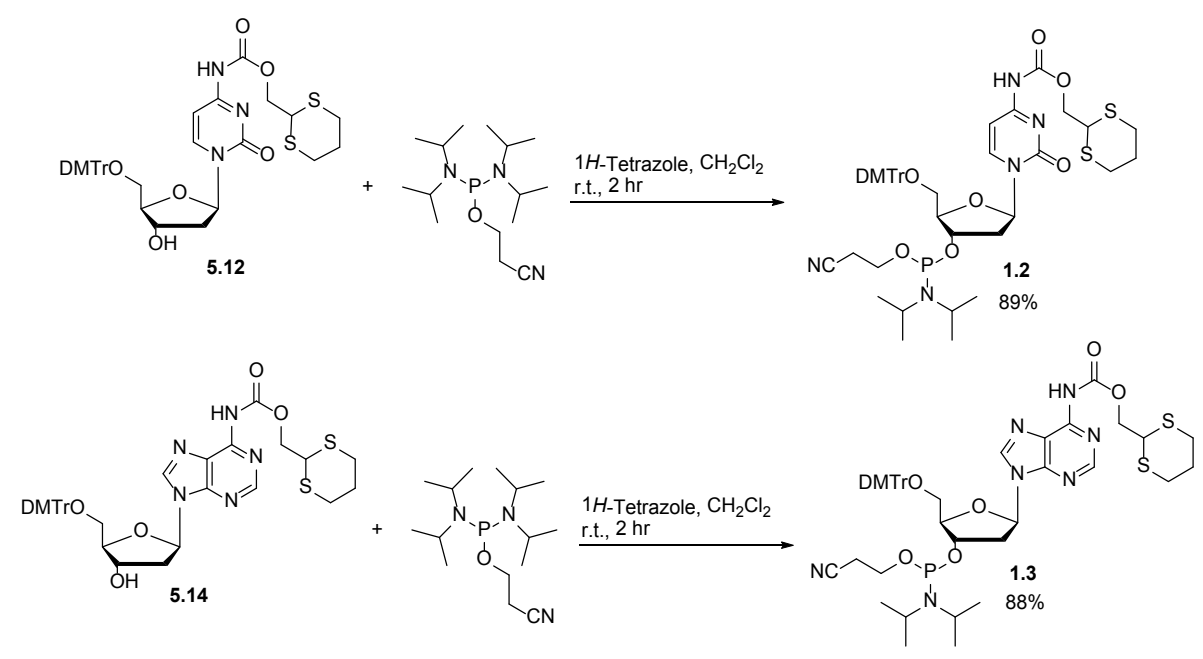

Scheme 5.3. Synthesis of Dmoc-dC-amidite and Dmoc dA-amidite

Phosphinylation of $\mathbf{5 . 1 2}$ and $\mathbf{5 . 1 4}$ using 2-cyano- $N, N, N^{\prime}, N^{\prime}-$ tetraisopropylphosphordiamidite gave the ODN synthesis phosphoramidite monomers Dmoc-dC-amidite 1.2 and Dmoc-dA-amidite 1.3, respectively in excellent yields.

With dT-Dmoc-CPG 1.1 and the phosphoramidite monomers 1.2 and 1.3, we synthesized an ODN sequence without dG (5.16, 5'-HO-TTA CTT CTA TTA TCA ATC CT-OH-3'). The synthesis procedure and conditions were the same as those in traditional ODN synthesis using the phosphoramidite chemistry. The phosphoramidite concentration was $0.1 \mathrm{M}$. At the end of synthesis, DMTr group was kept on the ODN sequence. According to trityl assay, the coupling steps have high efficiency with an average step- 
wise yield of $98 \%$ and an overall yield of $69 \%$, which showed no negative affect by using the dT-Dmoc-linker and Dmoc-protected phosphoramidites.
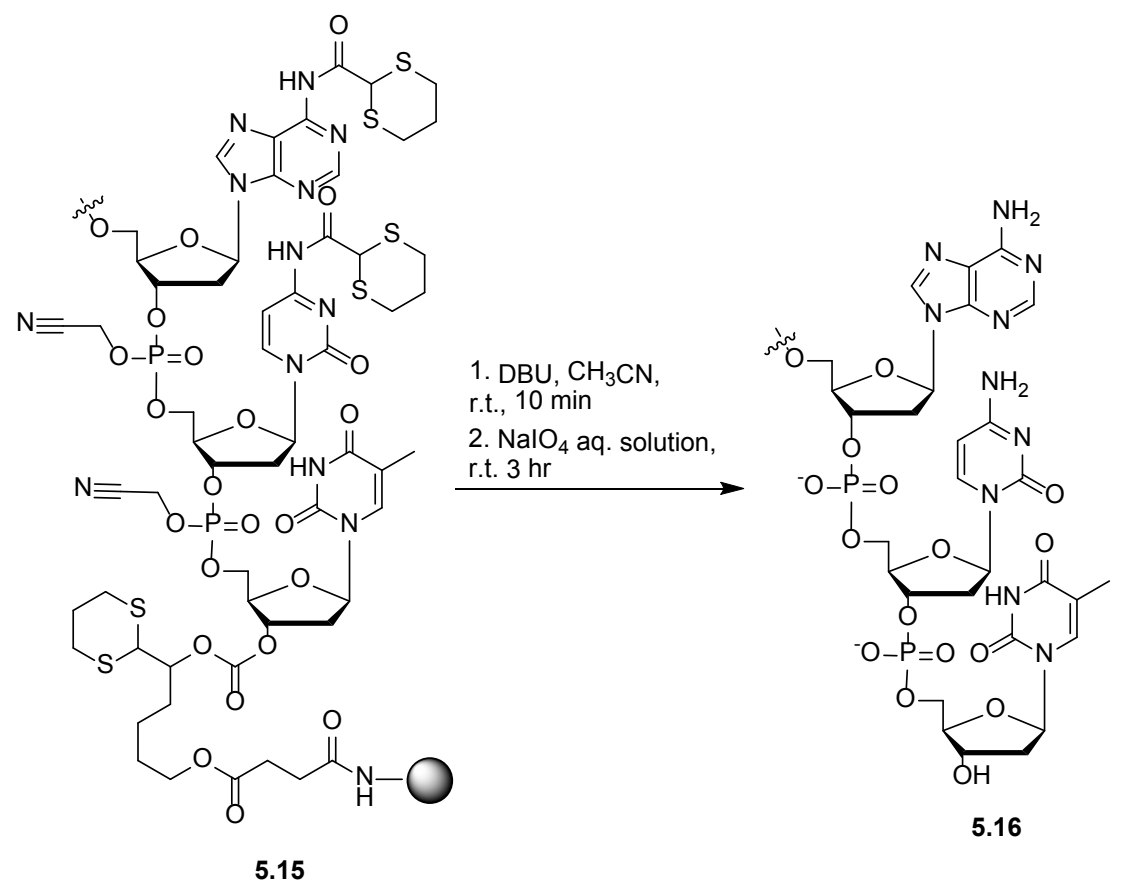

Scheme 5.4. The cleavage and deprotection of ODN $\mathbf{5 . 1 6}$

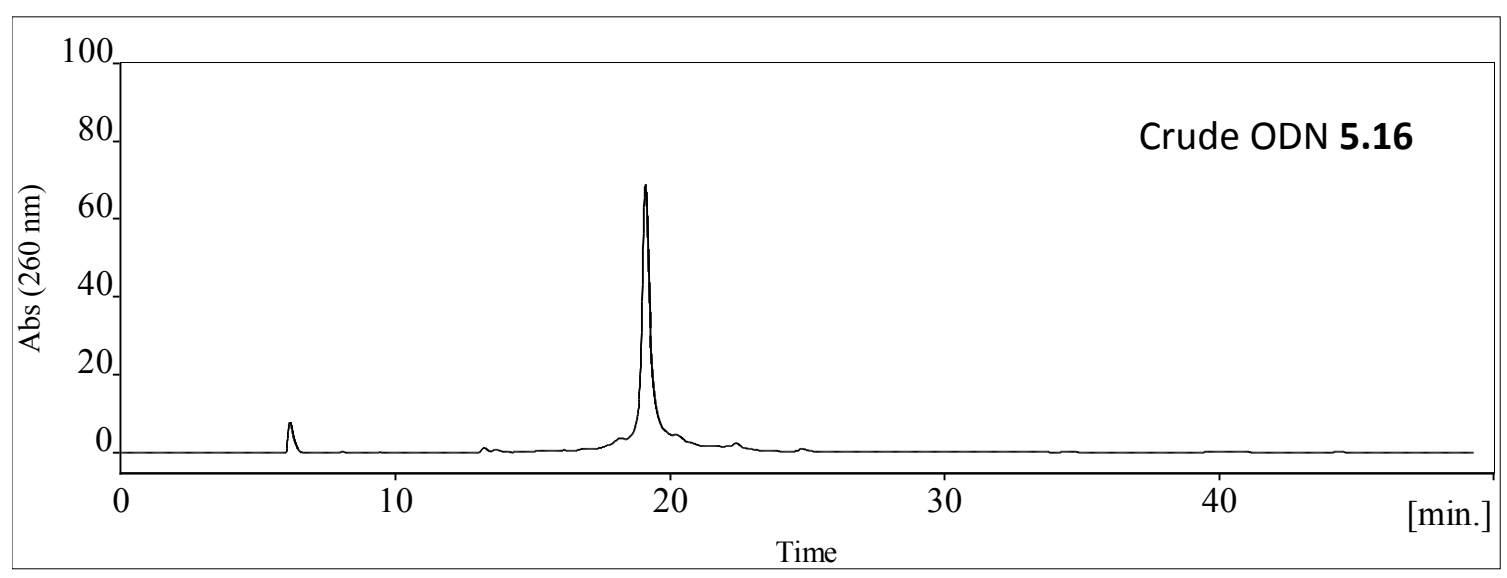

Figure 5.6. HPLC profile of ODN 5.16 
The cleavage and deprotection of ODN $\mathbf{5 . 1 6}$ is shown in Scheme 5.4. The 2cyanoethyl groups were removed by treating $\mathbf{5 . 1 5}$ with DBU. The sulfide functions of Dmoc moieties were then oxidized with $\mathrm{NaIO}_{4}$ aqueous solution. Followed with $\beta$ elimination, ODN 5.16 was obtained, which was analyzed by HPLC (Figure 5.6) and MALDI-TOF.

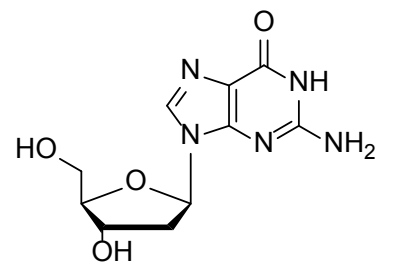

1. TMSCl, pyridine,

2. 5.10, DMAP, pyridine

r.t., $8 \mathrm{hr}$
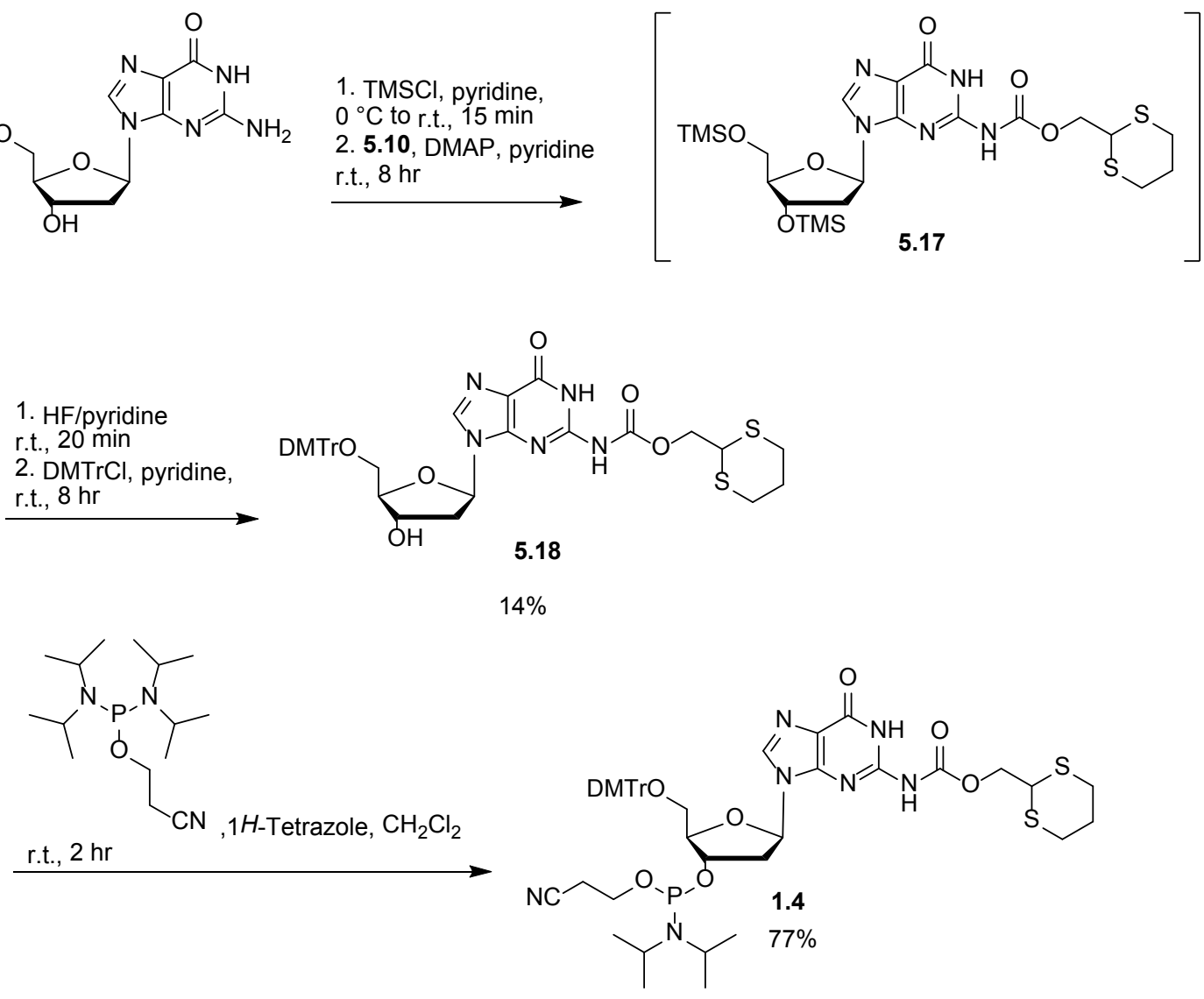

Scheme 5.5. Synthesis of Dmoc-dG-amidite

After the feasibility of ODN synthesis using Dmoc phosphoramidites and Dmoclinker is established, we came back to solve the problem of syntheisizng Dmoc-protected $\mathrm{dG}$ 5.18. The challenge of acylating $\mathrm{dG}$ could be attributed to the lower nucleophilicity of the exo-amino group on $\mathrm{dG}$ (pKa of conjugate acid 3.2) compared to those on $\mathrm{dC}$ (pKa of 
conjugate acid 4.4) and $\mathrm{dA}$ (pKa of conjugate acid 4.1). ${ }^{7}$ It is also possible that the acylation reaction occurred but the carboxyamide bond was broken during $\mathrm{NH}_{4} \mathrm{OH}$ treatment in the procedure for removal of TMS groups used for temporary protecting 3$\mathrm{OH}$. Based on these hypotheses, the procedure was modified (Scheme 5.5). Instead of using DMTr protected nucleoside, $\mathrm{dG}$ was used directly. The two hydroxyl groups were temporarily protected with TMS, and the acylation reaction was carried out with 10 equivalents of 5.10. The intermediate $\mathbf{5 . 1 7}$ was not isolated, and the TMS groups were removed by HF-pyridine. All volatiles were then evaporated with a nitrogen flow over the surface of the reaction mixture. The residue (5.17) was reacted with $\mathrm{DMTrCl}$ directly to give $\mathbf{5 . 1 8}$ in $14 \%$ yield after flash column chromatography. Phosphinylation of $\mathbf{5 . 1 8}$ using 2-cyano- $N, N, N^{\prime}, N^{\prime}$ - tetraisopropylphosphordiamidite gave Dmoc-dG-amidite $\mathbf{1 . 4}$ in excellent yield.

With dT-Dmoc-CPG 1.1 and all phosphoramidite monomers 1.2-1.4, we synthesized another four ODN sequences. They were 5'-OH-TCA TTG CTT CTG ATC CTG CT-3' (5.19), 5'-HO-TCA TTG CTG CTT ATA CCT CT-OH-3' (5.20), 5'-HOTCA TTG CTG CTT AGA CCG CT-OH-3' (5.21) and 5'-HO-TTA GTA GGA CCT ACA CCT GT-OH-3' (5.22). The syntheses of ODNs followed the synthesis of 5.16. According to trityl assay, high yields were achieved for each ODN sequence (overall yield: $82 \%$ for $\mathbf{5 . 1 9}, 77 \%$ for $\mathbf{5 . 2 0}, 79 \%$ for $\mathbf{5 . 2 1}$ and $78 \%$ for $\mathbf{5 . 2 2}$ ). The same cleavage and deprotection process of ODN 5.16 was applied for the retrieve of these ODNs. To our surprise, multiple peaks instead of one peak were observed, such as ODN 5.19 in 
trace a in Figure 5.7.
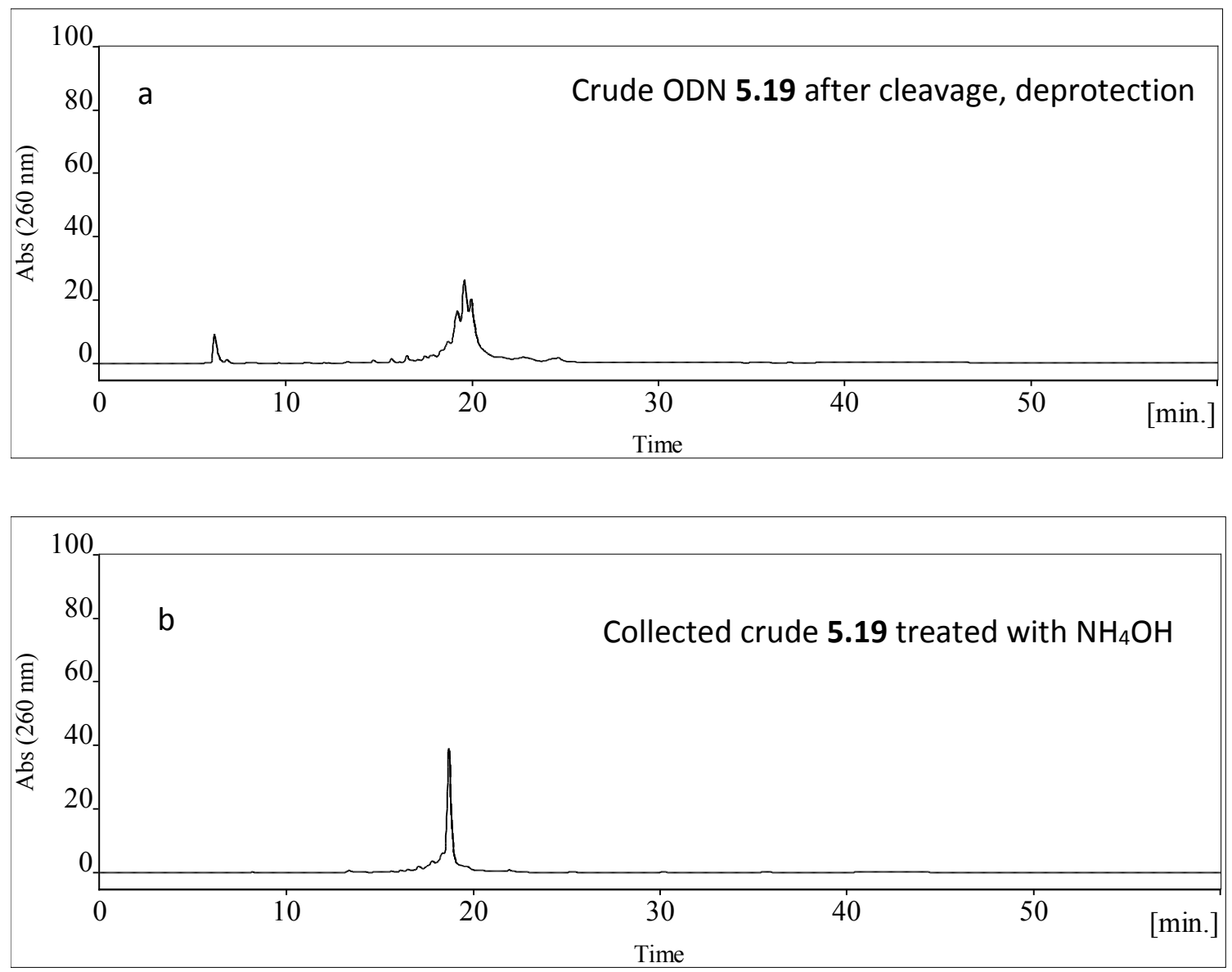

Figure 5.7. RP HPLC profile of ODN 5.19 from the unsuccessful deprotection

We repeated the experiments twice, and HPLC profiles were identical. The extracts had been passed through a polyacrylamide desalting column (6 K MWCO). Small molecules have been excluded by the desalting process. The peaks shown should be from large molecules. There was no ODN shown from the final ammonia cleavage of the residual CPG. The multiple peaks must be from ODNs in an unexpected forms. From our previous studies, we knew that ODN is stable under the used oxidizing conditions. These peaks should not be oxidatively damaged ODNs. From our group's ODN 
purification project, we have found similar peak pattern for ODNs, which was caused by the reaction of ODNs with Michael acceptors through conjugate addition. ${ }^{8}$ We believed that similar conjugate addition might have happened in the cleavage and deprotection process of ODNs. Nucleophilic sites of the full-length ODN reacted with $\mathbf{5 . 2 3}$, which is a side product from Dmoc deprotection, through conjugate addition (Scheme 5.6). If this is true, the conjugation adducts should be able to convert back to unmodified ODNs by removing the Michael acceptor moieties. Based on this hypothesis, the fractions of HPLC containing the ODNs from the multiple peaks were collected through HPLC. After concentration, the substrates were treated with concentrated $\mathrm{NH}_{4} \mathrm{OH}$ at $80^{\circ} \mathrm{C}$ for 1 hour, and analyzed with HPLC. As shown in in Figure 5.7 (trace b), the multiple peaks merged in to one peak. This observation supported our hypothesis. The reason that we didn't observe ODN conjugates from HPLC profiles of ODN 5.16, might be due to the differences of the nucleophilicity of nucleoside bases. Comparing to dA, dT and dC, dG is more reactive toward nucleophiles which is also the main cause of DNA alkylation. ${ }^{9}$

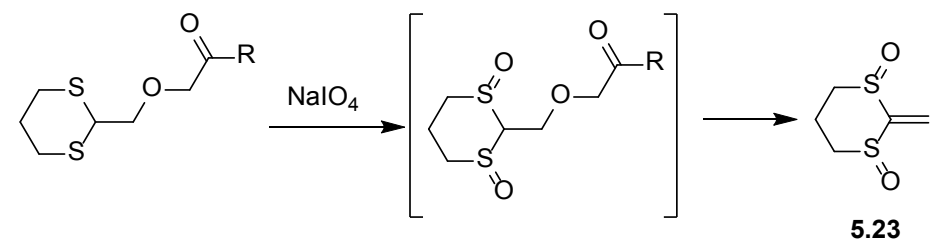

Scheme 5.6. Michael acceptor-an addcut from the removal of Dmoc protecting group

To avoid the Michael addition of Dmoc derivatives to ODNs, the Michael acceptor must be scavenged. Since our purpose is to synthesize electrophilic functionalized ODNs, the scavenger we tempt to introduce into the system should be mild enough to be compatible with electrophilic ODNs. The choices left to us were very 
limited. Aniline became the best candidate for this task. Aniline is a moderate nucleophiles and weak base. The pKa of aniline is 4.19. Any functionality that is not stable to aniline is not expected to be stable toward ODN itself. Moreover, there are many other nucleophiles stronger than aniline existing in living system. Incorporation of functionalities that are unstable toward aniline is not expected to be stable for in vivo study. The use of aniline in our procedure will not be a concern for electrophilic ODN synthesis. Further, the weak basity of aniline can help to induce the $\beta$-elimination of the Dmoc group after the sulfides are oxidized to sulfoxides.
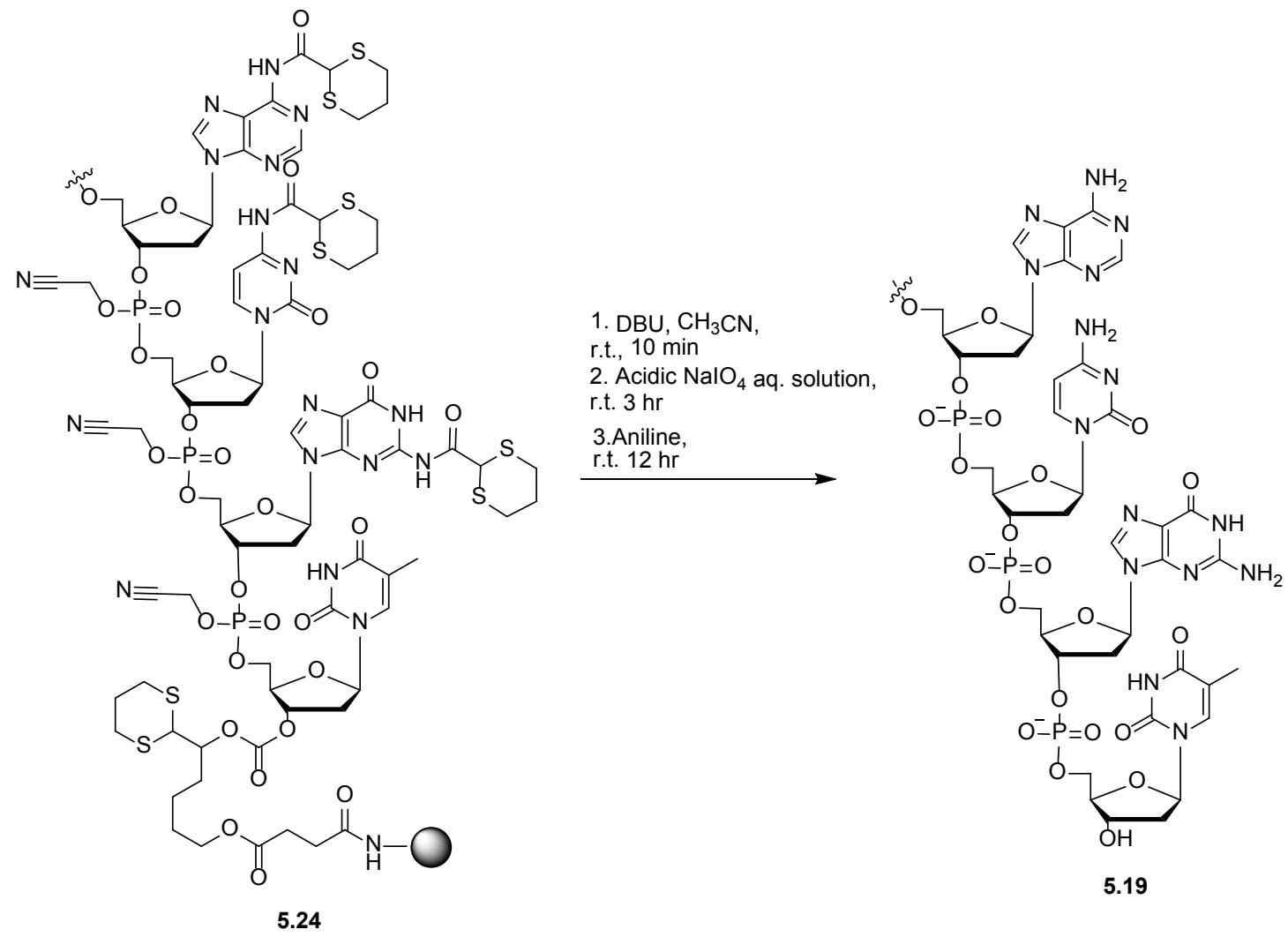

Scheme 5.7. Cleavage and deprotection of ODN 5.19 
However another issue came out. The incubation of CPG with aniline and $\mathrm{NaIO}_{4}$ gave lots of brownish precipitates. We later found out that the precipitates were from the reaction of aniline with $\mathrm{NaIO}_{4}$. To avoid the side reaction, we decided to use a 2-step process for deprotection and cleavage: 1) oxidization; 2) $\beta$-elimination/scavenging step. From previous studies, $\mathrm{NaIO}_{4}$ itself can oxidize sulfide and at the same time induce $\beta$ elimination to remove the Dmoc moieties. To limit the chances of removing Dmoc moieties, we introduced acetic acid into the oxidizing process to prevent $\beta$-elimination. After incubating with acetic $\mathrm{NaIO}_{4}$ solution at $\mathrm{pH} 2$ and washing with acetic acid solution (0.5M in water, $\mathrm{pH}$ 2), the CPG anchored with ODNs 5.24, of which sulfides on Dmoc groups have been oxidized, was treated with aniline solution at $\mathrm{pH}$ 8. Since the Michael reaction between aniline and Michael acceptor is reversible especially while concentrating, a D-Salt ${ }^{\mathrm{TM}}$ dextran column $(5 \mathrm{~K}$ MWCO) was used to remove the small molecules such as Michael addition adducts and extra aniline. The crude ODN 5.19 was purified with RP HPLC. The profiles of crude and purified $\mathbf{5 . 1 9}$ are shown in Figure 5.8. The MALDI-TOF analysis result of pure 5.19 indicated correct structure. From the extract of oxidation process, no cleaved/deprotected ODN was found in trace c, which suggested successful restriction of $\beta$-elimination by acetic acid. The treatment of residual CPG with concentrated $\mathrm{NH}_{4} \mathrm{OH}$ gave little ODN in trace $\mathrm{d}$. This indicates the cleavage of ODN was efficient. 

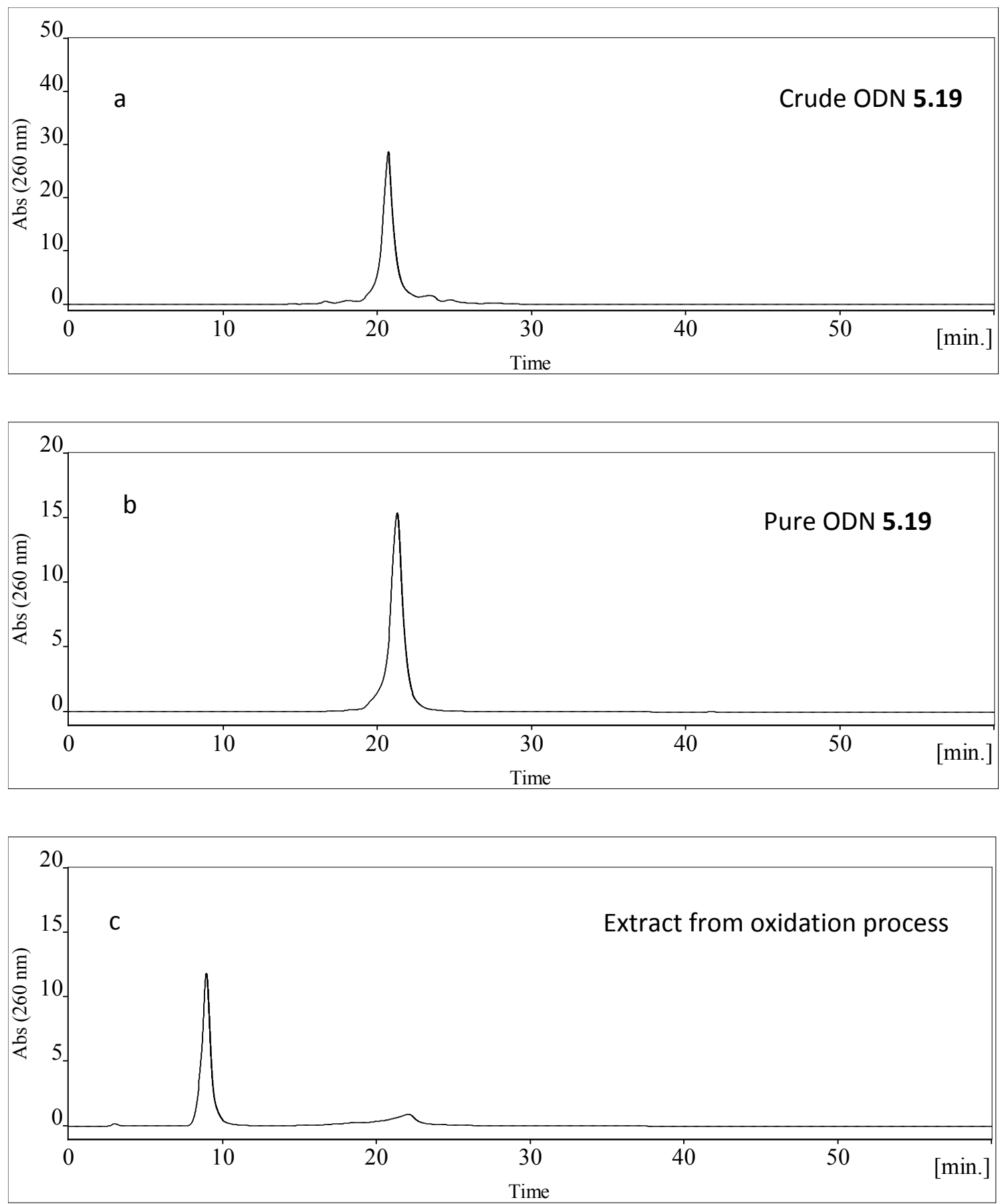

Figure 5.8. RP HPLC profiles of ODN 5.19 from the successful deprotection 


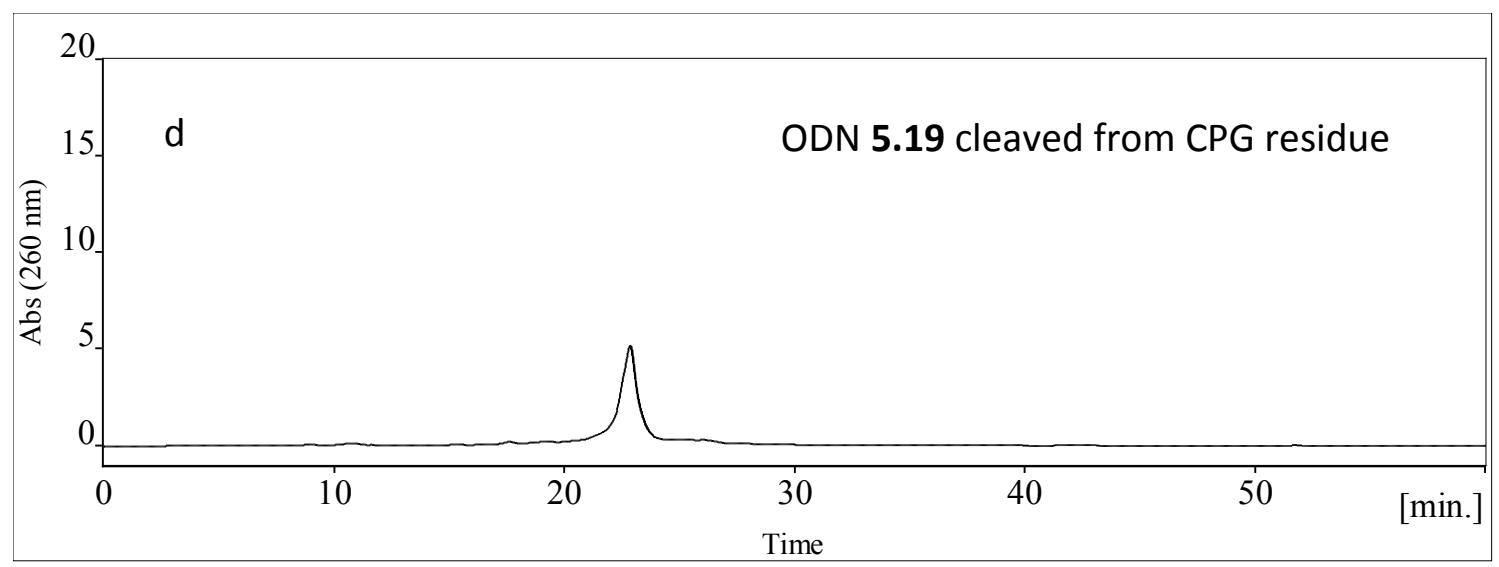

Figure 5.8. Cont'd

The two step strategy for the removal of Dmoc moieties was applied to the cleavage/deprotection of other three ODNs (5.20, 5.21 and 5.22). The profiles of crude and purified 5.20-5.22 are shown in Figure 5.9. All the ODNs were analyzed with MALDI-TOF MS, which indicated correct structure. One thing interesting was that the pure ODN 5.22 (a short piece of HIV protease gene) gave a peak with a small shoulder (trace f). While running ODN 5.22 sample with HPLC at $60{ }^{\circ} \mathrm{C}$, the shoulder disappeared in trace g. It is known that oligonucleotides with two successive Gs are capable of forming four-stranded helical structures called G-quadruplexes. ${ }^{10}$ The oddity we found might also be caused by the formation of G-quadruplexes. 

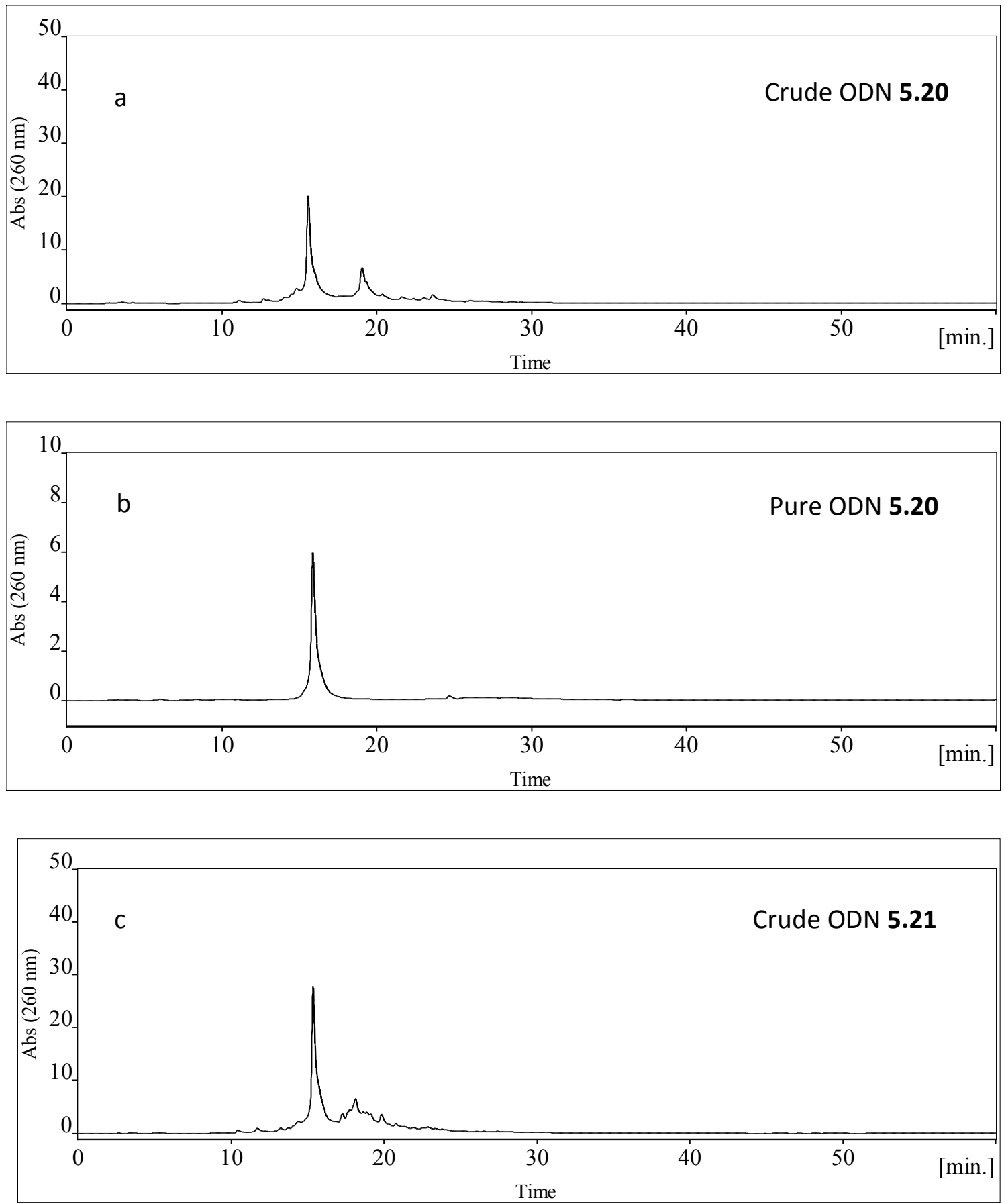

Figure 5.9. HPLC profiles of ODN 5.20-5.22 

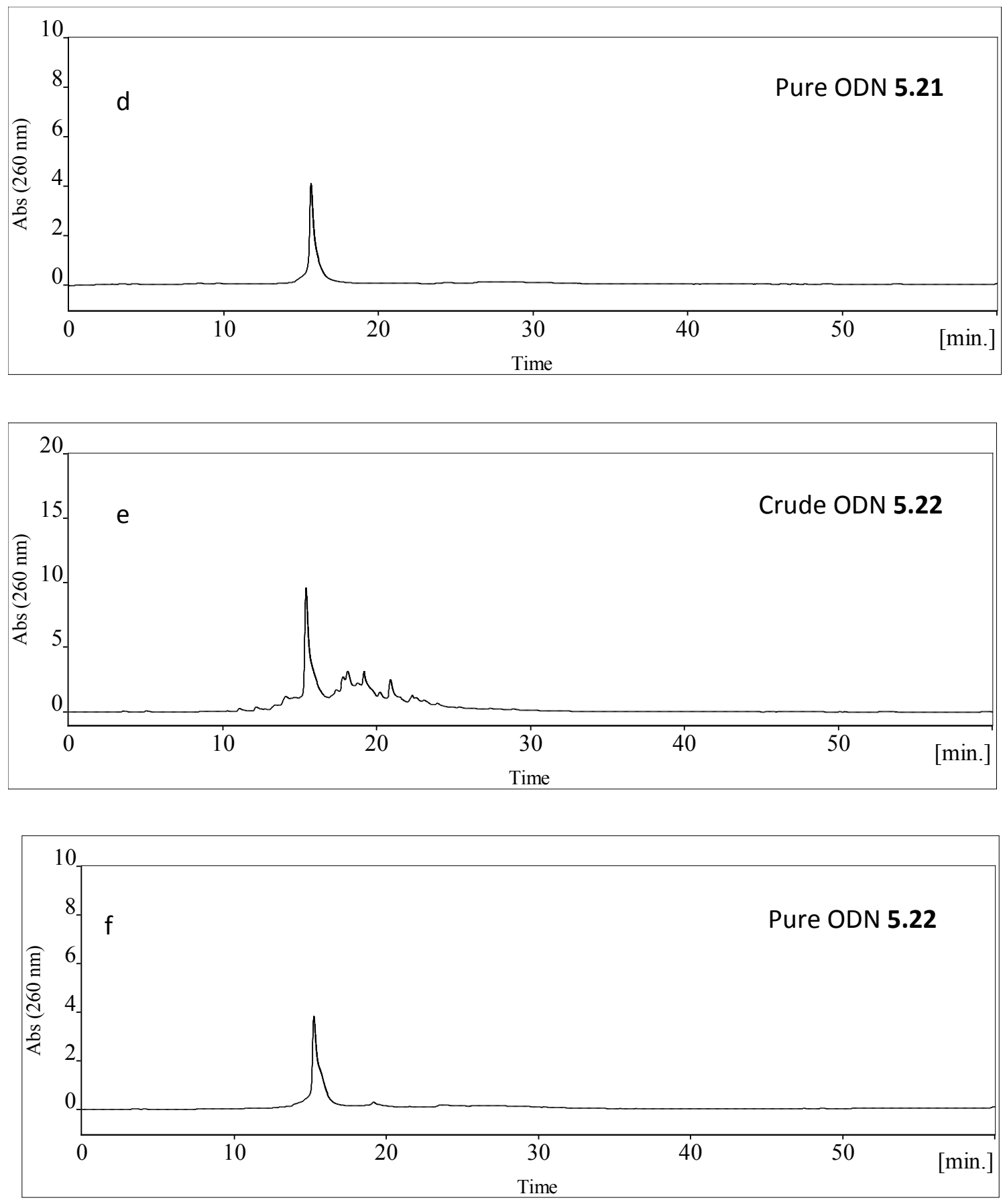

Figure 5.9. Cont'd 


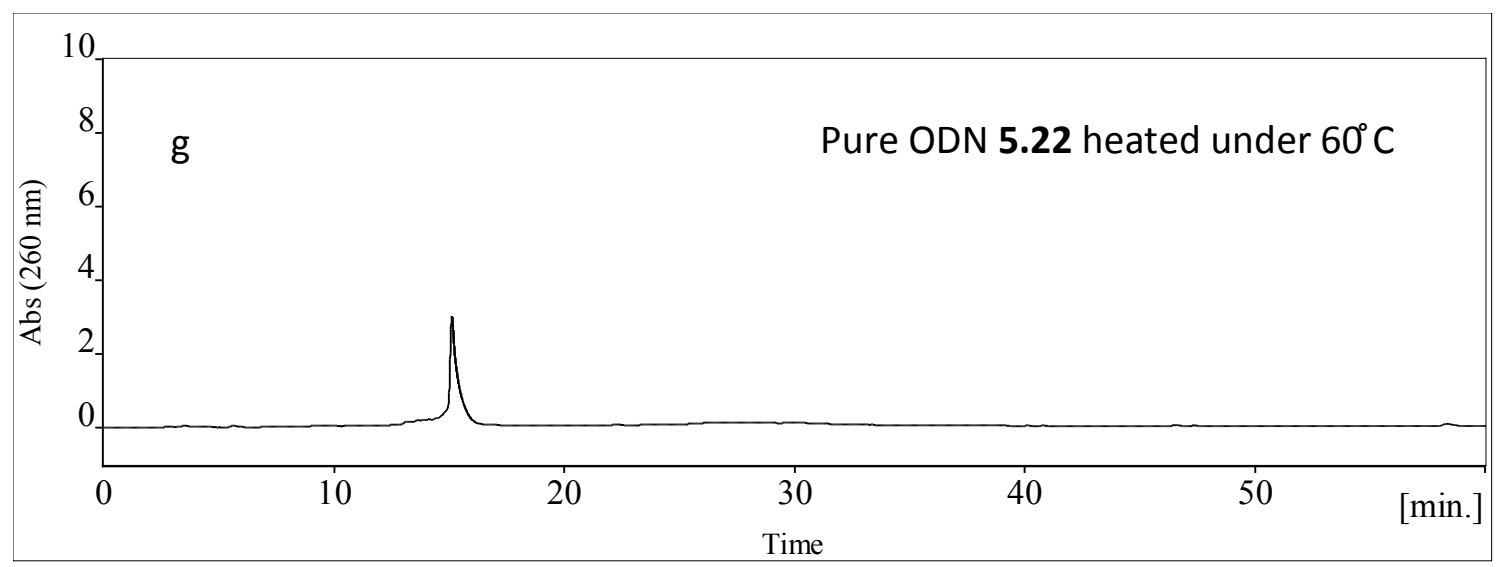

Figure 5.9. Cont'd

The Dmoc based linker and protecting groups are ideal for electrophilic ODN synthesis. Before oxidation, $\mathrm{H}-2$ in the function is not acidic in normal terms of organic chemistry ( $\mathrm{pKa} \sim 31$ ), which enables Dmoc to be completely stable during ODN synthesis. After oxidation, the pKa of $\mathrm{H}-2$ is lowered to $~ 12$. Compared to the Fmoc amino protecting group, in which case the $\mathrm{pKa}$ of $\mathrm{H}-9$ is $\sim 22$, and the group can be removed by the weak base piperidine ( $\mathrm{pKa}$ of conjugate acid $\sim 11$ ), the Dmoc linker and protecting group were predicted to be readily cleavable under nearly neutral and nonnucleophilic conditions. Our results have shown that this is indeed the case. Compared to the ODN synthesis methods that used the allyl and o-nitrobenzyl functionalities for protection and linking, the Dmoc method does not require any expensive transition metal and UV light for deprotection and cleavage. Instead, the readily available and easily removable $\mathrm{NaIO}_{4}$ and aniline can accomplish the complex task. 


\subsection{Conclusion}

We have developed a new ODN synthesis method using the Dmoc function as protecting groups. Along with the application of dT-Dmoc linker, we successfully synthesized the ODNs with the deprotection and cleavage method which is carried out under non-nucleophilic conditions. Therefore, this new method shall enable the synthesis of electrophilic ODN analogues

\subsection{Experimental Section}

\section{General Experimental}

All reactions were performed in over-dried glassware under a nitrogen atmosphere using standard Schlenk techniques. Reagents and solvents available from commercial sources were used as received unless otherwise noted. $\mathrm{CH}_{2} \mathrm{Cl}_{2}$, pyridine, toluene were distilled over $\mathrm{CaH}_{2}$, and THF was distilled over $\mathrm{Na}$. Thin layer chromatography (TLC) was performed using Sigma-Aldrich TLC plates, silica gel 60F254 over glass support, $0.25 \mu \mathrm{m}$ thickness. Flash column chromatography was performed using Selecto Scientific silica gel, particle size $32-63 \mu \mathrm{m} .{ }^{1} \mathrm{H},{ }^{13} \mathrm{C}$ and ${ }^{31} \mathrm{P}$ NMR spectra were measured on Varian UNITY INOVA spectrometer at 400, 100 and $162 \mathrm{MHz}$, respectively; chemical shifts $(\delta)$ were reported in reference to solvent peaks (residue $\mathrm{CHCl}_{3}$ at $\delta 7.24$ ppm for ${ }^{1} \mathrm{H}$ and $\mathrm{CDCl}_{3}$ at $\delta 77.00$ ppm for ${ }^{13} \mathrm{C}$ and $\mathrm{H}_{3} \mathrm{PO}_{4}$ at $\delta 0.00 \mathrm{ppm}$ for ${ }^{31} \mathrm{P}$ ), unless otherwise noted. High resolution mass spectra were obtained at Mass Spectrometry Technical Services at University of Michigan. 
ODNs were synthesized on a standard ABI 394 solid phase synthesizer. MALDITOF mass spectra were obtained on a Bruker Microflex LRF spectrometer. HPLC was perfomed on a JASCO LC-2000Plus System: pump, PU-2089Plus Quaternary Gradient; detector UV-2075Plus. A C-18 reverse phase analytical column (5 $\mu \mathrm{m}$ diameter, $100 \AA$, $250 \times 3.20 \mathrm{~mm}$ ) was used. Solvent A: $0.1 \mathrm{M}$ triethylammonium acetate, $5 \%$ acetonitrile. Solvent B: $90 \%$ acetonitrile. All profiles were generated by detection of absorbance of ODN at $260 \mathrm{~nm}$ using the linear gradient solvent system: solvent B (0\%-45\%) in solvent A over $60 \mathrm{~min}$ followed by solvent B (45\%-100\%) in solvent A over 20 min at a flow rate of $0.5 \mathrm{~mL} / \mathrm{min}$. Lcaa-CPG (pore size $497 \AA$ ) was sponsored by Prime Synthesis, Inc., and 5'-DMTr, 2-cyanoethyl phosphoramidites acetyl-dC, Pac-dA, 4-isopropyl-Pac-dG and dT were purchased from Glen Research, Inc. D-Salt ${ }^{\mathrm{TM}}$ dextran desalting column $(5 \mathrm{~K}$ MWCO, $10 \mathrm{~mL}$ ) was purchased from Pierce Biotechnology, Inc. MIX = $\mathrm{Et}_{2} \mathrm{O} / \mathrm{MeCN} / \mathrm{MeOH} / \mathrm{Et}_{3} \mathrm{~N}=5: 2: 2: 1$

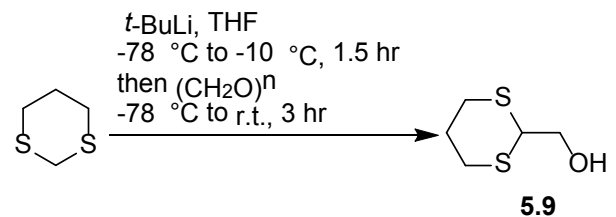

(1,3-Dithian-2-yl)methanol 5.9. A solution of dithiane (10.000 g, $83.167 \mathrm{mmol})$ in $\operatorname{THF}(50 \mathrm{~mL})$ was cooled at $-78^{\circ} \mathrm{C} . t$ - $\mathrm{BuLi}(1.7 \mathrm{M}$ in pentane, $58.7 \mathrm{~mL}, 99.800 \mathrm{mmol})$ was added dropwise. The reaction mixture was allowed to acclimate to $-10{ }^{\circ} \mathrm{C}$ and stay at the temperature for 1 hour. The mixture was cooled back to $-78{ }^{\circ} \mathrm{C}$ and was transferred slowly to a solution of paraformaldehyde $(7.492 \mathrm{~g}, 249.500 \mathrm{mmol})$ in THF $(50 \mathrm{~mL})$ at $78^{\circ} \mathrm{C}$. The whole mixture was allowed to acclimate to room temperature and stirred for 3 
hours. The mixture was partitioned between EtOAc and saturated $\mathrm{NH}_{4} \mathrm{Cl}$ solution. The aqueous layer was extracted with EtOAc $(50 \mathrm{~mL} \times 2)$. The combined organic layer was dried over anhydrous $\mathrm{Na}_{2} \mathrm{SO}_{4}$, filtered and concentrated. Flash column chromatography (2:1 hexanes/Et $2 \mathrm{O})$ gave compound 5.9 as pale yellow oil $(6.749 \mathrm{~g}, 54 \%): \mathrm{R}_{\mathrm{f}}=0.35$ (hexanes/ $\mathrm{Et}_{2} \mathrm{O}=1: 1$, brown spot with $\mathrm{I}_{2}$ stain); ${ }^{1} \mathrm{H}$ NMR (400 MHz, $\left.\mathrm{CDCl}_{3}\right) \delta 1.88-2.03$ (m, 2H), 2.58-2.63 (m, 3H), 2.82-2.86 (m, 2H), 3.77-3.86 (m, 3H); ${ }^{13} \mathrm{C}$ NMR (100 MHz, $\left.\mathrm{CDCl}_{3}\right) \delta$ 25.4, 26.5, 46.1, 63.0; HRMS (EI) $\mathrm{m} / z$ calcd for $\mathrm{C}_{5} \mathrm{H}_{10} \mathrm{OS}_{2}[\mathrm{M}]^{+}$150.0173, found 150.0171 .

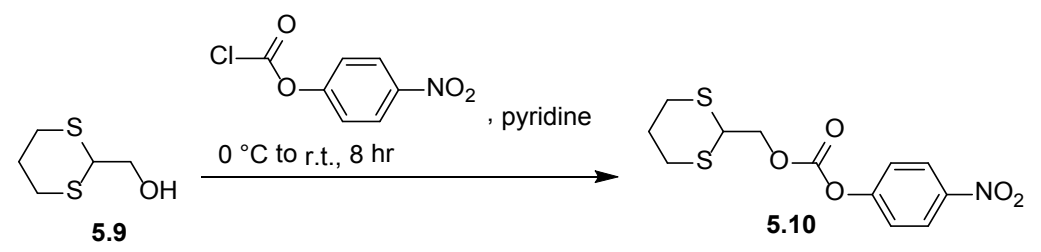

Compound 5.10. While cooled on an ice bath, to a solution of dithianylmethanol (2.499 $\mathrm{g}, 16.66 \mathrm{mmol})$ in pyridine $(30 \mathrm{~mL})$ was slowly added 4-nitrobenzyl chloroformate $(3.694 \mathrm{~g}, 18.326 \mathrm{mmol})$. The reaction mixture was left to stir at room temperature. After 8 hours, the mixture was kept in freezer for 1 hour, and then was quenched with cold $10 \% \mathrm{HCl}$ solution. The mixture was extracted with EtOAc. After the separation, the organic layer was washed sequentially with cold $10 \% \mathrm{HCl}$ solution, $\mathrm{H}_{2} \mathrm{O}$ and brine. The resulted organic layer was dried over anhydrous $\mathrm{Na}_{2} \mathrm{SO}_{4}$, filtered and concentrated. After recrystallization from EtOAc/hexanes, compound $\mathbf{5 . 1 0}$ was obtained as white crystals $(4.588 \mathrm{~g}, 87 \%)$ : M. P. $=79.2-81.6{ }^{\circ} \mathrm{C} ; \mathrm{R}_{\mathrm{f}}=0.25$ (hexanes $\left./ \mathrm{EtOAc}=1: 1\right)$; ${ }^{1} \mathrm{H}$ NMR (400 MHz, $\left.\mathrm{CDCl}_{3}\right) \delta 2.02-2.08(\mathrm{~m}, 2 \mathrm{H}), 2.68-3.01(\mathrm{~m}, 4 \mathrm{H}), 4.08-4.12(\mathrm{t}, J=8$ $\mathrm{Hz}, 1 \mathrm{H}), 4.59-4.61(\mathrm{~d}, J=8 \mathrm{~Hz}, 2 \mathrm{H}), 7.37-7.41(\mathrm{~m}, 2 \mathrm{H}), 8.25-8.29(\mathrm{~m}, 2 \mathrm{H}) ;{ }^{13} \mathrm{C} \mathrm{NMR}$ 
$\left(100 \mathrm{MHz}, \mathrm{CDCl}_{3}\right) \delta 25.2,26.9,42.0,68.3,121.8,125.3,145.4,152.3,155.4$; HRMS

(EI) $m / z$ calcd for $\mathrm{C}_{12} \mathrm{H}_{13} \mathrm{NO}_{5} \mathrm{~S}_{2}[\mathrm{M}]^{+} 315.0235$, found 315.0239 .

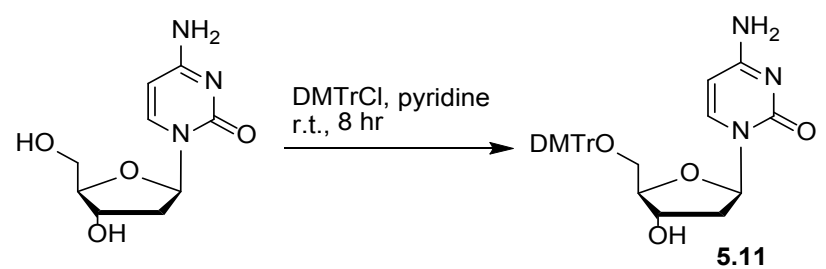

Compound 5.11. A round-bottom flask containing deoxycytidine $(0.500 \mathrm{~g}, 2.201$ mmol) and a magnetic stirring bar was evacuated and then refilled with nitrogen. The evacuation and nitrogen-filling cycle was repeated for two more times. Pyridine (15 mL) was added and a suspension was formed. The suspension was cooled on an ice bath. Under positive $\mathrm{N}_{2}$ pressure, dimethoxytrityl chloride $(0.820 \mathrm{~g}, 2.421 \mathrm{mmol})$ was added to the suspension and the reaction mixture was stirred while warming up to room temperature gradually. After 8 hours, $\mathrm{CH}_{2} \mathrm{Cl}_{2}$ and $5 \% \mathrm{NaHCO}_{3}$ solution were added. The mixture was partitioned. The aqueous portion was extracted with $\mathrm{CH}_{2} \mathrm{Cl}_{2}(15 \mathrm{~mL} \times 2)$. The extracts were combined and dried over anhydrous $\mathrm{Na}_{2} \mathrm{SO}_{4}$. After concentration, the crude product was purified by flash column chromatography (1:2:1 hexanes/EtOAc/MIX) and compound 5.11 was obtained as a white solid $(0.952 \mathrm{~g}, 82 \%): \mathrm{R}_{\mathrm{f}}=0.23$ (hexanes/EtOAc/MIX = 1:2:3); M. P. $=114.4-116.3{ }^{\circ} \mathrm{C},{ }^{1} \mathrm{H}$ NMR and ${ }^{13} \mathrm{C}$ NMR data can be found in literature ${ }^{11}$; HRMS (ESI) $m / z$ calcd for $\mathrm{C}_{30} \mathrm{H}_{32} \mathrm{~N}_{3} \mathrm{O}_{6}[\mathrm{M}+\mathrm{H}]^{+} 530.2286$, found 530.2293. 


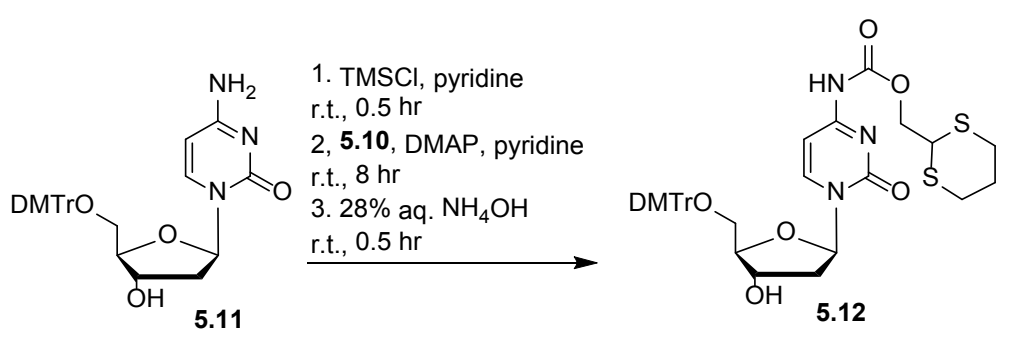

Compound 5.12. A solution of dimethoxyltrityl deoxycytidine 5.11 (2.598 g, $4.915 \mathrm{mmol})$ and chlorotrimethylsilane $(1.602 \mathrm{~g}, 1.87 \mathrm{~mL}, 14.744 \mathrm{mmol})$ in pyridine (50 $\mathrm{mL}$ ) was stirred at room temperature. After 30 minutes, a solution of compound $\mathbf{5 . 1 0}$ (3.100 g, $9.830 \mathrm{mmol})$ and DMAP (0.300 g, $2.457 \mathrm{mmol})$ in pyridine $(15 \mathrm{~mL})$ was added to the reaction mixture. The whole mixture was left to stir for 8 hours. The reaction mixture was cooled on an ice bath, quenched with $\mathrm{H}_{2} \mathrm{O}(10 \mathrm{~mL})$ and stirred for 5 minutes. $28 \% \mathrm{NH}_{4} \mathrm{OH}$ aqueous solution $(15 \mathrm{~mL})$ was added and the whole was stirred for an additional 30 minutes. The whole mixture was washed with $5 \% \mathrm{NaHCO}_{3}$ aqueous solution. The aqueous layer was extracted with $\mathrm{CH}_{2} \mathrm{Cl}_{2}(30 \mathrm{~mL} \times 2)$. The extracts were dried over anhydrous $\mathrm{Na}_{2} \mathrm{SO}_{4}$, filtered and concentrated. Flash column chromatography (1:2:1 hexanes/EtOAc/MIX) gave compound $\mathbf{5 . 1 2}$ as a white foam (4.022 g, 100\%): M. P. $=121.1-123.4{ }^{\circ} \mathrm{C}, \mathrm{R}_{\mathrm{f}}=0.32$ (hexanes/EtOAc/MIX $\left.=1: 2: 1\right) ;{ }^{1} \mathrm{H}$ NMR $(400 \mathrm{MHz}$, $\left.\mathrm{CDCl}_{3}\right) \delta 1.93-2.09(\mathrm{~m}, 2 \mathrm{H}), 2.21-2.27(\mathrm{~m}, 1 \mathrm{H}), 2.41$ (br s, $\left.1 \mathrm{H}\right), 2.62-2.96(\mathrm{~m}, 5 \mathrm{H}), 3.37-$ $3.41(\mathrm{~m}, 2 \mathrm{H}), 3.79(\mathrm{~s}, 6 \mathrm{H}), 4.07-4.10(\mathrm{t}, J=6 \mathrm{~Hz}, 1 \mathrm{H}), 4.46-4.48(\mathrm{~m}, 3 \mathrm{H}), 6.21-6.24(\mathrm{t}, J$ $=6 \mathrm{~Hz}, 1 \mathrm{H}), 6.82-6.84(\mathrm{~d}, J=8 \mathrm{~Hz}, 4 \mathrm{H}), 6.96(\mathrm{~d}, J=8 \mathrm{~Hz}, 1 \mathrm{H}), 7.20-7.39(\mathrm{~m}, 9 \mathrm{H}), 8.22-$ $8.24(\mathrm{~d}, J=8 \mathrm{~Hz}, 1 \mathrm{H}) ;{ }^{13} \mathrm{C} \mathrm{NMR}\left(100 \mathrm{MHz}, \mathrm{CDCl}_{3}\right) \delta 15.4,27.3,41.9,42.8,55.2,62.6$, $65.6,70.7,86.3,86.9,113.2,127.0,128.0,128.1,130.0,135.3,135.4,135.4,144.2$, 
158.6, 162.1; HRMS (ESI) $\mathrm{m} / \mathrm{z}$ calcd for $\mathrm{C}_{36} \mathrm{H}_{40} \mathrm{~N}_{3} \mathrm{O}_{8} \mathrm{~S}_{2}$ [M+H] 706.2251, found 706.2249 .

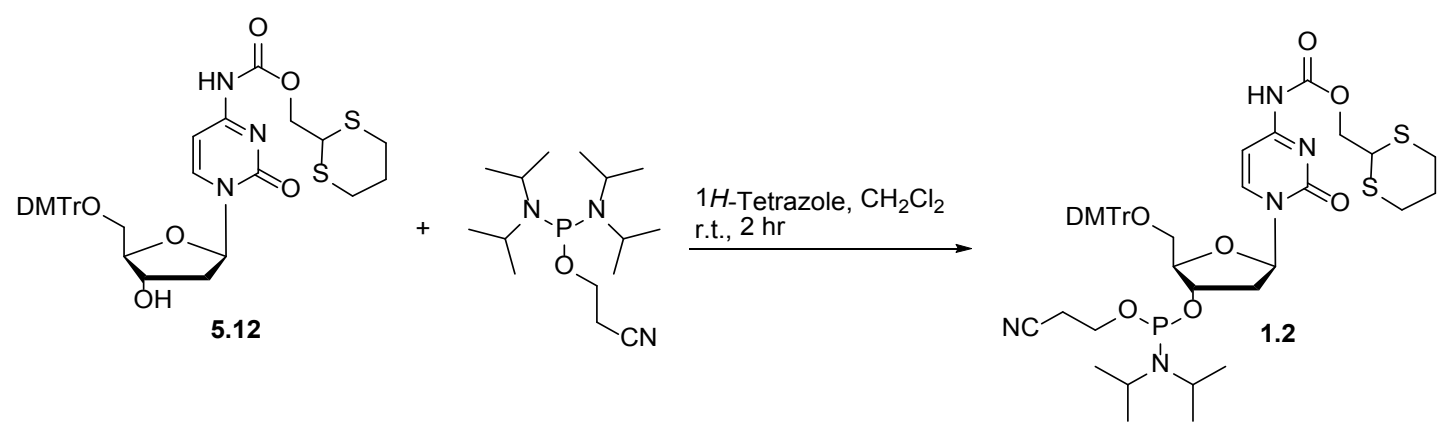

Compound 1.2. A round-bottom flask containing 5.12 (0.695 g, $0.987 \mathrm{mmol})$, and a magnetic stirring bar was evacuated and then refilled with nitrogen. The evacuation

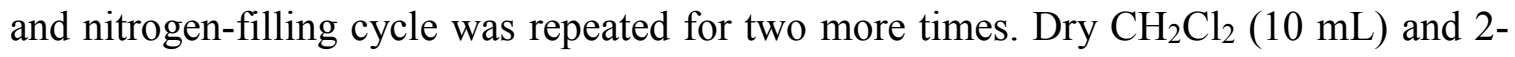
cyanoethyl- $N, N, N^{\prime}, N^{\prime}$-tetraisopropylphosphoramidite $(0.327 \mathrm{~g}, 0.34 \mathrm{~mL}, 1.086 \mathrm{mmol})$ were added via syringes. A $1 H$-tetrazole solution in $\mathrm{CH}_{3} \mathrm{CN}(0.45 \mathrm{M}, 2.413 \mathrm{~mL}, 1.086$ mmol) was added via a syringe in one portion. After stirring at room temperature for 2 hours, the reaction mixture was concentrated to dryness by blowing $\mathrm{N}_{2}$ to the surface. The residue was purified with flash column chromatography (1:1 hexane/EtOAc) giving compound 1.2 as a white foam $(0.800 \mathrm{~g}, 89 \%)$ : $\mathrm{R}_{\mathrm{f}}=0.32$ (hexanes/EtOAc $\left.=1: 3\right) ;{ }^{1} \mathrm{H}$ NMR (400 MHz CDCl $) \delta 1.12-1.15(\mathrm{t}, J=6 \mathrm{~Hz}, 12 \mathrm{H}), 1.90-2.07(\mathrm{~m}, 2 \mathrm{H}), 2.24-2.30(\mathrm{~m}$, $1 \mathrm{H}), 2.39-2.43(\mathrm{t}, J=8 \mathrm{~Hz}, 2 \mathrm{H}), 2.64-2.71(\mathrm{~m}, 3 \mathrm{H}), 2.88-2.93(\mathrm{~m}, 2 \mathrm{H}), 3.35-3.57(\mathrm{~m}$, $6 \mathrm{H}), 3.77(\mathrm{~s}, 6 \mathrm{H}), 4.17-4.18(\mathrm{~m}, 1 \mathrm{H}), 4.44-4.46(\mathrm{~d}, J=8 \mathrm{~Hz}, 2 \mathrm{H}), 4.57-4.64(\mathrm{~m}, 1 \mathrm{H})$, 6.20-6.23 (t, $J=6 \mathrm{~Hz}), 6.81-6.88(\mathrm{~m}, 5 \mathrm{H}), 7.22-7.38(\mathrm{~m}, 9 \mathrm{H}), 8.26-8.28(\mathrm{~d}, \quad J=8$ $\mathrm{Hz}, 1 \mathrm{H}) ;{ }^{13} \mathrm{C} \mathrm{NMR}\left(100 \mathrm{MHz}, \mathrm{CDCl}_{3}\right) \delta 20.1,24.6,27.2,29.9,40.8,42.7,43.3,55.2$, $58.1,58.3,61.9,65.6,71.6,85.6,86.8,94.5,113.2,117.3,127.0,127.9,128.2,129.6$, 
$130.0,130.1,135.2,135.3,144.0,144.3,158.6,162.0 ;{ }^{31} \mathrm{P}$ NMR $\left(162 \mathrm{MHz}, \mathrm{CDCl}_{3}\right) \delta$ 150.4 .

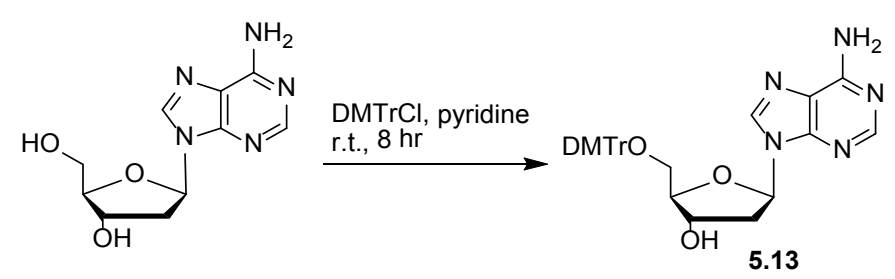

Compound 5.13. A round-bottom flask containing deoxyadenosine $(0.853 \mathrm{~g}$, $3.168 \mathrm{mmol}$ ) and a magnetic stirring bar was evacuated and then refilled with nitrogen. The evacuation and nitrogen-filling cycle was repeated for two more times. Pyridine (10 $\mathrm{mL}$ ) was added and a suspension was formed. The resulting suspension was cooled on an ice bath. Under positive $\mathrm{N}_{2}$ pressure, dimethoxytrityl chloride (1.073 g, $3.168 \mathrm{mmol}$ ) was added to the suspension and the reaction mixture was stirred while warming up to room temperature gradually. After 8 hours, $\mathrm{CH}_{2} \mathrm{Cl}_{2}(10 \mathrm{~mL})$ and $5 \% \mathrm{NaHCO}_{3}$ solution $(15 \mathrm{~mL})$ was added. The mixture was partitioned. The aqueous portion was extracted with $\mathrm{CH}_{2} \mathrm{Cl}_{2}$ $(10 \mathrm{~mL} \times 2)$. The extracts were combined, dried over anhydrous $\mathrm{Na}_{2} \mathrm{SO}_{4}$ and filtered. After concentration, the crude product was purified by flash column chromatography (1:2:1 hexanes/EtOAc/MIX) and compound $\mathbf{5 . 1 3}$ was obtained as a white solid (1.211 g, 69\%): $\mathrm{R}_{\mathrm{f}}=0.42$ (hexanes/EtOAc/MIX $=1: 2: 3$ ); M. P. $=83.7-85.5{ }^{\circ} \mathrm{C},{ }^{1} \mathrm{H}$ NMR and ${ }^{13} \mathrm{C}$ NMR data can be found in literature ${ }^{11}$; HRMS (ESI) $m / z$ calcd for $\mathrm{C}_{31} \mathrm{H}_{32} \mathrm{~N}_{5} \mathrm{O}_{5}[\mathrm{M}+\mathrm{H}]^{+}$ 554.2398, found 554.2408. 


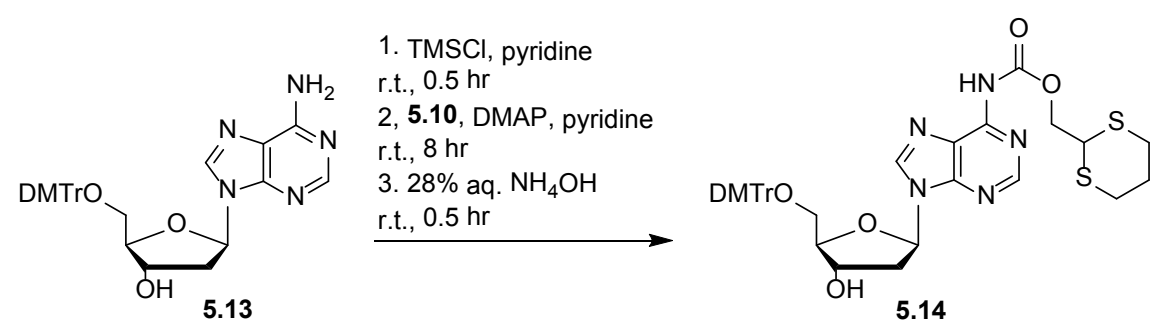

Compound 5.14. A solution of dimethoxyltrityl deoxyadenosine 5.13 (0.208 g, $0.376 \mathrm{mmol})$ and chlorotrimethylsilane $(0.082 \mathrm{~g}, 0.096 \mathrm{~mL}, 0.751 \mathrm{mmol})$ in pyridine (4 $\mathrm{mL}$ ) was stirred at room temperature. After 30 minutes, a solution of compound $\mathbf{5 . 1 0}$ (0.237 g, $0.751 \mathrm{mmol})$ and DMAP $(0.091 \mathrm{~g}, 0.751 \mathrm{mmol})$ in pyridine $(3 \mathrm{~mL})$ was added to the reaction mixture. The whole mixture was left to stir for 8 hours. The reaction mixture was cooled on an ice bath, quenched with $\mathrm{H}_{2} \mathrm{O}(2 \mathrm{~mL})$ and stirred for 5 minutes. $28 \% \mathrm{NH}_{4} \mathrm{OH}$ aqueous solution $(3 \mathrm{~mL})$ was added and the whole was stirred for additional 30 minutes. The whole mixture was washed with $5 \% \mathrm{NaHCO}_{3}$ solution. The aqueous layer was extracted with $\mathrm{CH}_{2} \mathrm{Cl}_{2}$ twice. The combined organic layer was dried over anhydrous $\mathrm{Na}_{2} \mathrm{SO}_{4}$, filtered and concentrated. Flash column chromatography (1:2:1 hexanes/EtOAc/MIX) gave compound $\mathbf{5 . 1 4}$ as a white foam $(0.175 \mathrm{~g}, 57 \%)$ : M. P. = 108.2-111.4 ${ }^{\circ} \mathrm{C} ; \mathrm{R}_{\mathrm{f}}=0.47($ Hexanes/EtOAc/MIX $=1: 2: 1) ;{ }^{1} \mathrm{H}$ NMR $\left(400 \mathrm{MHz}, \mathrm{CDCl}_{3}\right)$ $\delta$ 1.89-2.04 (m, 2H), 2.50-2.97 (m, 6H), 3.34-3.39 (d, $J=4 \mathrm{~Hz}, 2 \mathrm{H}), 3.72(\mathrm{~s}, 6 \mathrm{H}), 4.09-$ $4.16(\mathrm{~m} .1 \mathrm{H}), 4.16-4.19(\mathrm{~m}, 1 \mathrm{H}), 4.52-4.53(\mathrm{~d}, J=4 \mathrm{~Hz}, 2 \mathrm{H}), 4.68-4.71(\mathrm{~m}, 1 \mathrm{H}), 6.44-$ $6.47(\mathrm{t}, J=6 \mathrm{~Hz}, 1 \mathrm{H}), 6.73-6.75(\mathrm{~d}, J=8 \mathrm{~Hz}, 4 \mathrm{H}), 7.12-7.35(\mathrm{~m}, 9 \mathrm{H}), 8.13(\mathrm{~s}, 1 \mathrm{H}), 8.66$ $(\mathrm{s}, 1 \mathrm{H}) ;{ }^{13} \mathrm{C} \mathrm{NMR}\left(100 \mathrm{MHz}, \mathrm{CDCl}_{3}\right) \delta 25.4,27.3,40.2,43.0,55.2,65.3,72.2,84.6$, 86.2, 86.5, 113.1, 122.3, 126.9, 135.5, 141.4, 149.2, 158.4; HRMS (ESI) $m / z$ calcd for $\mathrm{C}_{37} \mathrm{H}_{40} \mathrm{~N}_{5} \mathrm{O}_{7} \mathrm{~S}_{2}[\mathrm{M}+\mathrm{H}]^{+} 730.2364$, found 730.2366 . 


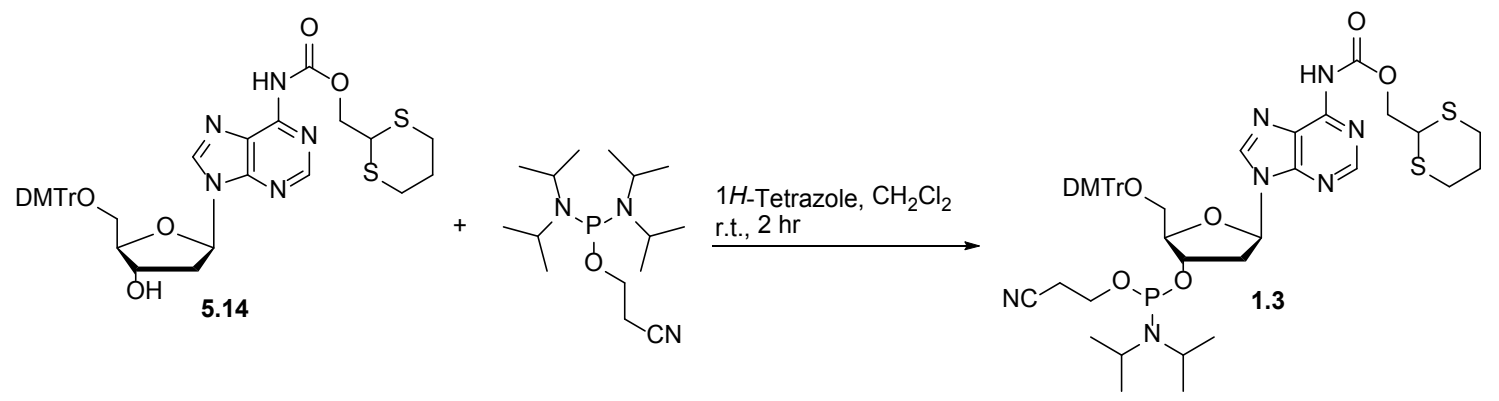

Compound 1.3. A round-bottom flask containing 5.14 (1.180 g, $1.555 \mathrm{mmol})$, and a magnetic stirring bar was evacuated and then refilled with nitrogen. The evacuation and nitrogen-filling cycle was repeated for two more times. Dry $\mathrm{CH}_{2} \mathrm{Cl}_{2}(10 \mathrm{~mL})$ and 2cyanoethyl- $N, N, N^{\prime}, N^{\prime}$-tetraisopropylphosphoramidite $(0.515 \mathrm{~g}, 0.54 \mathrm{~mL}, 1.710 \mathrm{mmol})$ were then added via syringes. A $1 H$-tetrazole solution in $\mathrm{CH}_{3} \mathrm{CN}(0.45 \mathrm{M}, 3.8 \mathrm{~mL}, 1.71$ mmol) was added via a syringe in one portion. After stirring at room temperature for 2 hours, the reaction mixture was concentrated to dryness by blowing nitrogen to the surface. The residue was purified with flash column chromatography (hexanes/EtOAc/Et $\left.{ }_{3} \mathrm{~N}=1: 1: 1\right)$ giving compound $\mathbf{1 . 3}$ as a white foam $(1.271 \mathrm{~g}, 88 \%)$ : $\mathrm{R}_{\mathrm{f}}$ $=0.4\left(\right.$ hexanes $\left./ \mathrm{EtOAc} / \mathrm{Et}_{3} \mathrm{~N}=1: 1: 1\right) ;{ }^{1} \mathrm{H} \mathrm{NMR}\left(400 \mathrm{MHz} \mathrm{CDCl}_{3}\right) \delta 1.15-1.18(\mathrm{t}, J=6$ $\mathrm{Hz}, 12 \mathrm{H}), 1.94-2.07$ (m, 2H), 2.52-2.99 (m, 6H), 3.31-3.43 (m, 2H), 3.55-3.72 (m, 4H), $3.76(\mathrm{~s}, 6 \mathrm{H}), 4.11-4.15(\mathrm{t}, J=8 \mathrm{~Hz}, 1 \mathrm{H}), 4.28-4.31(\mathrm{~m}, 1 \mathrm{H}), 4.55-4.57(\mathrm{~d}, J=8 \mathrm{~Hz}, 2 \mathrm{H})$, 4.74-4.79 (m, 1H), 6.43-6.46 (t, $J=6 \mathrm{~Hz}, 1 \mathrm{H}), 6.76-6.78(\mathrm{~d}, J=8 \mathrm{~Hz}, 4 \mathrm{H}), 7.16-7.37$ (m, 9H), $8.16(\mathrm{~s}, 1 \mathrm{H}), 8.68(\mathrm{~s}, 1 \mathrm{H}) ;{ }^{13} \mathrm{C}$ NMR $\left(100 \mathrm{MHz}, \mathrm{CDCl}_{3}\right) \delta 20.4,20.5,24.7,24.8$, $25.7,39.7,43.2,43.4,55.4,63.5,65.6,73.6,73.8,85.0,86.2,86.3,86.7,113.3,117.6$, $122.7,127.1,128.0,128.4,130.3,135.8,135.8,141.7,144.7,149.5,150.8,151.1,152.9$, $158.7 ;{ }^{31} \mathrm{P}$ NMR $\left(162 \mathrm{MHz}, \mathrm{CDCl}_{3}\right) \delta 150.0$. 


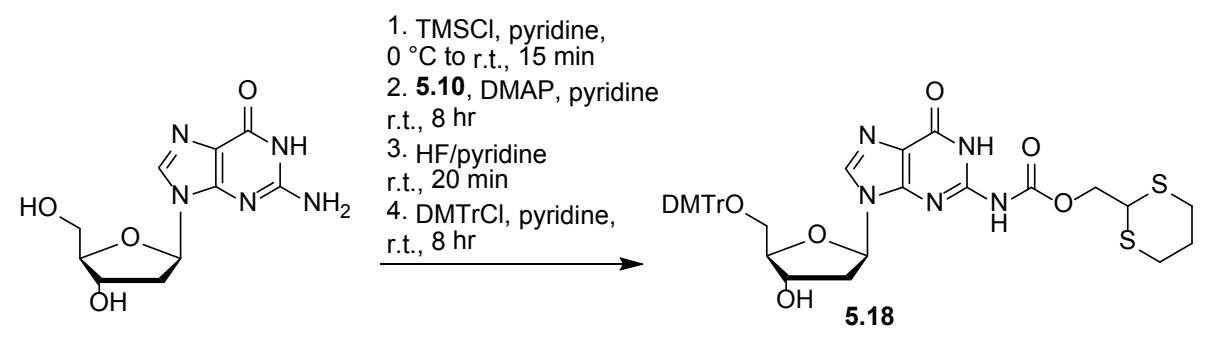

Compound 5.18. Deoxyguanosine monohydrate (0.159 g, $0.595 \mathrm{mmol})$ was coevaporated with dry pyridine three times ( $2 \mathrm{~mL}$ pyridine each time). The dry deoxyguanosine was suspended in dry pyridine $(6 \mathrm{~mL})$. The suspension was cooled on an ice bath and chlorotrimethylsilane $(0.651 \mathrm{~g}, 0.76 \mathrm{~mL}, 5.931 \mathrm{mmol})$ was added. The mixture was stirred for 15 minutes. Nitrobenzyl dithianyl carbonate $\mathbf{5 . 1 0}(1.870 \mathrm{~g}, 5.931$ mmol) and DMAP $(0.072 \mathrm{~g}, 0.593 \mathrm{mmol})$ were added to the reaction mixture. The mixture was stirred at room temperature for 8 hours. Under positive nitrogen pressure, $\mathrm{HF} /$ pyridine $(70 \%, 0.215 \mathrm{~mL}, 11.862 \mathrm{mmol})$ was added into the reaction mixture via a pipett. After stirring for 20 minutes, the reaction mixture was concentrated by blowing with nitrogen on the mixture surface. The resulting mixture was dissolved with EtOAc (5 $\mathrm{mL})$ and washed with $\mathrm{H}_{2} \mathrm{O}(5 \mathrm{~mL})$. The organic layer was concentrated and coevaporated with dry pyridine three times ( $2 \mathrm{~mL}$ pyridine each time). The residue was redissolved with dry pyridine $(5 \mathrm{~mL})$ and $\mathrm{DMTrCl}(0.161 \mathrm{~g}, 0.476 \mathrm{mmol})$ was added. The reaction mixture was stirred at room temperature for 8 hours. The reaction was quenched with 5\% $\mathrm{NaHCO}_{3}$ and the mixture was partitioned. The aqueous layer was extracted by EtOAc. The combined organic layer was dried over anhydrous $\mathrm{Na}_{2} \mathrm{SO}_{4}$, filtered and concentrated. Flash column chromatography (9:1 EtOAc/MeOH) gave compound $\mathbf{5 . 1 8}$ as a white foam $\left(0.060\right.$ g, 14\%): M. P. $=159-161{ }^{\circ} \mathrm{C} ; \mathrm{R}_{\mathrm{f}}=0.2(\mathrm{EtOAc} / \mathrm{MeOH}=9: 1) ;{ }^{1} \mathrm{H}$ NMR $(400$ 
$\left.\mathrm{MHz} \mathrm{CDCl}_{3}\right) \delta 1.94-2.06(\mathrm{~m}, 2 \mathrm{H}), 2.48-2.59(\mathrm{~m}, 2 \mathrm{H}), 2.63-2.96(\mathrm{~m}, 4 \mathrm{H}), 3.27-3.41(\mathrm{~m}$, 2H), $3.68(\mathrm{~s}, 6 \mathrm{H}), 4.08-4.12(\mathrm{t}, J=8 \mathrm{~Hz}, 1 \mathrm{H}), 4.15-4.18(\mathrm{~m}, 1 \mathrm{H}), 4.56-4.58(\mathrm{~d}, J=8 \mathrm{~Hz}$, 2H), 4.87-4.91 (m, 1H), 6.20-6.23 (t, $J=6 \mathrm{~Hz}, 1 \mathrm{H}), 6.67-6.70(\mathrm{dd}, J=9 \mathrm{~Hz}, 3 \mathrm{~Hz}, 4 \mathrm{H})$, 7.07-7.33 (m, 9H), $7.68(\mathrm{~s}, 1 \mathrm{H}) ;{ }^{13} \mathrm{C}$ NMR (100 MHz, $\left.\mathrm{CDCl}_{3}\right) \delta$ 10.8, 14.2, 25.4, 27.0, $40.1,42.6,45.8,55.2,60.4,64.3,65.7,71.7,84.3,86.4,86.5,113.0,120.9,126.8,135.7$, 144.5, 148.4, 154.4, 155.8, 158.4; HRMS (ESI) $m / z$ calcd for $\mathrm{C}_{37} \mathrm{H}_{40} \mathrm{~N}_{5} \mathrm{O}_{8} \mathrm{~S}_{2}[\mathrm{M}+\mathrm{H}]^{+}$ 746.2313, found 746.2311.

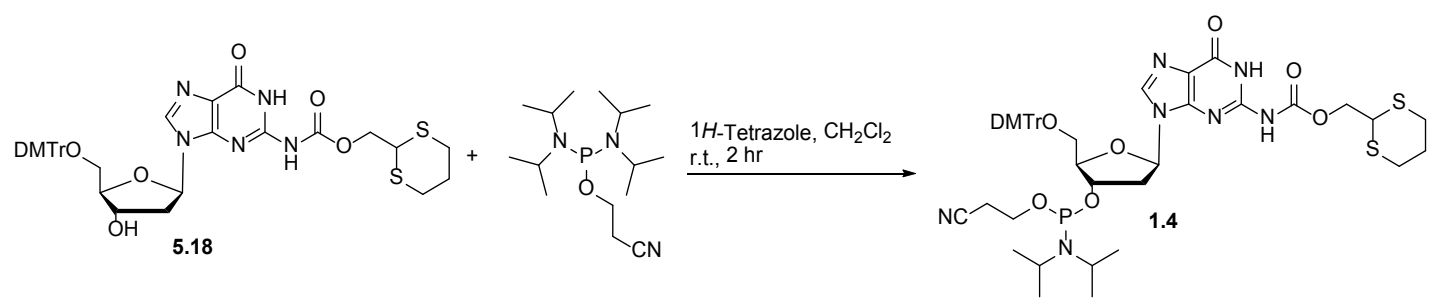

Compound 1.4. A round-bottom flask containing 5.18 (0.601 g, 0.821 mmol), and a magnetic stirring bar was evacuated and then refilled with nitrogen. The evacuation and nitrogen-filling cycle was repeated for two more times. Dry $\mathrm{CH}_{2} \mathrm{Cl}_{2}(6 \mathrm{~mL})$ and 2cyanoethyl- $N, N, N^{\prime}, N^{\prime}$-tetraisopropylphosphoramidite $(0.272 \mathrm{~g}, 0.29 \mathrm{~mL}, 0.903 \mathrm{mmol})$ were then added via syringes. A $1 H$-tetrazole solution in $\mathrm{CH}_{3} \mathrm{CN}(0.45 \mathrm{M}, 2.0 \mathrm{~mL}, 0.903$ mmol) was added via a syringe in one portion. After stirring at room temperature for 2 hours, the reaction mixture was concentrated to dryness by blowing nitrogen to the surface. The residue was purified with flash column chromatography $(1: 1$ hexanes/EtOAc) giving compound $\mathbf{1 . 4}$ as a white foam $(0.600 \mathrm{~g}, 77 \%)$ : $\mathrm{R}_{\mathrm{f}}=0.5$ $\left(\right.$ EtOAc/MeOH = 29:1); ${ }^{1} \mathrm{H}$ NMR $\left(400 \mathrm{MHz}^{\mathrm{CDCl}}{ }_{3}\right) \delta 1.12-1.15(\mathrm{~m}, 12 \mathrm{H}), 1.97-2.03(\mathrm{~m}$, 2H), 2.32-2.95 (m, 8H), 3.33-3.34 (d, $J=4 \mathrm{~Hz}, 2 \mathrm{H}), 3.51-3.63(\mathrm{~m}, 4 \mathrm{H}), 3.73(\mathrm{~s}, 6 \mathrm{H})$, 3.93-3.98 (t, $J=10 \mathrm{~Hz}, 1 \mathrm{H}), 4.24-4.47(\mathrm{~m}, 1 \mathrm{H}), 4.49-4.51(\mathrm{~d}, J=8 \mathrm{~Hz}, 2 \mathrm{H}), 4.68-4.74$ 
(m, 1H), 6.17-6.20 (t, $J=6 \mathrm{~Hz}, 1 \mathrm{H}), 6.73-6.76(\mathrm{~m}, 4 \mathrm{H}), 7.13-7.38(\mathrm{~m}, 9 \mathrm{H}), 7.74(\mathrm{~s}, 1 \mathrm{H})$;

${ }^{13} \mathrm{C}$ NMR (100 MHz, $\left.\mathrm{CDCl}_{3}\right) \delta$ 20.2, 20.3, 24.5, 24.5, 24.6, 26.8, 39.4, 42.1, 43.2, 43.3, $55.2,57.8,58.0,63.7,65.6,73.7,73.8,84.6,86.0,86.3,113.1,117.3,121.7,126.9,127.8$, $128.0,130.0,135.7,137.5,144.5,146.2,148.0,153.0,158.5 ;{ }^{31} \mathrm{P}$ NMR (162 MHz, $\left.\mathrm{CDCl}_{3}\right) \delta 149.4$

\section{ODN synthesis, deprotection, cleavage and analysis}

5'-HO-TTA CTT CTA TTA TCA ATC CT-OH-3' (5.16)

Synthesis. The CPG with Dmoc-dT linker $1.1(50 \mathrm{mg}, 5.35 \mu \mathrm{mol})$ with a pore size of $497 \AA$ was packed in a standard DNA synthesis column. The 20-mer was synthesized on an ABI DNA/RNA synthesizer at $1 \mu \mathrm{mol}$ scale.. The following 5'-DMTrprotected 2-cyanoethyl phosphoramidite monomers were used for the synthesis: DmocdA 1.3, Dmoc-dC 1.2, and dT. THF/pyridine/ $\mathrm{Pac}_{2} \mathrm{O}$ was used as the capping reagent. The manufacturer recommended synthetic cycle was followed. Manual cleavage and DMTr on functions were chosen. After synthesis, the CPG was dried, weighed and evenly distributed into 10 vials.

Cleavage and deprotection. One portion of CPG $(4.3 \mathrm{mg})$ was suspended with a solution of DBU in dry $\mathrm{CH}_{3} \mathrm{CN}(10 \%, \mathrm{v} / \mathrm{v}, 500 \mu \mathrm{L})$, and was hand shaken for 10 minutes. The supernatant was pipetted out and the $\mathrm{CPG}$ was washed with $\mathrm{CH}_{3} \mathrm{CN}$ three times (200 $\mu \mathrm{L}$ each time). To the $\mathrm{CPG}$, a $\mathrm{NaIO}_{4}$ aqueous solution $\left(0.1 \mathrm{M}, 1 \mathrm{~mL} \mathrm{DI}-\mathrm{H}_{2} \mathrm{O}\right)$ was added. The suspension was covered with aluminum foil and left to rotate for 3 hours. The 
supernatant was transferred to an Eppendorf tube. The CPG was washed with deionized water three times ( $200 \mu \mathrm{L}$ each time). The supernatant was transferred to an Eppendorf tube. The CPG was washed with deionized water three times (200 $\mu \mathrm{L}$ each time). The combined aqueous solution was desalted over dextran desalting column (5K MWCO, 10 $\mathrm{mL}$ ) with DI- $\mathrm{H}_{2} \mathrm{O}$ as the eluent. Fractions were collected every milliliter. Fractions 3, 4, 5, 6 were combined and concentrated. The obtained ODN was dissolved in $50 \mu \mathrm{L} \mathrm{H}_{2} \mathrm{O}$, and $20 \mu \mathrm{L}$ solution was injected into RP HPLC. ODN 5.16 was shown in Figure 5.6. MALDI-TOF MS calcd mass 5993, found 5992.3.

\section{5'-HO-TCA TTG CTT CTG ATC CTG CT-OH-3' (5.19)}

Synthesis. The CPG with Dmoc-dT linker $1.1(50 \mathrm{mg}, 5.35 \mu \mathrm{mol})$ with a pore size of $497 \AA$ was packed in a standard DNA synthesis column. The 20-mer was synthesized on an ABI DNA/RNA synthesizer at $1 \mu \mathrm{mol}$ scale.. The following 5'-DMTrprotected 2-cyanoethyl phosphoramidite monomers were used for the synthesis: DmocdA 1.3, Dmoc-dG 1.4, Dmoc-dC 1.2, and dT. THF/pyridine/ $\mathrm{Pac}_{2} \mathrm{O}$ was used as the capping reagent. The manufacturer recommended synthetic cycle was followed. Manual cleavage and DMTr on functions were chosen. After synthesis, the CPG was dried, weighed and evenly distributed into 10 vials.

Cleavage and deprotection. One portion of CPG $(4.3 \mathrm{mg})$ was suspended with a solution of DBU in dry $\mathrm{CH}_{3} \mathrm{CN}(10 \%, \mathrm{v} / \mathrm{v}, 500 \mu \mathrm{L})$, and was hand shaken for 10 minutes. The supernatant was pipetted out and the $\mathrm{CPG}$ was washed with $\mathrm{CH}_{3} \mathrm{CN}$ three times (200 $\mu \mathrm{L}$ each time). To the $\mathrm{CPG}$, an acidic $\mathrm{NaIO}_{4}$ aqueous solution $\left(0.1 \mathrm{M}, 970 \mu \mathrm{L}\right.$ DI- $\mathrm{H}_{2} \mathrm{O}$, 
$30 \mu \mathrm{L} \mathrm{AcOH}, \mathrm{pH}=2$ ) was added. The suspension was covered with aluminum foil and left to rotate for 3 hours. The supernatant was transferred to an Eppendorf tube. The CPG was washed with acidic deionized water three times $(3 \% \mathrm{AcOH}, \mathrm{v} / \mathrm{v}, 200 \mu \mathrm{L}$ each time $)$. To the resin was added an aniline aqueous solution ( $3 \%$ aniline, v/v, $1000 \mu \mathrm{L})$. After the suspension rotated for 8 hours, the supernatant was transferred to an Eppendorf tube. The CPG was washed with deionized water three times $(200 \mu \mathrm{L}$ each time $)$. The combined aqueous solution was desalted over dextran desalting column (5K MWCO, $10 \mathrm{~mL}$ ) with $\mathrm{DI}-\mathrm{H}_{2} \mathrm{O}$ as the eluent. Fractions were collected every milliliter. Fractions 3, 4, 5, 6 were combined and concentrated. The obtained ODN was dissolved in $50 \mu \mathrm{L} \mathrm{H}_{2} \mathrm{O}$, and $20 \mu \mathrm{L}$ solution was injected into RP HPLC. ODN 5.19 was shown in Figure 5.8. MALDI-TOF MS calcd mass 6025, found 6024.0.

\section{5'-HO-TCA TTG CTG CTT ATA CCT CT-OH-3' (5.20)}

Synthesis. The CPG with Dmoc-dT linker $1(50 \mathrm{mg}, 5.35 \mu \mathrm{mol})$ with a pore size

of $497 \AA$ was packed in a standard DNA synthesis column. The 20-mer was synthesized on an ABI DNA/RNA synthesizer at $1 \mu \mathrm{mol}$ scale. The following 5'-DMTr-protected 2cyanoethyl phosphoramidite monomers were used for the synthesis: Dmoc-dA 1.3, Dmoc-dG 1.4, Dmoc-dC 1.2, and dT. THF/pyridine/Pac $2 \mathrm{O}$ was used as the capping reagent. The manufacturer recommended synthetic cycle was followed. Manual cleavage and DMTr on functions were chosen. After synthesis, the CPG was dried, weighed and evenly distributed into 10 vials. 
Cleavage and deprotection. One portion of CPG (4.3 mg) was suspended with a solution of DBU in dry $\mathrm{CH}_{3} \mathrm{CN}(10 \%$, v/v, $500 \mu \mathrm{L})$, and was hand shaken for 10 minutes. The supernatant was pipetted out and the CPG was washed with $\mathrm{CH}_{3} \mathrm{CN}$ three times (200 $\mu \mathrm{L}$ each time). To the $\mathrm{CPG}$, an acidic $\mathrm{NaIO}_{4}$ aqueous solution $\left(0.1 \mathrm{M}, 970 \mu \mathrm{L}\right.$ DI- $\mathrm{H}_{2} \mathrm{O}$, $30 \mu \mathrm{L} \mathrm{AcOH}, \mathrm{pH}=2$ ) was added. The suspension was covered with aluminum foil and left to rotate for 3 hours. The supernatant was transferred to an Eppendorf tube. The CPG was washed with acidic deionized water three times (3\% AcOH, v/v, $200 \mu \mathrm{L}$ each time). To the resin was added an aniline aqueous solution ( $3 \%$ aniline, $v / v, 1000 \mu \mathrm{L})$. After the suspension rotated for 8 hours, the supernatant was transferred to an Eppendorf tube. The CPG was washed with deionized water three times (200 $\mu \mathrm{L}$ each time). The combined aqueous solution was desalted over dextran desalting column (5K MWCO, $10 \mathrm{~mL}$ ) with DI- $\mathrm{H}_{2} \mathrm{O}$ as the eluent. Fractions were collected every milliliter. Fractions 3, 4, 5, 6 were combined and concentrated. The obtained ODN was dissolved in $50 \mu \mathrm{L} \mathrm{H}_{2} \mathrm{O}$, and $20 \mu \mathrm{L}$ solution was injected into RP HPLC. ODN 5.20 was shown in Figure 5.9. MALDI-TOF MS calcd mass 6009, found 6008.193.

\section{5'-HO-TCA TTG CTG CTT AGA CCG CT-OH-3' (5.21)}

Synthesis. The CPG with Dmoc-dT linker $1.1(50 \mathrm{mg}, 5.35 \mu \mathrm{mol})$ with a pore size of $497 \AA$ was packed in a standard DNA synthesis column. The 20-mer was synthesized on an ABI DNA/RNA synthesizer at $1 \mu \mathrm{mol}$ scale. The following 5'-DMTrprotected 2-cyanoethyl phosphoramidite monomers were used for the synthesis: DmocdA 1.3, Dmoc-dG 1.4, Dmoc-dC 1.2, and dT. THF/pyridine/ $\mathrm{Pac}_{2} \mathrm{O}$ was used as the 
capping reagent. The manufacturer recommended synthetic cycle was followed. Manual cleavage and DMTr on functions were chosen. After synthesis, the CPG was dried, weighed and evenly distributed into 10 vials.

Cleavage and deprotection. One portion of CPG $(5.4 \mathrm{mg})$ was suspended with a solution of DBU in dry $\mathrm{CH}_{3} \mathrm{CN}(10 \%, \mathrm{v} / \mathrm{v}, 500 \mu \mathrm{L})$, and was hand shaken for 10 minutes. The supernatant was pipetted out and the CPG was washed with $\mathrm{CH}_{3} \mathrm{CN}$ three times (200 $\mu \mathrm{L}$ each time). To the $\mathrm{CPG}$, an acidic $\mathrm{NaIO}_{4}$ aqueous solution $\left(0.1 \mathrm{M}, 970 \mu \mathrm{L}\right.$ DI- $\mathrm{H}_{2} \mathrm{O}$, $30 \mu \mathrm{L} \mathrm{AcOH}, \mathrm{pH}=2$ ) was added. The suspension was covered with aluminum foil and left to rotate for 3 hours. The supernatant was transferred to an Eppendorf tube. The CPG was washed with acidic deionized water three times ( $3 \% \mathrm{AcOH}, \mathrm{v} / \mathrm{v}, 200 \mu \mathrm{L}$ each time). To the resin was added an aniline aqueous solution ( $3 \%$ aniline, $\mathrm{v} / \mathrm{v}, 1000 \mu \mathrm{L})$. After the suspension rotated for 8 hours, the supernatant was transferred to an Eppendorf tube. The CPG was washed with deionized water three times ( $200 \mu \mathrm{L}$ each time). The combined aqueous solution was desalted over dextran desalting column (5K MWCO, $10 \mathrm{~mL}$ ) with DI- $\mathrm{H}_{2} \mathrm{O}$ as the eluent. Fractions were collected every milliliter. Fractions 3, 4, 5, 6 were combined and concentrated. The obtained ODN was dissolved in $50 \mu \mathrm{L} \mathrm{H}_{2} \mathrm{O}$, and $20 \mu \mathrm{L}$ solution was injected into RP HPLC. ODN 5.21 was shown in Figure 5.9. MALDI-TOF MS calcd mass 6059, found 6058.594.

5'-HO-TTA GTA GGA CCT ACA CCT GT-OH-3' (5.22)

Synthesis. The CPG with Dmoc-dT linker $1.1(50 \mathrm{mg}, 5.35 \mu \mathrm{mol})$ with a pore size of $497 \AA$ was packed in a standard DNA synthesis column. The 20-mer was 104 
synthesized on an ABI DNA/RNA synthesizer at $1 \mu \mathrm{mol}$ scale. The following 5'-DMTrprotected 2-cyanoethyl phosphoramidite monomers were used for the synthesis: DmocdA 1.3, Dmoc-dG 1.4, Dmoc-dC 1.2, and dT. THF/pyridine/ $\mathrm{Pac}_{2} \mathrm{O}$ was used as the capping reagent. The manufacturer recommended synthetic cycle was followed. Manual cleavage and DMTr on functions were chosen. After synthesis, the CPG was dried, weighed and evenly distributed into 10 vials.

Cleavage and deprotection. One portion of CPG $(5.2 \mathrm{mg})$ was suspended with a solution of DBU in dry $\mathrm{CH}_{3} \mathrm{CN}(10 \%, \mathrm{v} / \mathrm{v}, 500 \mu \mathrm{L})$, and was hand shaken for 10 minutes. The supernatant was pipetted out and the $\mathrm{CPG}$ was washed with $\mathrm{CH}_{3} \mathrm{CN}$ three times (200 $\mu \mathrm{L}$ each time). To the $\mathrm{CPG}$, an acidic $\mathrm{NaIO}_{4}$ aqueous solution $\left(0.1 \mathrm{M}, 970 \mu \mathrm{L}\right.$ DI- $\mathrm{H}_{2} \mathrm{O}$, $30 \mu \mathrm{L} \mathrm{AcOH}, \mathrm{pH}=2$ ) was added. The suspension was covered with aluminum foil and left to rotate for 3 hours. The supernatant was transferred to an Eppendorf tube. The CPG was washed with acidic deionized water three times ( $3 \% \mathrm{AcOH}, \mathrm{v} / \mathrm{v}, 200 \mu \mathrm{L}$ each time). To the resin was added an aniline aqueous solution ( $3 \%$ aniline, $v / v, 1000 \mu \mathrm{L})$. After the suspension rotated for 8 hours, the supernatant was transferred to an Eppendorf tube. The CPG was washed with deionized water three times ( $200 \mu \mathrm{L}$ each time). The combined aqueous solution was desalted over dextran desalting column (5K MWCO, $10 \mathrm{~mL})$ with DI- $\mathrm{H}_{2} \mathrm{O}$ as the eluent. Fractions were collected every milliliter. Fractions 3, 4, 5, 6 were combined and concentrated. The obtained ODN was dissolved in $50 \mu \mathrm{L} \mathrm{H}_{2} \mathrm{O}$, and $20 \mu \mathrm{L}$ solution was injected into RP HPLC. ODN 5.22 was shown in Figure 5.9. MALDI-TOF MS calcd mass 6092, found 6089.606. 


\section{References}

1. Cashion, P. J.; Fridkin, M.; Agarwal, K. L.; Jay, E.; Khorana, H. G., Use of tritylcarbamoylcellulose and alpha-naphthylcarbamoylcellulose derivatives in oligonucleotide synthesis. Biochemistry 1973, 12 (10), 1985-1990.

2. (a) Vandesande, J. H.; Caruthers, M. H.; Kumar, A.; Khorana, H. G., Studies on polynucleotides 132: total synthesis of structural gene for precursor of a tyrosine suppressor transfer-RNA from escherichia-coli 2: chemical synthesis of deoxypolynucleotide segments corresponding to nucleotide-sequence 1-31. Journal of Biological Chemistry 1976, 251 (3), 571-586; (b) Minamoto, K.; Caruthers, M. H.; Ramamoorthy, B.; Vandesande, J. H.; Sidorova, N.; Khorana, H. G., Studies on polynucleotides 133: total synthesis of structural gene for precursor of a tyrosine suppressor transfer-RNA from escherichia-coli 3: synthesis of deoxyribopolynucleotide segments corresponding to nucleotide-sequence 27-51. Journal of Biological Chemistry 1976, 251 (3), 587-598; (c) Agarwal, K. L.; Caruthers, M. H.; Fridkin, M.; Kumar, A.; Vandesande, J. H.; Khorana, H. G., Studies on polynucleotides 134. Total synthesis of structural gene for precursor of a tyrosine suppressor transfer-RNA from escherichia-coli 4: synthesis of deoxyribopolynucleotide segments corresponding to nucleotide-sequence 47-78. Journal of Biological Chemistry 1976, 251 (3), 599-608; (d) Jay, E.; Cashion, P. J.; Fridkin, M.; Ramamoorthy, B.; Agarwal, K. L.; Caruthers, M. H.; Khorana, H. G., Studies on polynucleotides 135: total synthesis of structural gene for precursor of a tyrosine suppressor transfer-RNA from escherichia-coli 5: synthesis of deoxyribopolynucleotide segments representing nucleotide-sequence 71-103. Journal of 
Biological Chemistry 1976, 251 (3), 609-623; (e) Agarwal, K. L.; Caruthers, M. H.; Buchi, H.; Vandesande, J. H.; Khorana, H. G., Studies on polynucleotides 136: total synthesis of structural gene for precursor of a tyrosine suppressor transfer-RNA from escherichia-coli 6: synthesis of deoxyribopolynucleotide segments corresponding to nucleotide-sequence 100-126. Journal of Biological Chemistry 1976, 251 (3), 624-633.

3. (a) Letsinger, R. L.; Finnan, J. L.; Heavner, G. A.; Lunsford, W. B., Nucleotide chemistry 20: phosphite coupling procedure for generating internucleotide links. Journal of the American Chemical Society 1975, 97 (11), 3278-3279; (b) Beaucage, S. L.; Caruthers, M. H., Deoxynucleoside phosphoramidites-a new class of key intermediates for deoxypolynucleotide synthesis. Tetrahedron Letter 1981, 22 (20), 1859-1862; (c) McBride, L. J.; Caruthers, M. H., Nucleotide chemistry 10: an investigation of several deoxynucleoside phophoramidites useful for synthesizing deoxynucleotides. Tetrahedron Letter 1983, 24 (3), 245-248.

4. Ohkubo, A.; Kasuya, R.; Aoki, K.; Kobori, A.; Taguchi, H.; Seio, K.; Sekine, M., Efficient synthesis of functionalized oligodeoxyribonucleotides with base-labile groups using a new silyl linker. Bioorganic \& Medicinal Chemistry 2008, 16 (9), 5345-5351.

5. (a) Ohkubo, A.; Ezawa, Y.; Seio, K.; Sekine, M., O-Selectivity and utility of phosphorylation mediated by phosphite triester intermediates in the $N$-unprotected phosphoramidite method. Journal of the American Chemical Society 2004, 126 (35), 10884-10896; (b) Ohkubo, A.; Seio, K.; Sekine, M., A new strategy for the synthesis of oligodeoxynucleotides directed towards perfect $O$-selective internucleotidic bond formation without base protection. Tetrahedron Letter 2004, 45 (2), 363-366; (c) 
Ohkubo, A.; Kuwayama, Y.; Nishino, Y.; Tsunoda, H.; Seio, K.; Sekine, M., Oligonucleotide synthesis involving deprotection of amidine-type protecting groups for nucleobases under acidic conditions. Organic Letters 2010, 12 (11), 2496-2499.

6. Hayakawa, Y.; Wakabayashi, S.; Kato, H.; Noyori, R., The allylic protection method in solid-phase oligonucleotide synthesis - an efficient preparation of solidanchored DNA oligomers. Journal of the American Chemical Society 1990, 112 (5), 1691-1696.

7. Verdolino, V.; Cammi. R.; Munk, B. H.; Schlegel, H. B., Calculation of pKa values of nucleobases and the guanine oxidation products guanidinohydantoin and spiroiminodihydantoin using density functional theory and a polarizable continuum model. Journal of Physical Chemistry B 2008, 112 (51), 16860-16873.

8. Fang, S. Y.; Fueangfung, S.; Lin, X.; Zhang, X. A.; Mai, W. P.; Bi, L. R.; Green, S. A., Synthetic oligodeoxynucleotide purification by polymerization of failure sequences. Chemical Communications 2011, 47 (4), 1345-1347.

9. Drablos, F.; Feyzi, E.; Aas, P. A.; Vaagbo, C. B.; Kavli, B.; Bratlie, M. S.; PenaDiaz, J.; Otterlei, M.; Slupphaug, G.; Krokan, H. E., Alkylation damage in DNA and RNA - repair mechanisms and medical significance. DNA Repair 2004, 3 (11), 13891407.

10. Do, N. Q.; Lim, K. W.; Teo, M. H.; Heddi, B.; Phan, A. T., Stacking of Gquadruplexes: NMR structure of a G-rich oligonucleotide with potential anti-HIV and anticancer activity. Nucleic Acids Research 2011, 39 (21), 9448-57. 
11. Hayakawa, Y.; Kataoka, M., Facile synthesis of oligodeoxyribonucleotides via the phosphoramidite method without nucleoside base protection. Journal of the American Chemical Society 1998, 120 (48), 12395-12401. 


\title{
Chapter 6
}

\section{Improved Synthesis of Dmoc-dG-amidite ${ }^{1}$}

\begin{abstract}
An improved protocol for the synthesis of Dmoc-dG-amidite is described. The step for acylation of $\mathrm{dG}$ was accomplished in fair to good yields. The advantages of the new protocol include much less starting materials, greener conditions and higher yield. The novel synthetic strategy is expected to be widely useful for the acylation of the exoamino groups on nucleoside bases.
\end{abstract}

\subsection{Introduction}

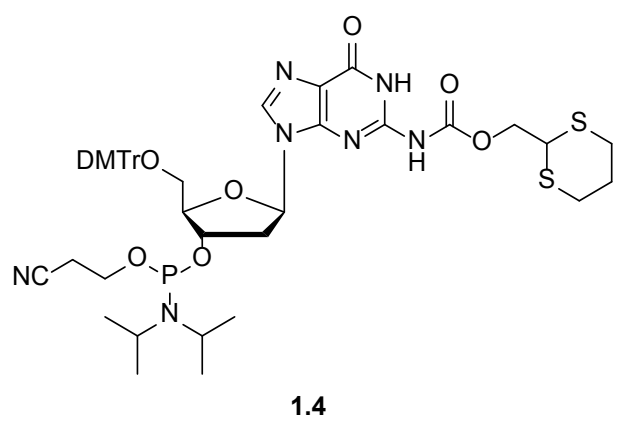

Figure 6.1. Dmoc-dG-amidite 1.4

Latent electrophilic ODNs are expected to have great potentials as therapeutics and diagnostic probes. ${ }^{1}$ However the synthesis of such ODN analogues has been extremely difficult. Due to the strongly nucleophilic conditions used for deprotection and cleavage, current ODN synthesis technology is not suitable for the synthesis of

\footnotetext{
${ }^{1}$ The contents in Chapter 6 will be revised and be submitted to the Tetrahedron Letters.
} 
electrophilic ODNs. Many attempts have been made to avoid strong nuclephiles in ODN synthesis, such as utilizing photo-labile groups, allyloxyl groups.

We have reported our own solution to the synthesis of electrophilic ODNs in previous chapters. We synthesized Dmoc-protected nucleoside phosphoramidite monomers and dT-Dmoc-CPG, and successfully applied these compounds in ODN synthesis. By removing Dmoc moieties under oxidizing conditions, we provided a universal deprotection/cleavage method for ODN synthesis using non-nucleophilic conditions. However, for our method to be practically useful, the yield of synthesizing 1.4 (Figure 6.1) has to be improved. Although we were pleased at the initial 14\% yield in our reported synthesis of $\mathbf{1 . 4}$, we knew that it needed to be improved if we were going to advance our technology to practical use. Moreover, in our initial studies, the introduction of Dmoc group to dG required excess dithianyl-nitrobenzyl formate $\mathbf{5 . 1 0}$ (10 equivalent). If we can reduce the starting material, we can make our synthesis greener and reduce the working load. In this chapter, we describe our efforts on developing a more efficient protocol for the synthesis of Dmoc-dG-amidite 1.4.

\subsection{Results and Discussion}

Our first effort on improving the synthesis procedure for Dmoc-dG-amidite is shown in Scheme 6.1. Deoxyguanosine was first protected with tetraisopropyldisiloxyl groups in quantitative yield. The protected deoxyguanosine derivative 6.1 was reacted with tert-butyl magnesium chloride in THF in the presence of HMPA. The introduction of Dmoc group to dG moiety was achieved by the reaction of the Grignard derivative with 5.10 and gave $\mathbf{6 . 2}$ in $44 \%$ yield. This procedure reduced the loading of $\mathbf{5 . 1 0}$ from 10 
equivalents to 2.5 equivalents. However the successful synthesis lies on the addition of HMPA, which is highly toxic, has a high boiling poin, and very painful to remove with common organic chemistry techniques.
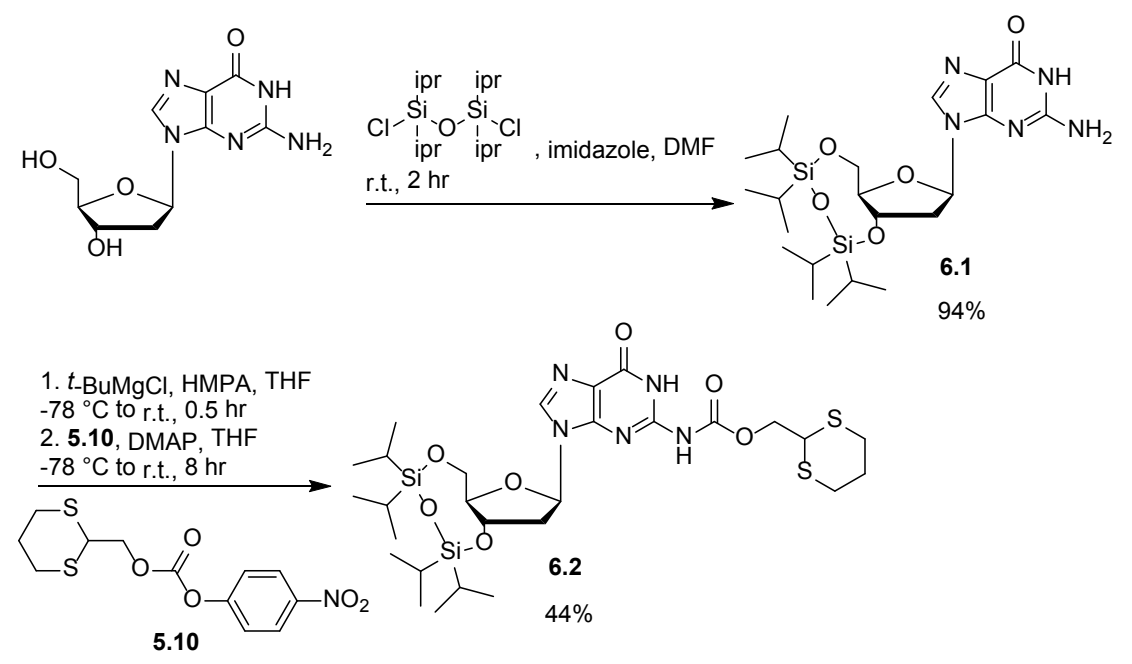

Scheme 6.1. Method A of introducing dG with Dmoc group

To avoid the issues caused by HMPA, we developed another method shown in Scheme 6.2. We treated 6.1 with tert-butyl lithium. The resulting anion was reacted with chlorotrimethysilane chloride. The intermediate $\mathbf{6 . 3}$ was deprotonated with tert-butyl lithium, and reacted with 5.10. The acylated compound $\mathbf{6 . 2}$ was obtained in $40 \%$ yield. The reaction mixture only gave 2 dots on TLC plates, which greatly reduce the labor needed for purification. 

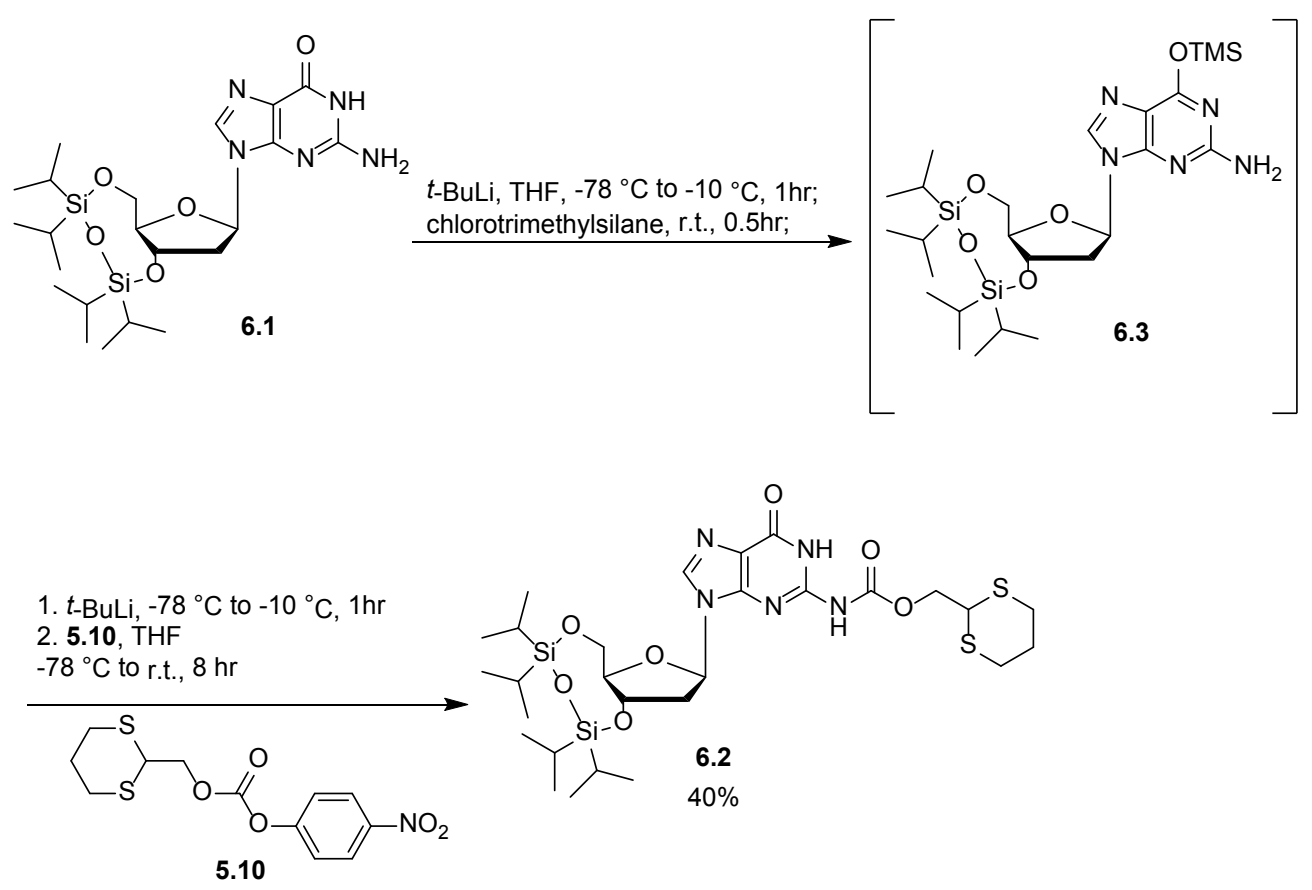

Scheme 6.2 Method B of introducing dG with Dmoc group

The silyl-type protecting groups are usually removed by fluoride, ${ }^{2}$ such as hydrogen fluoride (HF) and tetrabutylammonium fluoride (TBAF). Because HF is more toxic, TBAF is usually preferred. We developed a new way of applying HF to remove tetraisopropyldisiloxyl group (Scheme 6.3). Compound 6.2 was treated with excess HF/pyridine. The siloxyl groups were removed. The extra HF was quenched with methoxytrimethylsilane and the resulted products such as methol and trimethylsilane fluoride and extra methoxytrimethylsilane were simply removed by rotary evaporation due to their low boiling points. Without purification, the resulting mixture was reacted with $\mathrm{DMTrCl}$ and gave $\mathbf{5 . 1 8}$ in $80 \%$ yield. Phophorylation of $\mathbf{5 . 1 8}$ was accomplished by 2-cyano- $N, N, N^{\prime}, N^{\prime}$ - tetraisopropylphosphordiamidite. Dmoc-dG-amidite $\mathbf{1 . 4}$ was obtained in $77 \%$ yield. 


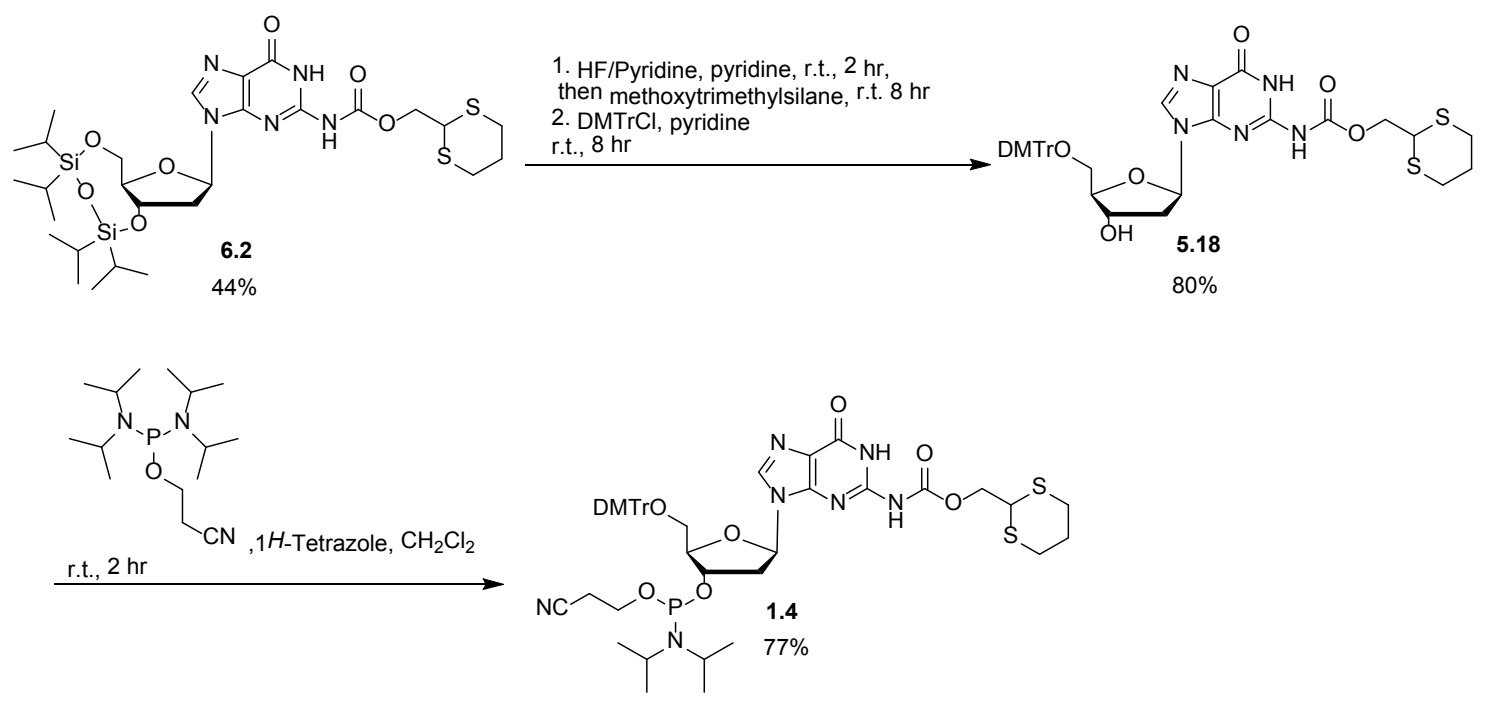

Scheme 6.3. Synthesis of Dmoc-dG-amidite 1.4

\subsection{Conclusion}

An improved synthetic protocol for the synthesis of Dmoc-dG-amidite was developed. This protocol might be used as a generally applicable strategy for the acylation of nucleoside bases.

\subsection{Experimental Section}

\section{General Experimental}

All reactions were performed in over-dried glassware under a nitrogen atmosphere using standard Schlenk techniques. Reagents and solvents available from commercial sources were used as received unless otherwise noted. $\mathrm{CH}_{2} \mathrm{Cl}_{2}$, pyridine, toluene were distilled over $\mathrm{CaH}_{2}$, and THF was distilled over Na. Thin layer chromatography (TLC) was performed using Sigma-Aldrich TLC plates, silica gel 60F254 over glass support, $0.25 \mu \mathrm{m}$ thickness. Flash column chromatography was performed using Selecto Scientific silica gel, particle size $32-63 \mu \mathrm{m} .{ }^{1} \mathrm{H}$ and ${ }^{13} \mathrm{C}$ spectra were 
measured on Varian UNITY INOVA spectrometer at 400, 100 and $162 \mathrm{MHz}$, respectively; chemical shifts $(\delta)$ were reported in reference to solvent peaks (residue $\mathrm{CHCl}_{3}$ at $\delta 7.24$ ppm for ${ }^{1} \mathrm{H}$ and $\mathrm{CDCl}_{3}$ at $\delta 77.00 \mathrm{ppm}$ for ${ }^{13} \mathrm{C}$ ), unless otherwise noted. High resolution mass spectra were obtained were obtained at Mass Spectrometry Technical Services at University of Michigan.

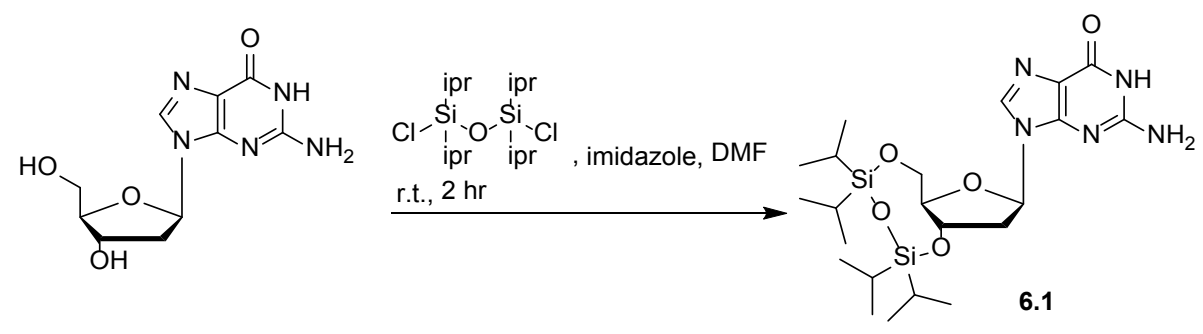

Compound 6.1. Deoxyguanosine monohydrate (6.000 g, $21.040 \mathrm{mmol})$ was coevaporated with pyridine three times $(10 \mathrm{~mL}$ each time $)$ and was suspended in anhydrous DMF (50 mL) with imidazole (5.729 g, $23.142 \mathrm{mmol})$. To the suspension, 1,3dichloro-1,1,3,3-tetraisopropyldisiloxane $(7.300 \mathrm{~g}, 23.142 \mathrm{mmol})$ was added dropwise. The reaction mixture was stirred at room temperature for 2 hours. The resulting mixture was partitioned between EtOAc and $\mathrm{H}_{2} \mathrm{O}$. The organic layer was dried over anhydrous $\mathrm{Na}_{2} \mathrm{SO}_{4}$, filtered and concentrated. Column chromatography $\left(9: 1 \mathrm{CHCl}_{3} / \mathrm{MeOH}\right)$ gave compound $6.1(10.611 \mathrm{~g}, 99 \%)$ as a white solid. M.P. $>285{ }^{\circ} \mathrm{C}$ (dec.); $\mathrm{R}_{\mathrm{f}}=0.37$ $\left(\mathrm{CHCl}_{3} / \mathrm{MeOH}=9: 1\right) ;{ }^{1} \mathrm{H}$ NMR $\left(400 \mathrm{MHz}, \mathrm{DMSO}-\mathrm{d}_{6}\right) \delta 0.86-1.11(\mathrm{~m}, 28 \mathrm{H}), 2.41-2.63$ $(\mathrm{m}, 2 \mathrm{H}), 3.72-3.76(\mathrm{~m}, 1 \mathrm{H}), 3.83-3.92(\mathrm{~m}, 2 \mathrm{H}), 4.61-4.66(\mathrm{~m}, 1 \mathrm{H}), 6.01-6.04(\mathrm{~m}, 1 \mathrm{H})$, $6.43(\mathrm{~s}, 2 \mathrm{H}), 7.79(\mathrm{~s}, 1 \mathrm{H}), 10.61(\mathrm{~s}, 1 \mathrm{H}) ;{ }^{13} \mathrm{C}$ NMR (100 MHz, DMSO-d 6$) \delta 12.7,12.9$, $13.2,13.4,17.5,17.6,17.6,17.7,17.9,18.0,62.8,71.6,81.5,85.1,117.3,135.2,151.3$ 
154.4, 157.3; HRMS (ESI) $m / z$ calcd for $\mathrm{C}_{22} \mathrm{H}_{40} \mathrm{~N}_{5} \mathrm{O}_{5} \mathrm{Si}_{2}[\mathrm{M}+\mathrm{H}]^{+}$: 510.2562, found $[\mathrm{M}+\mathrm{H}]^{+} 510.2560$.

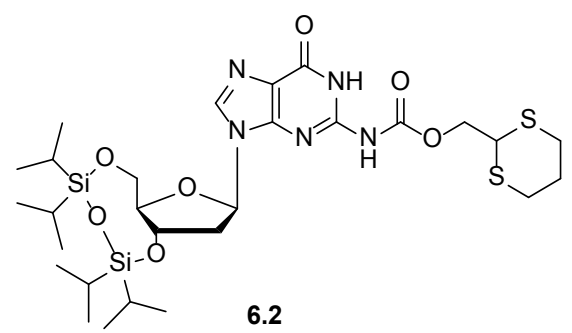

Compound 6.2 made using either method A or B (see below). M.P. $130-132{ }^{\circ} \mathrm{C}$; $\mathrm{R}_{\mathrm{f}}=0.3\left(\mathrm{CHCl}_{3} / \mathrm{MeOH}=19: 1\right) ;{ }^{1} \mathrm{H}$ NMR $\left(400 \mathrm{MHz}, \mathrm{CDCl}_{3}\right) \delta 0.99-1.09(\mathrm{~m}, 28 \mathrm{H}), 2.00-$ $2.07(\mathrm{~m}, 2 \mathrm{H}), 2.53-2.56(\mathrm{~m}, 2 \mathrm{H}), 2.66-2.99(\mathrm{~m}, 2 \mathrm{H}), 3.83-4.11(\mathrm{~m}, 4 \mathrm{H}), 4.53-4.62(\mathrm{~m}$, $2 \mathrm{H}), 4.68-4.74(\mathrm{~m}, 1 \mathrm{H}), 6.09-6.11(\mathrm{~m}, 1 \mathrm{H}), 7.85(\mathrm{~s}, 1 \mathrm{H}) ;{ }^{13} \mathrm{C} \mathrm{NMR}\left(100 \mathrm{MHz}, \mathrm{CDCl}_{3}\right) \delta$ $12.7,13.2,13.3,13.6,17.1,17.2,17.3,17.4,17.5,17.6,25.5,27.1,40.3,42.5,62.0,66.1$, $70.0,82.8,85.4,121.8,136.9,146.3,153.0,155.6$; HRMS (ESI) $\mathrm{m} / \mathrm{z}$ calcd for $\mathrm{C}_{28} \mathrm{H}_{48} \mathrm{~N}_{5} \mathrm{O}_{7} \mathrm{~S}_{2} \mathrm{Si}_{2}[\mathrm{M}+\mathrm{H}]^{+}: 686.2528$, found $[\mathrm{M}+\mathrm{H}]^{+} 686.2535$.

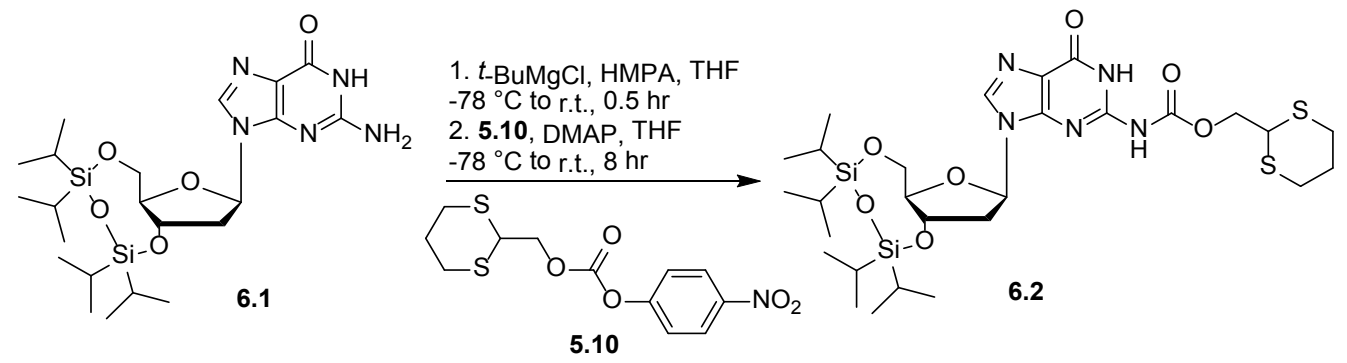

Method A: To a solution of tetraisopropyldisiloxane-diyl deoxyguanosine 6.1 $(2.555 \mathrm{~g}, 5.037 \mathrm{mmol})$ in HMPA $(5 \mathrm{~mL})$ and THF $(50 \mathrm{~mL})$ was added dropwise tertbutylmagnesium chloride ( $1 \mathrm{M}$ in THF, $15.1 \mathrm{~mL}, 15.101 \mathrm{mmol})$ at $-78{ }^{\circ} \mathrm{C}$. The reaction was allowed to acclimate to room temperature and stirred for 30 minutes. The reaction 
mixture was cooled back to $-78{ }^{\circ} \mathrm{C}$, and was added a solution of nitrobenzyl dithianyl carbonate 5.10 (3.971 g, $12.592 \mathrm{mmol})$ and DMAP (1.538 g, $12.591 \mathrm{mmol})$ in THF (25 $\mathrm{mL}$ ) slowly. After stirring for 8 hours at room temperature, the reaction mixture was quenched with $\mathrm{MeOH}(8 \mathrm{~mL})$ and concentrated. The resulting residue was redissolved with EtOAc and washed sequentially with $0.15 \mathrm{M}$ EDTA, saturated $\mathrm{NaHCO}_{3}$ aqueous solution and brine. The organic layer was dried over anhydrous $\mathrm{Na}_{2} \mathrm{SO}_{4}$, filtered and concentrated. Column chromatography $\left(19: 1 \mathrm{CHCl}_{3} / \mathrm{MeOH}\right)$ gave compound $6.2(1.528 \mathrm{~g}$, $44 \%)$ as a white solid.

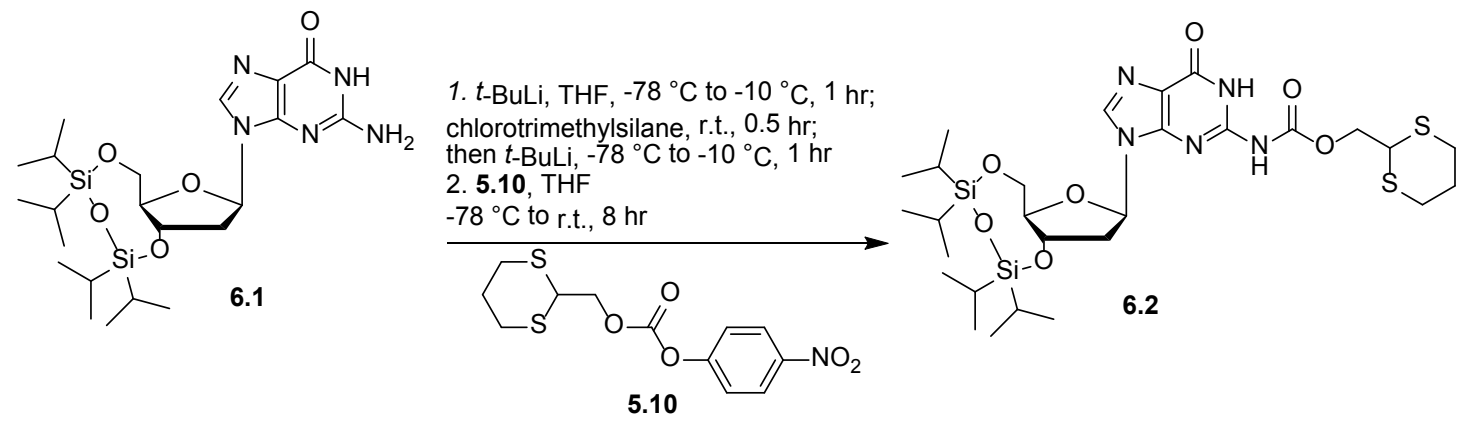

Method B: Tetraisopropyldisiloxane-diyl deoxyguanosine 6.1 (1.100 g, 2.168 $\mathrm{mmol})$ and nitrobenzyl dithianyl carbonate $(0.821 \mathrm{~g}, 2.602 \mathrm{mmol})$ was put in a desiccator and dried over fresh drierite under high vacuum overnight. The dry deoxyguanosine derivative was added to a two neck round bottom flask, and dry THF (15 mL) was added. To the solution of deoxyguanosine derivative was slowly added tert-butyllithium solution (1.7 $\mathrm{M}$ in pentane, $1.53 \mathrm{~mL}, 2.602 \mathrm{mmol}$ ) at $-78{ }^{\circ} \mathrm{C}$. The reaction mixture was allowed to warm up to $-10^{\circ} \mathrm{C}$ and stay at the temperature for one hour. Then the mixture was cooled back to $-78{ }^{\circ} \mathrm{C}$, and was added chlorotrimethylsilane $(0.283 \mathrm{~g}, 2.602 \mathrm{mmol})$. The reaction mixture was allowed to warm up to room temperature and stir for one hour. The mixture 
was cooled back to $-78^{\circ} \mathrm{C}$, and was added a THF $(15 \mathrm{~mL})$ solution of dry nitrobenzyl dithianyl carbonate $\mathbf{5 . 1 0}$ slowly. The whole mixture was acclimate to room temperature and was left to stir for 8 hour. The reaction mixture was partitioned between EtOAc and $\mathrm{H}_{2} \mathrm{O}$. The organic layer was dried over anhydrous $\mathrm{Na}_{2} \mathrm{SO}_{4}$, filtered and concentrated. Column chromatography $\left(19: 1 \mathrm{CHCl}_{3} / \mathrm{MeOH}\right)$ gave compound $6.2(0.581 \mathrm{~g}, 40 \%)$ as a white solid.

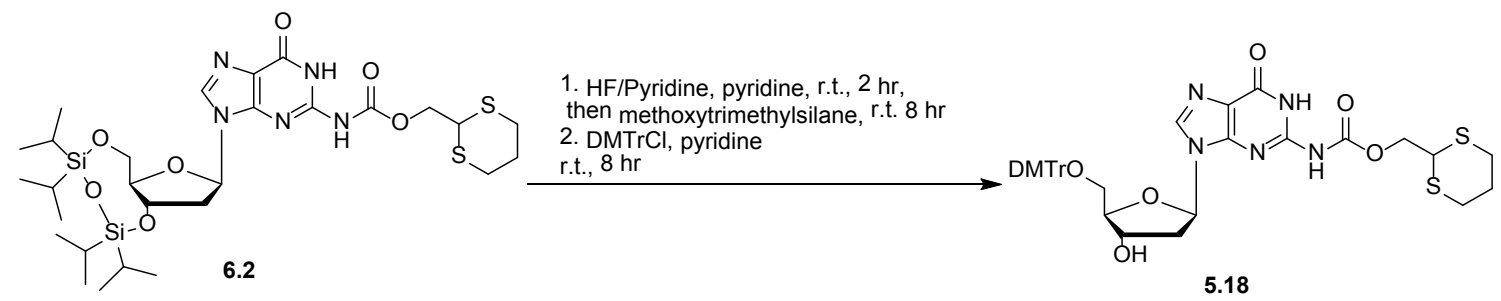

Compound 5.18. To a solution of deoxyguanosine derivative $6.2(0.569 \mathrm{~g}, 0.832$ mmol) in dry pyridine $(10 \mathrm{~mL})$ was added $\mathrm{HF} /$ pyridine $(70 \%, 0.357 \mathrm{~g}, 12.477 \mathrm{mmol})$ at $0{ }^{\circ} \mathrm{C}$. After 2 hours, methoxyltrimethylsilane (1.300 g, $\left.12.477 \mathrm{mmol}\right)$ was added. The whole reaction mixture was stirred for 8 hours. The reaction mixture was concentrated and coevaporated with dry pyridine three times $(5 \mathrm{~mL}$ each time). The residue was dissolved with dry pyridine $(20 \mathrm{~mL})$. Under positive $\mathrm{N}_{2}$ pressure, dimethoxytrityl chloride $(0.282 \mathrm{~g}, 0.832 \mathrm{mmol})$ was added to the solution. The whole mixture was left to stir for 8 hours. The reaction mixture was partitioned between $\mathrm{CH}_{2} \mathrm{Cl}_{2}$ and $5 \% \mathrm{NaHCO}_{3}$ aqueous solution. The organic layer was dried over anhydrous $\mathrm{Na}_{2} \mathrm{SO}_{4}$, filtered and concentrated. After column chromatography (9:1 EtOAc/MeOH), compound 5.18 (1.062 g, 80\%) was obtained as a white foamy solid. M.P. $159-161{ }^{\circ} \mathrm{C} ; \mathrm{R}_{\mathrm{f}}=0.2$ $(\mathrm{EtOAc} / \mathrm{MeOH}=9: 1) ;{ }^{1} \mathrm{H}$ NMR $\left(400 \mathrm{MHz}, \mathrm{CDCl}_{3}\right) \delta 1.94-2.06(\mathrm{~m}, 2 \mathrm{H}), 2.48-2.59(\mathrm{~m}$, 
2H), 2.63-2.96 (m, 4H), 3.27-3.41 (m, 2H), $3.68(\mathrm{~s}, 6 \mathrm{H}), 4.08-4.12(\mathrm{t}, J=8 \mathrm{~Hz}, 1 \mathrm{H})$, 4.15-4.18 (m, 1H), 4.56-4.58 (d, $J=8 \mathrm{~Hz}, 2 \mathrm{H}), 4.87-4.91(\mathrm{~m}, 1 \mathrm{H}), 6.20-6.23(\mathrm{t}, J=6 \mathrm{~Hz}$, 1H), 6.67-6.70 (dd, $J=9 \mathrm{~Hz}, 3 \mathrm{~Hz}, 4 \mathrm{H}), 7.07-7.33$ (m, 9H), $7.68(\mathrm{~s}, 1 \mathrm{H}) ;{ }^{13} \mathrm{C}$ NMR (100 $\left.\mathrm{MHz}, \mathrm{CDCl}_{3}\right) \delta 10.8,14.2,25.4,27.0,40.1,42.6,45.8,55.2,60.4,64.3,65.7,71.7,84.3$, 86.4, 86.5, 113.0, 120.9, 126.8, 135.7, 144.5, 148.4, 154.4, 155.8, 158.4; HRMS (ESI) $m / z$ calcd for $\mathrm{C}_{37} \mathrm{H}_{40} \mathrm{~N}_{5} \mathrm{O}_{8} \mathrm{~S}_{2}[\mathrm{M}+\mathrm{H}]^{+}:$746.2313, found $[\mathrm{M}+\mathrm{H}]^{+} 746.2311$.

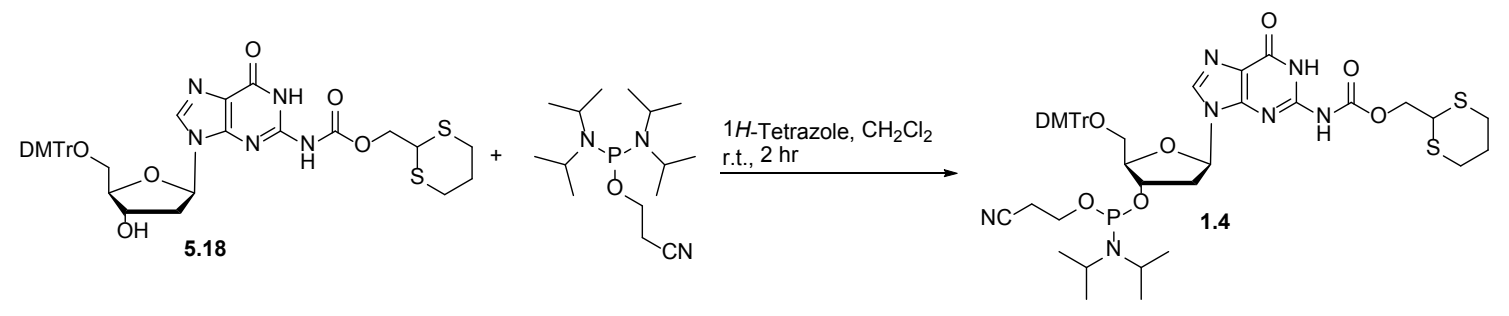

Compound 1.4. A round-bottom flask containing $5.18(0.601 \mathrm{~g}, 0.821 \mathrm{mmol})$, and a magnetic stirring bar was evacuated and then refilled with nitrogen. The evacuation and nitrogen-filling cycle was repeated for two more times. Dry $\mathrm{CH}_{2} \mathrm{Cl}_{2}(6 \mathrm{~mL})$ and 2cyanoethyl- $N, N, N^{\prime}, N^{\prime}$-tetraisopropylphosphoramidite $(0.272 \mathrm{~g}, 0.29 \mathrm{~mL}, 0.903 \mathrm{mmol})$ were then added via syringes. A $1 H$-tetrazole solution in $\mathrm{CH}_{3} \mathrm{CN}(0.45 \mathrm{M}, 2.0 \mathrm{~mL}, 0.903$ mmol) was added via a syringe in one portion. After stirring at room temperature for 2 hours, the reaction mixture was concentrated to dryness by blowing nitrogen over the surface. The residue was purified with flash column chromatography (1:1 hexanes/EtOAc) giving compound 1.4 as a white foam $(0.600 \mathrm{~g}, 77 \%)$ : $\mathrm{R}_{\mathrm{f}}=0.5(\mathrm{EtOAc} / \mathrm{MeOH}=29: 1)$; ${ }^{1} \mathrm{H}$ NMR (400 MHz CDCl 3$) \delta 1.12-1.15(\mathrm{~m}, 12 \mathrm{H}), 1.97-2.03(\mathrm{~m}, 2 \mathrm{H}), 2.32-2.95(\mathrm{~m}, 8 \mathrm{H})$, 3.33-3.34 (d, $J=4 \mathrm{~Hz}, 2 \mathrm{H}), 3.51-3.63(\mathrm{~m}, 4 \mathrm{H}), 3.73$ (s, 6H), 3.93-3.98 (t, $J=10 \mathrm{~Hz}, 1 \mathrm{H})$, 4.24-4.47 (m, 1H), 4.49-4.51 (d, $J=8 \mathrm{~Hz}, 2 \mathrm{H}), 4.68-4.74(\mathrm{~m}, 1 \mathrm{H}), 6.17-6.20(\mathrm{t}, J=6 \mathrm{~Hz}$, 
1H), 6.73-6.76 (m, 4H), 7.13-7.38 (m, 9H), $7.74(\mathrm{~s}, 1 \mathrm{H}) ;{ }^{13} \mathrm{C} \mathrm{NMR}\left(100 \mathrm{MHz}, \mathrm{CDCl}_{3}\right) \delta$ $20.2,20.3,24.5,24.5,24.6,26.8,39.4,42.1,43.2,43.3,55.2,57.8,58.0,63.7,65.6,73.7$, $73.8,84.6,86.0,86.3,113.1,117.3,121.7,126.9,127.8,128.0,130.0,135.7,137.5,144.5$, 146.2, 148.0, 153.0, 158.5; ${ }^{31} \mathrm{P}$ NMR $\left(162 \mathrm{MHz}, \mathrm{CDCl}_{3}\right) \delta 149.4$.

\section{References}

1. Kachalova, A. V.; Zubin, E. M.; Orestskaya, T. S., Methods for the synthesis of oligonucleotides containing reactive electrophilic groups. Russian Chemical Reviews 2002, 71 (12), 1041-1059.

2. (a) Prakash, C.; Saleh, S.; Blair, I. A., Selective deprotection of silyl ethers. Tetrahedron Letter 1989, 30 (1), 19-22; (b) Markiewicz, W. $\quad$ T.; Tetraisopropyldisiloxane-1,3-diyl, a group for simultaneous protection of 3'-hydroxy and 5'-hydroxy functions of nucleosides. Journal of Chemical Research 1979, 1, 24-25; (c) Lalonde, M.; Chan, T. H., Use of organo-silicon reagents as protective groups in organic synthsis. Synthesis-Stuttgart 1985, (9), 817-845. 


\section{Chapter 7}

\section{Future Research Plan}

Modified ODNs that contain electrophilic and base-labile functionalities have important applications in many research areas including antisense drug development and chemical biology. In the previous chapters, we have described our development of a novel ODN synthesis technology. We used the Dmoc function to protect the amino groups of nucleoside bases and to link ODNs to solid support. With this protecting and linking strategy, deprotection and cleavage were able to be carried out under nonnucleophilic conditions. This technology shall enable the synthesis of electrophilic ODN analogues. However, at the current state, in the deprotection step, we used the nonnucleophilic base DBU to remove the 2-cyanoethyl phosphate protecting groups. As a result, we could not use the technology to synthesize base-labile ODNs. One future direction of this project will be to replace the 2-cyanoethyl phosphate protecting groups with Dim groups so that the technology is not only suitable for the synthesis of electrophilic but also base-labile ODNs. Furthermore, the deprotection technology of ODN synthesis under non-nucleophilic oxidative conditions can be optimized by using other Dmoc-alike protecting groups. For example, the protecting groups using 1,3dithianylethoxycarbonyl (Deoc) function, which can also be removed upon oxidative conditions, will be applied to protect the exo-amino groups of nucleoside bases. Due the more stable side product from the removal of Deoc functions, we are expecting less occurance of ODN conjugates from Michael addition. 


\subsection{Dim Protecting Groups for Phosphoramidites}

Although we are satisfied with the non-nucleophilic conditions for the deprotection and cleavage of ODN synthesis, our technology is still limited. As we used DBU for removing cyanoethyl group, some base-labile ODN analogues are not compatible with our technology. In this case, we designed another type of protecting groups using 1,3-dithian-2-yl-methyl (Dim) moiety to protect $\mathrm{P}(\mathrm{III})$ of phosphoramidite. The resulted phosphoramidites are shown in Figure 7.1.

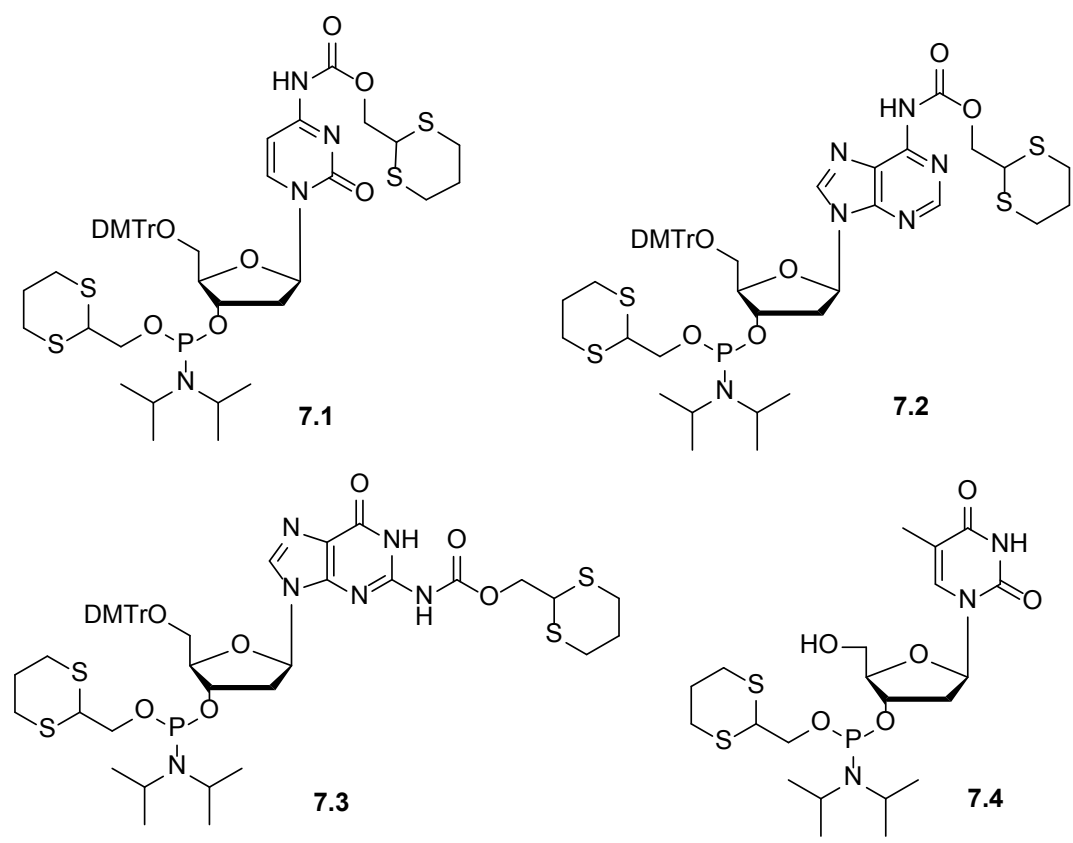

Figure 7.1. Dim-protected phosphoramidites

Applying dT-Dmoc-CPG 1.1 and phosphoramidites (7.1-7.4) on ODN synthesis,

ODN anchored CPG 7.5 will be obtained. Upon oxidation of the sulfide in Dim and Dmoc moieties, due to the drastically increased acidity of H-2, the Dim groups, Dmoc 
groups and linker are expected to be readily cleaved under oxidizing conditions without any base present. As shown in Scheme 7.1, the deprotection and cleavage of 7.5 under neutral conditions will afford ODN 7.6.

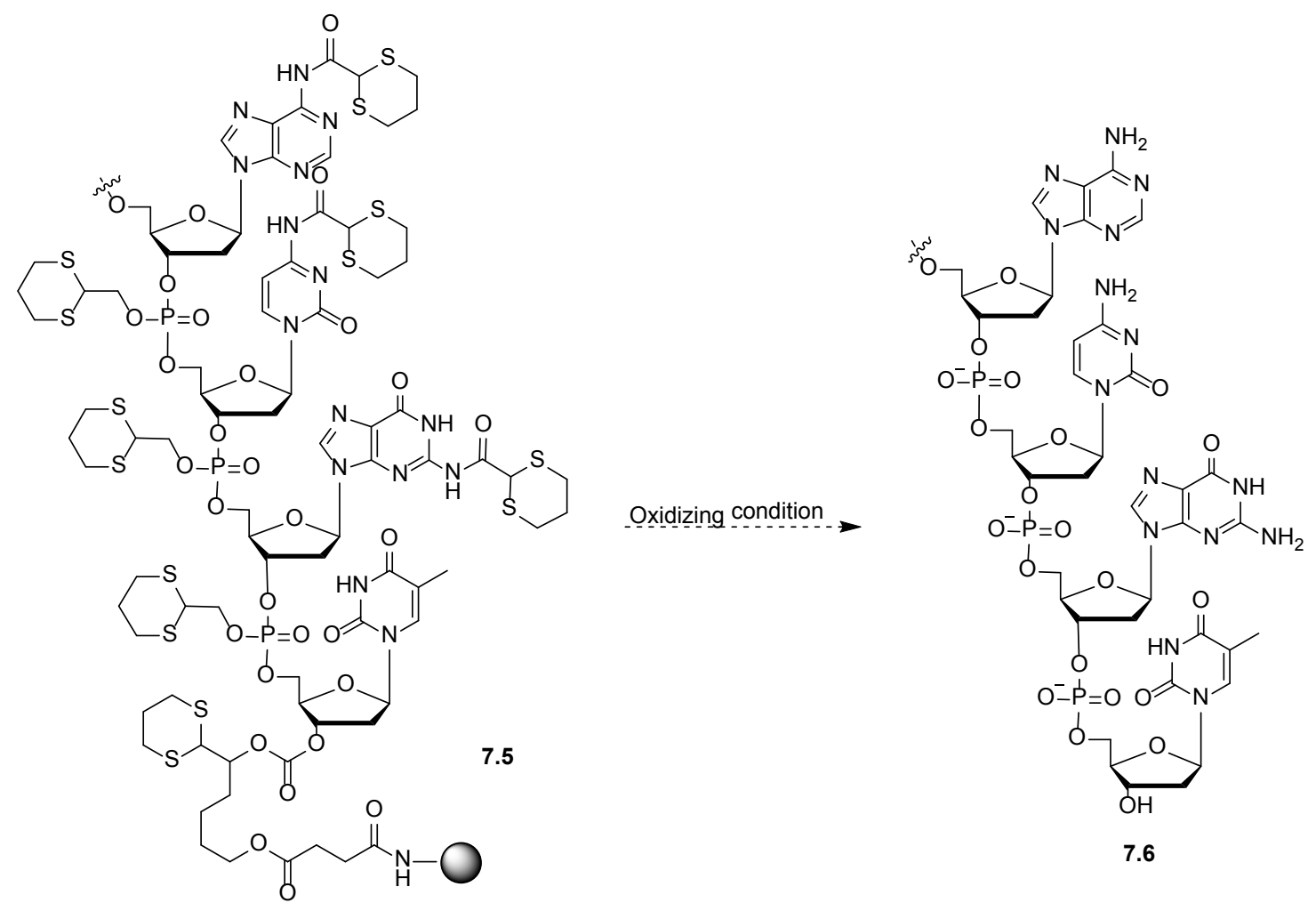

Scheme 7.1. Proposed deprotection and cleavage utilizing Dim-protected phosphoramidites

\subsection{Deoc Protecting Groups for Nucleoside Bases}

In our described technology, aniline was used as a scavenger to deactivate the produced Michael acceptors from removal of Dmoc moieties. To simplify deprotection process, we designed a 1,3-dithianyl-ethoxycarbonyl (Deoc) function as protecting groups for nucleoside bases. The designed Deoc-protected phosphoramidite monomers are shown in Figure 7.2. Due to the additional methyl group, the adducts from removing 
Deoc moieties will be more stable comparing to the adducts from Dmoc moieties. They will be less reactive toward nucleoside bases through Michael conjugative addition. Therefore, we might be able to avoid adding scavengers during the deprotection and cleavage process.
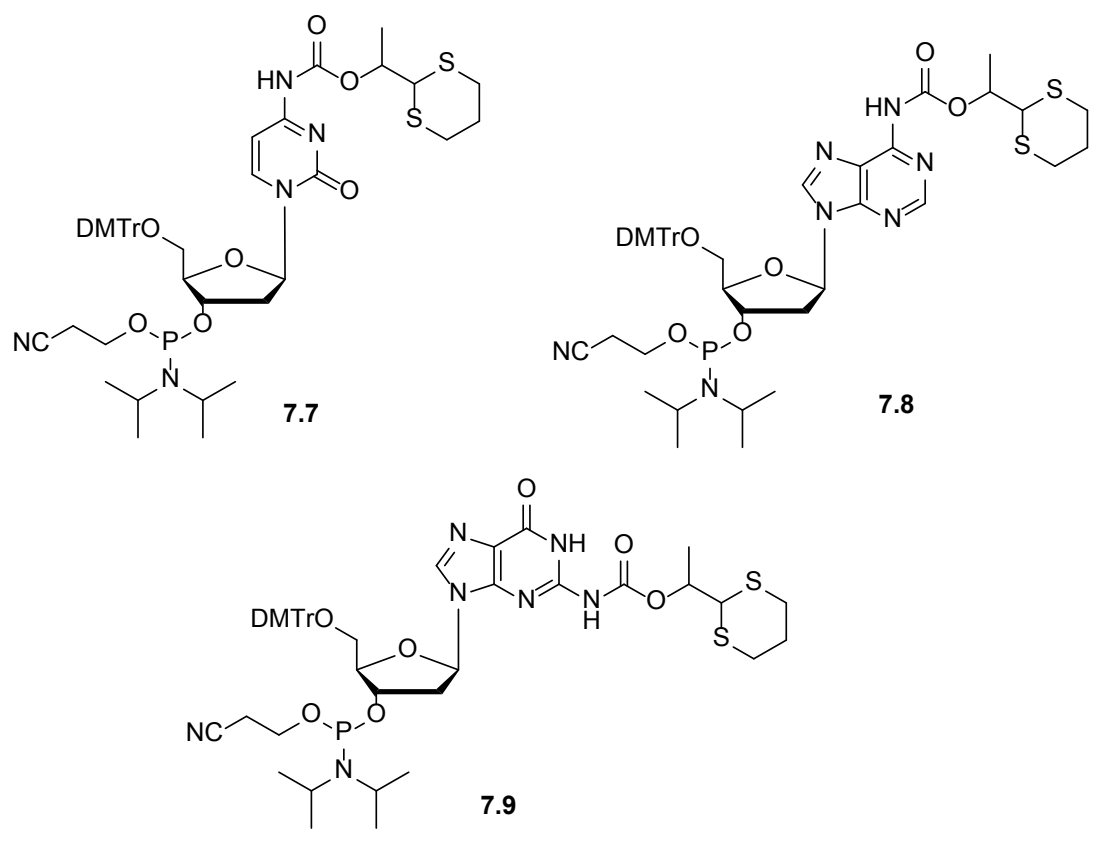

Figure 7.2. Deoc-protected phosphoramidite monomers

The syntheses of Deoc-protected phosphoramidites have already been carried out. So far, we have successfully introduced Deoc function to nucleoside bases (Scheme 7.2). Phosphorylation of $\mathbf{7 . 1 0}$ will give 7.7. With several more steps ahead such as DMTr protection and phosphorylation, reactions of 7.12 and 7.13 will afford corresponding phosphoramidites 7.8 and 7.9 . 

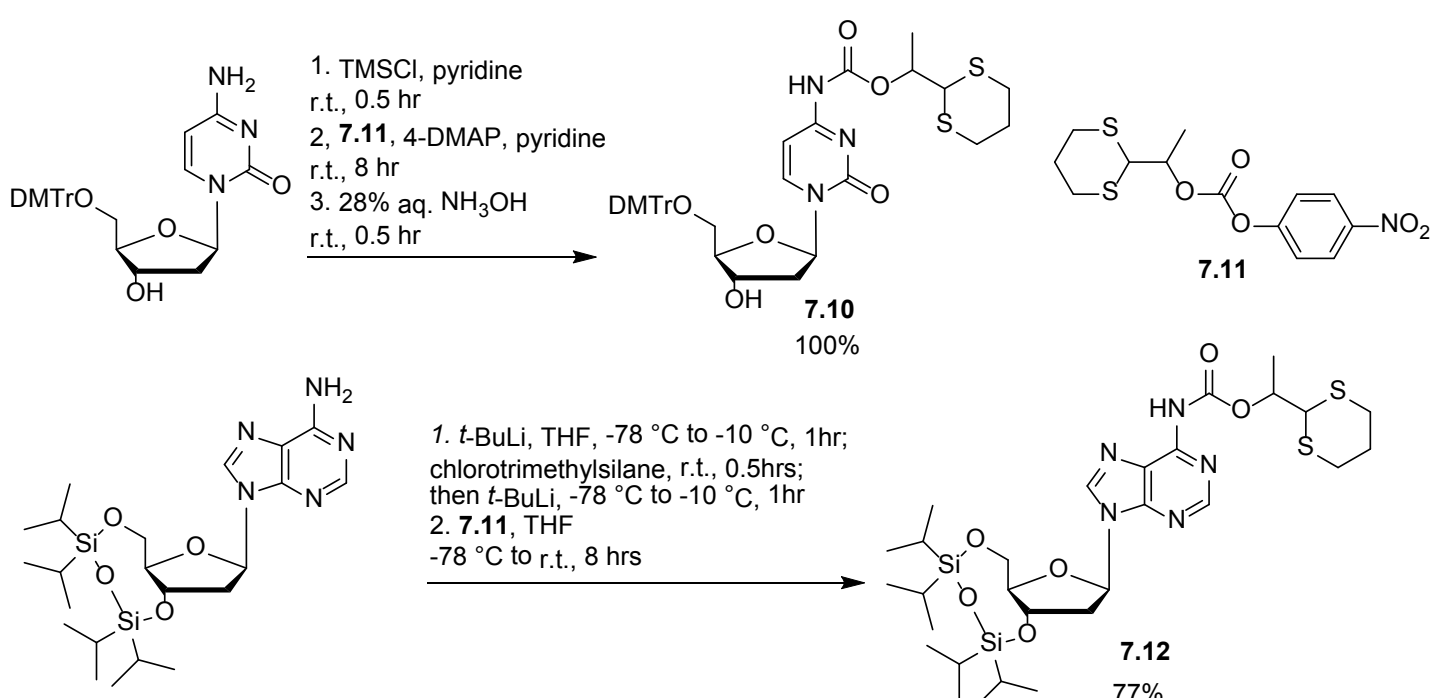

1. $t$-BuLi, THF, $-78^{\circ} \mathrm{C}$ to $-10{ }^{\circ} \mathrm{C}, 1 \mathrm{hr}$;

chlorotrimethylsilane, r.t., $0.5 \mathrm{hrs}$;

then $t$-BuLi, $-78{ }^{\circ} \mathrm{C}$ to $-10{ }^{\circ} \mathrm{C}, 1 \mathrm{hr}$

2. 7.11, THF

$-78^{\circ} \mathrm{C}$ to r.t., $8 \mathrm{hrs}$

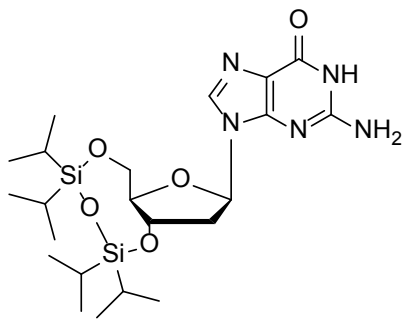

1. $t$-BuLi, THF, $-78^{\circ} \mathrm{C}$ to $-10{ }^{\circ} \mathrm{C}, 1 \mathrm{hr}$ chlorotrimethylsilane, r.t., $0.5 \mathrm{hrs}$; then $t$-BuLi, $-78{ }^{\circ} \mathrm{C}$ to $-10{ }^{\circ} \mathrm{C}, 1 \mathrm{hr}$

2. 7.11, THF

$-78^{\circ} \mathrm{C}$ to r.t., $8 \mathrm{hrs}$

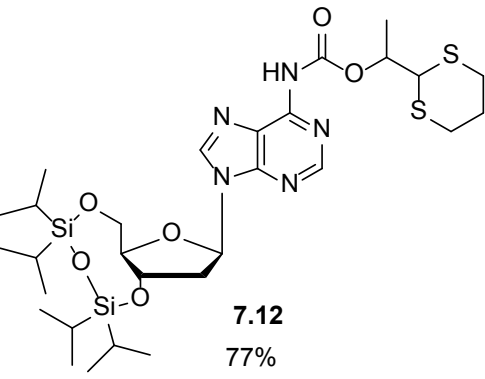

Scheme 7.2. Introduction of Deoc moieties to nucleoside bases

\subsection{Conclusion}

The future research plan will extend our ODN synthesis technology from being only useful for the synthesis of electrophilic ODNs to being useful for the synthesis of base-labile ODNs as well. In addition, with the introduction of the Dim phosphate protecting groups, DBU treatment can be avoided, which can simplify the deprotection step. That is, deprotection can then be achieved in a single step instead of two steps. The introduction of Deoc protecting groups to replace the Dmoc groups in the technology will help to avoid using aniline as a scavenger. At the current stage of the technology, we used large amount of this scavenger, which takes efforts to remove it from product. With Deoc, the deprotection and cleavage procedure can be further simplified. 


\section{Appendix A}

Supporting Information for Chapter 4

Synthesis of Dmoc-dT Linker and Evaluation of Its Application in ODN Synthesis 


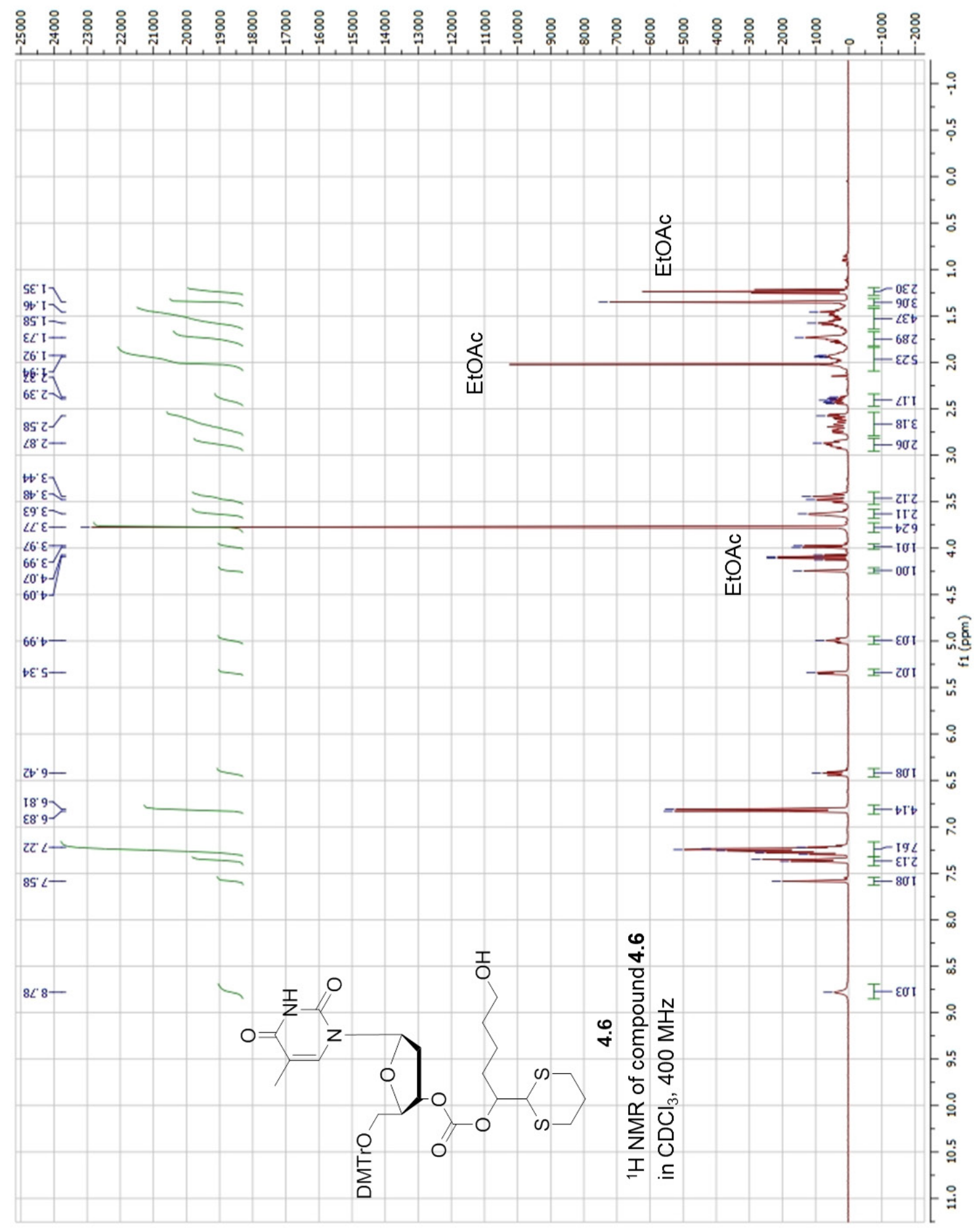

Figure A.1. ${ }^{1} \mathrm{H}$ NMR of compound 4.6 


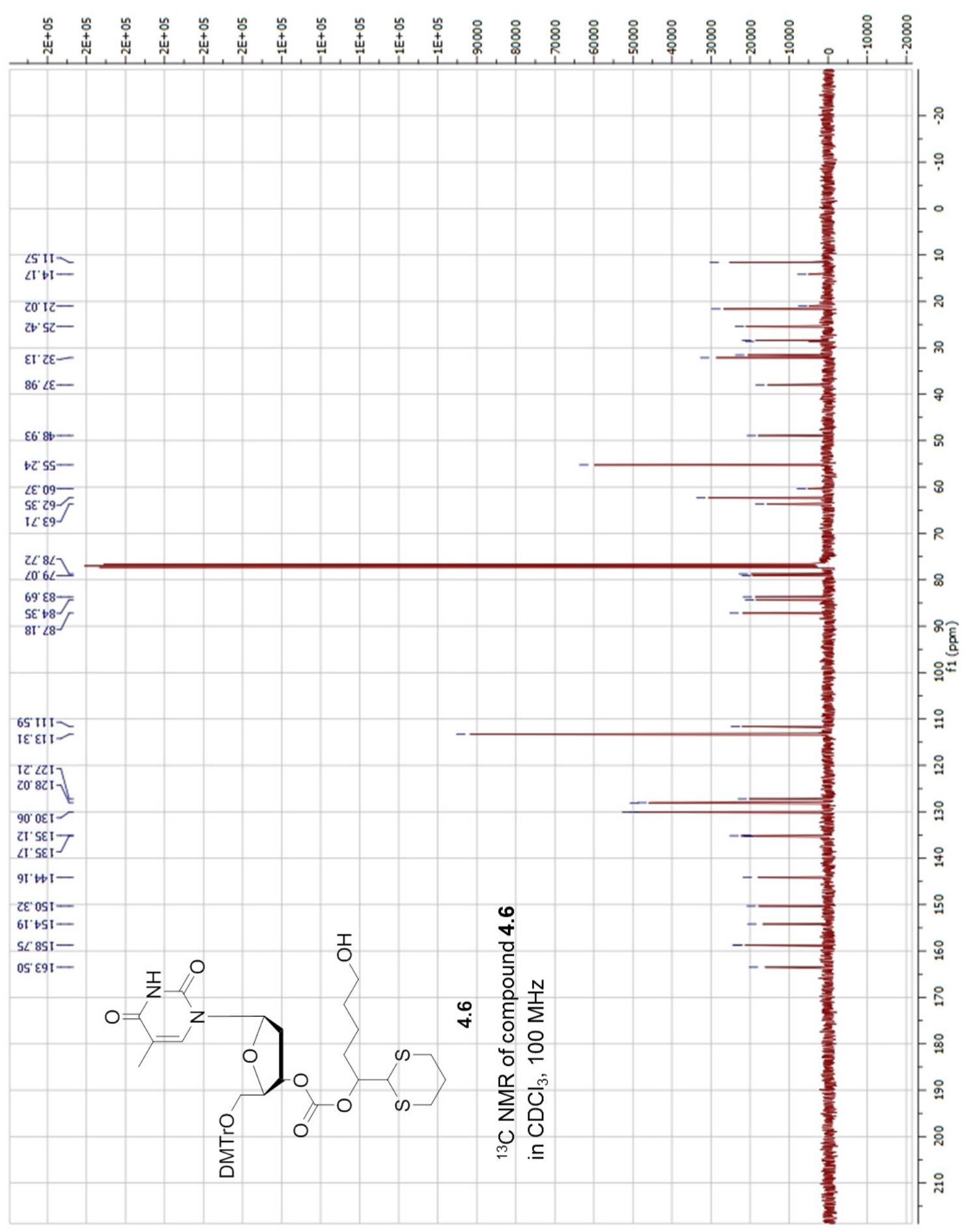

Figure A.2. ${ }^{13} \mathrm{C}$ NMR of compound 4.6 


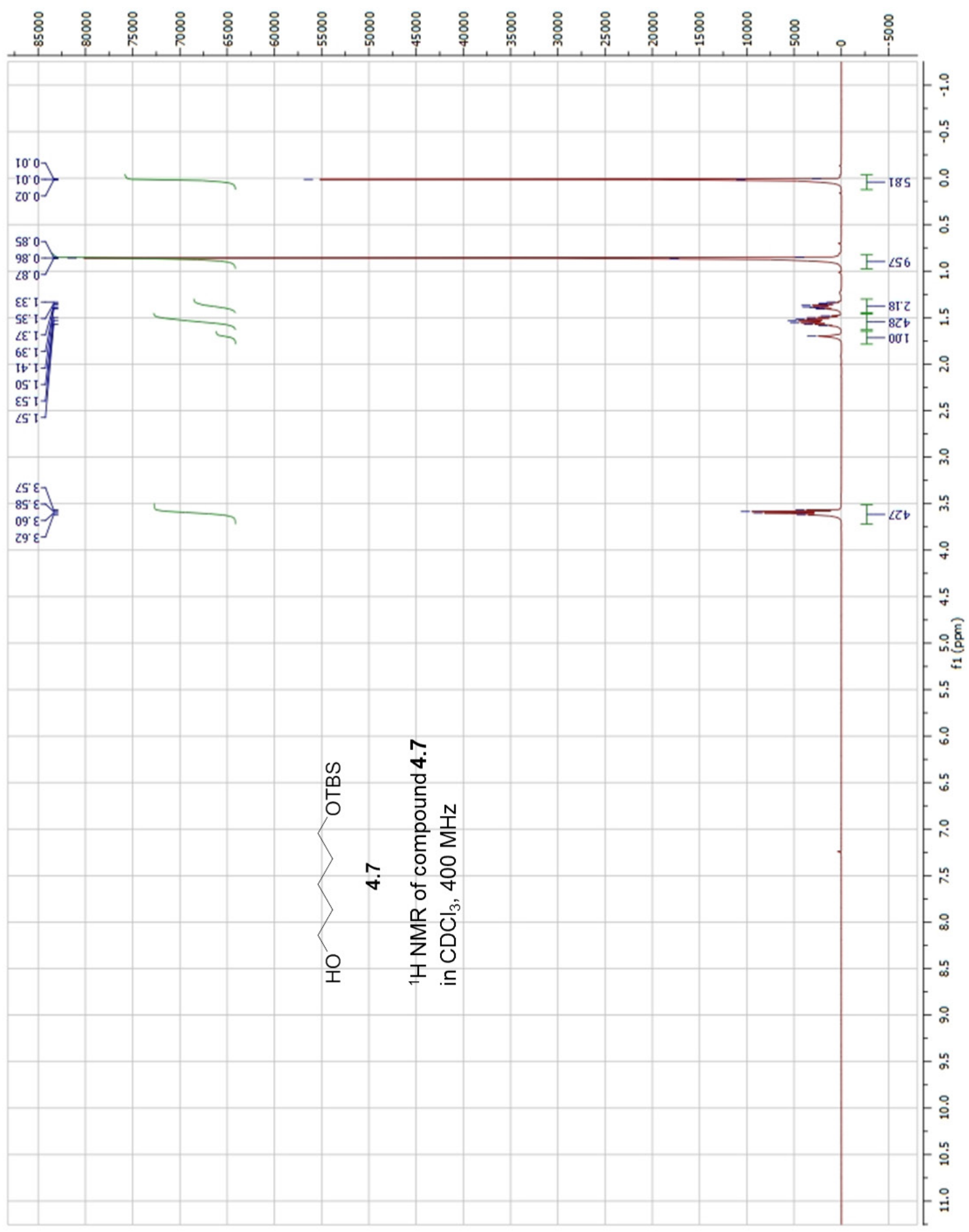

Figure A.3. ${ }^{1} \mathrm{H}$ NMR of compound 4.7 


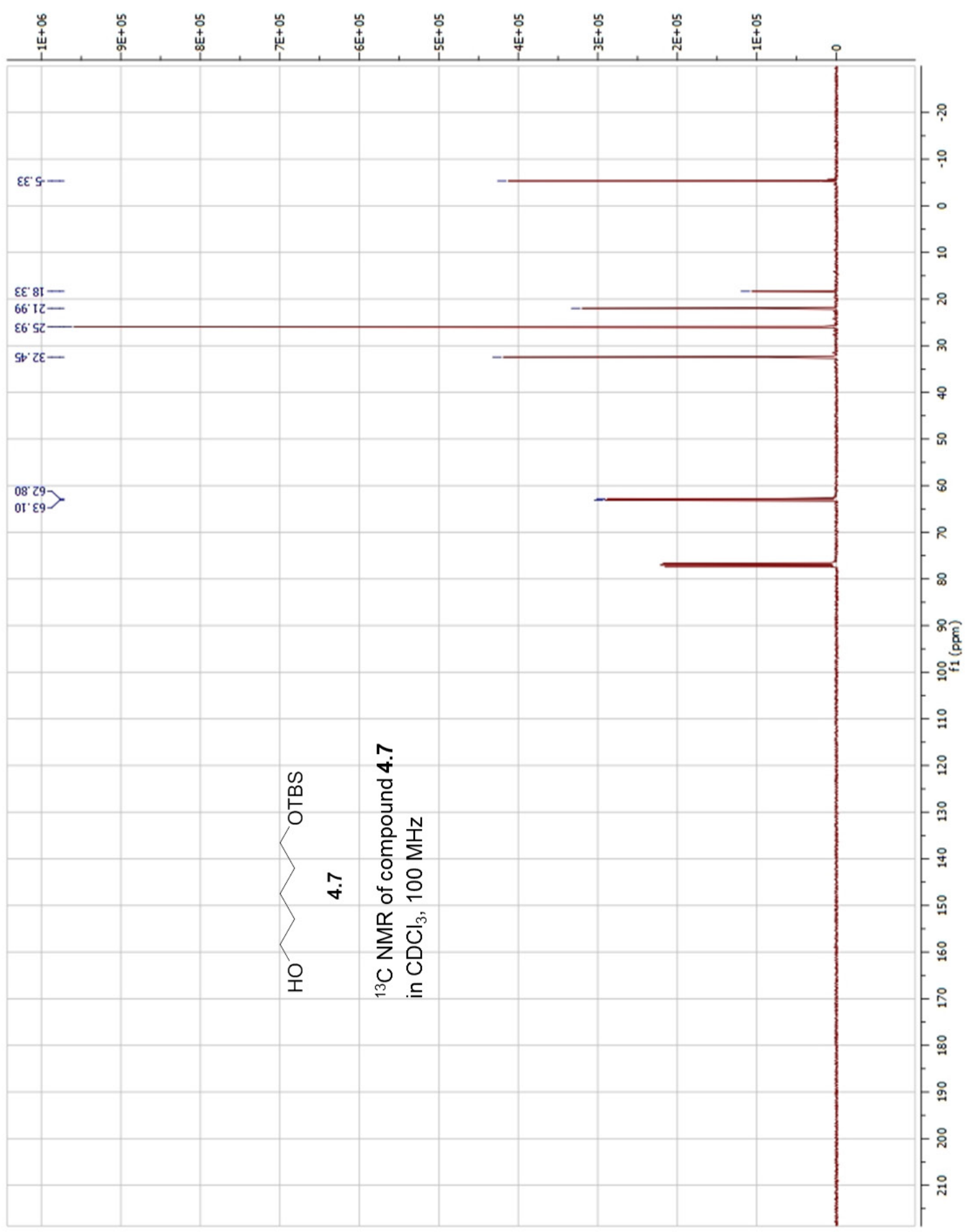

Figure A.4. ${ }^{13} \mathrm{C}$ NMR of compound 4.7 


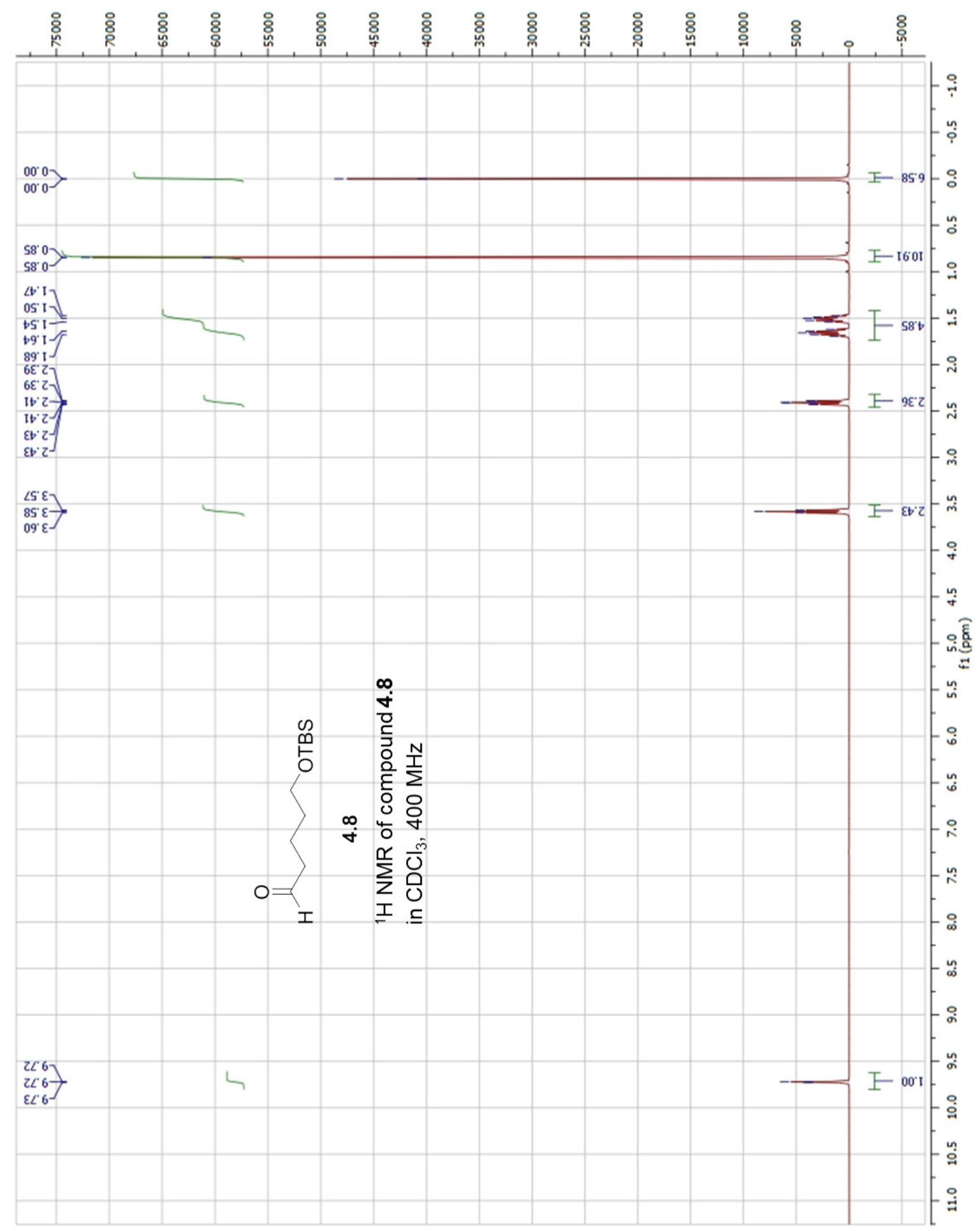

Figure A.5. ${ }^{1} \mathrm{H}$ NMR of compound 4.8 


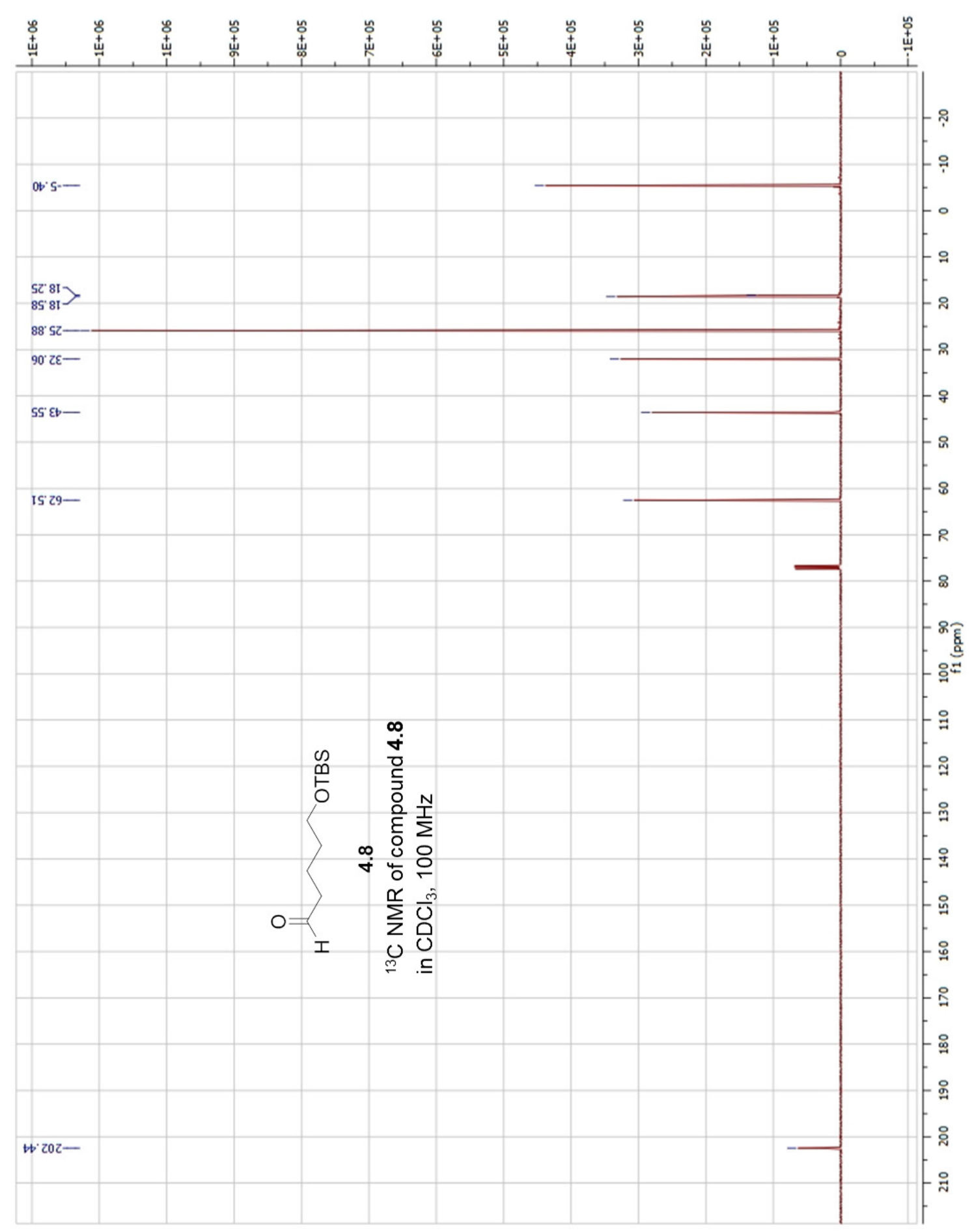

Figure A.6. ${ }^{13} \mathrm{C}$ NMR of compound 4.8 


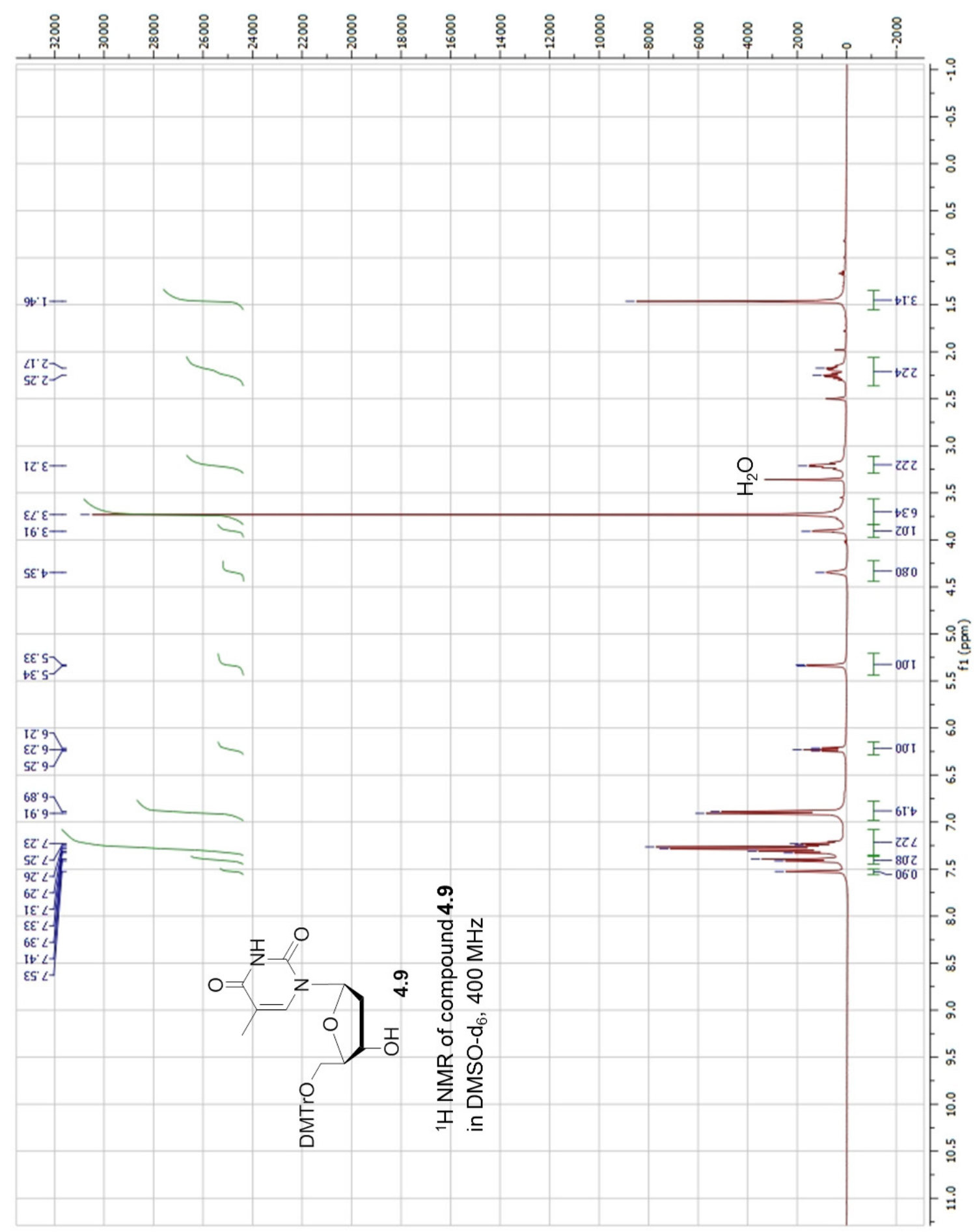

Figure A. 7. ${ }^{1} \mathrm{H}$ NMR of compound 4.9 


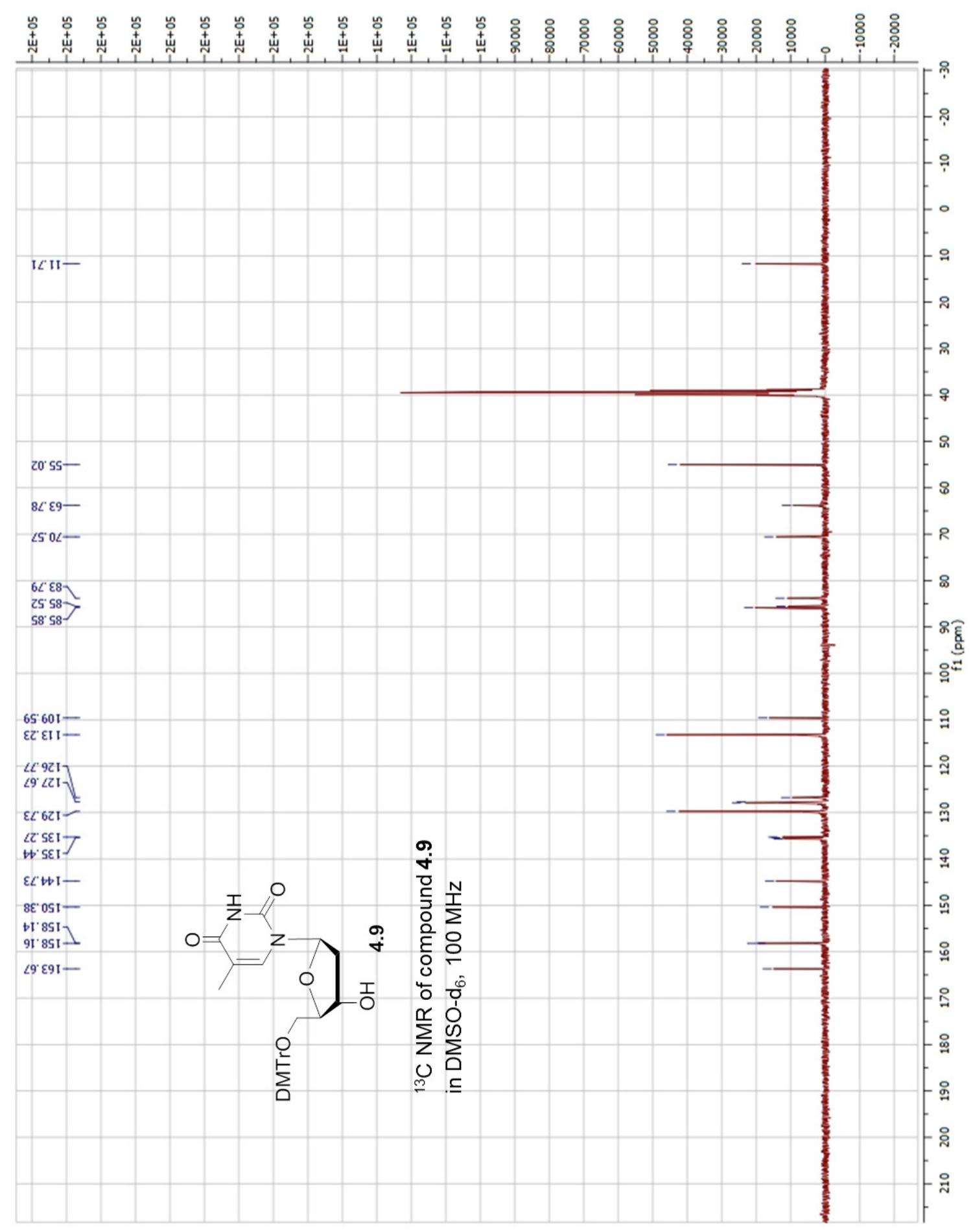

Figure A.8. ${ }^{13} \mathrm{C}$ NMR of compound 4.9 


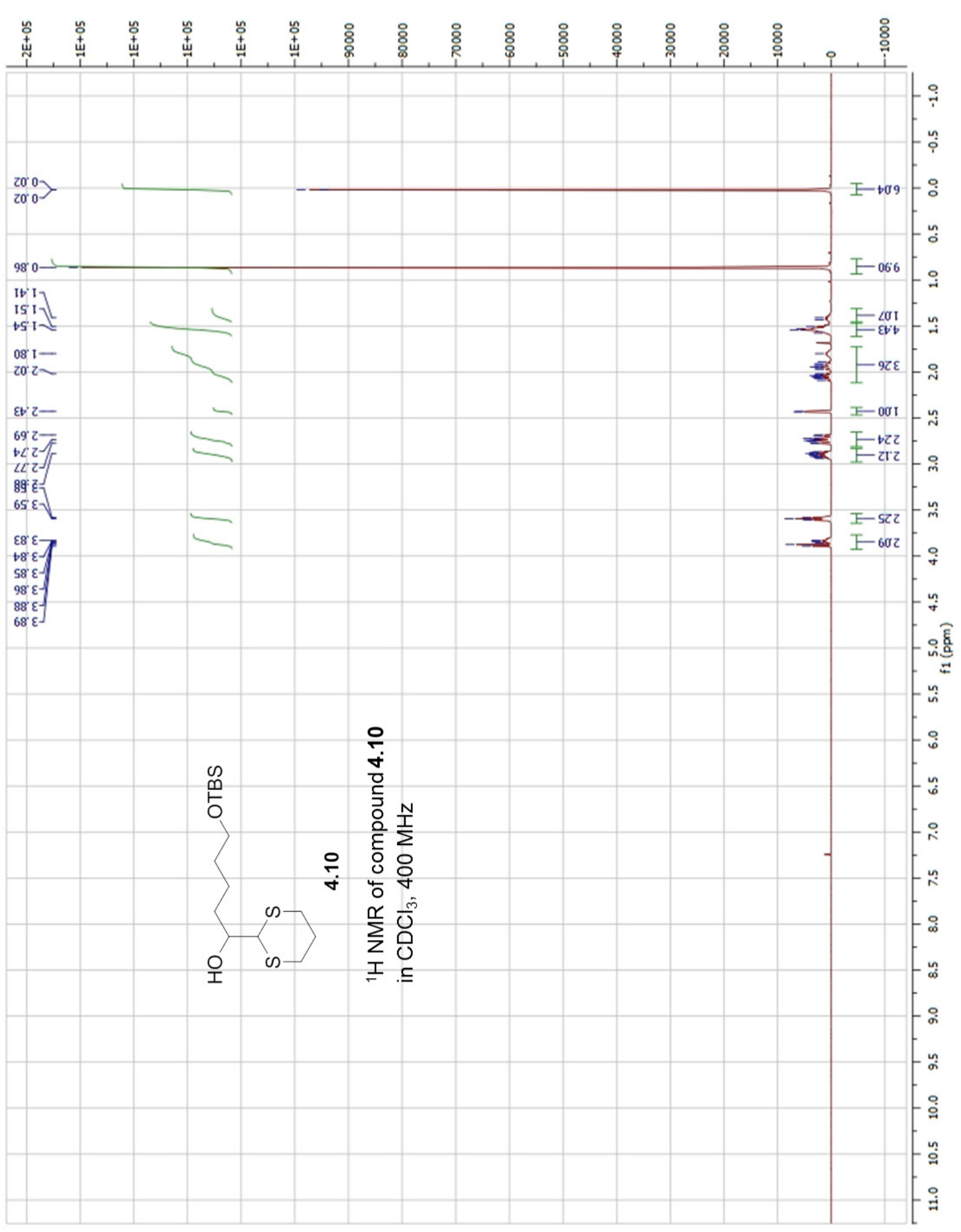

Figure A.9. ${ }^{1} \mathrm{H}$ NMR of compound 4.10 


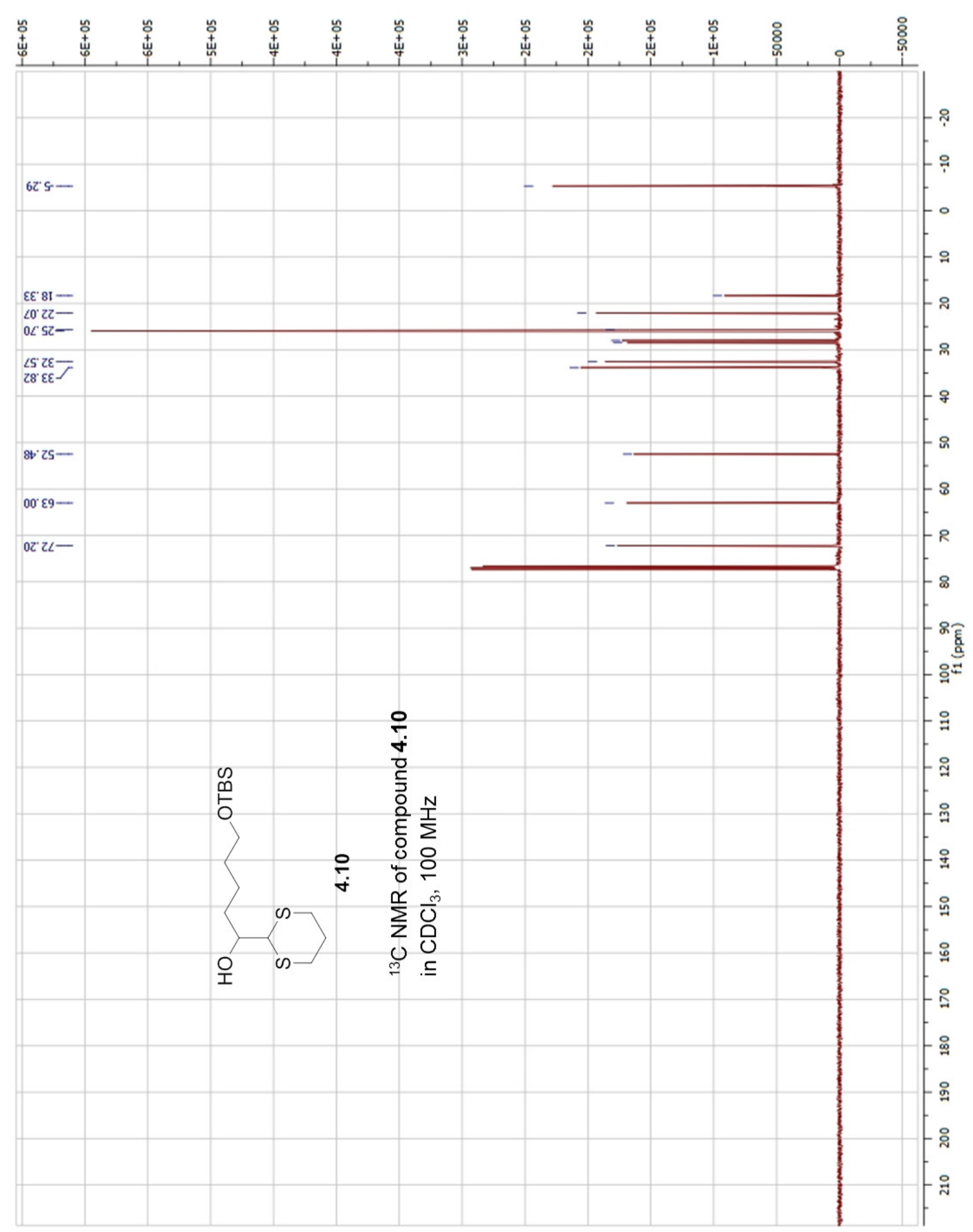

Figure A.10. ${ }^{13} \mathrm{C}$ NMR of compound 4.10 


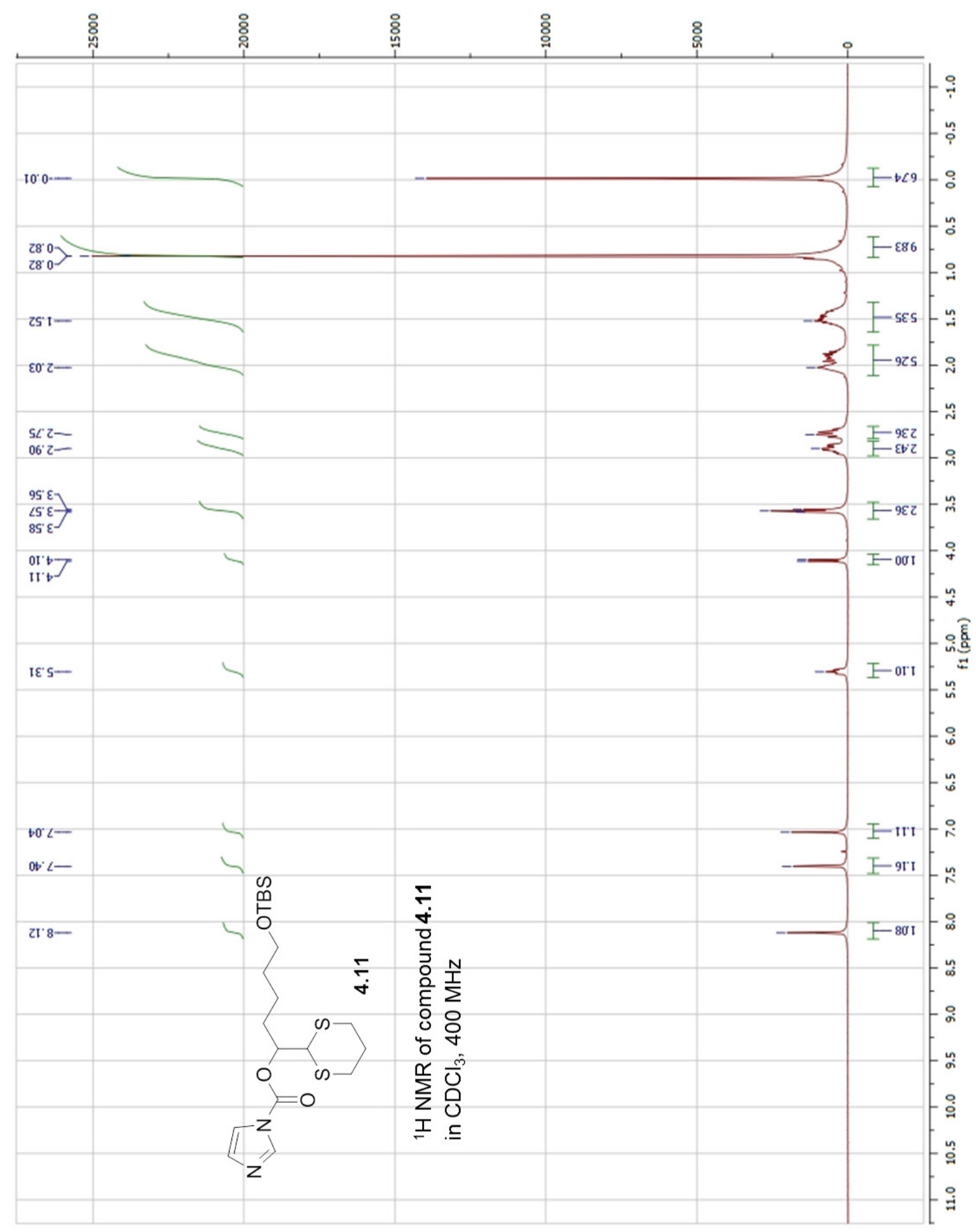

Figure A.11. ${ }^{1} \mathrm{H}$ NMR of compound 4.11 


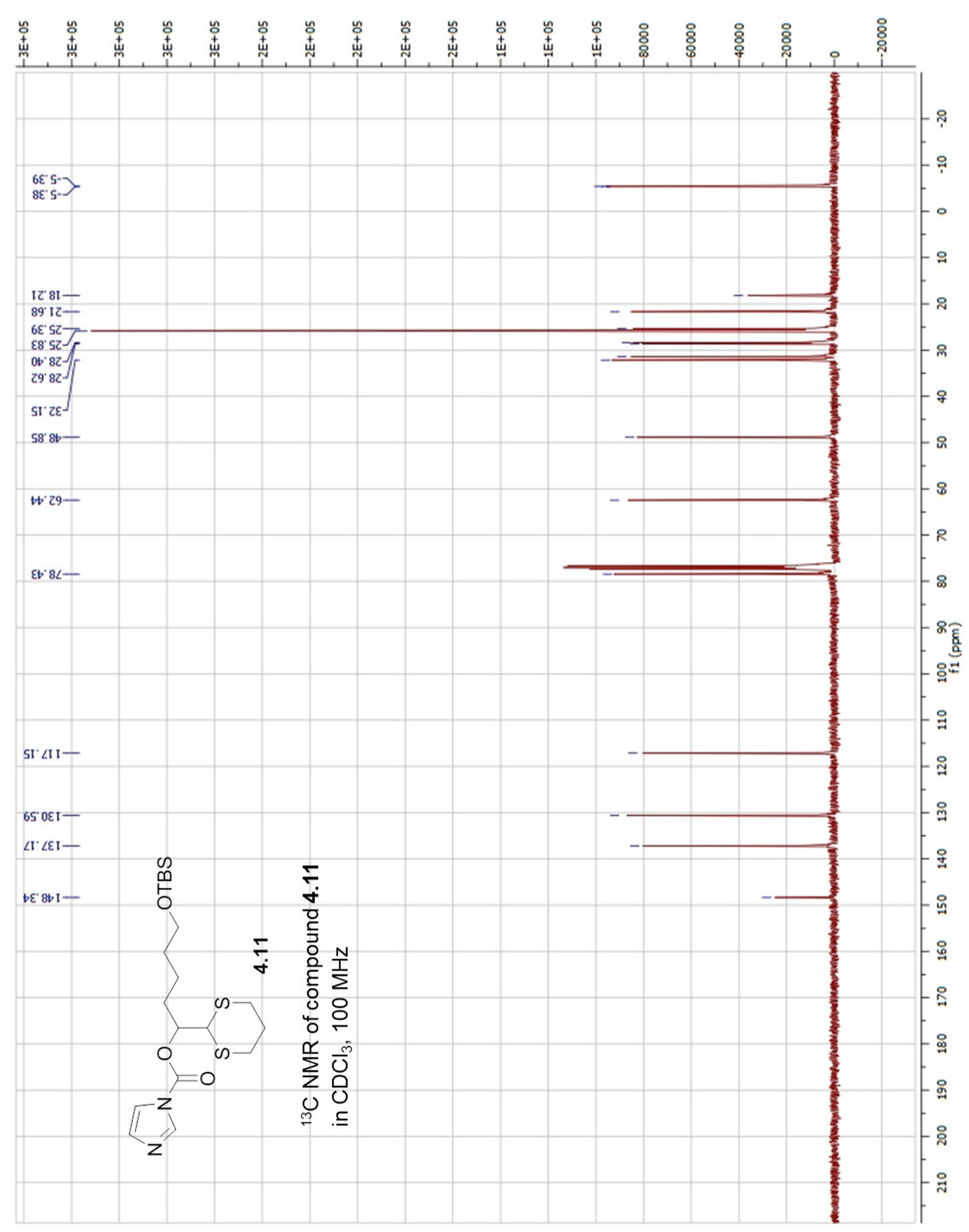

Figure $\boldsymbol{A} .12 .{ }^{13} \mathrm{C}$ NMR of compound 4.11 


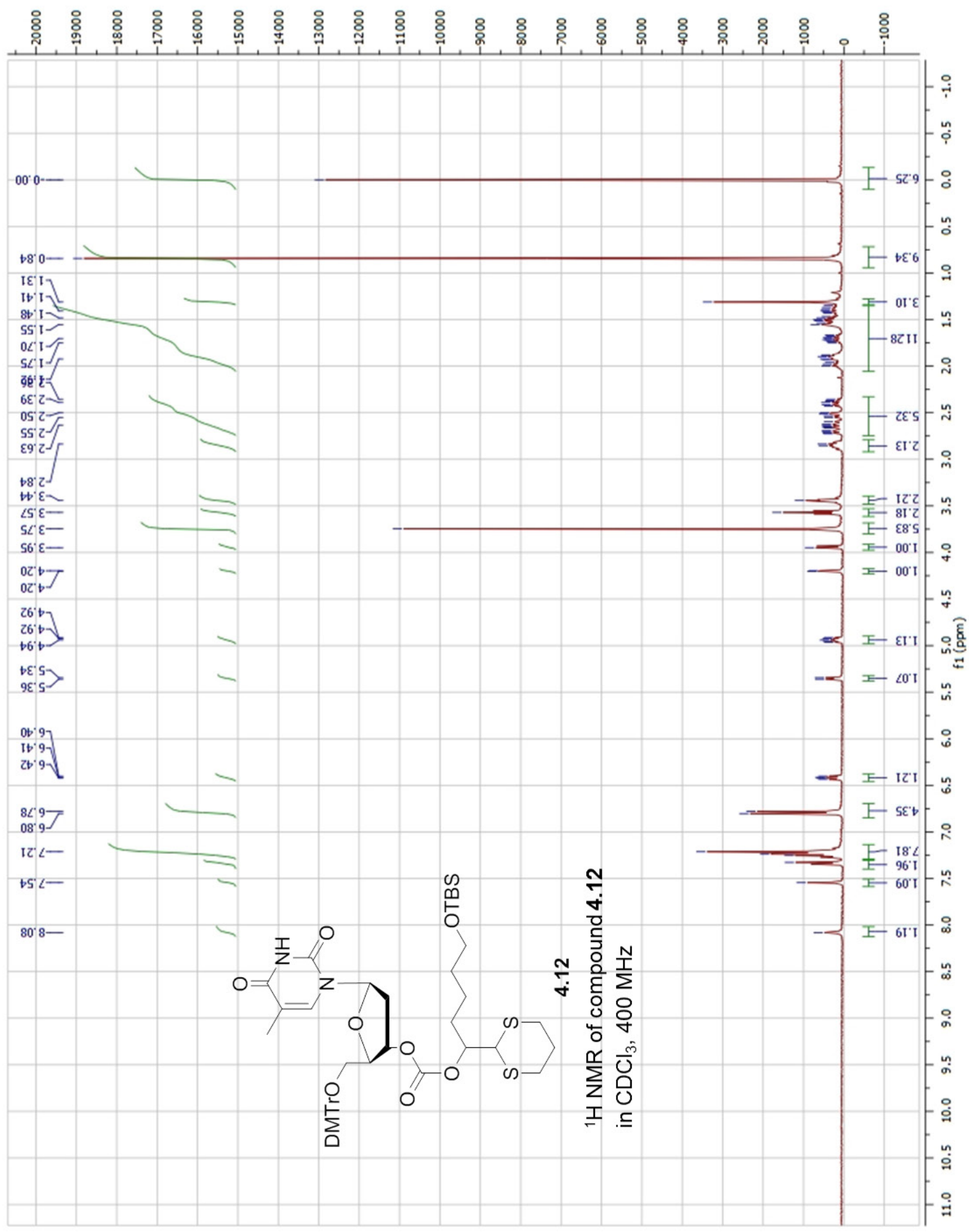

Figure A. 13. ${ }^{1} \mathrm{H}$ NMR of compound 4.12 


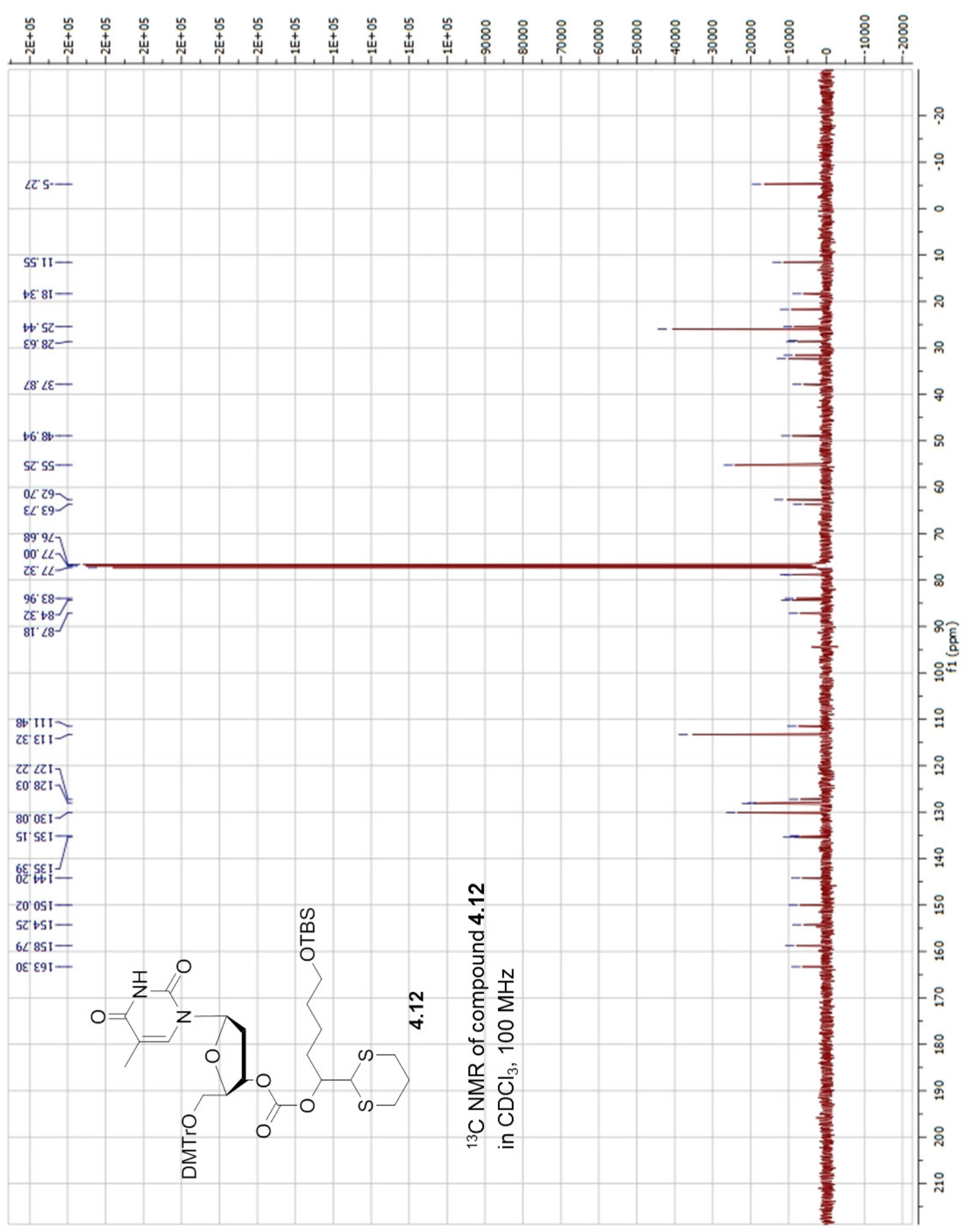

Figure A.14. ${ }^{13} \mathrm{C}$ NMR of compound 4.12 


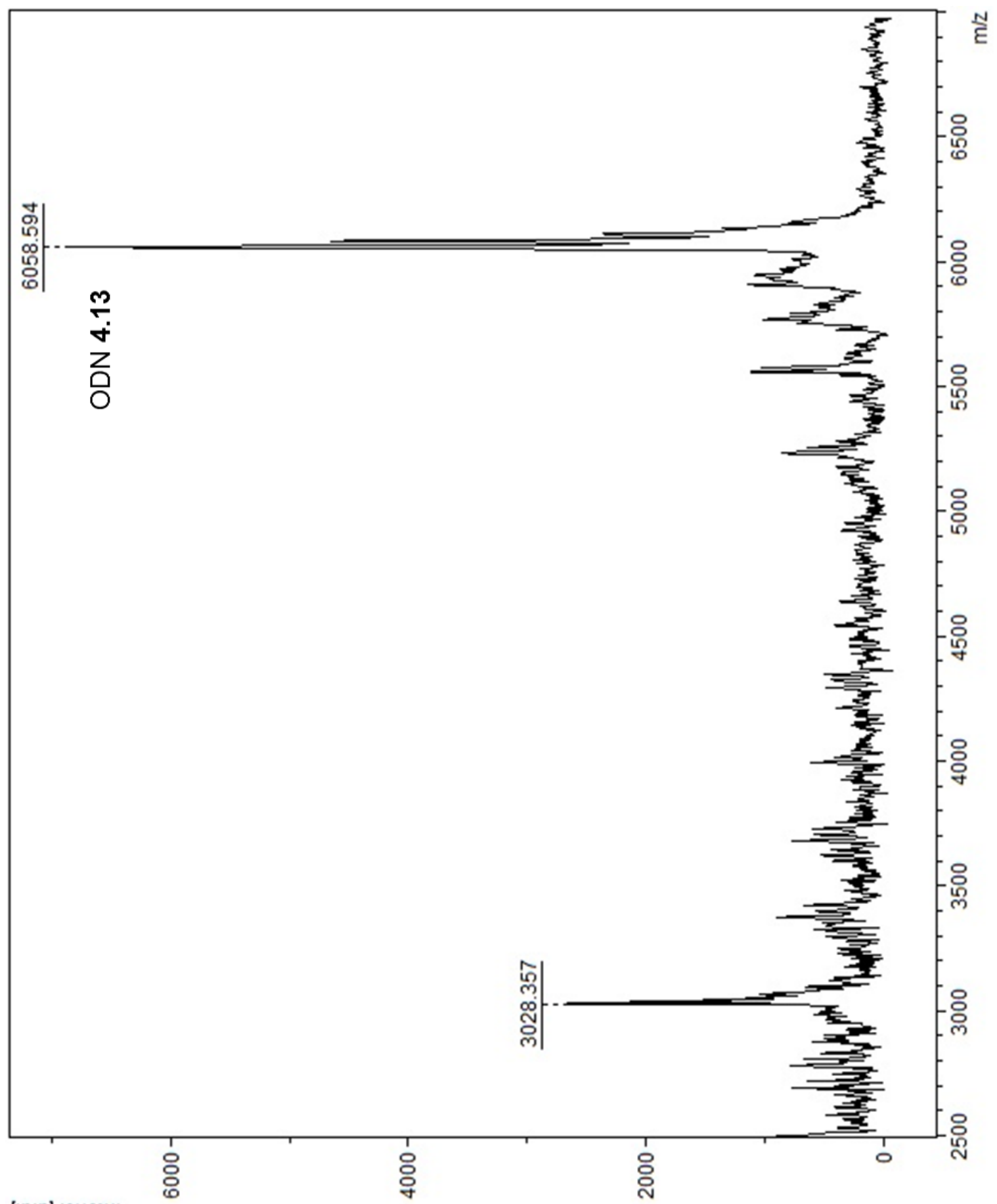

[n'e] 'suə̨u|

Figure A.15. MALDI-TOF spectrum of compound 4.13 


\section{Appendix B}

Supporting Information for Chapter 5

Synthesis of Dmoc-protected Phosphoramidites and Evaluation of Their Applications in ODN Synthesis 


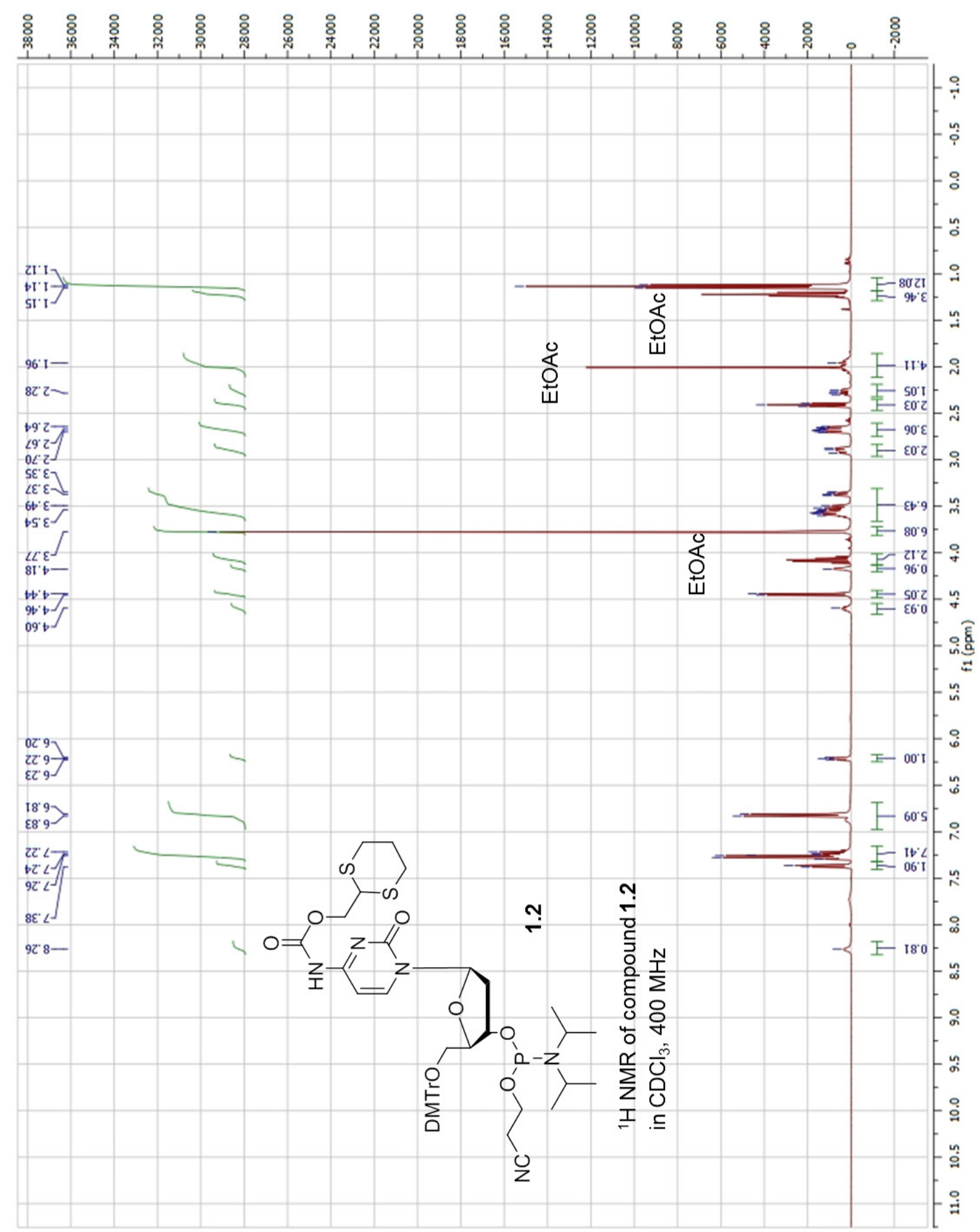

Figure B.1. ${ }^{1} \mathrm{H}$ NMR of compound $\mathbf{1 . 2}$ 


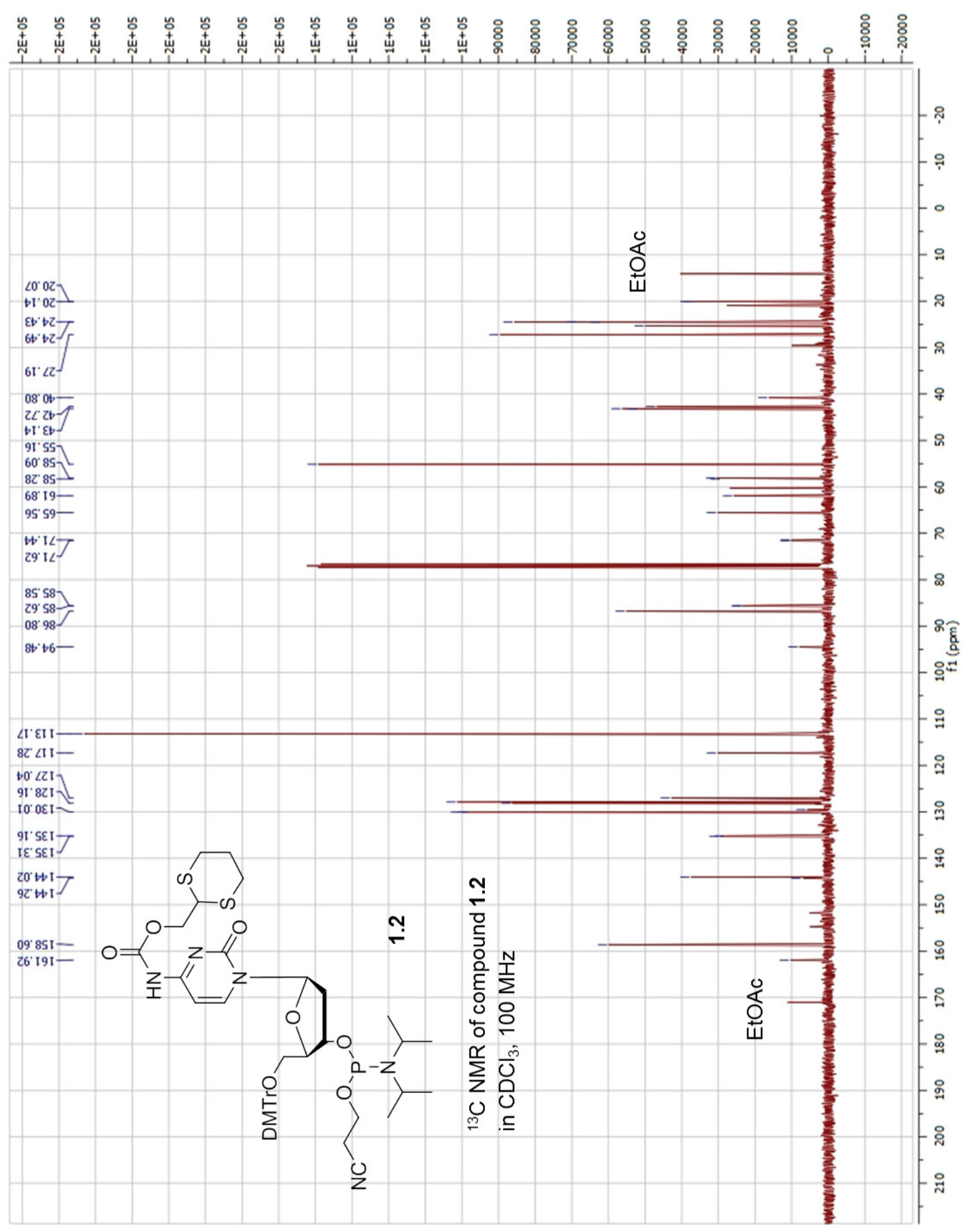

Figure B.2. ${ }^{13} \mathrm{C}$ NMR of compound 1.2 


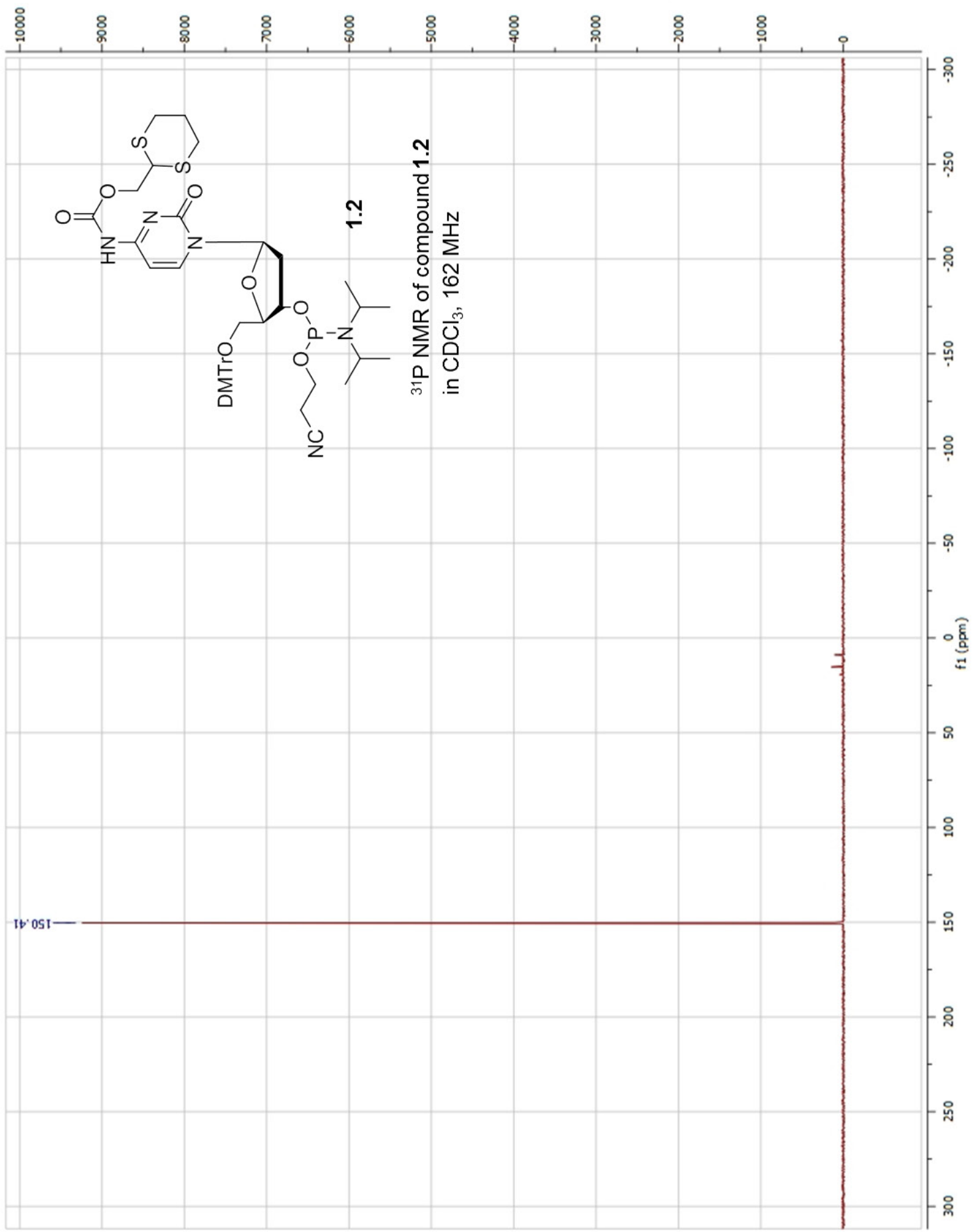

Figure B.3. ${ }^{31} \mathrm{P}$ NMR of compound $\mathbf{1 . 2}$ 


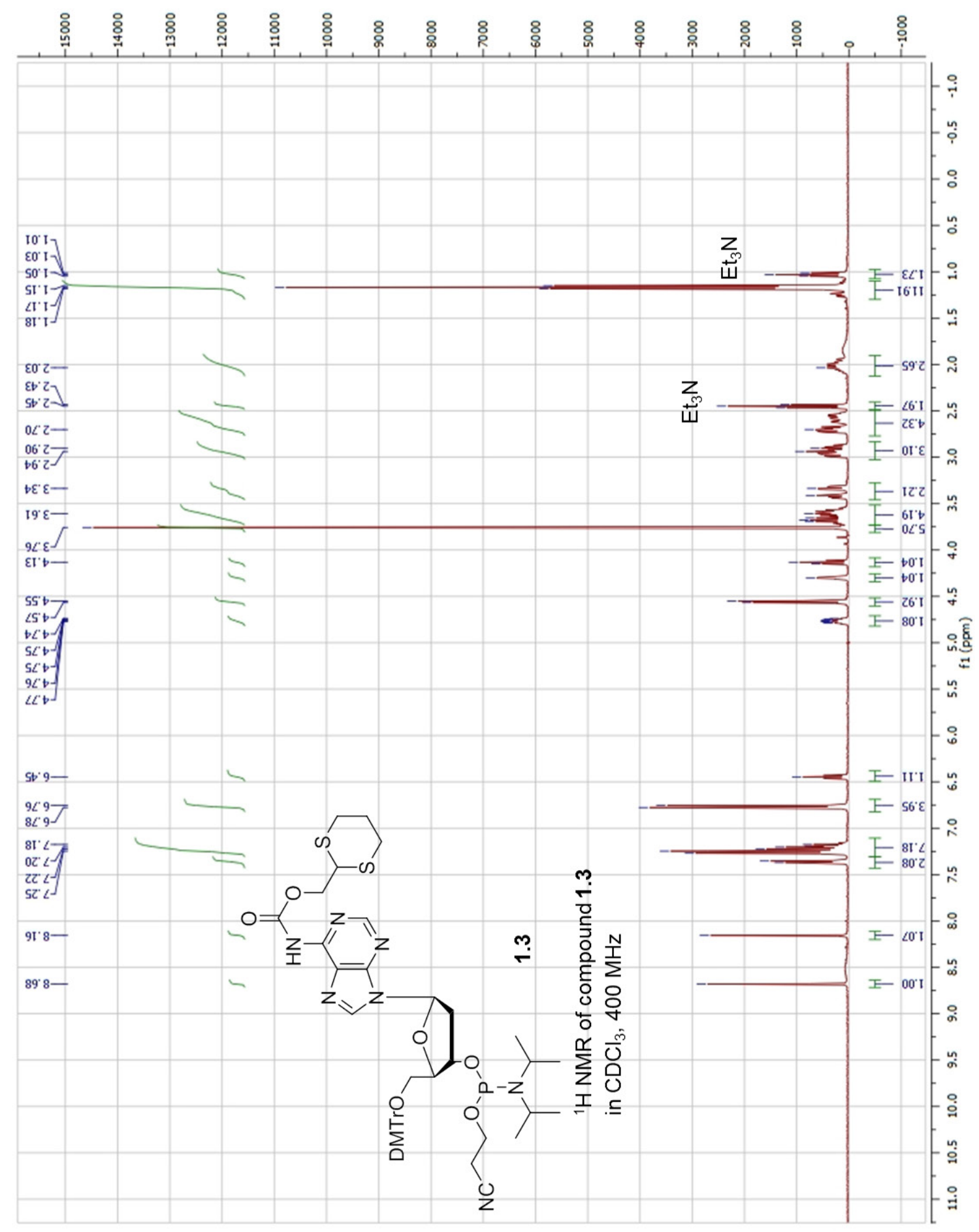

Figure B.4. ${ }^{1} \mathrm{H}$ NMR of compound 1.3 


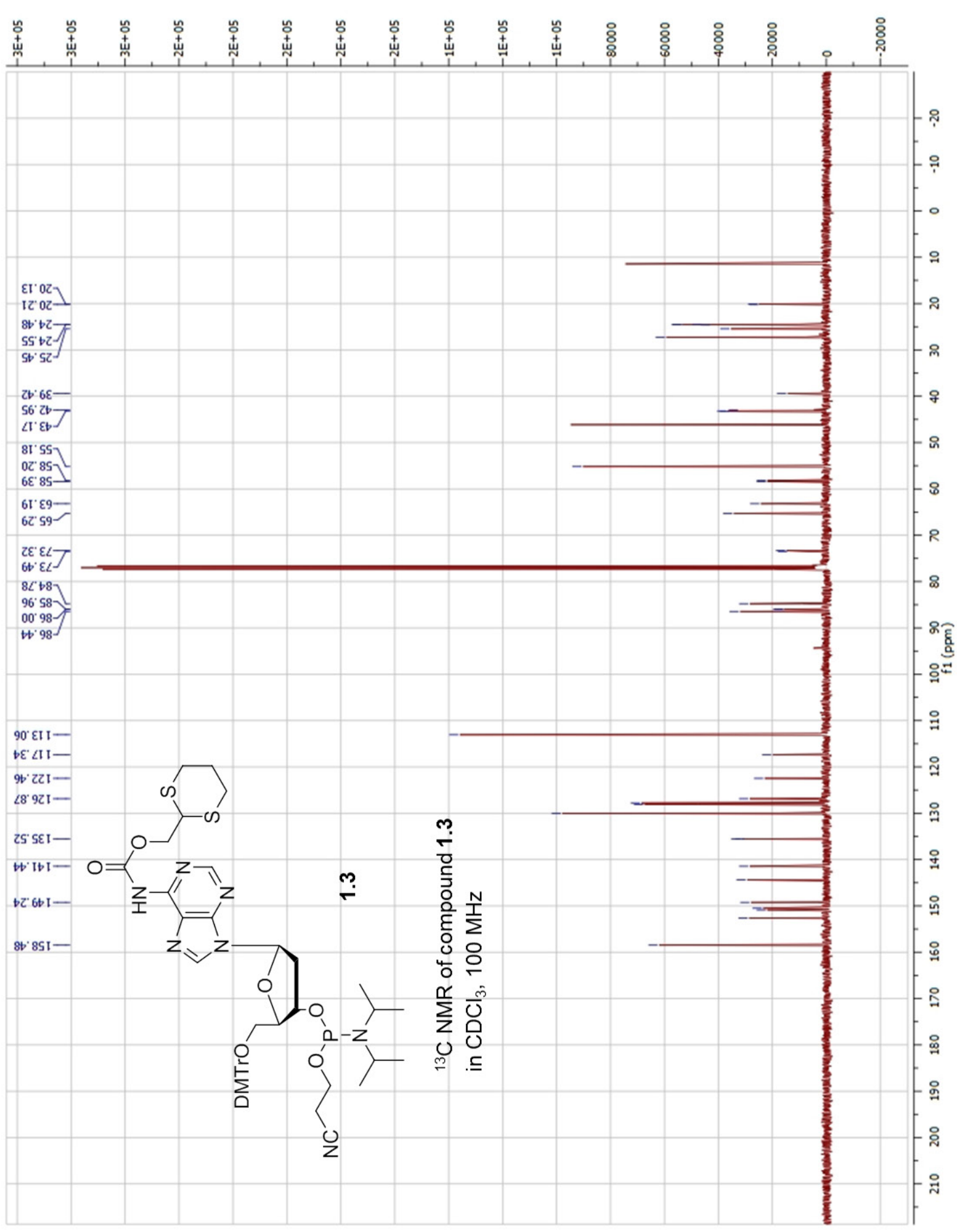

Figure B.5. ${ }^{13} \mathrm{C}$ NMR of compound 1.3 


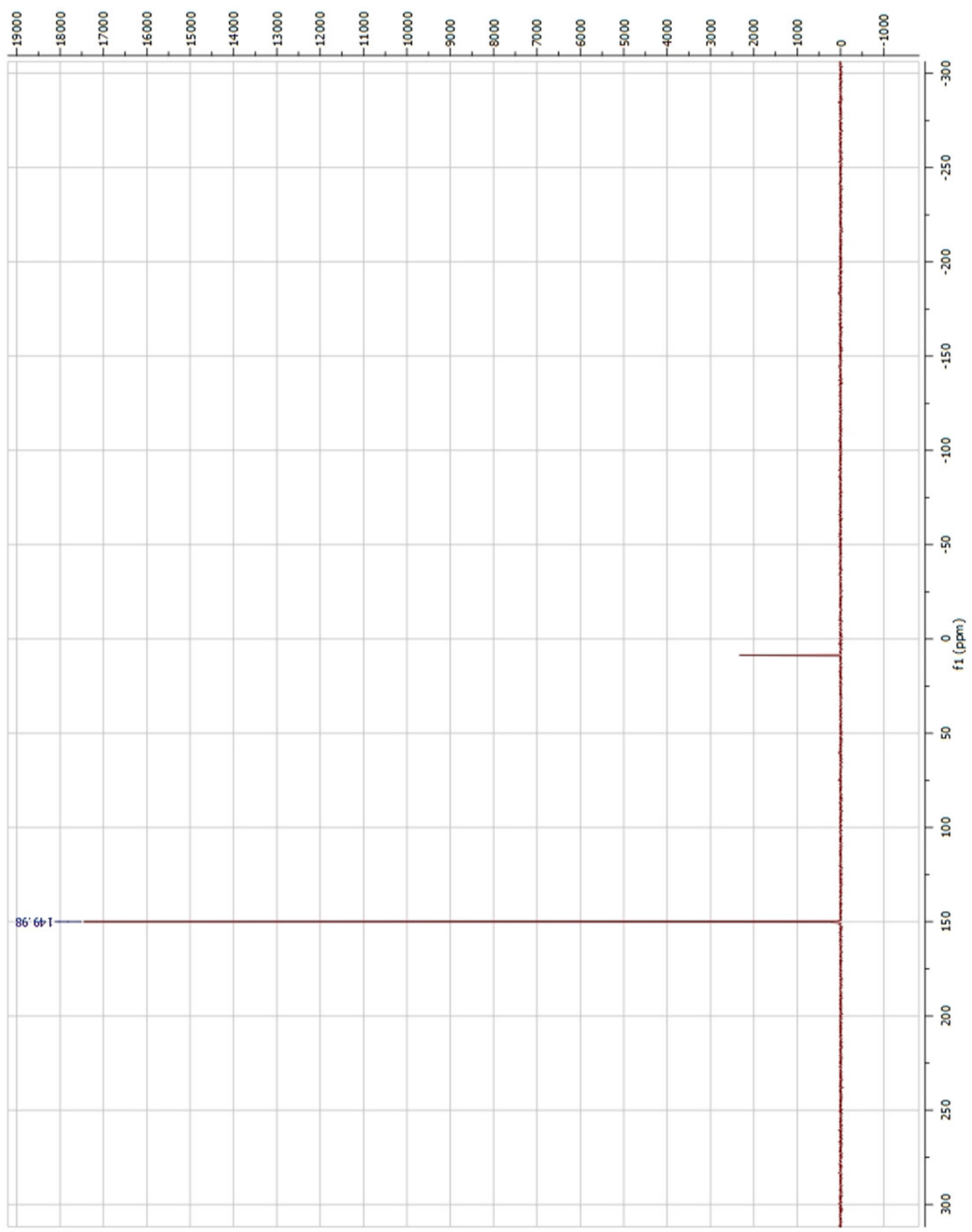

Figure B.6. ${ }^{31} \mathrm{P}$ NMR of compound 1.3 


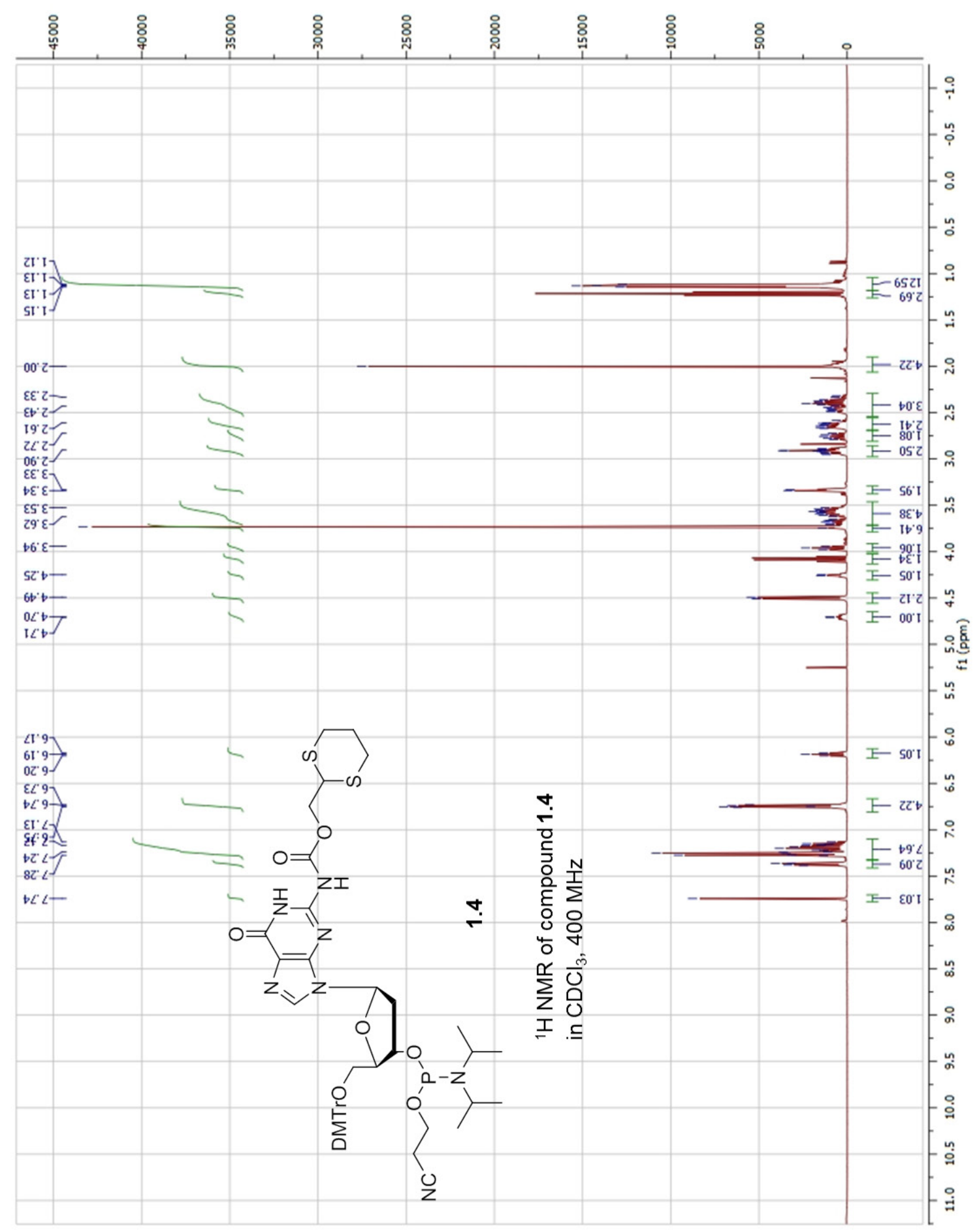

Figure B. 7. ${ }^{1} \mathrm{H}$ NMR of compound 1.4 


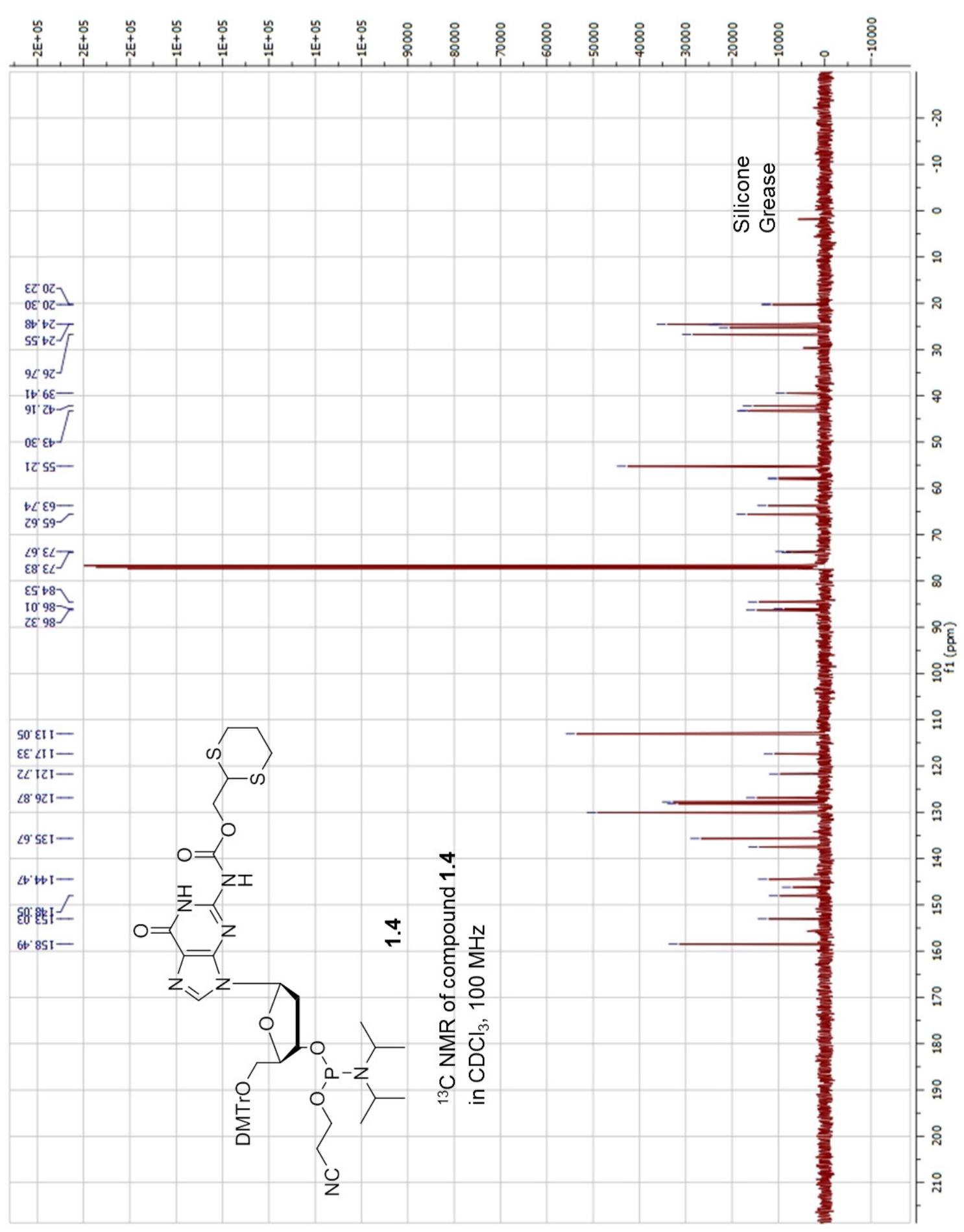

Figure B.8. ${ }^{13} \mathrm{C}$ NMR of compound 1.4 


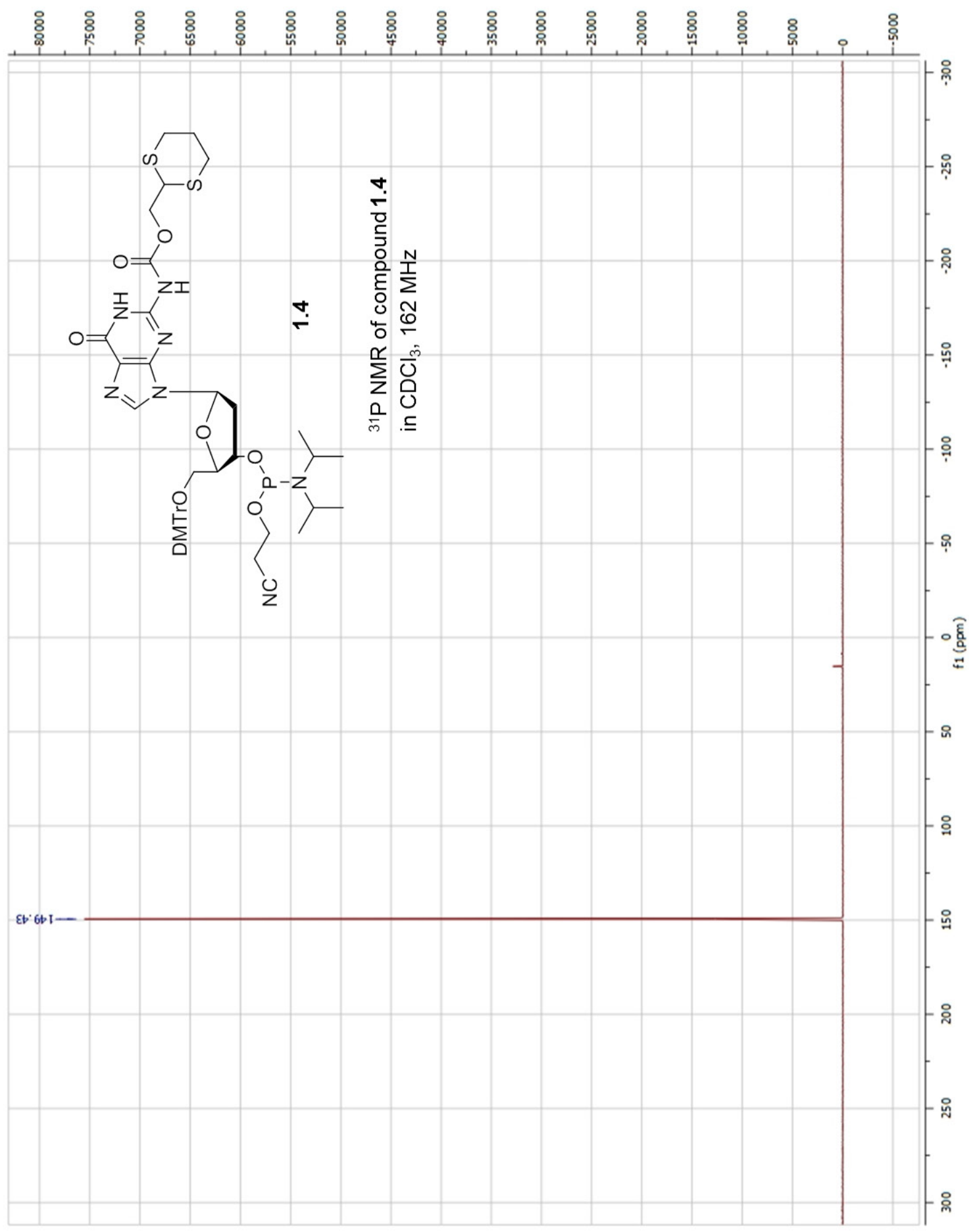

Figure B.9. ${ }^{31} \mathrm{P}$ NMR of compound 1.4 


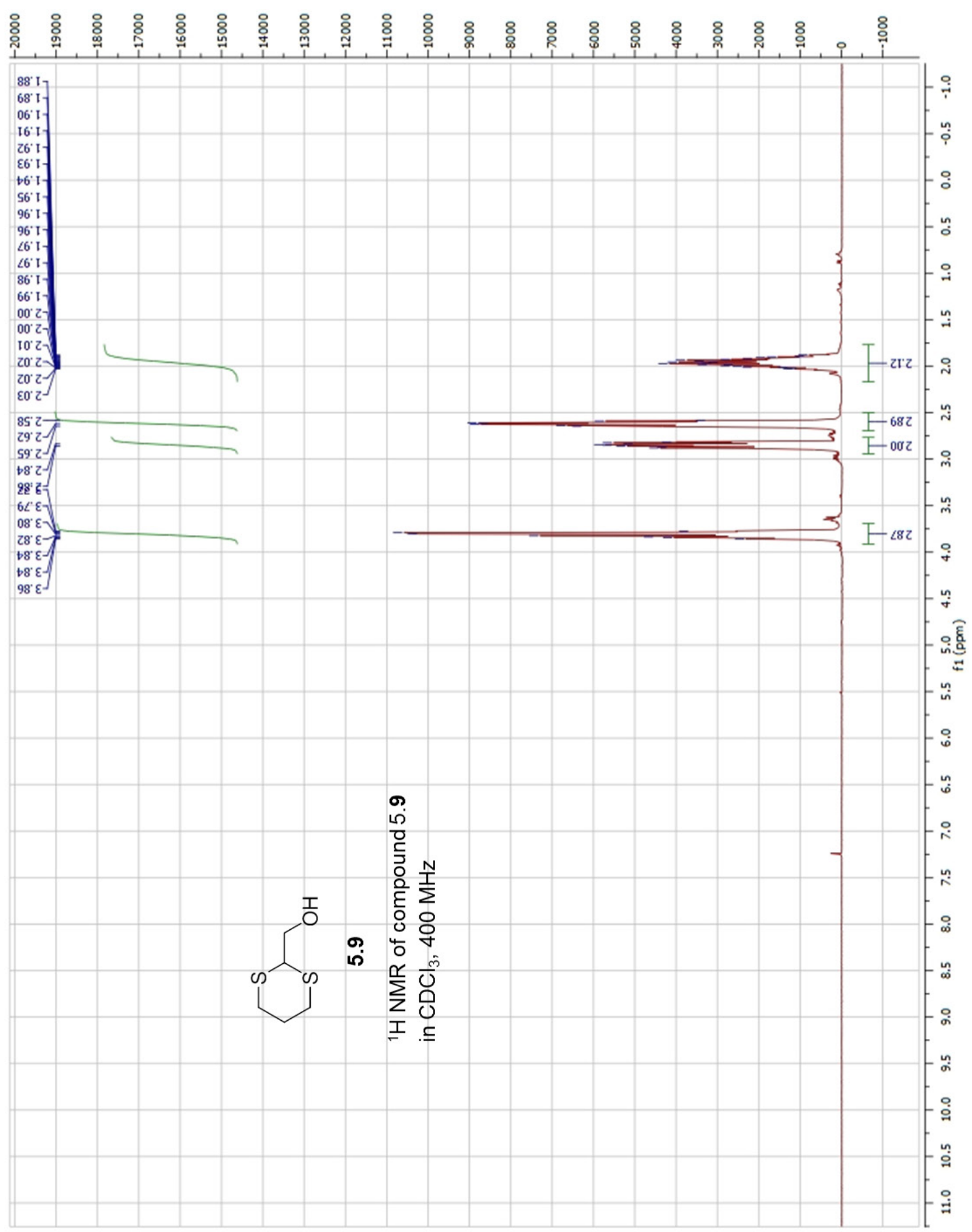

Figure B.10. ${ }^{1} \mathrm{H}$ NMR of compound 5.9 


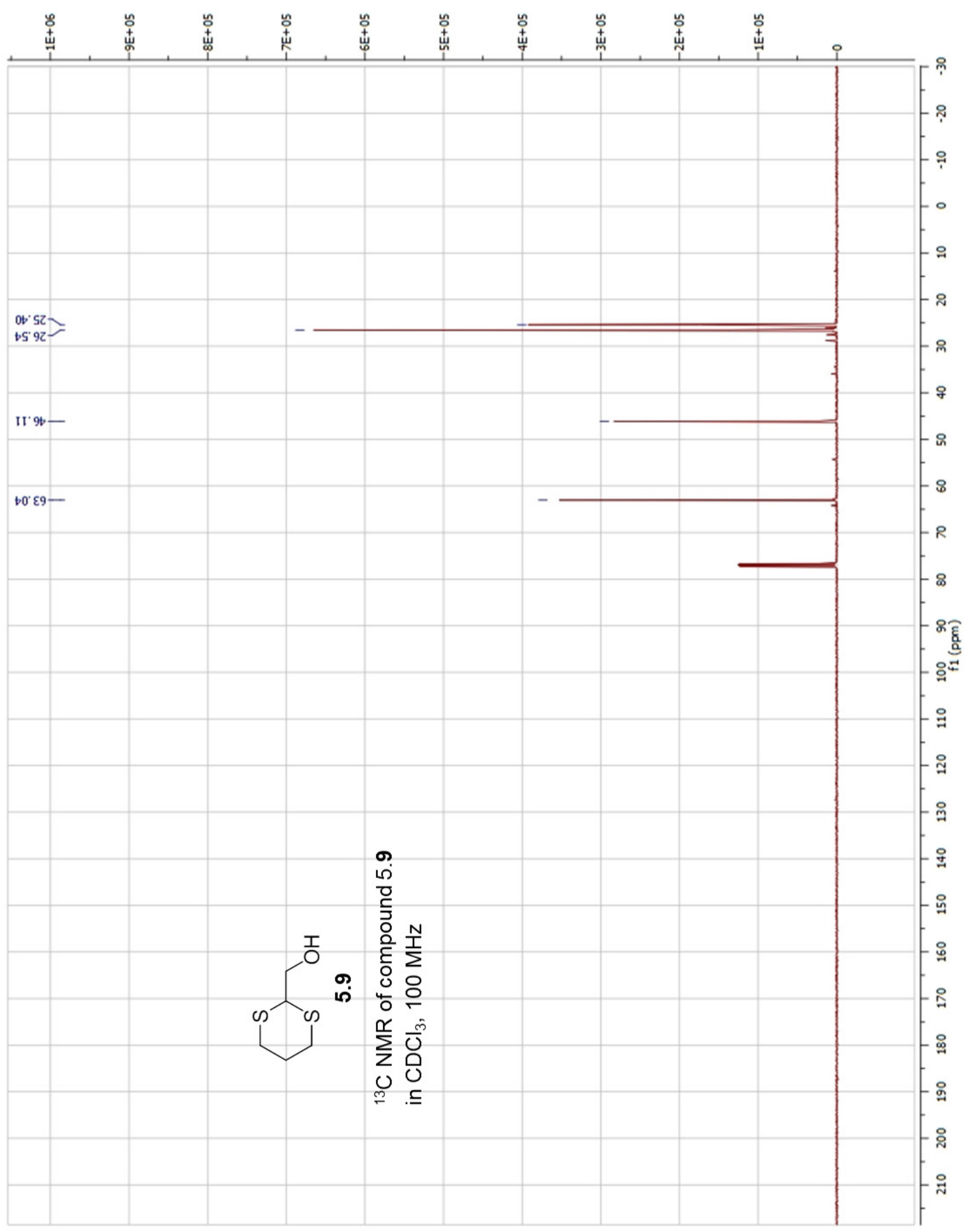

Figure B.11. ${ }^{13} \mathrm{C}$ NMR of compound 5.9 


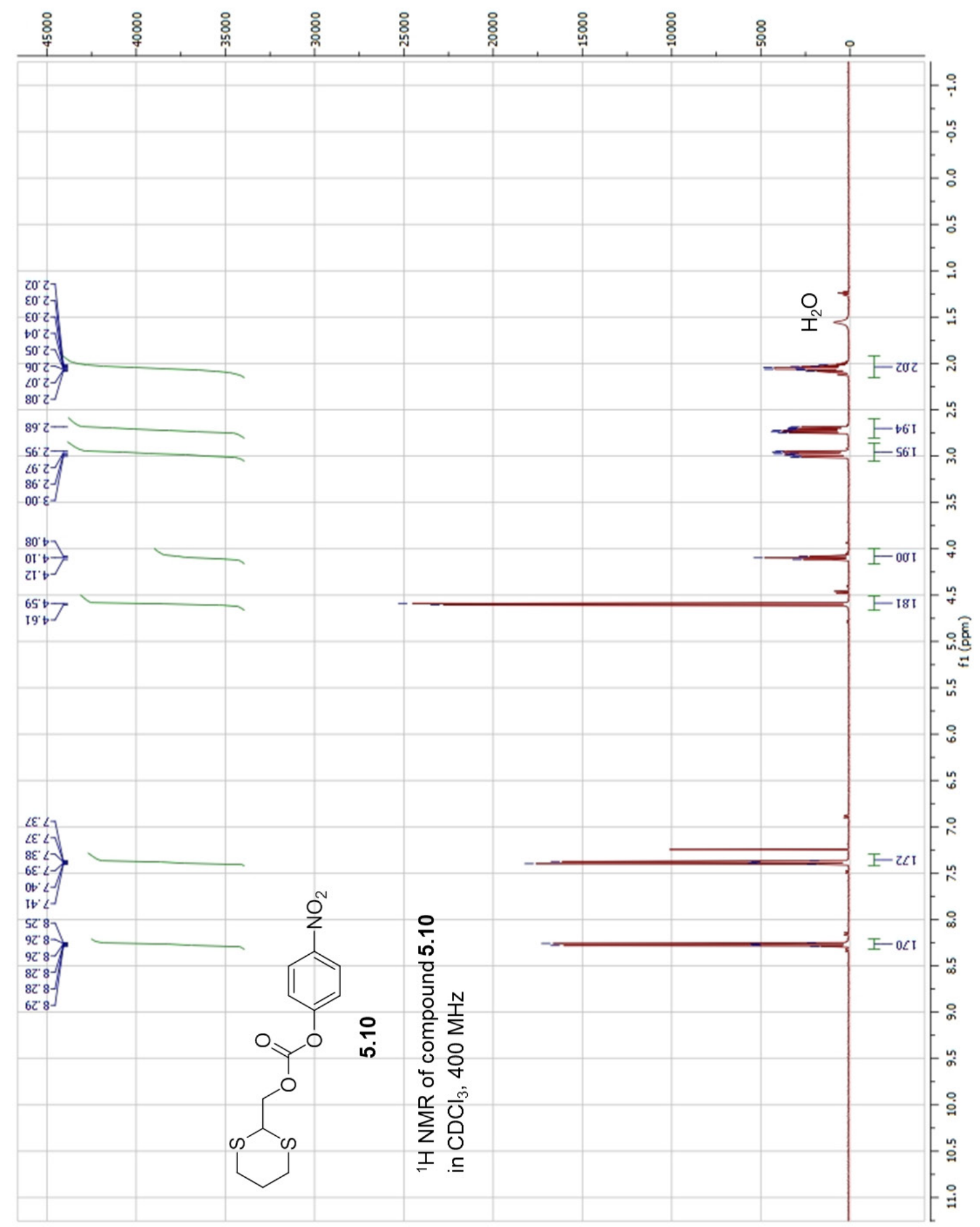

Figure B.12. ${ }^{1} \mathrm{H}$ NMR of compound $\mathbf{5 . 1 0}$ 


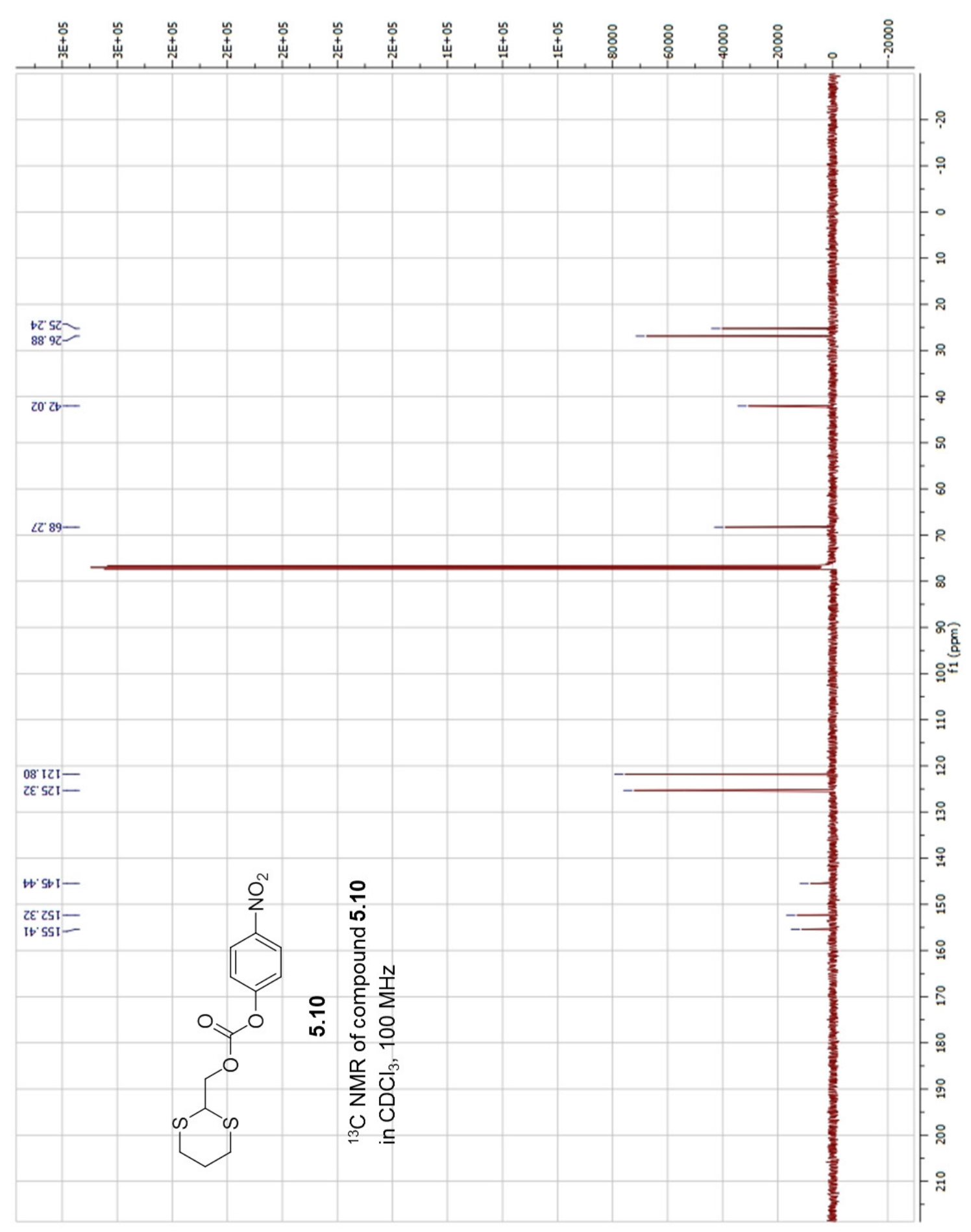

Figure B.13. ${ }^{13} \mathrm{C}$ NMR of compound 5.10 


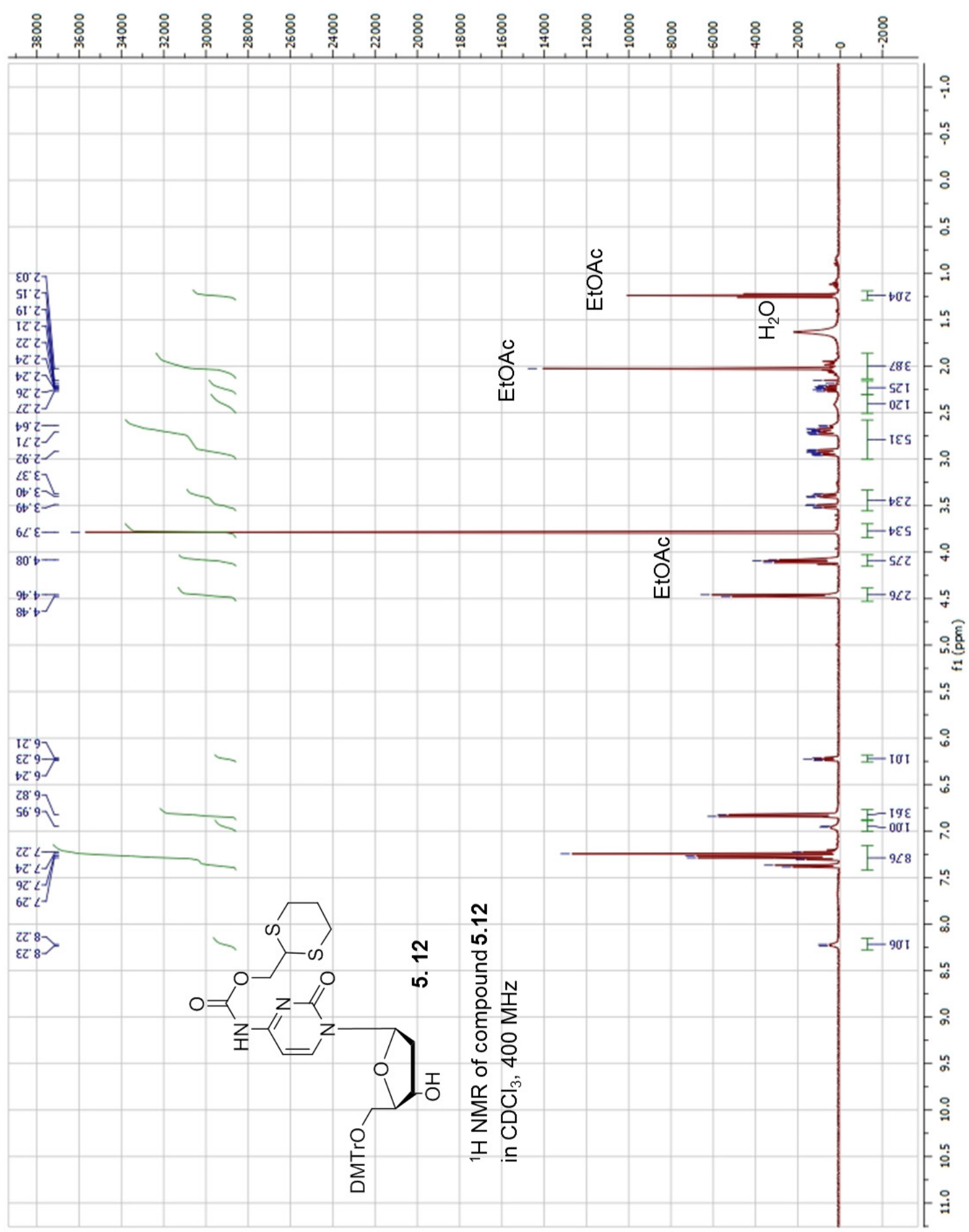

Figure B.14. ${ }^{1} \mathrm{H}$ NMR of compound 5.12 


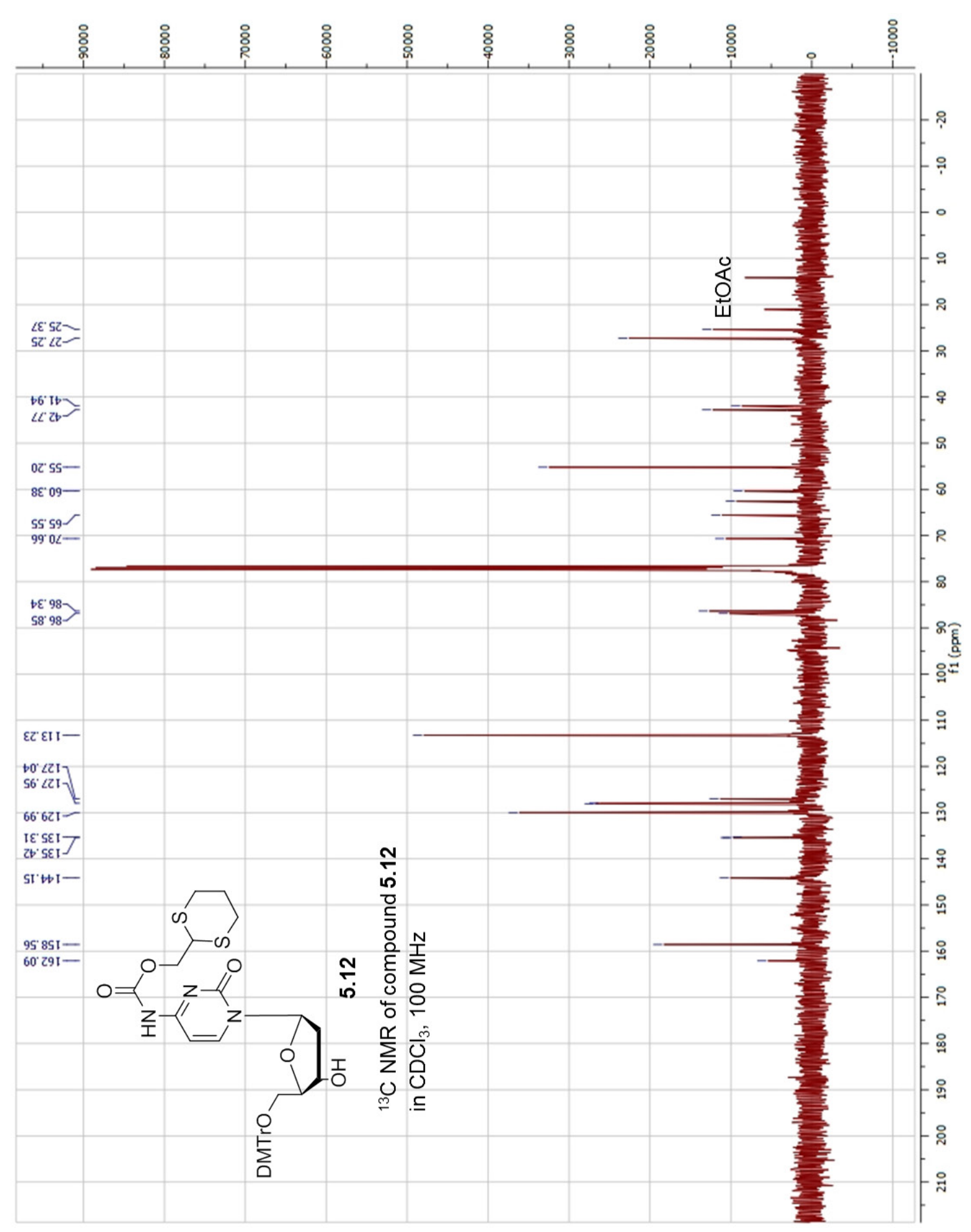

Figure B.15. ${ }^{13} \mathrm{C}$ NMR of compound 5.12 


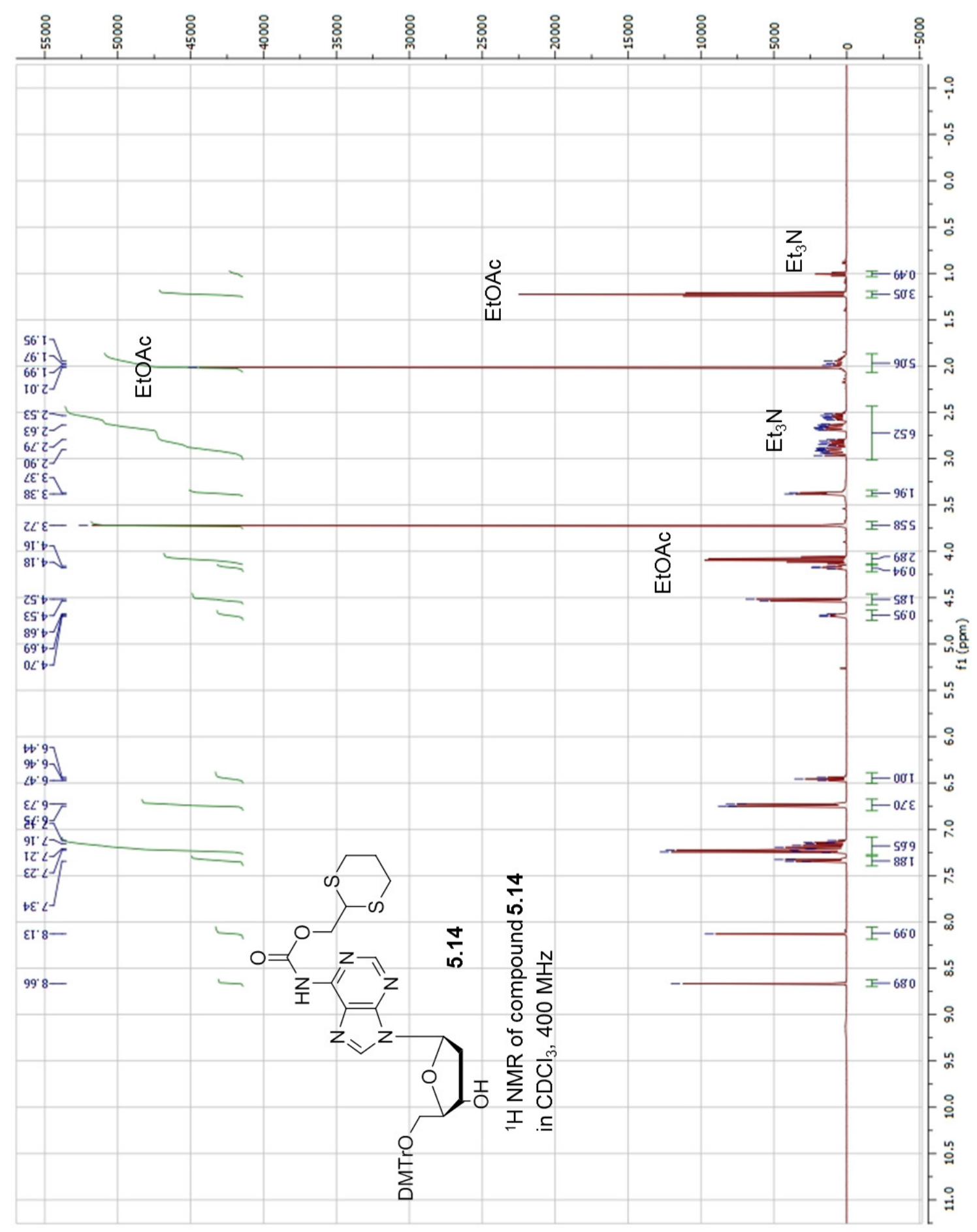

Figure B.16. ${ }^{1} \mathrm{H}$ NMR of compound 5.14 


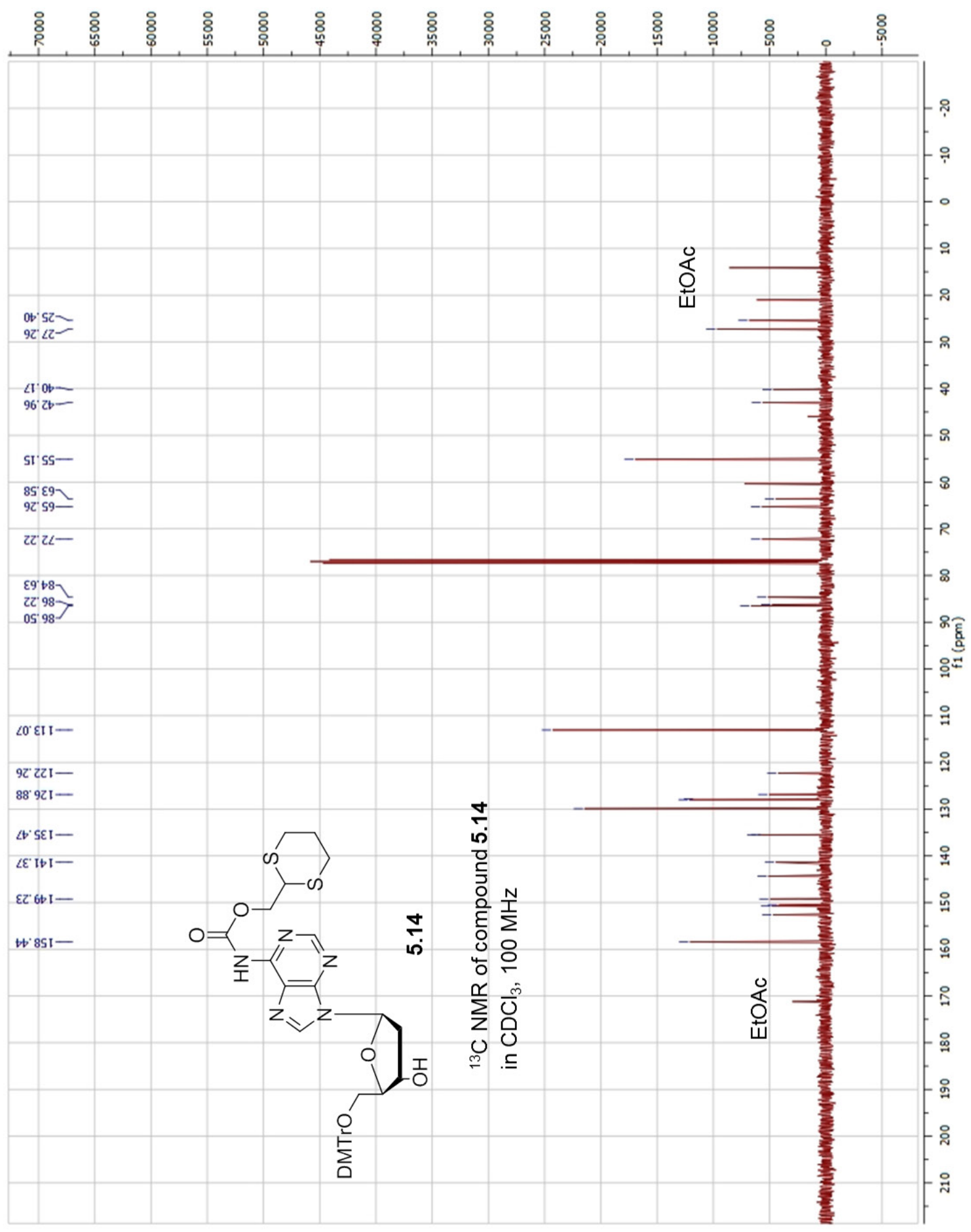

Figure B.17. ${ }^{13} \mathrm{C}$ NMR of compound $\mathbf{5 . 1 4}$ 


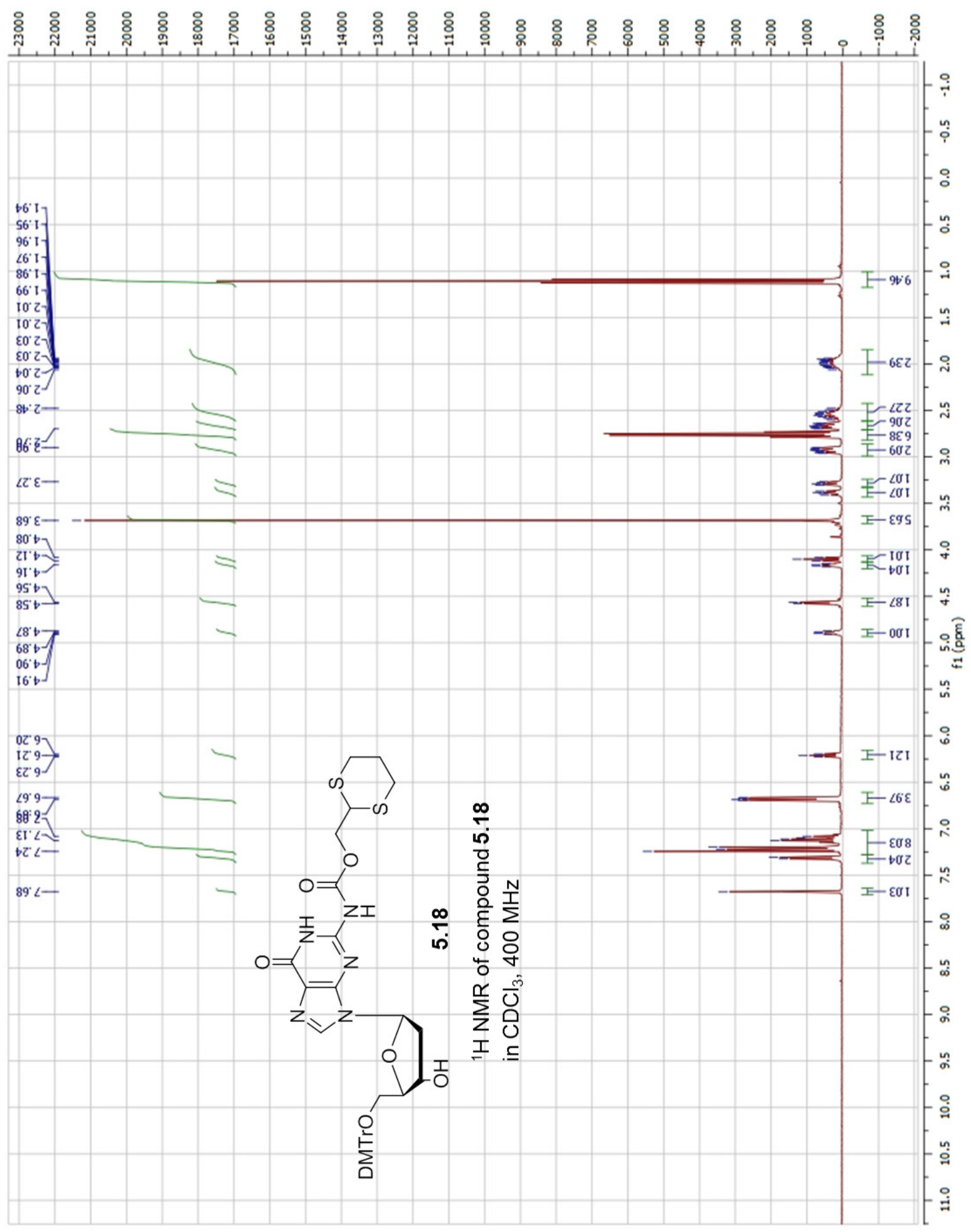

Figure B.18. ${ }^{1} \mathrm{H}$ NMR of compound 5.18 


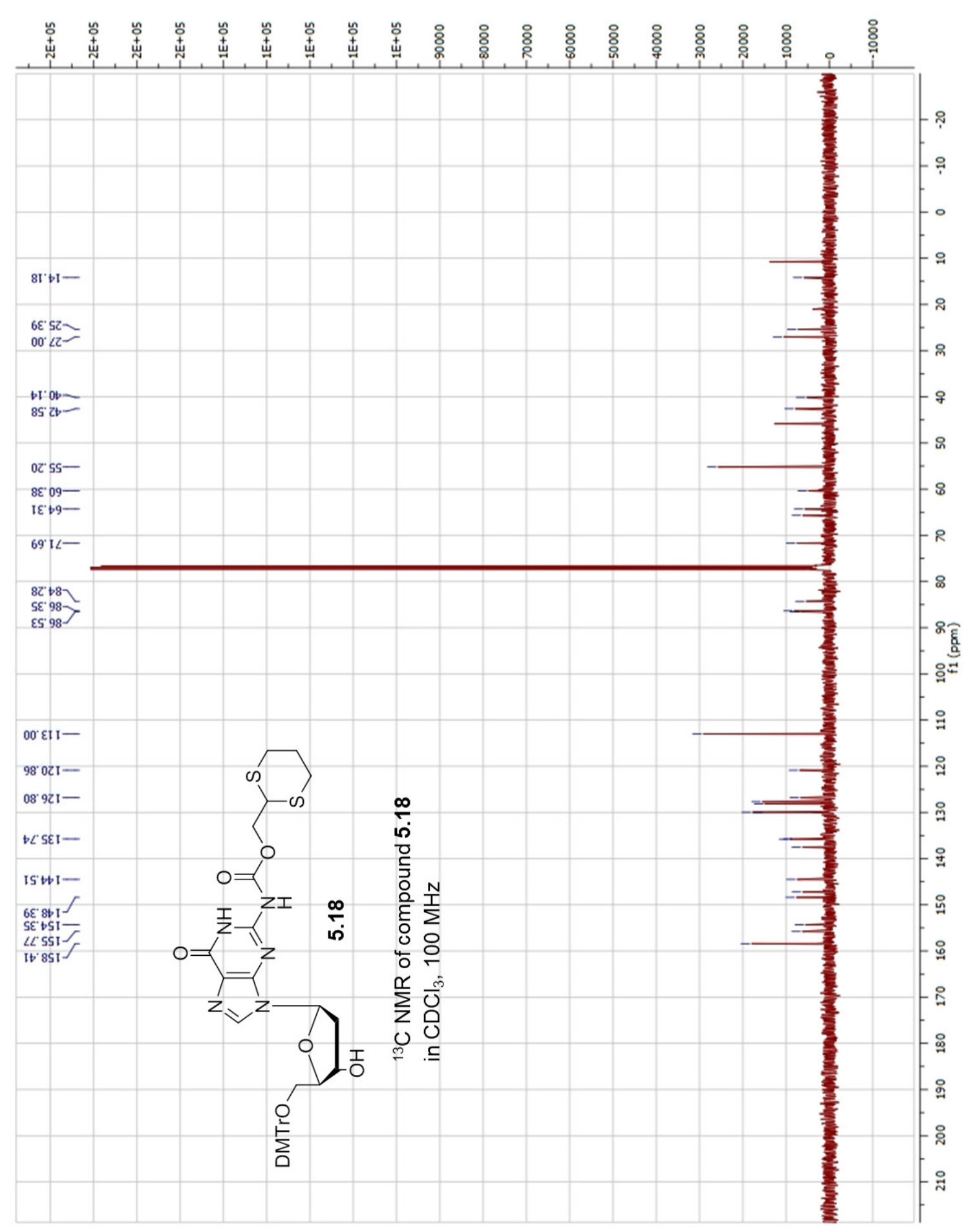

Figure B.19. ${ }^{13} \mathrm{C}$ NMR of compound 5.18 


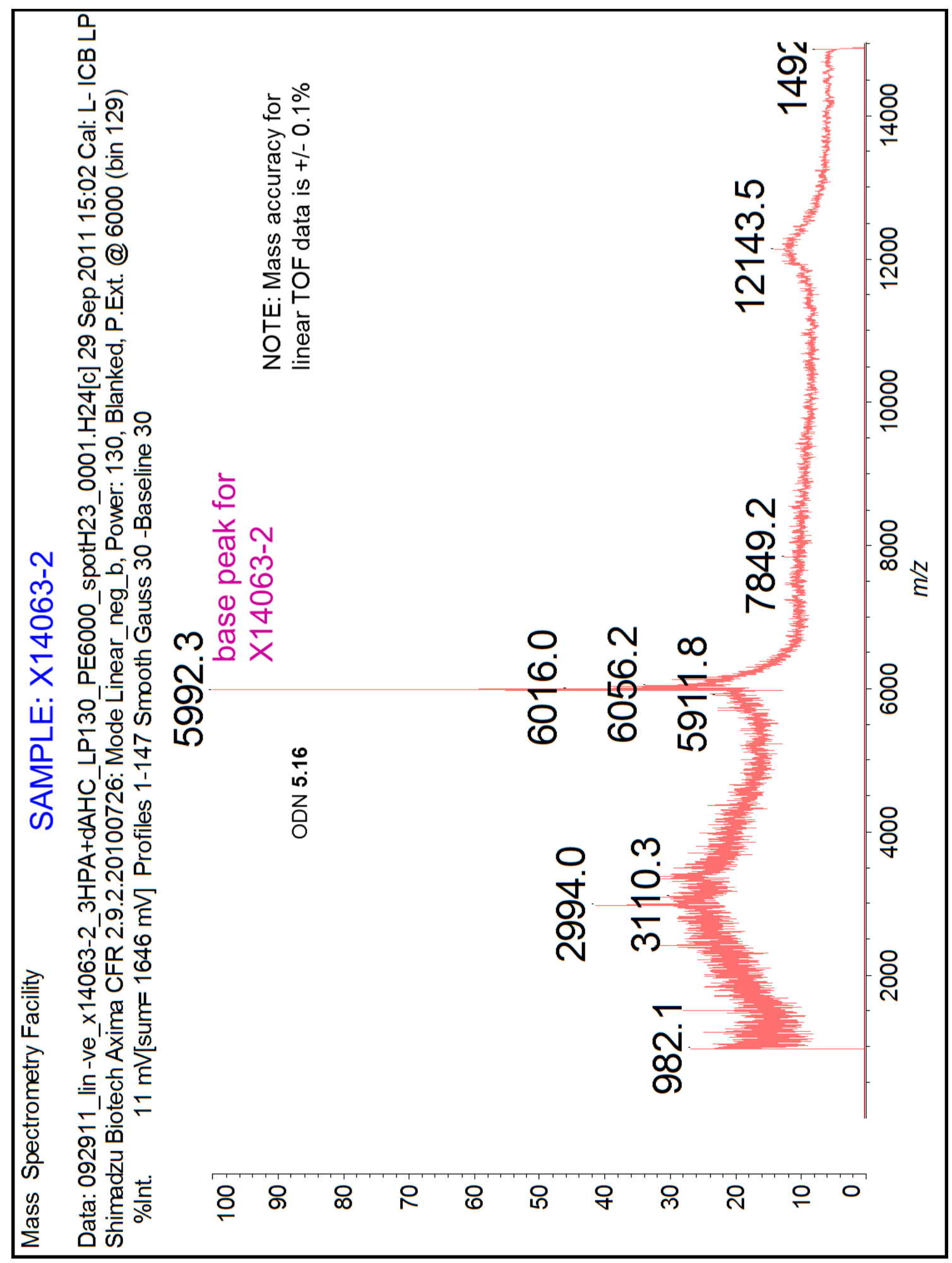

Figure B.20. MALDI-TOF spectrum of compound 5.16 


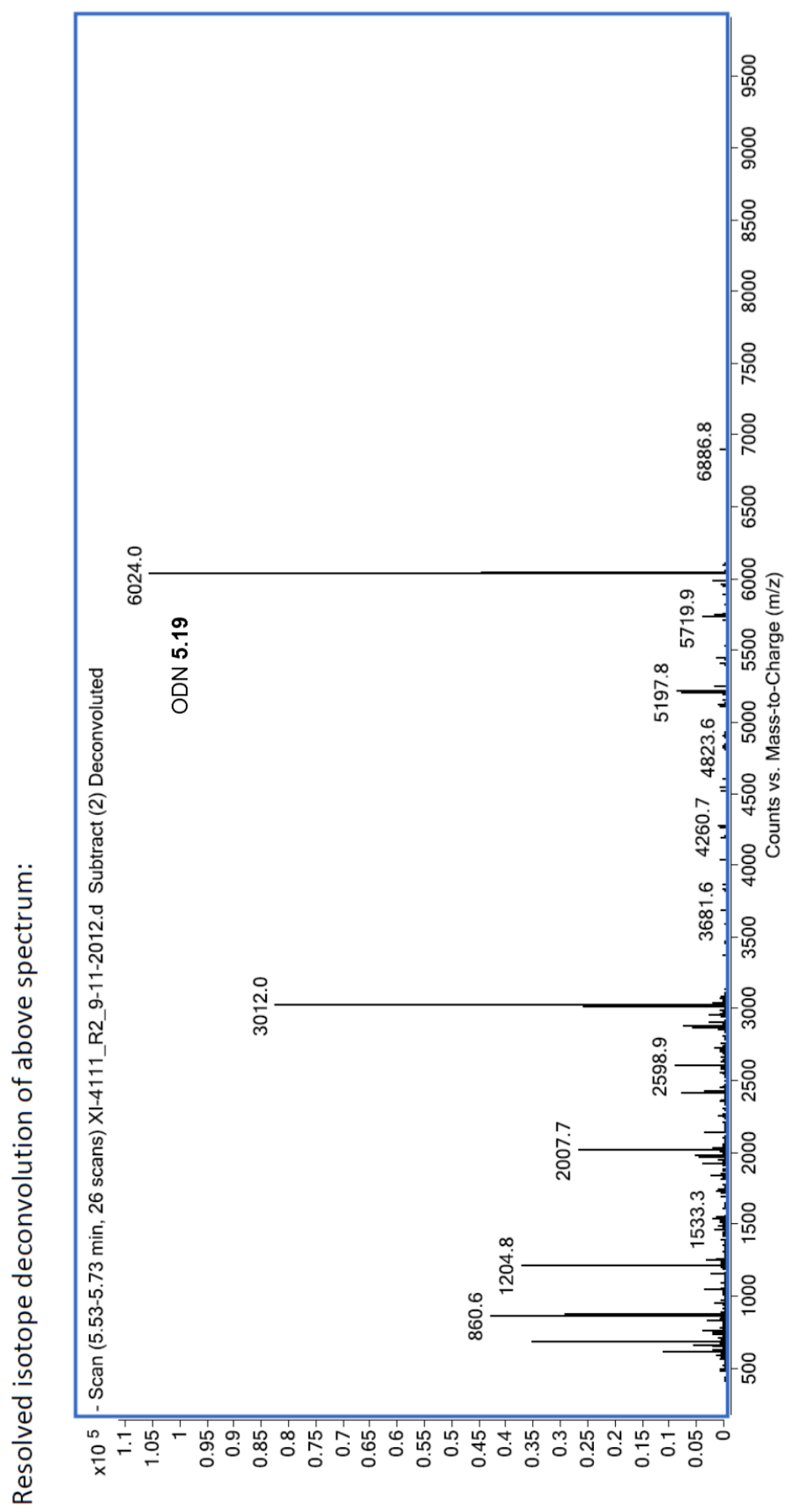

Figure B.21. MALDI-TOF spectrum of compound 5.19 


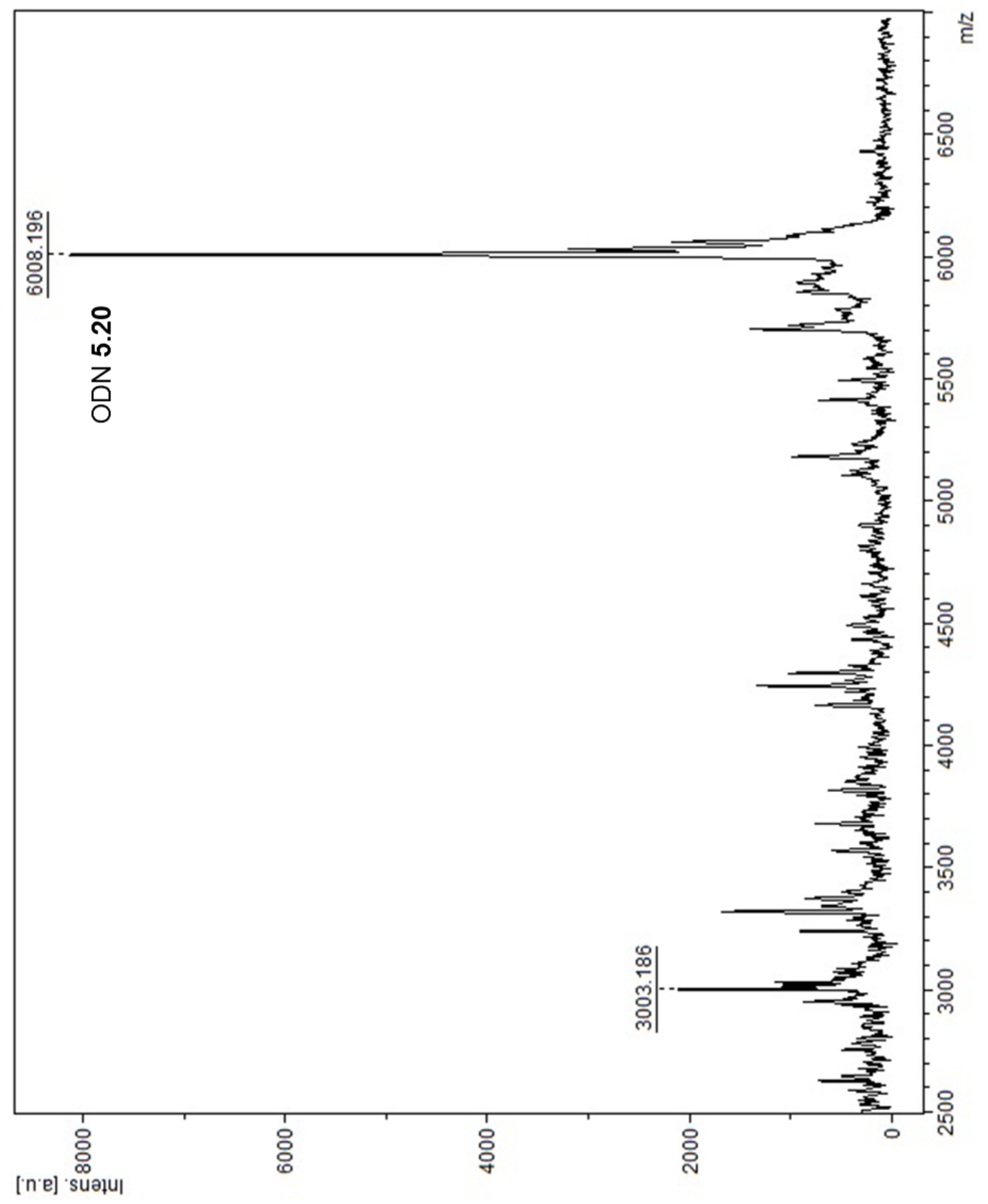

Figure B.22. MALDI-TOF spectrum of compound $\mathbf{5 . 2 0}$ 


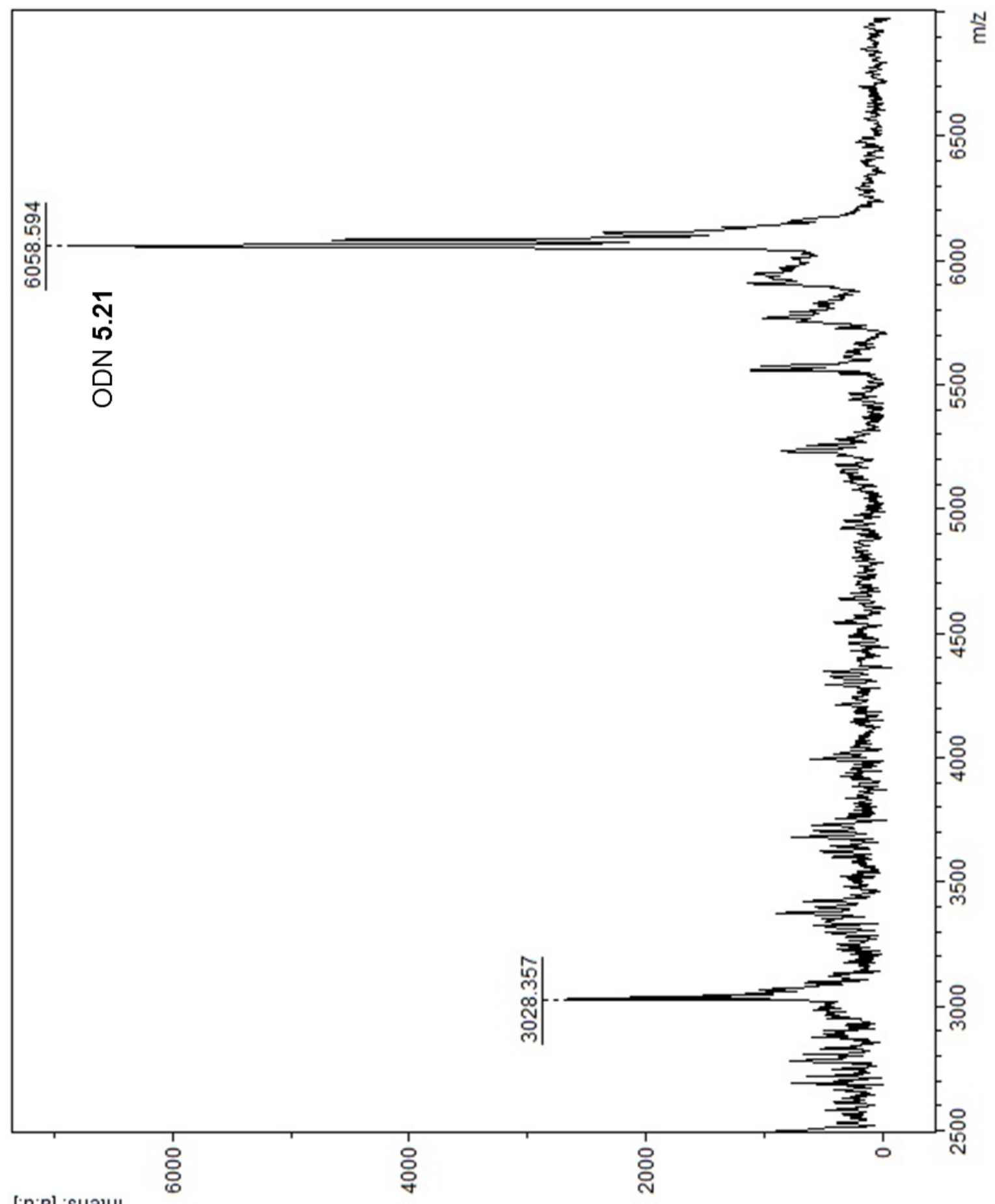

['n'e] 'suąuu

Figure B.23. MALDI-TOF spectrum of compound $\mathbf{5 . 2 1}$ 


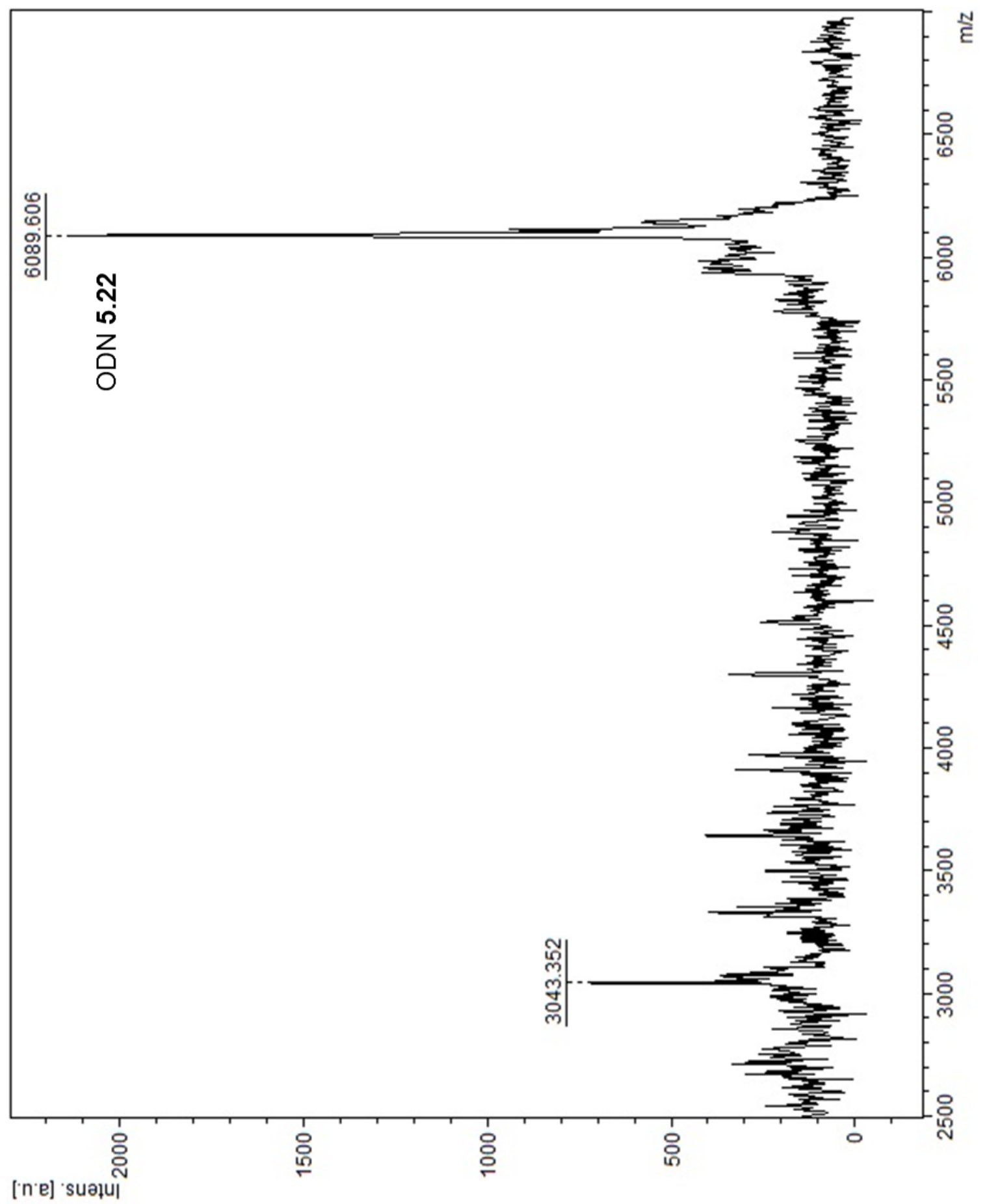

Figure B.24. MALDI-TOF spectrum of compound $\mathbf{5 . 2 2}$ 


\section{Appendix C}

Supporting Information for Chapter 6

Improved Synthesis of Dmoc-dG-amidite 


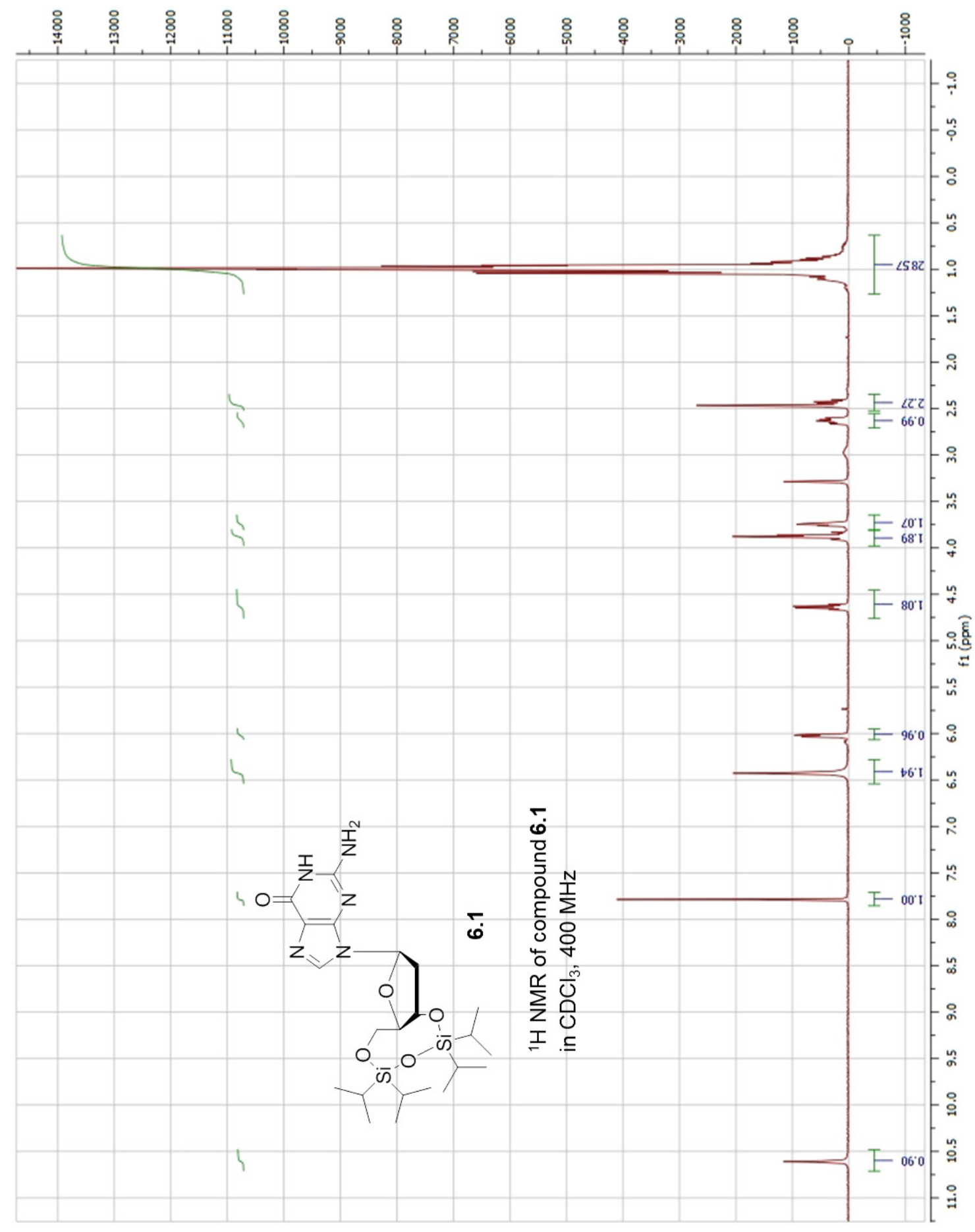

Figure C.1. ${ }^{1} \mathrm{H}$ NMR of compound 6.1 


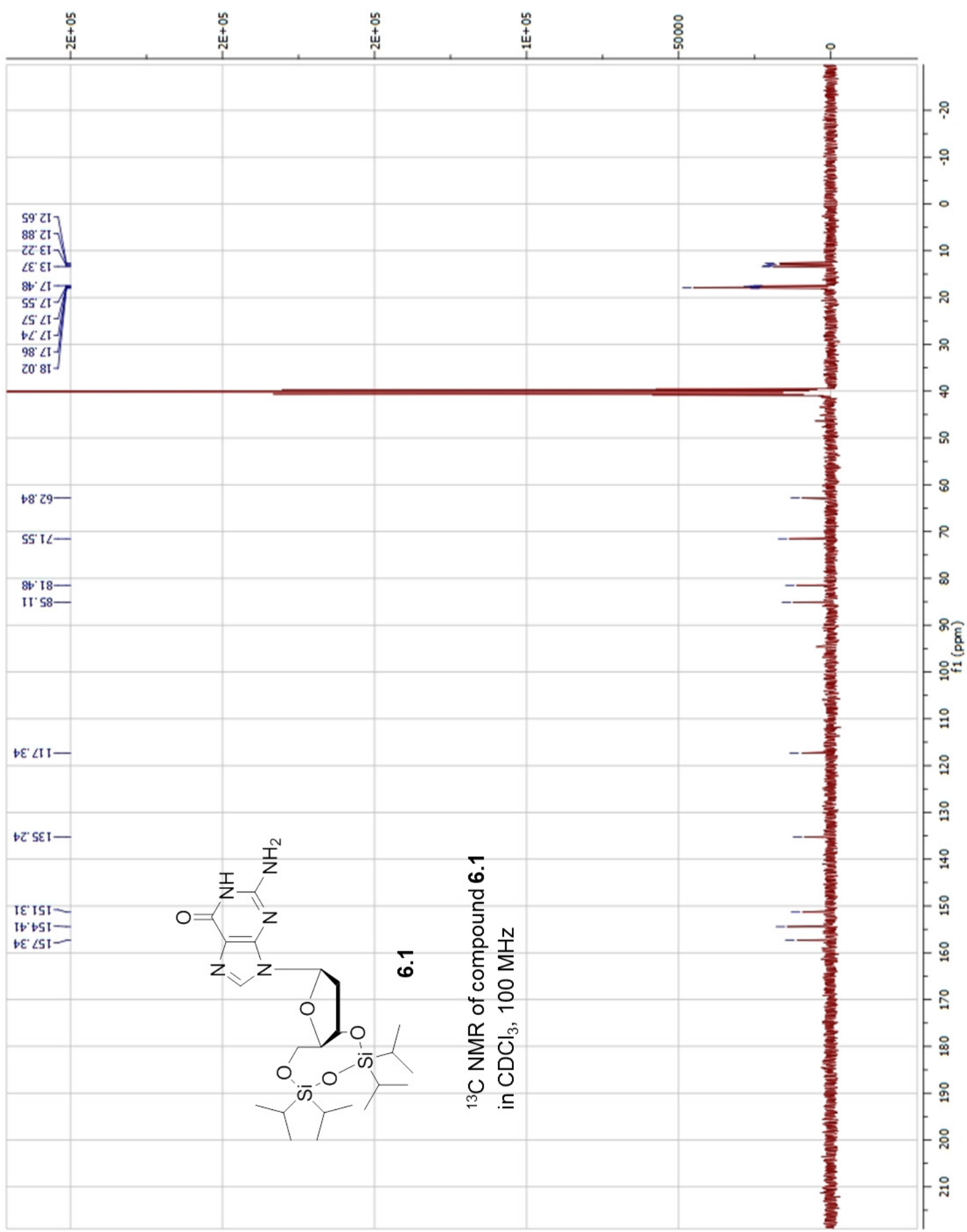

Figure C.2. ${ }^{13} \mathrm{C}$ NMR of compound 6.1 


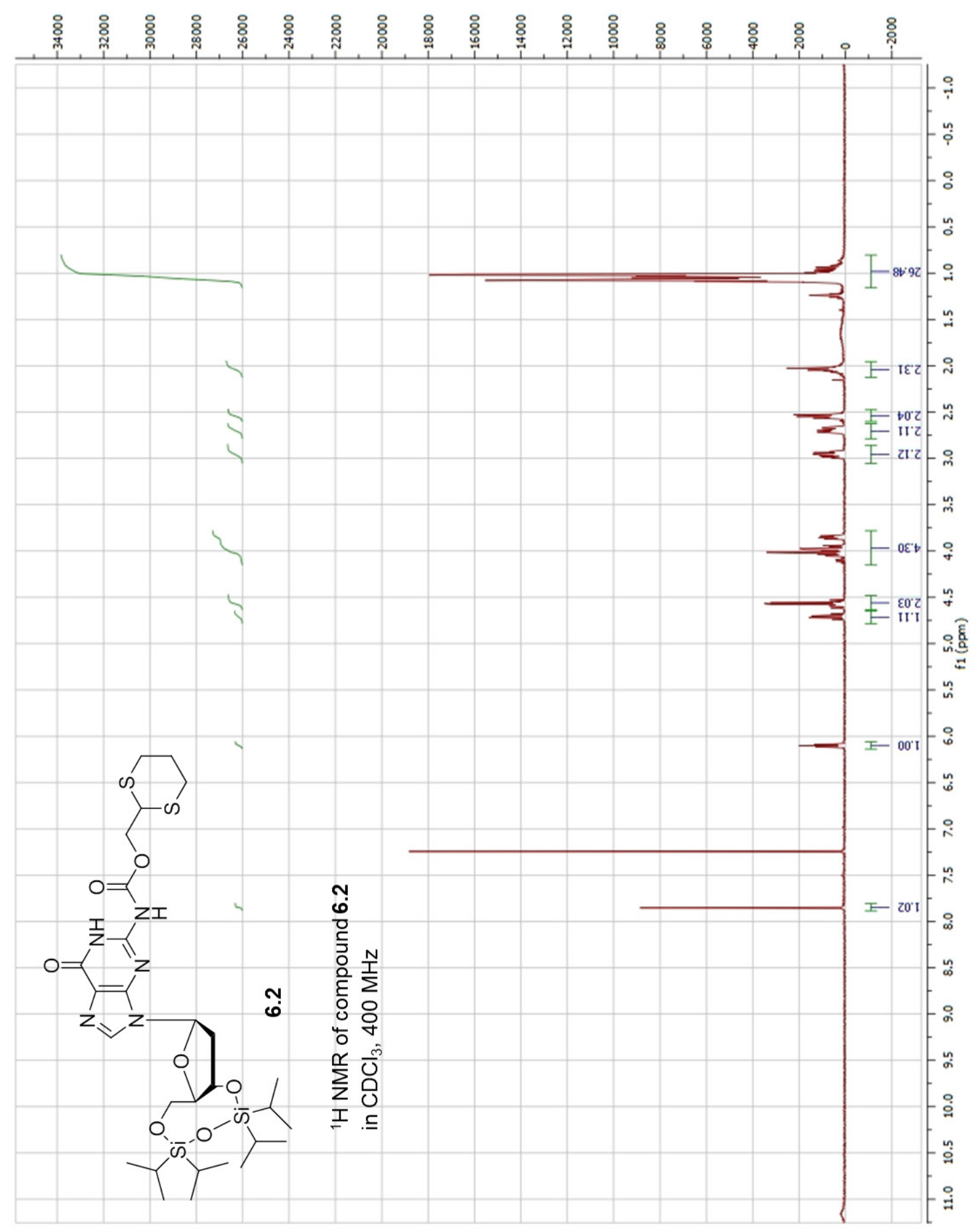

Figure C.3. ${ }^{1} \mathrm{HNMR}$ of compound $\mathbf{6 . 2}$ 


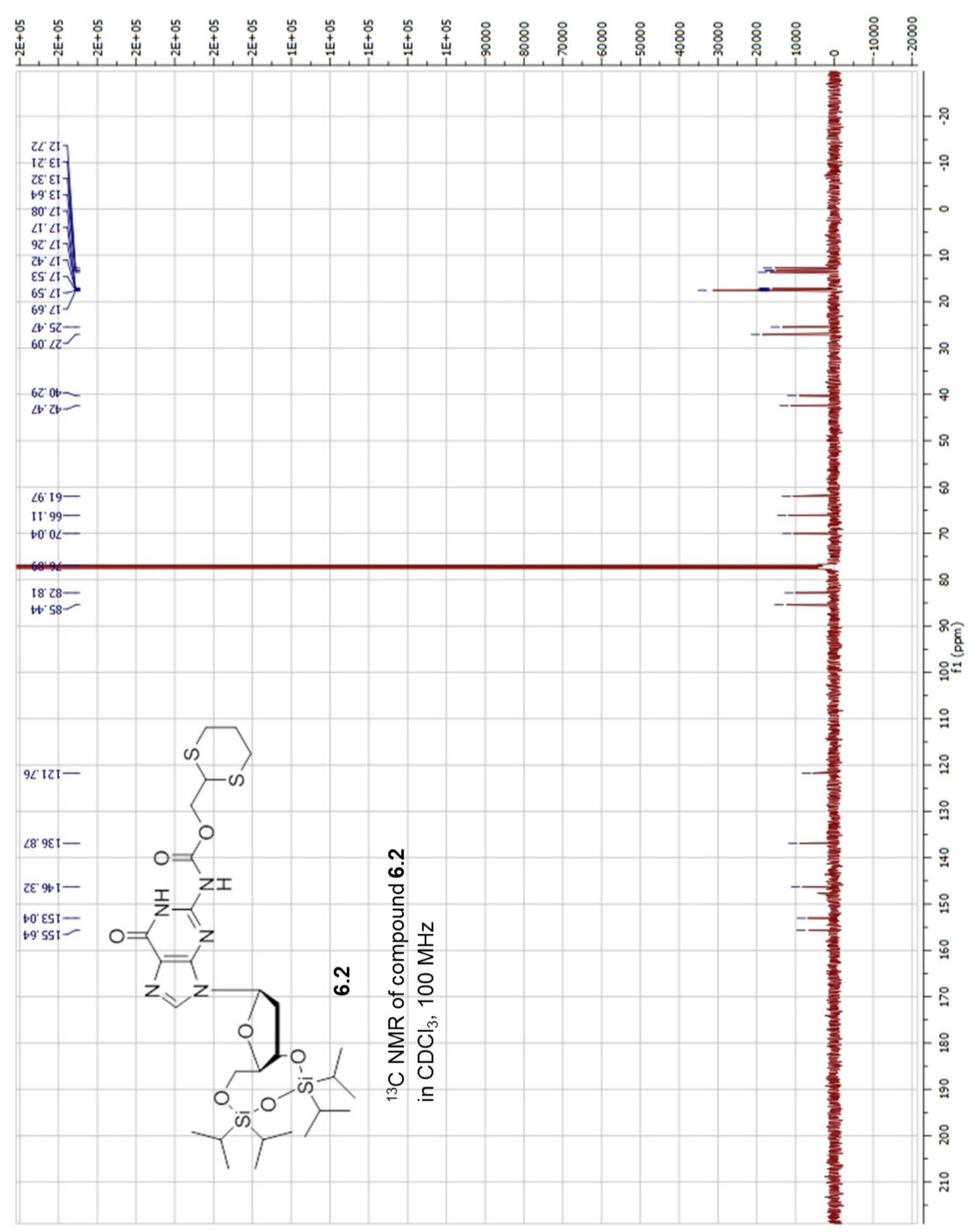

Figure C.4. ${ }^{13} \mathrm{C}$ NMR of compound $\mathbf{6 . 2}$ 